\title{
Seismic Performance of Perforated Steel Plate Shear Walls Designed According to Canadian Seismic Provisions
}

\section{Kallol Barua}

\author{
A Thesis in \\ The Department of \\ Building, Civil and Environmental Engineering
}

\begin{abstract}
Presented in Partial Fulfillment of the Requirements for the Degree of Master of Applied Science (Civil Engineering) at Concordia University, Montreal, Quebec, Canada
\end{abstract}

May 2016

(C) Kallol Barua, 2016 


\section{CONCORDIA UNIVERSITY \\ School of Graduate Studies}

This is to certify that the thesis prepared

By:

Kallol Barua

Entitled: $\quad$ Seismic Performance of Perforated Steel Plate Shear Walls Designed According to

\section{$\underline{\text { Canadian Seismic Provision }}$}

and submitted in partial fulfillment of the requirements for the degree of

Master of Applied Science (Civil Engineering)

complies with the regulations of the University and meets the accepted standards with respect to originality and quality.

Signed by the final examining committee:

Dr. Ashutosh Bagchi

Chair

Dr. Lucia Tirca

Examiner

Dr. M. Zahangir Kabir

Examiner

Dr. Anjan Bhowmick

Supervisor

Approved by

Chair of Department or Graduate Program Director

Dean of Faculty

Date: 


\section{Abstract \\ Seismic Performance of Perforated Steel Plate Shear Walls Designed According to Canadian Seismic Provision}

\section{Kallol Barua}

Perforated Steel Plate Shear Wall (P-SPSW) is a relatively new lateral load resisting system used for resisting wind and earthquake loads. Current North American standards have recently adopted this new lateral load resisting system and proposed guidelines for the design of P-SPSWs. Research on P-SPSW is in the initial stage and to the best of this researcher's knowledge, no seismic performance of code designed P-SPSWs has been studied yet. The main objective of this study was to evaluate the seismic performance of code designed P-SPSWs. Three multi-storey (4-, 8-, and 12-storey) P-SPSWs were designed according to the seismic provisions in NBCC 2010 and CSA/CAN S16-09. Nonlinear time history (NTH) analysis was conducted using detailed finite element (FE) modeling techniques. The finite element (FE) model developed was validated with two experiments results for quasi- static monotonic and cyclic analysis. Excellent correlation was found between detailed FE analysis and tests result. For seismic analysis a series of ten ground motion data were chosen which were compatible with Vancouver response spectrum. All the perforated shear walls exhibited excellent seismic behavior including high stiffness, stable ductility, and good energy dissipation during nonlinear time history (NTH) analysis. It was observed from the seismic analysis that proposed code equation provided a good estimation of the shear strength of the perforated plate when the plate was fully yielded. Thus, it can be concluded that recommended equation of CSA/CAN S16-09 is conservative to select the infill plate thickness of perforated steel plate shear wall.

The N2 method has been used as an easy means of seismic demand evaluation compared to nonlinear time history analysis. The applicability of the N2 method for seismic demand assessment 
of P-SPSWs is investigated in this research. Results from N2 method was compared with the more accurate NTH analysis results. It was observed that the N2 method predicted seismic response parameters such as roof displacement reasonably accurately for 4-and 8-storey P-SPSW. For 12storey P-SPSW N2 method slightly overestimated the roof displacement. The applicability of the modified strip model (MSM) was also evaluated in this research for unstiffened P-SPSW. After validating two experiments, the model was used for the three selected P-SPSWs. Monotonic pushover analysis results were compared with detailed FE analysis results. It was observed that the modified strip model efficiently captures the inelastic behavior of multi-storey unstiffened PSPSWs with adequate accuracy. The ultimate strength was predicted well, and the initial stiffness was slightly underestimated. 


\section{ACKNOWLEDGMENTS}

Accomplishing Master's degree is quite challenging and at the same time rewarding for anyone. By the course of time, many people contributed which is not forgettable. The first author would like to convey his gratitude to supervisor Dr. Anjan Bhowmick for his continuous support, guidance to pursue his graduate studies.

Besides author would like to convey his gratefulness for funding this research project by the Faculty of Engineering and Computer Science, Concordia University, Montreal, Canada and the Natural Sciences and Engineering Research Council of Canada (NSERC). The author also

expresses his gratitude for nominating Armand C. Archambault Fellowship - ENCS (2015) and Avtar Pall Graduate Award in Earthquake Engineering (2016) scholarship for this research project.

Thanks to all my colleagues and friends especially Imran Kabir, Moon Moon Dhar, Manik Mia, Mona Raissi, Mirnmoy Nath and Amit Chanda for inspiring and supporting me during my graduate studies. Finally, I would like to express my deepest appreciation to my parents because of their unlimited supports throughout my studies. 


\section{TABLE OF CONTENTS}

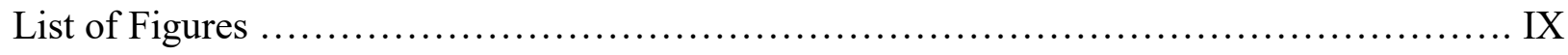

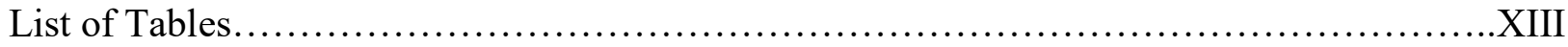

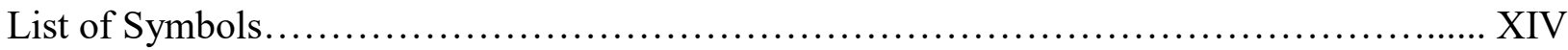

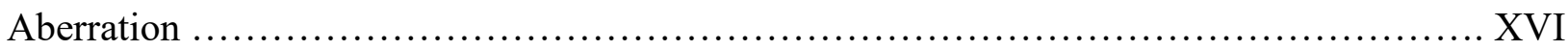

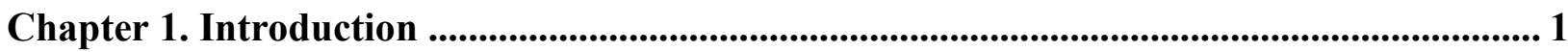

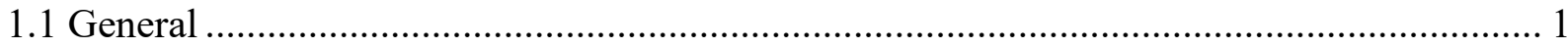

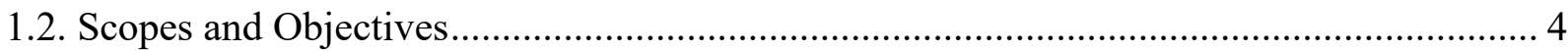

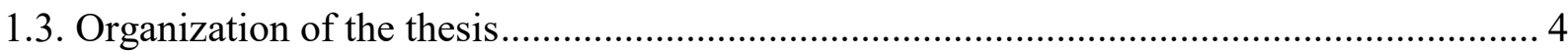

Chapter 2. Previous Research on Unstiffened Steel Plate Shear Walls and Perforated Steel

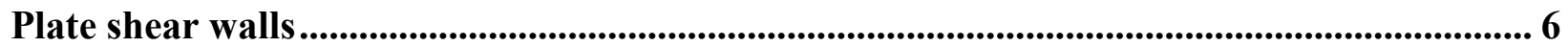

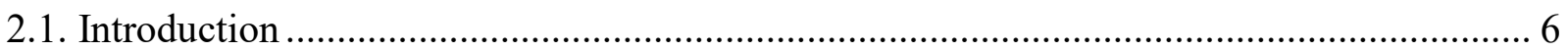

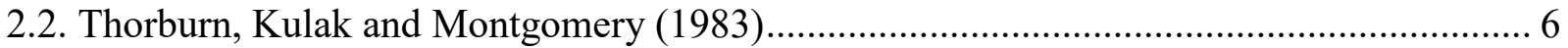

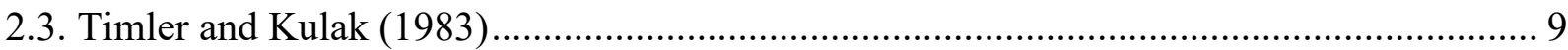

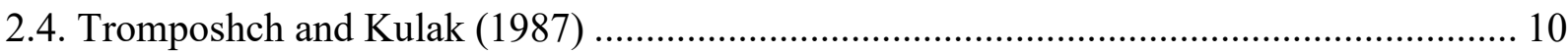

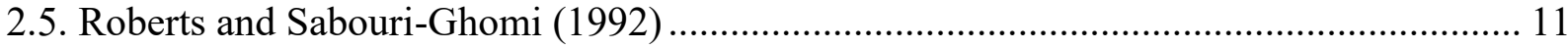

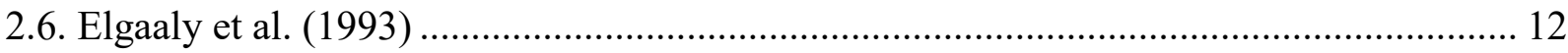

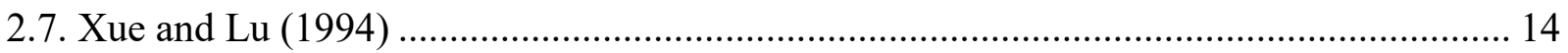

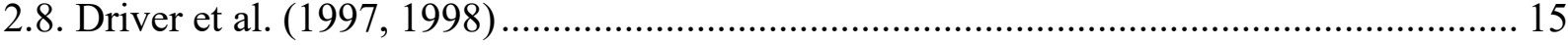

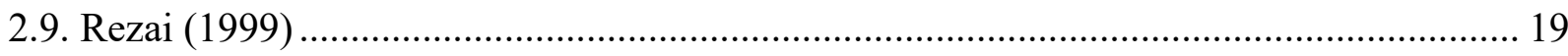

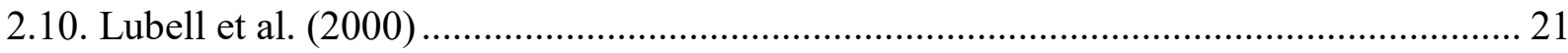

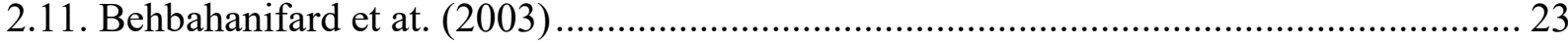

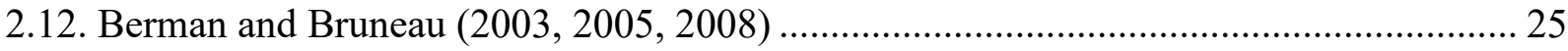

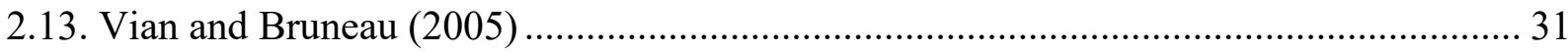

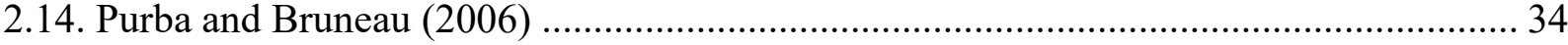

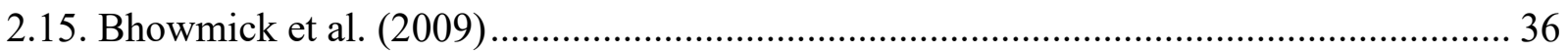

Chapter 3. Finite Element (FE) Modeling and Design of P-SPSW ........................................ 39

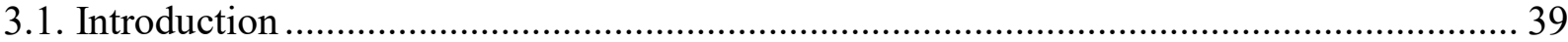

3.2. Selection of Finite Element Analysis (FEA) Techniques ......................................... 40

3.2.1. Geometric Definition and Mesh Generation .................................................. 41

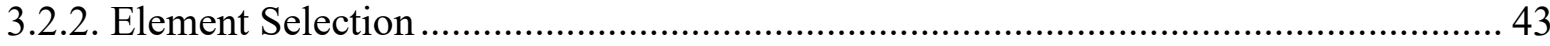




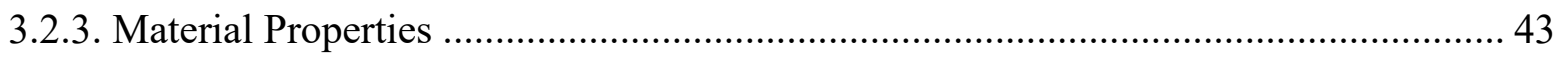

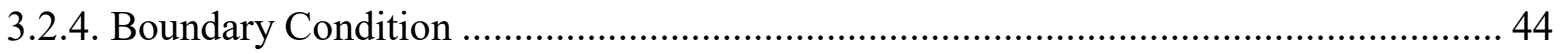

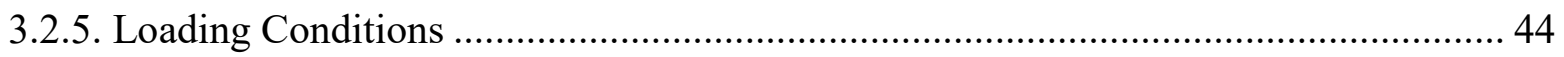

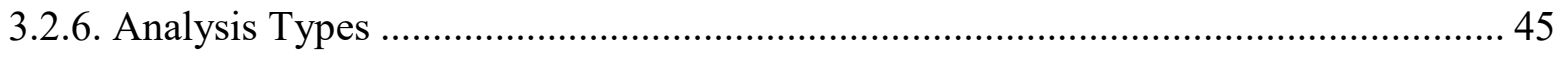

3.3. Validation of Test Specimen by Finite Element Method (FEM) ………………….......... 45

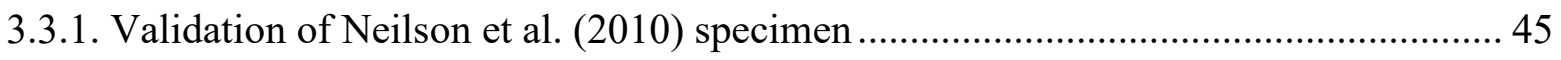

3.3.2. Validation of Vian et al. (2005) experiment ................................................................. 49

3.4. Design of Multi-Storey Perforated Steel Plate Shear Wall (P-SPSW) ............................... 51

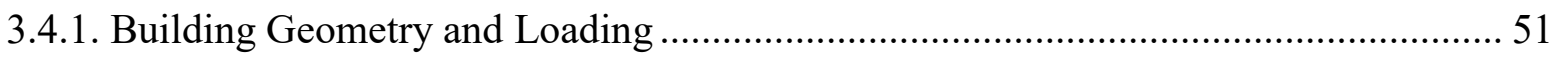

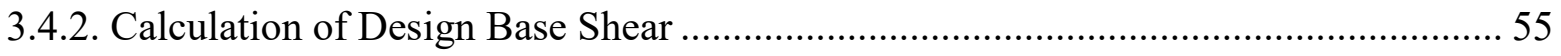

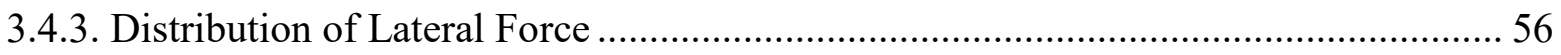

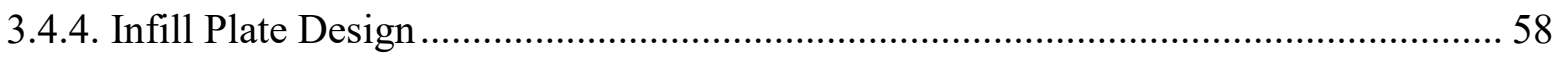

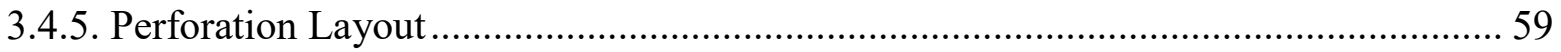

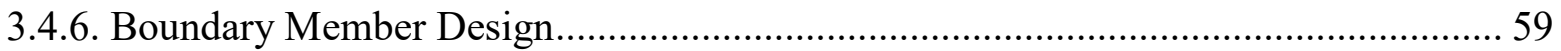

3.4.7. Horizontal Boundary Element and Vertical boundary Element design ..................... 61

3.5. Finite Element Modeling of 4-, 8 - and 12-storey P- SPSW for Pushover Analysis ........ 65

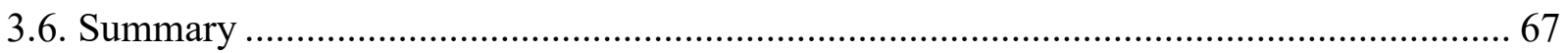

Chapter 4. Seismic Response of Perforated Steel Plate Shear Wall (P-SPSW) ..................... 68

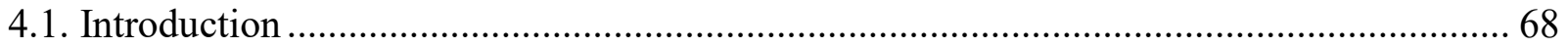

4.2. Nonlinear Dynamic Analysis of Perforated Steel Plate Shear Wall (P-SPSW)................. 69

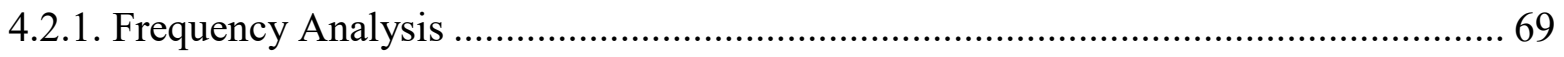

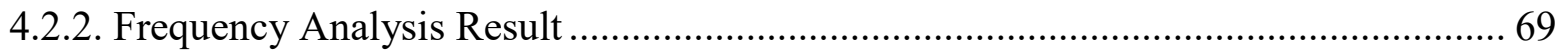

4.3. Selection of Ground Motion Records........................................................................... 70

4.4. Time Period Selection for The Scaling of Ground Motion ................................................... 73

4.5. Scaling of Ground Motion Data ...................................................................................... 73

4.6. Seismic Responses of 4-, 8-, and 12-storey P-SPSWs ..................................................... 88

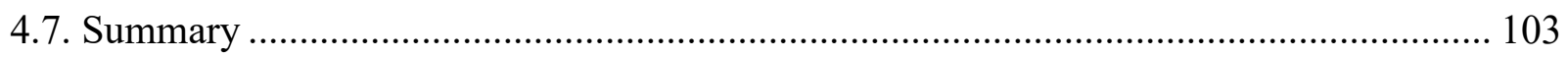

Chapter 5. N2 Method for the Perforated Steel Plate Shear Wall (P-SPSW)...................... 104

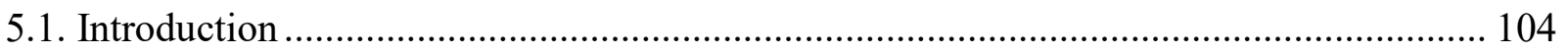

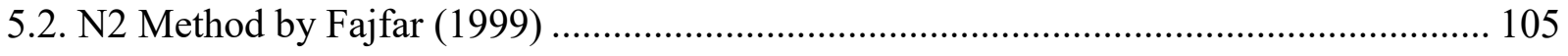


5.2.1. Development of Capacity Curve of Equivalent Single Degree of Freedom (ESDF) System 105

5.2.2. Determination of Seismic Demand for a particular location..................................... 107

5.3. Application of N2 Method for Selected P-SPSWs........................................................ 109

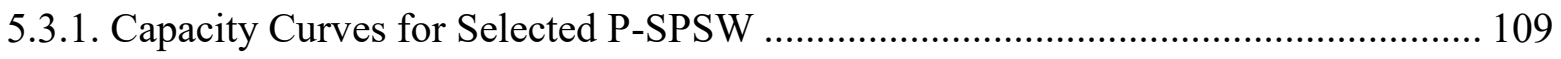

5.3.2. Demand Spectrum for the Vancouver Area .......................................................... 112

5.4. Seismic Demand of P-SPSWs Using N2 method ........................................................... 113

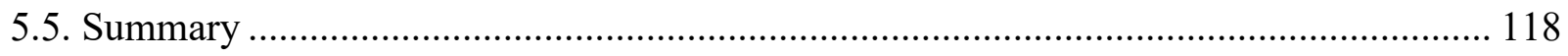

Chapter 6. Modified Strip Model for the Perforated Steel Plate Shear Wall ....................... 119

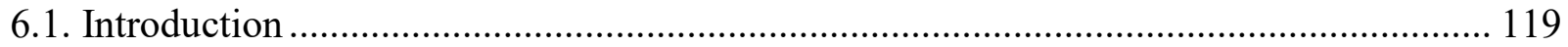

6.2. Modeling Techniques of Modified Strip Method for the Selected P-SPSWs.................. 121

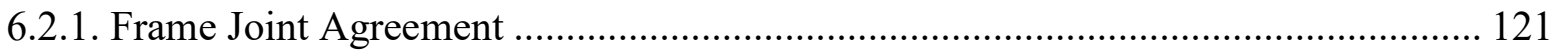

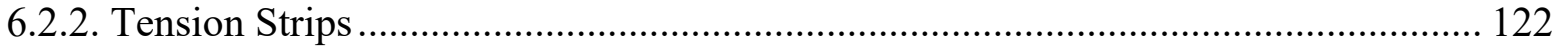

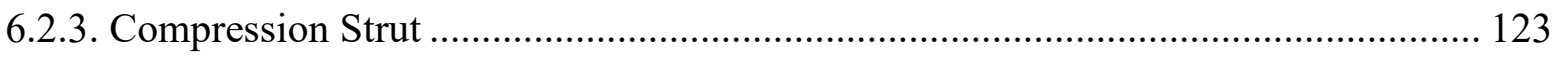

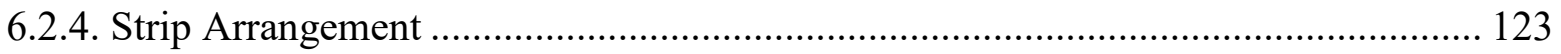

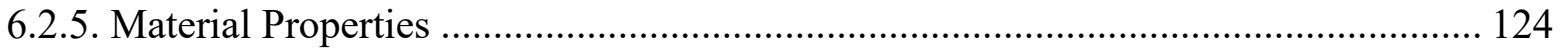

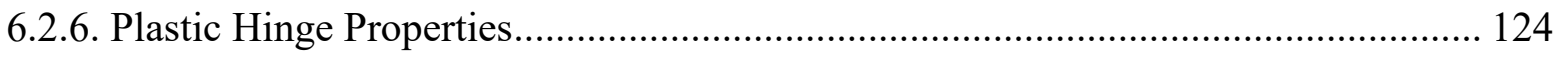

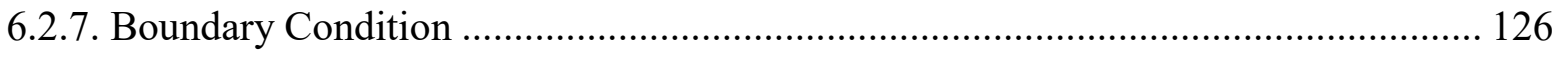

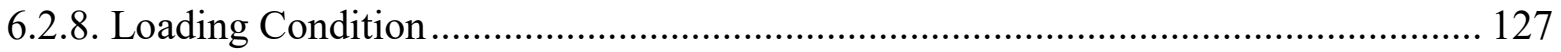

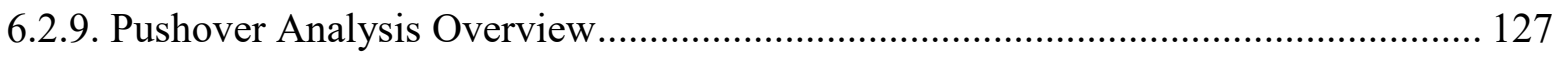

6.3 Validation of Modified Strip Model (MSM) .................................................................. 128

6.3.1. Driver et al. (1997, 1998a) Test Specimen .............................................................. 128

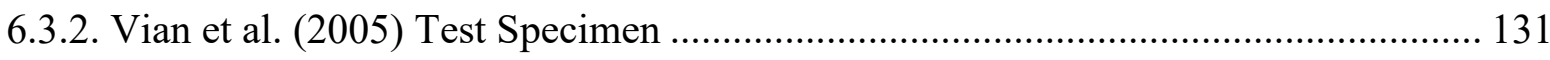

6.4. Modified Strip Model (MSM) for the Selected P-SPSWs (4-, 8- and 12-Storey) ........... 133

6.5. Pushover Analysis Results for the Modified Strip Model for P-SPSWs .......................... 134

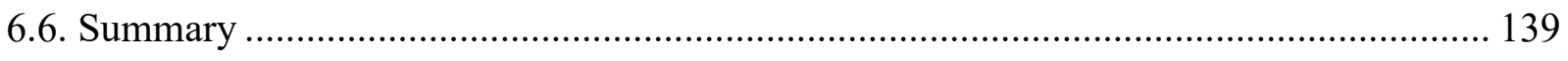

Chapter 7. Summary, Conclusions, and Recommendations .................................................... 141

7.1. Summary ………

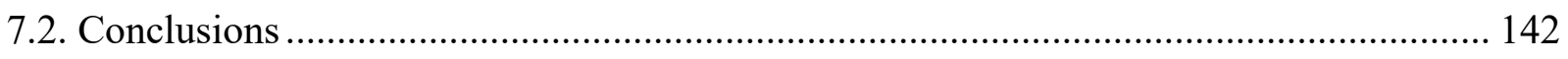

7.3. Recommendations for future works ....................................................................... 144

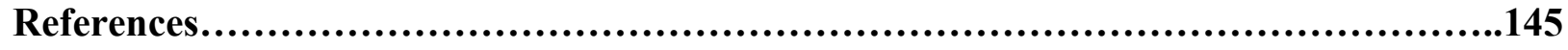




\section{LIST of FIGURES}

Figure 1.1: Schematic diagram of P-SPSW by Vian et al. (2005).......................................... 3

Figure 2.1: Strip model proposed by Thorburn et al. (1983) .............................................. 7

Figure 2.2: Equivalent bracing model proposed by Thorburn et al. (1983) ............................... 8

Figure 2.3: Test specimen conducted by Timler and Kulak (1983) ........................................ 9

Figure 2.4: Test specimen of Tromposhch and Kulak (1987) ............................................... 11

Figure 2.5: Centrally placed perforated test specimen by Roberts and Sabouri-Ghomi (1992)... 12

Figure 2.6: Test specimens by Elgaaly et al. (1993), Left (Phase I) and Right (phase II)........... 13

Figure 2.7: Cross-strip model proposed by Elgaaly (1993) .................................................. 14

Figure 2.8: The four storey test specimen by Driver et al. (1997) ........................................... 17

Figure 2-9: Finite Element Model of Test Specimen by Driver et al. (1998)........................... 18

Figure 2-10: Strip Model of Test specimen conducted by Driver et al. 1998b ......................... 19

Figure 2-11: Multi-angle stripe model proposed by Rezai (1999) ........................................... 20

Figure 2-12: Detail finite element modeling of the test specimen conducted by Rezai(1999).... 21

Figure 2-13: The test specimens conducted by Lubell et al. (2000) ......................................... 23

Figure 2.14: 3-storey test specimen by Behbahanifard et al. (2003). ........................................ 24

Figure 2.15: Detail FE model of the 3-storey test specimen by Behbahanifard et al. (2003)...... 25

Figure 2-16: Single storey failure mechanism by Berman and Bruneau (2003)...................... 26

Figure 2.17: Collops mechanism of the multi-storey SPSW ................................................. 28

Figure 2.18: Loading frame with test specimen by Berman and Breunue(2005) ..................... 29

Figure 2.19: Free body diagram of the VBEs by Berman and Breunue (2008). ....................... 30

Figure 2.20: Schematic details of perforated SPSW and individual strip by Vian et al. (2005) .. 31

Figure 2.21 Perforated SPSW (P-specimen) by Vian et al. (2005) .......................................... 32

Figure 2.22: Corner cut-out test sample (CR) by Vian et al. (2005) ........................................ 33

Figure 2.23: Finite element model of perforated SPSW by Vian et al. (2005).......................... 34

Figure 2.24: Schematic Representation of Individual Strip by Purba et al. (2006) .................... 35

Figure 2.25: Yielding of elements of Ductile (left) and Limited Ductile (Right) by Bhowmick et

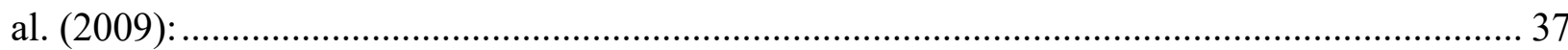

Figure 2.26 Perforated steel plate (type 8) by Bhowmick et al. (2009) .................................... 38

Figure 3.1: Validation of Neilson et al. (2005) test specimen: FE model ................................ 47

Figure 3.2: Cyclic analysis of Neilson et al. (2005) test: yielding of element (red color)........... 48 
Figure 3.3: Base Shear vs. Floor Displacement Curve (Neilson et al. 2005) .......................... 48

Figure 3.4: Hysteric curves s of Neilson et al. (2005) test and finite element model................. 48

Figure 3.5 : Cyclic analysis of Vian et al.(2005) test specimen in FE :yielding of elements (red color)

Figure 3.6 : Force-displacement curves of the Vian et al.(2005) test and finite element result ... 50

Figure 3.7: Hysteresis curves of the test specimen and finite element analysis....................... 51

Figure 3.8: Typical Floor Plan of the Office Building (Gravity System and two SPSW in each

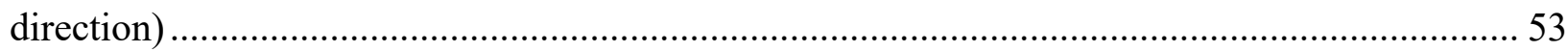

Figure 3.9: Elevation view of the P- SPSW (a) 12-storey (b) 8-storey and (c) 4-storey ............. 54 Figure 3.10: Pushover analysis (a) Meshing of 4-storey P-SPSW (b) yield at ultimate load (red

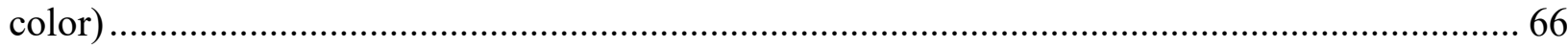

Figure 4.1: Unscaled Acceleration spectra for selected ground motions and Vancouver design

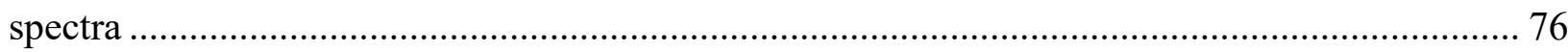

Figure 4.2: Scaled Acceleration spectra for the ground motions \& Vancouver design spectra for

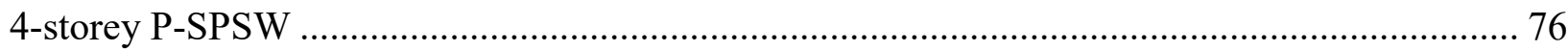

Figure 4.3: Scaled Acceleration spectra for the ground motions \& Vancouver design spectra for

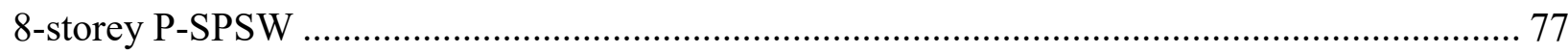

Figure 4.4: Scaled Acceleration spectra for the ground motions \& Vancouver design spectra for

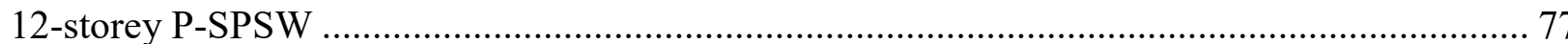

Figure 4.5: Unscaled San Fernando, 1972 earthquake and scaled for 4, 8 \& 12-storey P-SPSW 78 Figure 4.6: Unscaled Kobe, 1975 earthquake and scaled for 4, 8 \& 12-storey P-SPSW ............ 79 Figure 4.7: Unscaled Imperial Valley and scaled for 4, 8 \& 12-storey P-SPSW ....................... 80

Figure 4.8: Unscaled Kern Country earthquake and scaled for 4, 8 \& 12-storey P-SPSW ......... 81 Figure 4.9: Unscaled Northridge earthquake and scaled for 4, 8 \& 12-storey P-SPSW ............. 82 Figure 4.10: Unscaled Loma Perita earthquake and scaled for 4, 8 \& 12-storey P-SPSW ......... 83

Figure 4.11: Unscaled Simulated 6C1 earthquake and scaled for 4, 8 \& 12-storey P-SPSW ...... 84 Figure 4.12: Unscaled Simulated 6C2 earthquake and scaled for 4, 8 \& 12-storey P-SPSW ...... 85 Figure 4.13: Unscaled Simulated 7C1 earthquake scaled for 4, 8 \& 12-storey P-SPSW ........... 86

Figure 4.14: Unscaled Simulated 7C2 earthquake and scaled for 4, 8 \& 12-storey P-SPSW ...... 87

Figure 4.15: Inter-storey drift for a) 4-storey b) 8-storey and c) 12-storey P-SPSW ................. 92 Figure 4.16: Storey Shear force for a) 4-storey b) 8-storey and c) 12-storey P-SPSW .............. 93

Figure 4.17: Base shear for a) 4-storey b) 8-storey and c) 12-storey P-SPSW ........................ 94 
Figure 4.18: Mid-section force of the perforated steel plate for a) 4-storey b) 8-storey \& c) 12storey.

Figure 4.19: Peak column axial force for 4-storey P- SPSW a) Left column \& b) Right column 98 Figure 4.20: Peak column axial force for 8-storey P-SPSW a) Left column \& b) Right column 99 Figure 4.21: Peak column axial force in 12-storey P-SPSW 100

Figure 4.25: Yeilding pattern of the plate in the lower two stories a) the 4-storey P-SPSW for the Northridge earthquake b) the 8-storey P-SPSW for the Loma Peratrio earthquake 101

Figure 4.26: Yielding pattern of the plate in the lower stories of the 12 storey P-SPSW for the Kobe City 1995 earthquake 102

Figure 5.1 Development of the capacity spectrum of an equivalent SDOF system by Fajfar (1999). 106

Figure 5.2: Schematic figure of a seismic demand spectrum (constant ductility response spectrum in ADRS format) by Fajfar (1999). 108

Figure 5.3: First mode pushover curve for a) 4-storey (Top), b) 8-storey (Middle) and c)12-storey (bottom) P-SPSW. 110

Figure 5.4: Force-Displacement Idealized Curve as well as Spectral Acceleration vs. Spectral Displacement Curve of Equivalent SDOF System for 4-Storey (top), 8-Storey (middle), and 14Storey (bottom) for P-SPSW.

Figure5.5: Elastic Acceleration $\left(\mathrm{S}_{\mathrm{ae}}\right)$ \& Displacement $\left(\mathrm{S}_{\mathrm{de}}\right)$ Response Spectrum for the Vancouver.

Figure 5.6: Seismic demand spectrum (constant ductility response spectrum in ADRS format) for the Vancouver. 113

Figure 5.7: Graphical Representation of N2 method for 4-Storey P-SPSW in ADRS format. .. 115 Figure 5.8: Graphical Representation of N2 method for 8-Storey P-SPSW in ADRS format ... 116 Figure 5.9: Graphical Representation of N2 method for 12-Storey P-SPSW in ADRS format. 116 Figure 5.10: Comparison of the N2 method Inter-storey Drift with NTH analysis a) 4-storey, b) 8-storey and c)12-storey P-SPSW. 117

Figure 6.1: Frame joint agreement, hinges at panel node by Shishkin et al. (2005)................ 122 Figure 6.2: Tension strips width from a)edge to edge $(\mathrm{E} / \mathrm{E})$ and $\mathrm{b})$ center to center $(\mathrm{C} / \mathrm{C}) \ldots . .123$ Figure 6.4: Schematic diagram of the base support for pin connection................................. 127 Figure 6.5: Geometry arrangement of Driver et al. (1997) test specimen for the MSM. .......... 130 Figure 6.6: Comparisons of base shear vs. displacement curve for the Driver et al. (1998a) .... 131 and modified strip model. 
Figure 6.7: Geometry arrangement and loading condition of Vian et al. (2005) test specimen for the modified strip model.

Figure 6.8: Comparison of Pushover curve of Vian et al. (2005) test and MSM. 133

Figure 6.9: Geometric and loading arraignment of the Modified strip model for 4-storey P-SPSW

Figure 6.10: Base shear versus top displacement curve for the 4-storey P-SPSW for detailed finite element and MSM exact layout 136

Figure 6.11: Base shear versus top displacement curve for different layout of the tension ....... 136

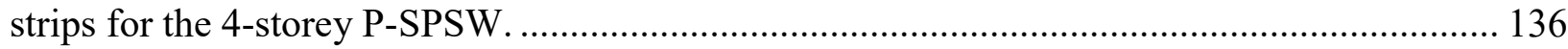

Figure 6.12: Base shear versus top displacement curve for the 8-storey P-SPSW................. 137

Figure 6.13: Base shear versus top displacement curve for the 12-storey P-SPSW ................. 138

Figure 6.14: Axial force from MSM and design for 4-storey P-SPSW ................................. 138

Figure 6.15: Axial force from MSM and design for 8-storey P-SPSW ................................ 139

Figure 6.16: Axial force from MSM and design for 12-storey P-SPSW .....................139 


\section{LIST OF TABLES}

Table 3.1(a): Material Properties of Neilson et al. (2010) test specimen .................................. 46

Table 3.1(b): Time dispalcement curve for Neilson et al. (2010) cyclic test ............................ 47

Table 3.1(c): Time displacement curve for Vian et al. (2005) cyclic test ................................ 50

Table 3.2: Equivalent Static Lateral force and Storey Shear force for the 4-storey P-SPSW ..... 57

Table 3.3: Equivalent Static Lateral force and Storey Shear force for the 8-storey P- SPSW ..... 57

Table 3.4: Equivalent Static Lateral force and Storey Shear force for the 12-storey P- SPSW ... 58

Table 3.5: Plate thickness, openings diameter, and beam, column sections for the 4-storey...... 63

Table 3.6: Plate thickness, openings diameter, and beam, column sections for the 8-storey....... 64

Table 3.7: Plate thickness, openings diameter, and beam, column sections for the 12-storey..... 64

Table 3.8: Comparison of Base shear from NBCC 2010 and Pushover Analysis ..................... 66

Table 4.1: Frequency and corresponding time periods of the 4-, 8- and 12-storey P-SPSWs..... 70

Table 4.2: Selected real time ground motions records from PEER database ............................ 72

Table 4.3: Selected Simulated ground motions records from Eng. Seismology toolbox website 73

Table 4.4: Comparison of Time period from code equation and FE modeling ......................... 73

Table 4.5: Scaling factors of the selected ground motions for selected P-SPSWs ................... 75

Table4.6: Shear force $(\mathrm{kN})$ in the perforated steel plate for the 4-storey ............................... 95

Table 4.7: Shear force $(\mathrm{kN})$ in the perforated steel plate for 8 -storey .................................... 95

Table 4.8: Shear force $(\mathrm{kN})$ in the perforated steel plate for the 12 -storey ............................... 96

Table 5.1: Structural Properties of Equivalent SODF system. .............................................. 112

Table 5.2: Seismic demand for 4-,8- and 12-storey P-SPSW.............................................. 115

Table 6.1: Bi-linear Flexure Hinges Properties by Shishkin et al. (2005).............................. 126

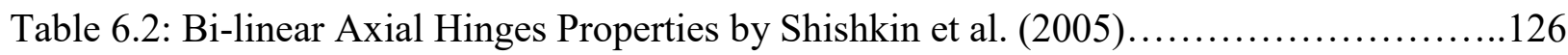




\section{List of Symbols}

\begin{tabular}{|c|c|}
\hline$M$ & Ductility of the system \\
\hline$A b$ & Cross-sectional area of boundary beam \\
\hline$A c$ & Cross-sectional area of boundary column \\
\hline$B$ & $\begin{array}{l}\text { Amplification factor in indirect capacity designs approach } \\
\text { Classical damping of SDOF, Matrix of classical damping of } \\
M D O F\end{array}$ \\
\hline$D L$ & Dead load \\
\hline$D t$ & Displacement of MDOF system \\
\hline$D t^{*}$ & Displacement of SDOF and ESDOF system \\
\hline$D y^{*}$ & Yield displacement of ESDOF system \\
\hline$E$ & Earthquake load \\
\hline Es & Elastic modulus of steel \\
\hline$F i$ & Applied lateral forces at ith storey \\
\hline Fsn & Lateral force of "nth-mode" SDOF system \\
\hline$F x$ & Storey lateral force \\
\hline Fy & Nominal strength of the infill plate \\
\hline$F y^{*}$ & Yield strength of the ESDOF system xiv \\
\hline Fyp & Yield strength of the infill plate \\
\hline$h i$ & Height above the ground to ith storey \\
\hline$h n$ & Total building height \\
\hline$h s$ & Storey Height \\
\hline$I b b$ & Moment of inertia of cross-section of bottom beam \\
\hline Ic & Moment of inertia of cross-section of boundary column \\
\hline$I E$ & Earthquake importance factor \\
\hline$I t b$ & Moment of inertia of cross-section of top beam \\
\hline$L$ & $\begin{array}{l}\text { Steel frame width from center to center distance of boundary } \\
\text { columns }\end{array}$ \\
\hline$L L$ & Live load \\
\hline$L c f$ & Clear distance between column flanges \\
\hline$m^{*}$ & Ln Mass of "nth-mode" SDOF system \\
\hline$m i$ & Storey mass of ith storey \\
\hline$M n$ & Effective modal mass of nth mode of vibration \\
\hline$M v$ & Amplification factor to account higher mode effect \\
\hline$P$ & Point load \\
\hline Peff & Effective earthquake force \\
\hline$P i$ & Lateral force distribution for inertia force \\
\hline$R$ & Force reduction factor \\
\hline
\end{tabular}




\begin{tabular}{|c|c|}
\hline Ro & Over strength related factor \\
\hline$R \mu, R d$ & Ductility related force reduction factor $x v$ \\
\hline$R \mu, R d$ & Ductility related force reduction factor $x v$ \\
\hline$S(T a)$ & $\begin{array}{l}\text { Design Spectral Acceleration for fundamental period of the } \\
\text { building }\end{array}$ \\
\hline$S a$ & Inelastic spectral acceleration \\
\hline Sae & Elastic spectral acceleration \\
\hline$S d$ & Inelastic spectral displacement \\
\hline Sde & Elastic spectral displacement \\
\hline$S n$ & Effective lateral force distribution for nth mode of vibration \\
\hline$S n L$ & Snow load \\
\hline$T$ & Fundamental time period \\
\hline$T^{*}$ & Elastic period of SDOF system \\
\hline$T a$ & Fundamental period of the system \\
\hline$T s$ & Characteristics Period of response spectrum \\
\hline$t w$ & Infill plate thickness \\
\hline$g(t)$ & Earthquake ground motion \\
\hline$V b$ & Design base shear \\
\hline$V b n$ & Base shear for nth mode of vibration of MDOF system \\
\hline$V e$ & Expected shear strength of SPSW \\
\hline Vre & Probable shear resistance of SPSW \\
\hline$V S$ & Storey shear of SPSW \\
\hline$w, t w i$ & Infill plate thickness \\
\hline$W$ & Seismic weight of the building \\
\hline$W i$ & Seismic weight of the ith storey \\
\hline$w$ & Vertical distributed force applicable to the columns \\
\hline$W x c i$ & Horizontal distributed force applicable to the columns \\
\hline Wybi & Vertical distributed load applicable to the beams \\
\hline Wxbi & Horizontal distributed load applicable to the beams \\
\hline$\alpha$ & Angle of inclination of tension field of steel infill plate \\
\hline$\alpha n$ & Strain hardening of "nth mode" pushover analysis \\
\hline$\Gamma$ & Modal participation factor; Modal transformation factor \\
\hline$\xi n$ & Damping of "nth mode" SDOF system \\
\hline$\varphi$ & Elastic mode shape \\
\hline$\varphi b$ & Inclination of equivalent brace \\
\hline$\omega n$ & Natural frequency of vibration of the system \\
\hline$\Omega s$ & System overstrength factor \\
\hline
\end{tabular}




\[ \text { Abbreviation } \]
Acceleration displacement response spectrum
American Institute of Steel Construction
American Society of Civil Engineers
Applied Technology Council
Canadian Standards Association
Capacity spectrum method
Finite Element Model
Finite Element Analysis
Equivalent Single degree of freedom
Federal Emergency Management Agency
Low Yield Strength or Low Yield Steel
Ground motion record
Hilber hughes taylor
Multi degree freedom system
Modified Strip Model
Multidisciplinary Center for Earthquake Engineering Research (Buffalo)
National Building Code of Canada
Ponlinear time history
Pacific Earthquake Engineering Research

ADRS

AISE

ASCE

ATC

CSA

CSM

FEM

FEA

ESDOF

FEMA

LYS

GMR

HHT

$M D O F$

MSM

MCEER

$N B C C$

NTH

PBSD

PEER

P-SPSW

SDOF

SPSW 


\section{Chapter 1. Introduction}

\subsection{General}

Over the last two decades, unstiffened SPSW has become a popular and efficient wind and earthquake load resisting system in North America and Japan. High initial stiffness, excellent ductility, and energy dissipation capacity and tremendous post-buckling strength make this system unique compared to other conventional systems.

Before the 1980s, the design philosophy of SPSW was aimed to prevent shear buckling in the infill plate. Thus, inhibiting folding action in infill plate, relatively thick plate or stiffeners were added into the thin infill plate to work the plate in the elastic range.

Thorburn et al. (1983) proposed strip model for the thin unstiffened SPSW, taking into account the post-buckling strength in the infill plate. While designing unstiffened SPSW, it is considered that column overturning moment will be resisted by axial coupling loads, whereas storey shear will be resisted by the diagonal tension field in the infill plate. Often, from practical availability and to meet welding and handling requirement, minimum infill plate thickness being used is thicker than the required plate thickness. The larger infill plate results in large demand in the boundary members which consequently increases member sizes and cost of the project. Recently few recommendations have been made by researchers to alleviate this problem. These are the use of light gauge cold-formed steel plate instead of hot rolled (Berman and Bruneau 2003a, 2005), connect the infill plate only with floor beams (Xue and Lu 1994), use of circular perforations (Vian et al. 2005; Purba et al. 2006). Among these alternatives, perforated SPSW has drawn more attentions from the engineering community because the perforated system can accommodate 
passing of utilities like electric lines, water pipes, etc. through the infill plate. Also, during construction, lifting and handling of the infill plate become easy as well.

Thus, CSA/CAN-S16-09 and AISC 2010 have included perforated steel plate shear wall (PSPSW) system in their current editions. As an improved version of unstiffened SPSW, this system is equally applicable to new buildings as well as retrofitting of existing buildings. According to Canadian standard, openings should be spread uniformly over the entire plate in a staggered position with a certain distance from the boundary (Figure: 1.1). The openings are oriented in such a way that the plate buckling is independent of loading direction. Both Canadian and American steel design standards have design guidelines for this perforated SPSW system. It is recommended that the P-SPSW system is designed according to the capacity design approach. As per capacity design approach, for P-SPSW yielding of infill plate and the plastic hinges at the end of beams are considered as ductile fuses which dissipate most of the seismic energy. However, the proposed PSPSW system has never been studied under real seismic loading. Thus, the objective of this research is to study the seismic performance of code designed P-SPSW system. Three multi-storey P-SPSWs (4-, 8- \& 12-storey) were designed as per NBCC 2010 and CSA/CAN-S16-09. A detailed finite element modeled is developed to study the monotonic and dynamic behavior of unstiffened P-SPSW. Both material and geometric nonlinearities were included in the FE model. The applicability of FE model was first validated with results from two experiments: SPSW with solid infill plate and SPSW with perforated infill plate. Later, seismic performance of selected PSPSWs is studied using nonlinear time history analysis.

On the other hand, for seismic performance evaluation of lateral load resisting systems, various guidelines (like FEMA-273, FEMA-356) offer several simplified analysis procedures. Among them, one of the most popular simplified procedures is N2 Method. The N2 method is a nonlinear 
static analysis procedure which has been successfully used for the frame structure. This research investigates the applicability of the N2 method for seismic performance evaluation of P-SPSW.

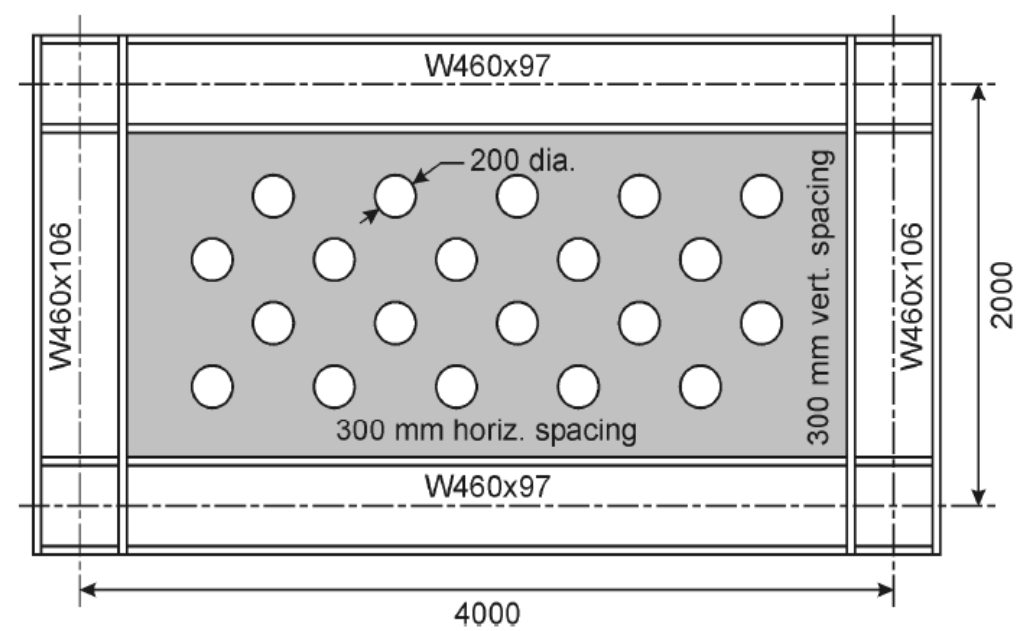

Figure 1.1: Schematic diagram of P-SPSW by Vian et al. (2005)

Analysis of SPSWs using detailed finite element model is very time-consuming. The strip method proposed by Thorburn et al. (1983) for unstiffened SPSW is a simplified procedure that can be used for analysis of unstiffened SPSW. The strip model can be used in commercial finite element software. Several modifications have recently been proposed by various researchers to predict exact seismic responses of unstiffened SPSW using strip model. Modified strip model suggested by Shishkin et al. (2005) is an effective tool for performance assessment of SPSW with solid infill plate. The applicability of the modified strip model to assess inelastic responses of P-SPSWs has been studied in this research. In this regard, some modifications have been proposed to the existing modified strip model. The proposed strip model has been used in conventional software (like SAP2000) to estimate inelastic seismic responses of the selected 4-, 8, and 12-storey P-SPSWs. 


\subsection{Scopes and Objectives}

The main objectives of this research are as follows:

1. To investigate seismic performance of code designed P-SPSWs. It was done by conducting nonlinear time history analysis on selected P-SPSWs using the validated detailed finite element model.

2. To examine the accuracy of the proposed shear strength equation for perforated infill plate in the steel standard. This was done by comparing the shear strength of perforated infill plate from non-linear time history analysis with that from the code specified equation.

3. To estimate seismic demands of perforated SPSW by a more simplified method based on a nonlinear static analysis. In this study, N2 method was used to estimate seismic demands of the selected P-SPSWs.

4. Another important objective is to study the applicability of strip model for analysis of unstiffened P-SPSW. The modified strip model, which is currently recommended in CAN/CSA S16-09 for SPSW with solid infill plate, is modified and applied for SPSW with perforated infill plate. A widely used commercial finite element software, SAP2000, is used for this investigation.

\subsection{Organization of the Thesis}

The present chapter offers an introduction to the P-SPSW systems along with a brief background preview and objectives of this present study.

Chapter 2 presents a literature review of earlier work done on both unstiffened SPSWs and PSPSWs. This chapter includes several experimental work as well as analytical work on the above topics. 
Chapter 3 demonstrates the selection of detailed finite element modeling techniques and validation of chosen techniques with two experimental results. Design and modeling technique of the selected P-SPSWs are present in this chapter as well.

Chapter 4 presents the seismic performance of code designed P-SPSWs. This chapter first discusses the selection of ground motions data incompatible with Vancouver region. Along with frequency analysis, nonlinear time history $(\mathrm{NTH})$ analysis is conducted for the selected P-SPSWs. Critical response parameters of the designed P-SPSWs subjected to the selected earthquakes are obtained and discussed.

Chapter 5 examines the effectiveness of widely used simplified N2 method/capacity spectrum method (CSM) for the selected P-SPSWs. Inelastic seismic demands such as roof displacements and inter-storey drifts are compared with the nonlinear seismic analysis results.

Chapter 6 presents the strip model for the 4-, 8-, and 12-storey P-SPSWs. Using modified strip model the responses are evaluated and compared it with the detailed finite elements analysis techniques.

Finally, Chapter 7 provides the major outcomes of this research. Future scopes and recommendations are also presented in this chapter. 


\section{Chapter 2. Previous Research on Unstiffened Steel Plate Shear Wall (SPSW) and Perforated Steel Plate Shear Wall (P-SPSW)}

\subsection{Introduction}

Unstiffened SPSW is an excellent lateral load resisting system because of its robustness, high initial stiffness, substantial ductility, firm hysteric nature, incredible post-buckling strength and tremendous energy dissipation capacity. Although numerous research has been done in last three decades to make the system more efficient, still practical applicability of this system is limited. First in 1970, the extraordinary potentiality of unstiffened steel plate shear wall was recognized by researchers. Since then several analytical, experimental and finite element analysis were conducted to evaluate its pre-buckling to post-buckling behavior. However, the main theory named "Diagonal Tension Field" was proposed by Wagner (1931), while designing aircraft wings. Later, Basler (1961) extended the diagonal tension field theory for civil engineering purpose, particularly for plate girder in the bridge. After all, the first breakthrough for unstiffened SPSW was "strip model"

proposed by Thorburn et al. (1983). Besides, the researchers expanded their horizon for a different type of unstiffened SPSW system such as cold rolled light gauge infill, perforated, composite, corner cutout, etc. The aim of this chapter is to present the previous research done on unstiffened SPSW, especially for solid and perforated infill.

\subsection{Thorburn, Kulak and Montgomery (1983)}

An analytical model for unstiffened SPSW was developed by Thorburn et al. (1983) in which the researcher considered diagonal tension field action. In this model, infill panel was replaced by series of pin ended tension only strips (truss members) with the equal angle of inclination in the direction of loading. Therefore, this model is commonly known as strip model or multi-stipe model. 
Figure 2.1 shows the strip model proposed by Thorburn (1983). Even though this model captured the post-buckling strength of the thin plate, panel strength before buckling was neglected. The researchers assumed that the initial stiffness of the infill plate before buckling was very small compared to global behavior. Despite this fact, it was the first step for designing the unstiffened steel plate.

To predict the ultimate strength of the unstiffened steel plate, boundary members i.e. beams \& columns were considered to be infinitely rigid. Thus, the following Equation for the angle of inclinations of the tension field action was proposed using least work method.

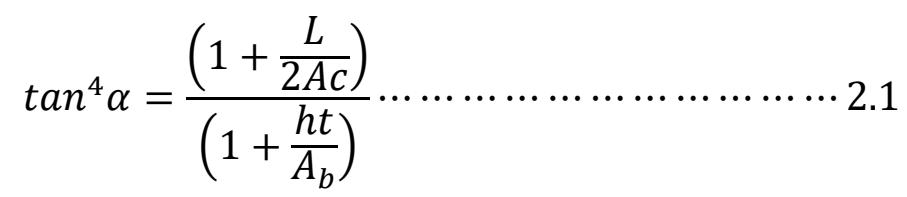

where $\mathrm{L}$ is the width and $\mathrm{h}$ are the bay height respectively, $\mathrm{t}$ is the infill plate thickness, and $\mathrm{A}_{\mathrm{b}}$ is cross-section area of beam and $\mathrm{A}_{\mathrm{c}}$ is cross-sectional area of the storey column.

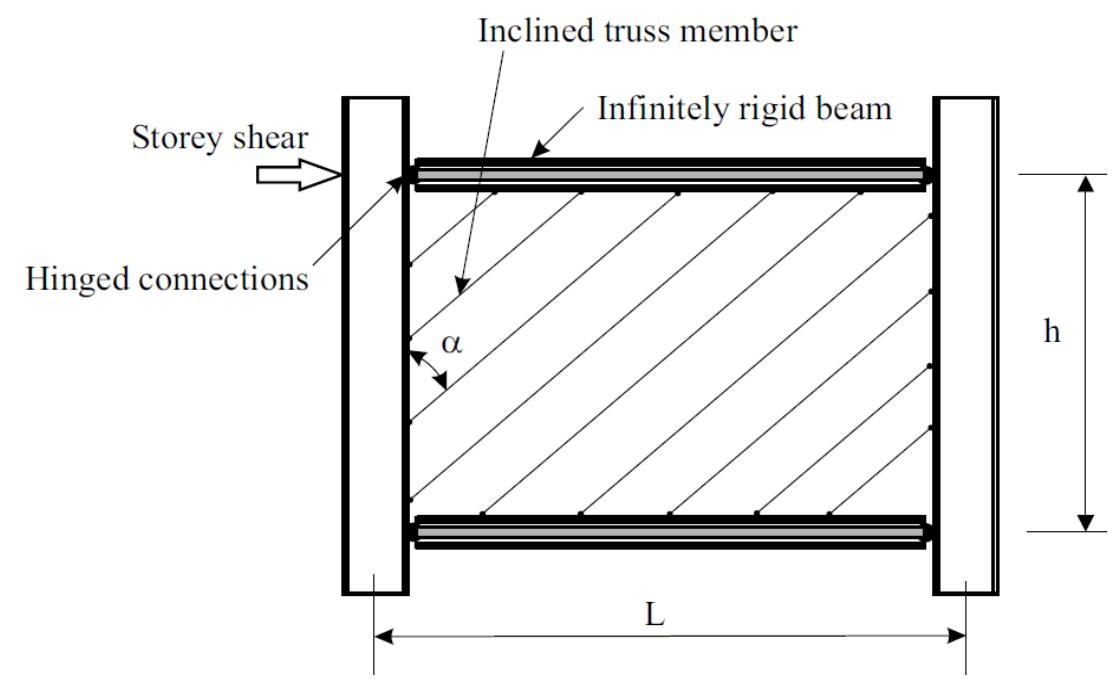

Figure 2.1: Strip model proposed by Thorburn et al. (1983)

Therefore, it was recommended to consider at least ten strips for estimating the strength of SPSW preciously. Additionally, the area of the individual strip must be equal to plate thickness times the strip width, where stripes were oriented at an angle of inclination calculated by above Equation 
(2.1). Even though the equation was proposed for the single storey unstiffened SPSW, it is equally applicable for the multistory SPSW. However, the behavior was not same for the bottom panels and the upper panels in case of multi-storey SPSW. Another drawback was that the little contribution of diagonal compression action which acts opposite to tension filed action was neglected. Above all, considering its effectiveness, Canadian as well as US standard incorporated the model as an analytical tool.

Later, to make the model more simplified for the multi-storey SPSW, instead of multi-strips, a single strip solution was proposed. Only one diagonal bracing in the tension field direction was considered, and Equation (2.2) was proposed for the equivalent bracing area. This single strip model is commonly known as an equivalent bracing model (Figure 2.2). In the end, this model reduced the computation time, but the distribution of plate force over the boundary element was not considered.

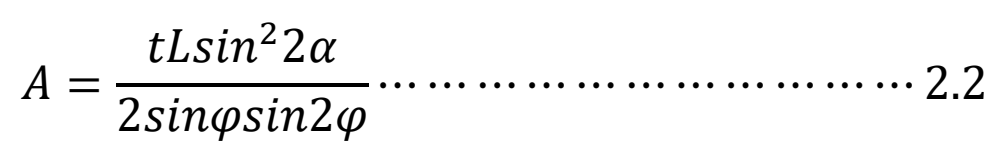

where. $\Phi$ is the angle of the brace on the column; $t$ is the infill plate thickness, and other parameters are defined early.

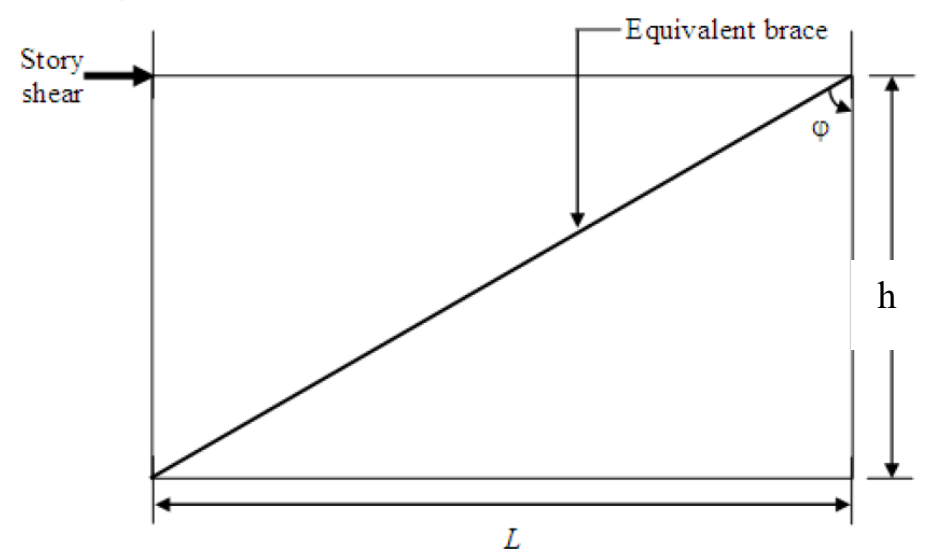

Figure 2.2: Equivalent bracing model proposed by Thorburn et al. (1983) 


\subsection{Timler and Kulak (1983)}

A large scale, one storey, one bay specimen was tested by Timler and Kulak (1983) to validate the analytical model proposed by Thorburn et al.(1983). Moment resisting beam to column connection was considered for the interior beam, on the other hand, pin connection was taken into account for the exterior beam. In this experiment, the test specimen was oriented in such a way that the beams were vertical, and the columns were horizontal as shown in Figure 2.3. Hence, the lateral load was applied along gravity direction at beam-column joint for both service and ultimate level.

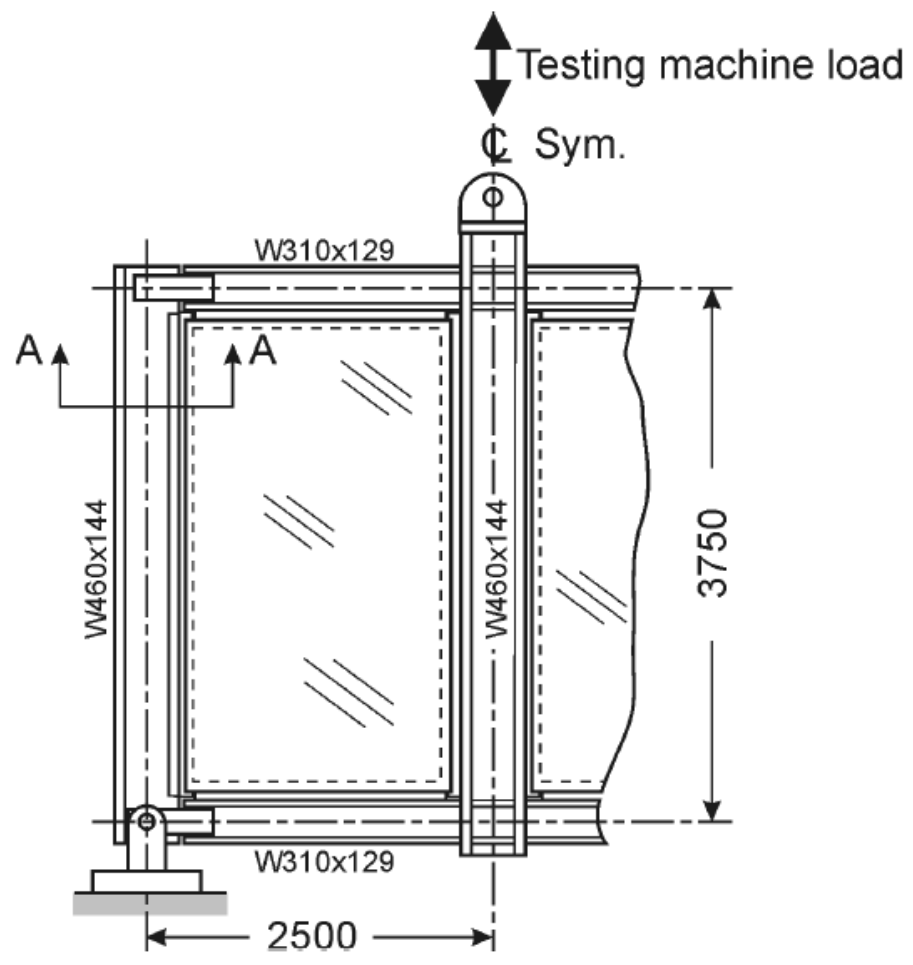

Figure 2.3: SPSW specimen tested by Timler and Kulak (1983)

Therefore, the cyclic load was applied until the attainment of deflection limit. From the experiment, it was observed that predicted load versus deflection curve from the strip model was almost similar to strip model. Moreover, the researchers noted that stiffness of column had some 
influence over tension field action. So, incorporating column stiffness, the Equation 2.1 was modified. The modified equation suggested by Timler and Kulak (1983) is presented below.

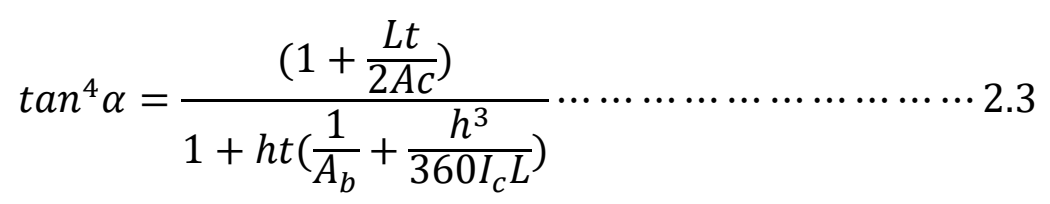

where $I_{c}$ is the column moment of inertia and other parameters were defined in strip model.

\subsection{Tromposch and Kulak (1987)}

Similar to Timler and Kulak (1983), one storey two-panel test specimen was conducted by Tromposch and Kulak (1987). The main difference over the Timler and Kulak (1983) test sample was that the beam and columns were connected by bolts as shown in Figure 2.4. Instead of applying gravity load, the columns were pre-stressed before applying quasi-static cyclic load. After all, the objective of this experiment was to validate the strip model proposed by Thorburn et al. (1983). The hysteretic behavior was also examined and showed excellent ductile behavior. Besides, it was observed that strip model conservatively estimates the initial stiffness and ultimate strength over test results. Hence, it was suggested that the infill plate eccentricity has a negligible effect on global behavior. 


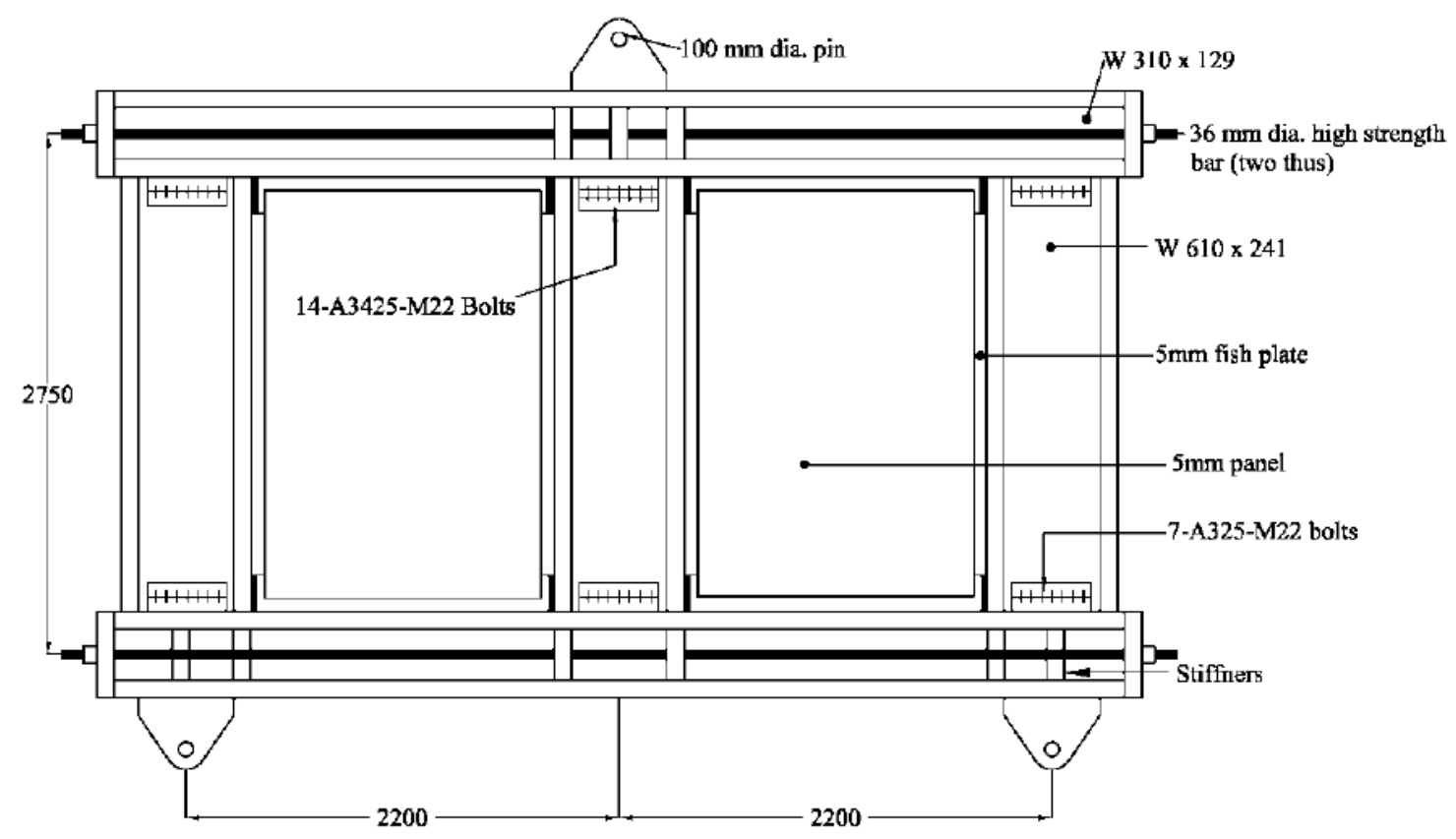

Figure 2.4: Test specimen of Tromposch and Kulak (1987)

\subsection{Roberts and Sabouri-Ghomi (1992)}

First ever perforated SPSW specimen was tested by Roberts et al. (1992) at University of Alberta, Canada. The test specimen was unreinforced, unstiffened as well as single perforation was considered in the center of the infill as shown in Figure 2.5. Subsequently, a series of 16 test specimens with a circular opening at the center of infill plate were conducted for quasi-static cyclic loading protocol. The test specimens were pin ended frame members with dimensions of $300 \mathrm{~mm}$ $\mathrm{x} 300 \mathrm{~mm}$ or $300 \mathrm{~mm} \times 450 \mathrm{~mm}$. Plate thickness was taken either $0.83 \mathrm{~mm}$ or $1.23 \mathrm{~mm}$ for the test samples. Along with solid infill, three centrally spaced opening with diameters of $50 \mathrm{~mm}, 105 \mathrm{~mm}$, and $150 \mathrm{~mm}$ were considered as test samples. 
Based on the experimental result they proposed an equation for linear interpolation of solid infill to perforated infill. The relationship between the solid and perforated infill SPSW is presented in Equation 2.4

$$
\frac{V_{y p, p e r f}}{V_{y p}}=\frac{K_{\text {perf }}}{K_{\text {panel }}}=\left[1-\frac{D}{d}\right] \cdots \cdots \cdots \cdots \cdots \cdots \cdots \cdots \cdots \cdots \cdots \cdots \cdots \cdots \cdot 4
$$

where $\mathrm{V}_{\text {yp }}$ and $K_{\text {panel }}$ are strength and stiffness of solid infill respectively, $\mathrm{V}_{\text {yp, perforated and } K_{\text {perf, are }}}$ the strength and stiffness of perforated infill respectively, $\mathrm{D}$ is the diameter of the opening, and $\mathrm{d}$ is the height of the infill as shown in figure 2.5.

The Equation 2.4 was used to calculate the strength of infill plate for single perforation. However, it was not equally applicable for multiple perforations. Additionally, the test was conducted only for pin ended beam-column connection and strain hardening effect was neglected.

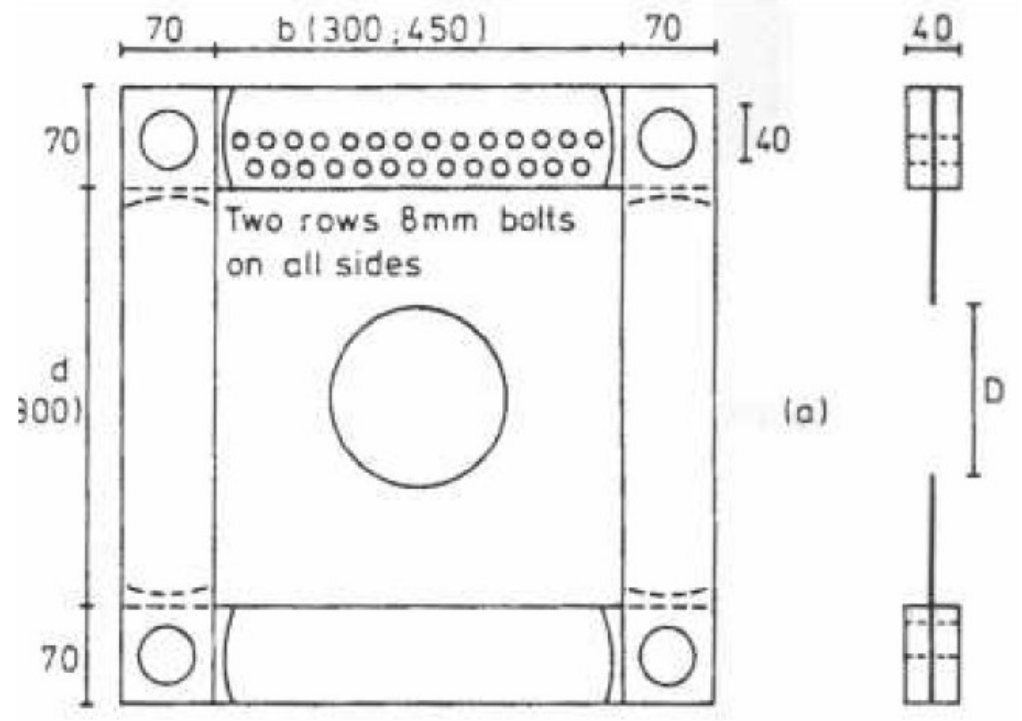

Figure 2.5: Centrally placed perforated specimen (Roberts and Sabouri-Ghomi 1992) 


\subsection{Elgaaly et al. (1993)}

At the University of Maine, small-scale samples were tested for cyclic loading in two phases (I\&II) by Elgaaly et al. (1993). The objective of the experiment was to observe the post-buckling behavior of unstiffened SPSW. In phase I, the test samples was eight-quarter scale, on the other hand, in phase II the test samples were one-third scale. Figure 2.6 is illustrating test specimen conducted by Elgaaly et al. (1993). Both types of connection i.e. bolted and welded were used and it was found that during cyclic loading welded connection exhibited higher stiffness than bolted connection. Also, outstanding post-buckling behavior was observed in unstiffened steel plate for cyclic loading.

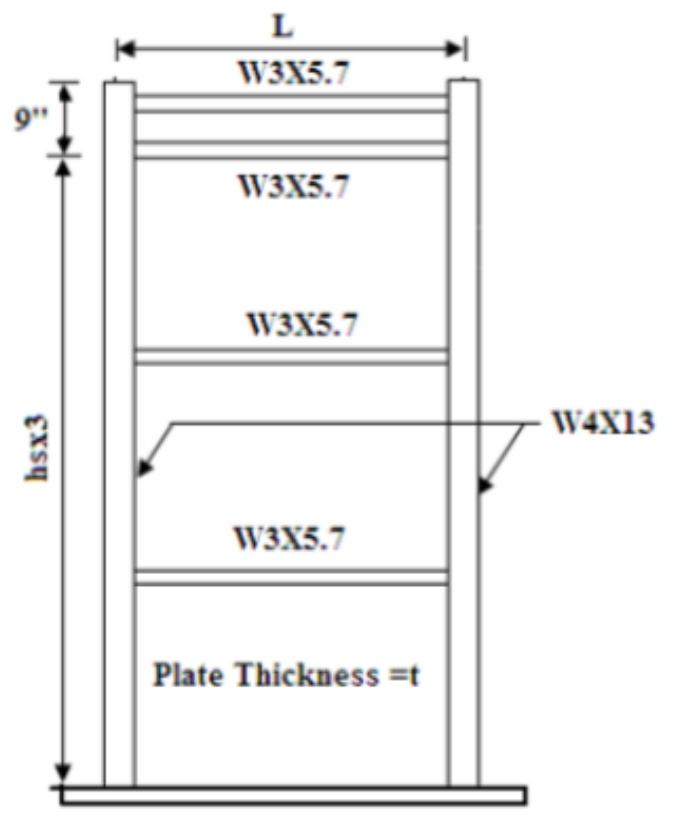

L=49",hs=33" for \$1, MI1, S2, ML2, M[3, F,MI1-O and MI1-W Specimen $\mathrm{t}=0.0299^{\prime \prime}$ for \$1, Mn,MI-O,Mn-W Specimen $t=0.0747$ "for S2,ML2 Specimen $t=1.047$ ' for $\$ 3$ Specimen

\section{$\underline{\text { Test Specimen For Phase I Program }}$}

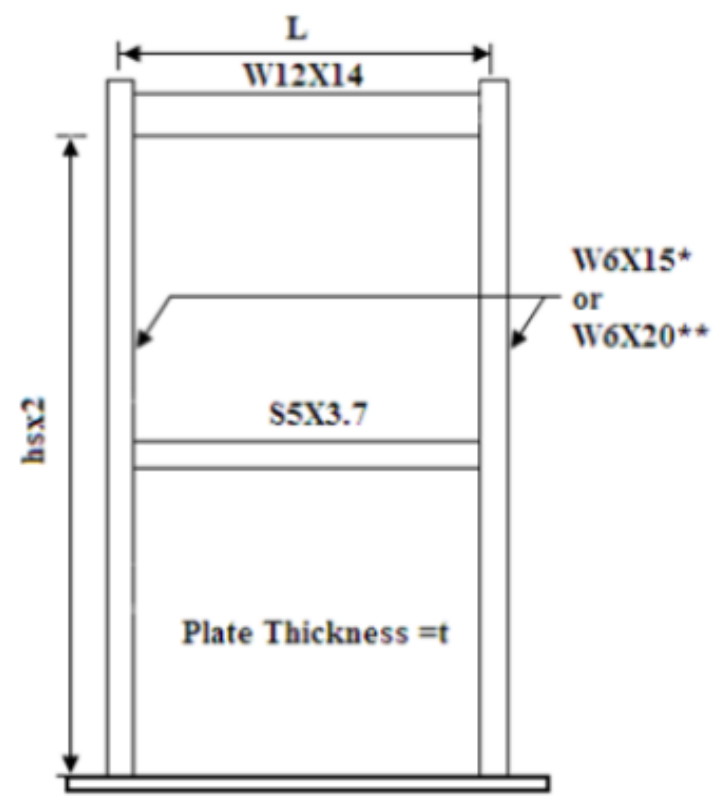

$\mathrm{L}=58$ ",hs=45.5" t=0.0897" for all Specimen *W6X15 for SWT11,SWT12,SWT13 Specimen *W6X20 for SWT15,SWT16,SWT16B Specimen Test Specimen For Phase II Program

Figure 2.6: Test specimens by Elgaaly et al. (1993), Left (Phase I) and Right (phase II) 
Later, Elgaaly et al. (1993) conducted an FE analysis on SPSW to validate his experimental result. Material and geometric nonlinearities were included in the modeling which made the approach more compatible with the real test. For FE modeling, three node beam element was used for boundary members, on the other hand, iso-parametric doubly curved 3D shell element was used for the solid infill. Where, $6 \times 6$ mesh size for infill and six beam members for the boundary element were taken into consideration. Using Newton-Raphson iteration, a monotonically increasing lateral load was applied up to its stability. Nevertheless, results from finite element analysis were higher than the test results because of element selection in FE modeling. In addition, initial imperfection was neglected in the infill. It was the first finite element model where shell element was used for infill panel. Therefore, the FE model was capable of capturing the buckling and post-buckling behavior of the thin panel as well.

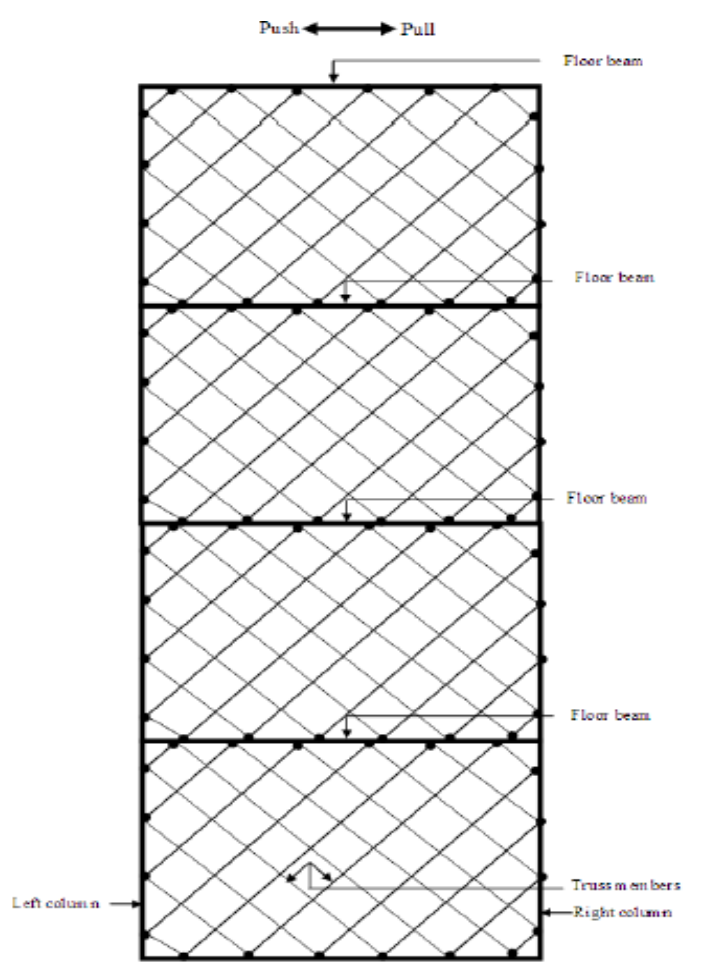

Figure 2.7: Cross-strip model proposed by Elgaaly (1993) 
The strip model only predicts ultimate strength for the monotonically increased lateral load in the direction of tension field action. Therefore, the strip model is not equally applicable for cyclic and seismic loading. To overcome discrepancy, Elgaaly et al. (1993) proposed a cross-strip model. In this model, an equal number of strips were oriented in both directions as shown in Figure 2.7. The hysteretic stress-strain curve was considered for the truss members (stripes) as material property.

\subsection{Xue and Lu (1994)}

A numerical study was conducted by Xue and $\mathrm{Lu}$ (1994) for the three bay and twelve storey frame. The purpose of this study was to assess the behavior of SPSW for different connections. The structures were designed in such a way that only the mid bay consisted of infill plate. Besides, four distinct configurations of the frame were considered in this study. The outer bay connections were always maintained as moment resisting, but beam to column connection in the inner bay was either simple or the rigid. Accordingly, the configurations were i) Beam column moment connection with infill fully attached boundary members ii) Beam column connection with infill only attached with the beams iii) Beam column simple connection with infill fully attached with boundary member's iv) Beam column simple connection with infill connected with beams.

The effect on tension field action for both rigid and pin connection were not reported. It was found that the tension field has little effect whether infill plate connected only with beams or with surrounding boundary member. Moreover, the infill plate connected only with beams can be an efficient solution to reduce the force over the column.

Later, an FE analysis of 12-storey, one bay MRF-SPSW was investigated in this study. Elastic frame element for beam-column and four node shell element for the infill were modeled. After monotonically applying lateral forces to each floor, it was found that beam to column connection 
has little effect on the initial stiffness. During analysis, it was also observed that the SPSW was working like a cantilever beam with the tension field action of infill panel. However, they didn't perform any experiment to validate their findings from finite element modeling.

\subsection{Driver et al. (1997, 1998)}

The extensive and full-scale test was conducted at University of Alberta by Driver et al. (1997). The test was pioneered because of its robustness and also the consideration of real structural condition. Where the specimen was four storey with beam and column size of W310x60 and W310x118 respectively except top beam was W530x118. Additionally, $4.8 \mathrm{~mm}$ and $3.4 \mathrm{~mm}$ plate thickness were used for lower and upper two stories respectively. Besides, moment resisting beam to column connection as well as the infill plates was connected with boundary frame by the fish plate. Where welding connection was used in the entire joint. The test specimen is presented in Figure 2.8. Before applying the cyclic loads, gravity load was applied at the top of the columns. Instead of beam-column joint, cyclic loads had been implemented at the floor levels because this position will be subjected to earthquake loads. Out of 30 cycles, 20 cycles have been applied in the inelastic range during cyclic loading.

From the rest result, it was found that the SPSW provided good initial stiffness, high post-buckling strength, great ductility and excellent energy dissipation capacity. It was also reported that properly designed unstiffened SPSW can be a good lateral load resisting system for high to the medium seismic region. 


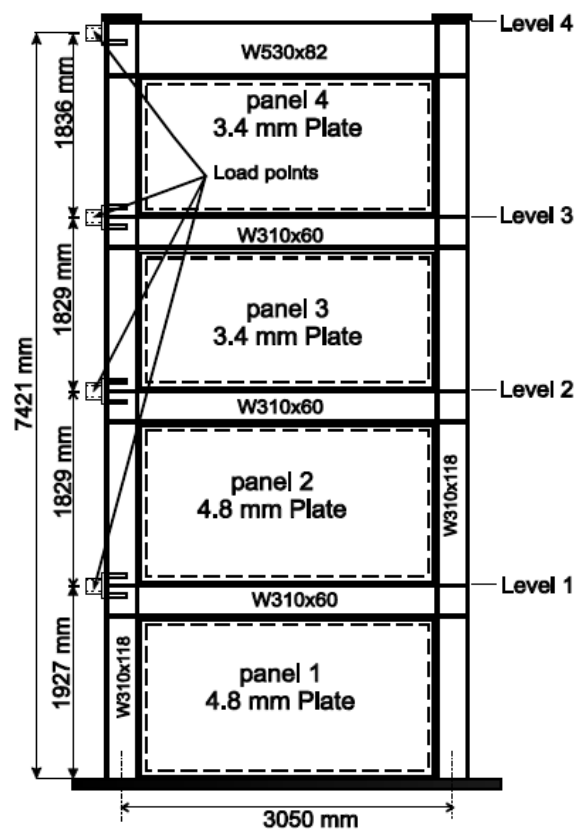

Figure 2.8: TFour storey SPSW specimen tested by Driver et al. (1997)

Driver et al. (1998) developed a finite element model using FE package ABAQUS (Hibbit et al. 1994). Implicit analysis technique was adopted for this study. While modeling the FE of 4-storey SPSW, eight nodes quadratic shell element (S8R5) and three node beam element (3B2) were chosen for the infill and boundary element respectively. Different mesh sizes were considered for different floor during modeling. Mesh size of $6 \times 9,5 \times 9,4 \times 9$ was taken into account for the lower, middle and upper panel respectively. Figure 2.9 represents the finite element modeling developed by Driver et al. (1998). Elastic- plastic material property was considered in modeling Actual moment resisting beam column connection was modeled but instead of a modeling fish plate, direct welding connection between infill and boundary elements was considered. Besides, to simulate the initial imperfection in the infill, the first mode of buckling was incorporated. Out of plane, the movement was restrained at the beam-column connections and fixed boundary conditions were applied at the lower end. 


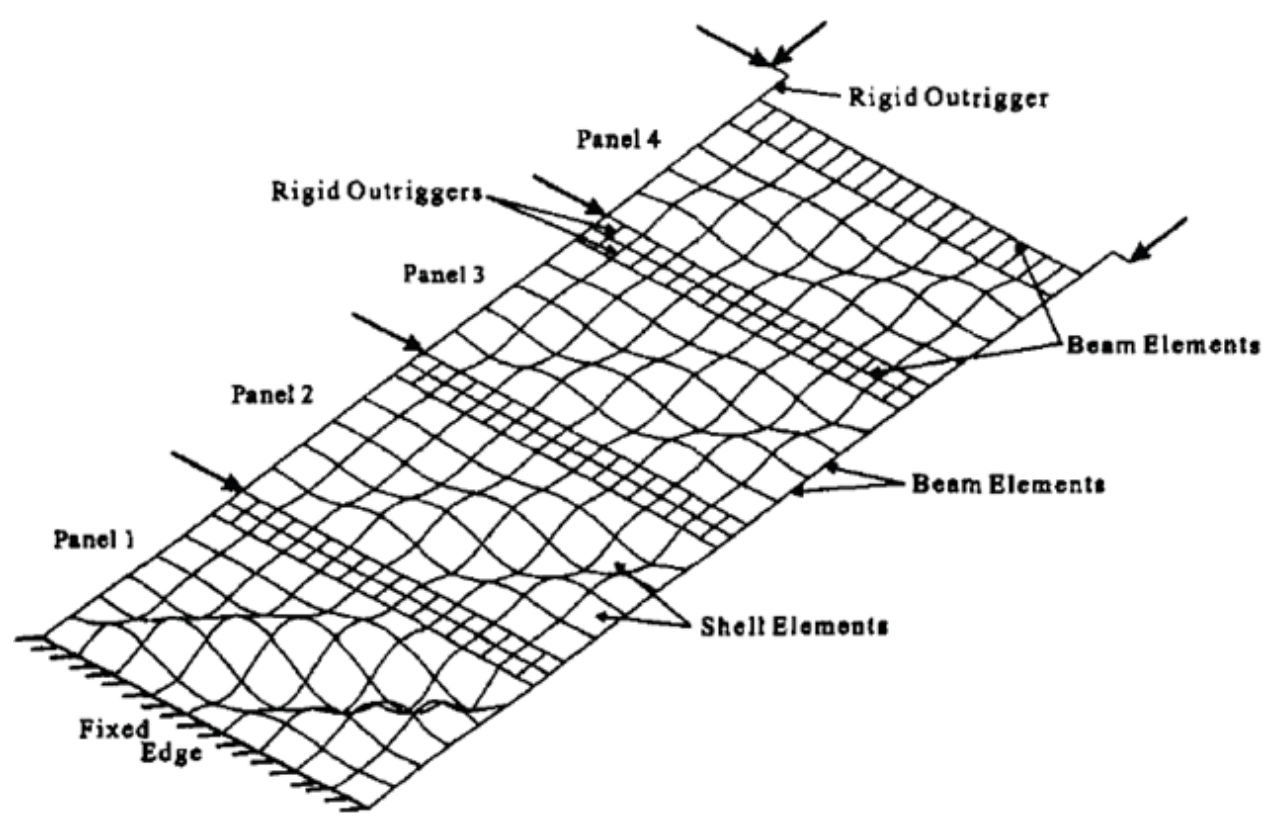

Figure 2.9: Finite element model of specimen tested by Driver et al. (1998) (Deformation scale factor $=5$ )

During analysis, severe convergence problem was reported for the monotonically applied lateral load. After cyclic analysis in FE modeling, it was reported that the FE results over-predicted the test result. Therefore, the researchers recommended that geometric non-linarites should be included during the study. In addition, it was found that including a fish plate or not, the effect was very negligible to provide the global behavior.

The researchers also investigated the strip model (figure: 2-10) for the same experiment using commercially available three-dimensional structural software package S-Frame. The infill panel was replaced by equally spaced pin ended tension only strips with the angle of inclination of $45^{\circ}$. Plastic hinges were incorporated in the frame members to capture the inelastic nature. Even though the result underestimated the both initial stiffness and ultimate strength but capable of capturing the elastic to post-buckling strength. A parametric study was then conducted by changing the number of strips and angle of inclination of tension field ranging from $42^{\circ}$ to $50^{\circ}$. It was suggested 
that using 20 strips instead of 10 had no significant effect on global behavior. Also, the angle of inclination has no effect on global behavior as well if the angle is in between $42^{\circ}$ to $50^{\circ}$.

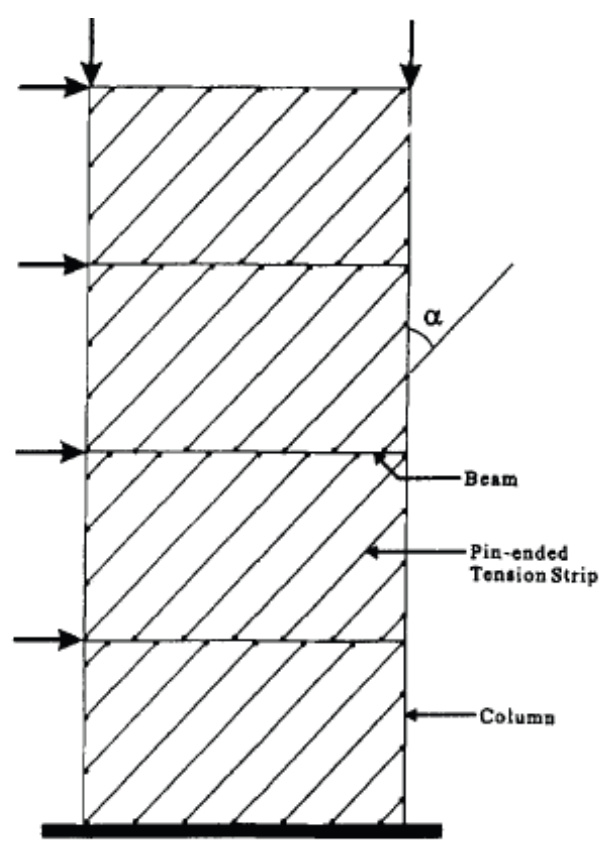

Figure 2.10: Strip model of the test specimen of Driver et al. (1998)

\subsection{Rezai (1999)}

For the first time, shake table test was conducted over SPSW by Rezai (1999) at University of British Colombia. The test specimen was 4-storey one-quarter scale model, where fully moment resisting beam to column connections were used. The infill panel thickness was $1.5 \mathrm{~mm}$ for all the stories. Along with three real ground motions and one synthetically ground motion compatible with Vancouver, were simulated on a shake table. Before applying ground motions, gravity load of $1700 \mathrm{~kg}$ was applied as a floor mass at each level.

During the testing, it was observed that fundamental mode effects the vibration mainly, besides higher modes had little effect on overall vibration pattern. While testing, it was also observed that 
vibration mode exhibited flexural behavior and bottom stories were acted as a shear panel. It was also mentioned that only first-floor shear panel dissipates all the input energy, moreover, the top panel was acted as a rigid body. After all, the inelastic response was prevented due to the lower capacity of the shake table, thus during earthquake loading SPSW was acted in the elastic range.

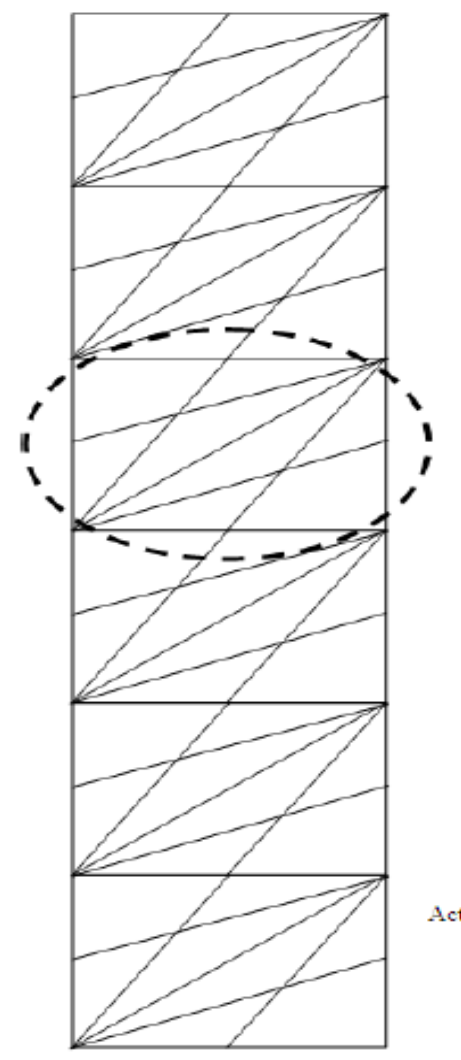

(a) Steel plate shear wall system

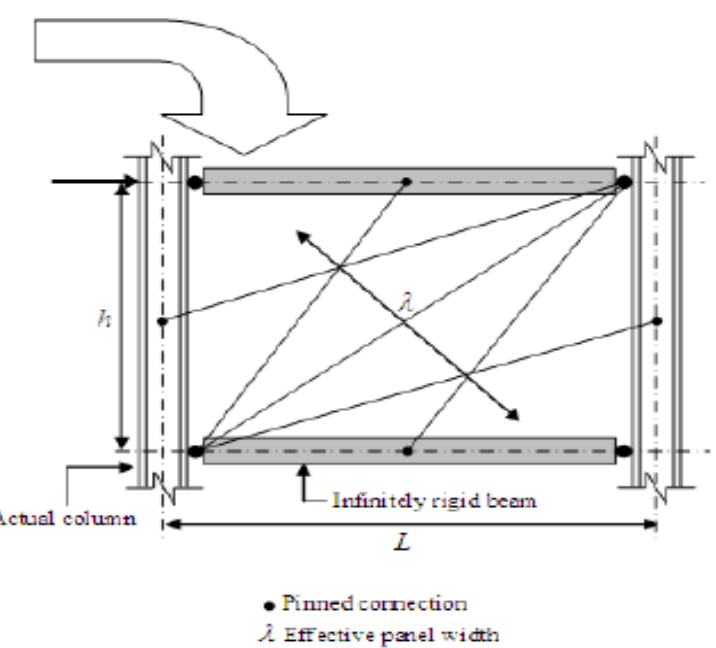

(b) Multi-angle strip model

Figure 2-11: Multi-angle strip model proposed by Rezai (1999)

To overcome the discrepancy in the equivalent brass model, Rezai (1999) proposed multi-angle strip model. In spite of parallel strips oriented at a particular angle along the direction of tension field, only five strips were adopted at a different angle which is represented in Figure 2.11. One truss member has connected both corners in a panel, and other truss members were connected to opposite corner with mid-point of the beam and column. Beam-column connections were 
mentioned as pin and columns were joined continuously with another column. The finite element analysis of the multi-angle strip model closely predicts the exact result but underestimate the ultimate strength.

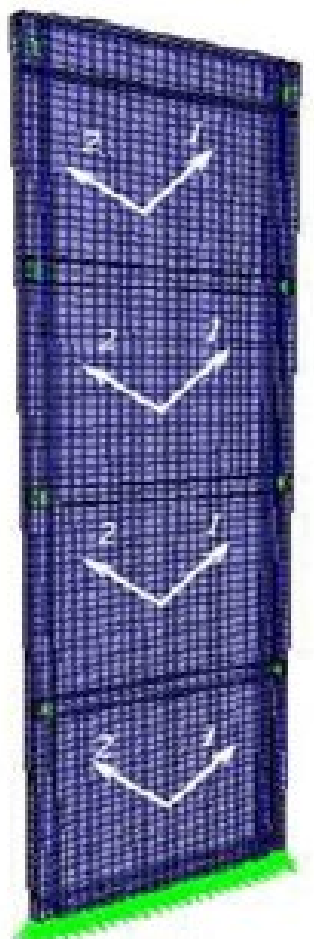

Figure 2-12: Detail finite element modeling of the test specimen of Rezai (1999).

In this study, detail FE modeling was established as well. Instead of an isotropic material, the orthotropic material property was preferred for the infill. Full elastic modules were taken in tension field direction, but $2-5 \%$ of elastic modules was included in the opposite of tension filed because of a small contribution to initial stiffness of steel plate. The orthotropic FE model was validated against the result found by Rezai (1999) at University of British Colombia. Figure 2.12 showing the detail FE modeling of the test specimen. The result provided the high initial stiffness compared to the test result. 


\subsection{Lubell et al. (2000)}

An extensive experimental analysis was conducted by Lubell et al. (2000) for thin steel plate (1.5mm) SPSW at University of British Columbia, Vancouver. The objective of this experiment was to evaluate the applicability of thin plate SPSW for mid to high-rise building because the infill plate thickness requirement is very small compared to available one. For this reason, two single (SPSW1, SPSW2) and one multi-storey (SPSW4) test specimen were designed for Vancouver region. The one storey test samples were one-quarter scale. Similar width and height dimensions of 900mm were considered for each test specimen. Besides, SPSW1 specimen consisted of same beam column size of S75X8 (Figure 2.13a top), however for the SPSW2 specimen, another S75x8 beam was added to the top beam (Figure 2.13a bottom). On the other hand, for the four storey test specimen SPSW4, a deep beam of size S200x34 was used on the top floor (Figure 2.13b). For all the test specimens hot rolled infill plate of $1.5 \mathrm{~mm}$ thickness was used. Even though no external gravity load was applied for the SPSW1 and SPSW2 but the SPSW4 specimen, an amount of $13.5 \mathrm{KN}$ gravity load had been applied on each floor. Finally, all the specimens were subjected to cyclic loading at the beam-column joint.

Well-defined hysteric loops along with excellent initial stiffness were found from the cyclic test but not expected energy dissipation for the selected SPSWs. While testing SPSW4 specimen the columns yielded before the inelastic action of the plate, however for SPSW1 and SPSW2 specimens, infill plate yielded prior to yielding of beam and column. 

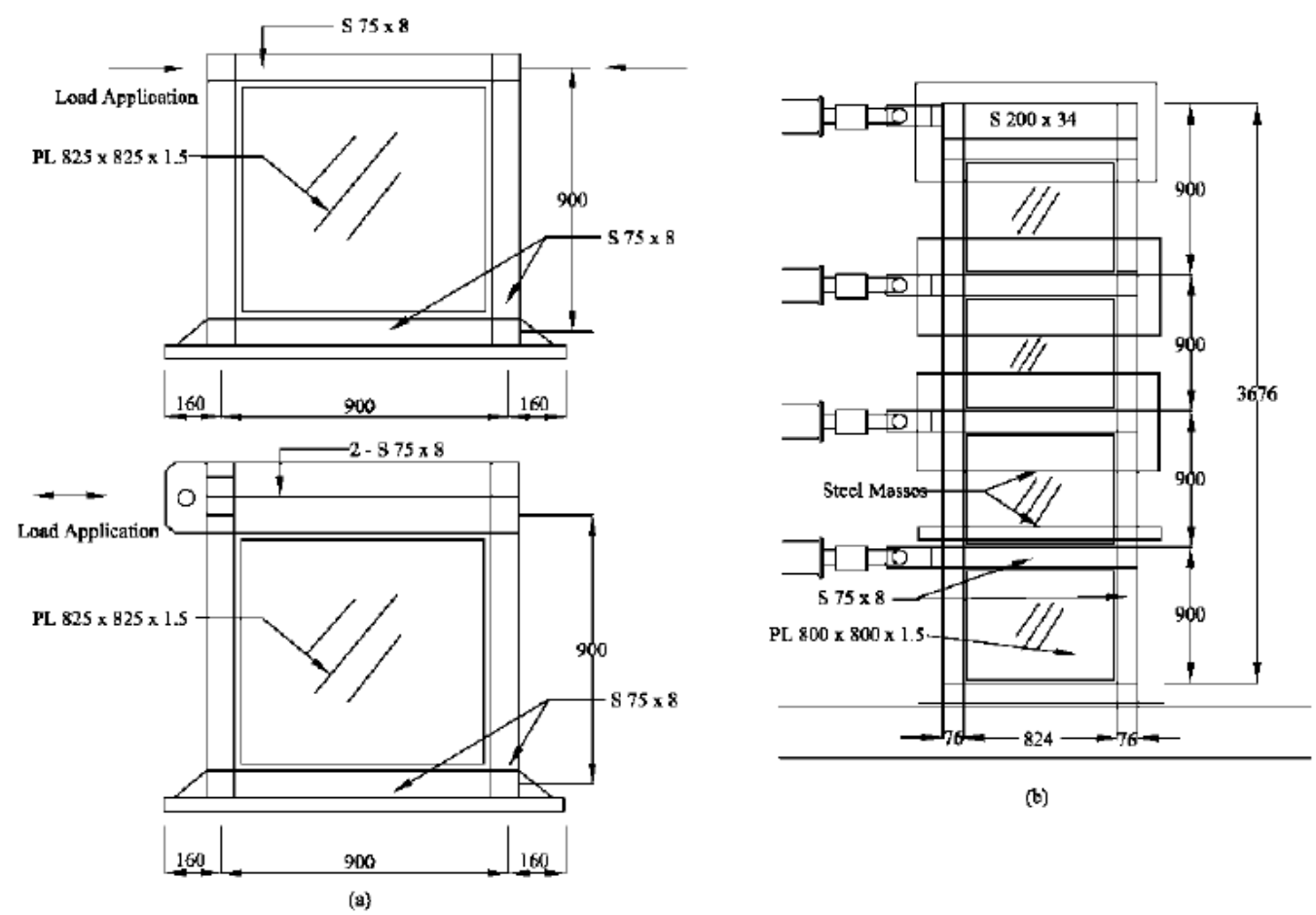

(b)

Figure 2.13: SPSW specimens tested by Lubell et al. (2000): a) SPSW1 (top) \& SPSW2 (bottom) and b) SPSW4

\subsection{Behbahanifard et al. (2003)}

Upper three stories (Figure 2.14) of the 4-storey test specimen conducted by Driver (1997) was considered again as test specimen by Behbahanford et al. (2003). Even though the second story of the 4-storey test specimen was buckled elastically during the test but no reasonable yielding occurred. Besides similar loading condition was maintained for the 3-storey SPSW. Above all, the test sample provided similar initial stiffness, higher ductility, post-buckling strength and good energy dissipation.

A detail finite element model was developed by Behbahanifard et al. (2003) to validate the experimental results. Where the researchers selected explicit finite element analysis using commercial FE package ABAQUS (2001) considering kinematic hardening. Four node shell element (S4R) was considered both for infill and boundary element in FE modeling. The detailed 
modeling of Behbahanifard et al. (2003) is presented in Figure 2.15. Even though the test specimen had some degree of deformation due to its previous test but no residual stress and plastic deformation were included into this FE model.

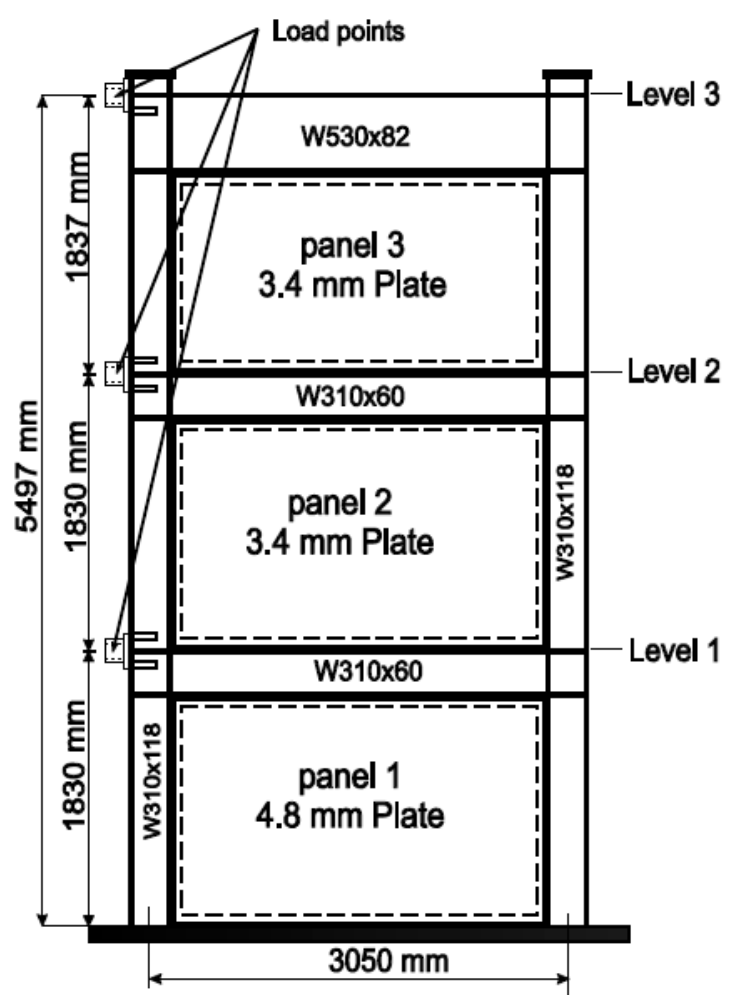

Figure 2.14: 3-storey SPSW specimen tested by Behbahanifard et al. (2003).

Out of plane movements were restrained at the same location of the test during FE modeling. Besides, the first mode buckling of infill plate was included as initial imperfection. No fish plate was modeled as its effect is very negligible over global behavior. It was reported that convergence problem can be easily achieved using explicit analysis technique. Where explicit analysis technique implements Newton-Raphson central difference method without no iteration. After all, monotonic pushover curve was matched with test result but the cyclic test result slightly underestimated the test result which was around $7.8 \%$. In conclusion, the researchers 
recommended the ABAQUS/Explicit analysis to predicted the overall behavior of the large-scale SPSW.

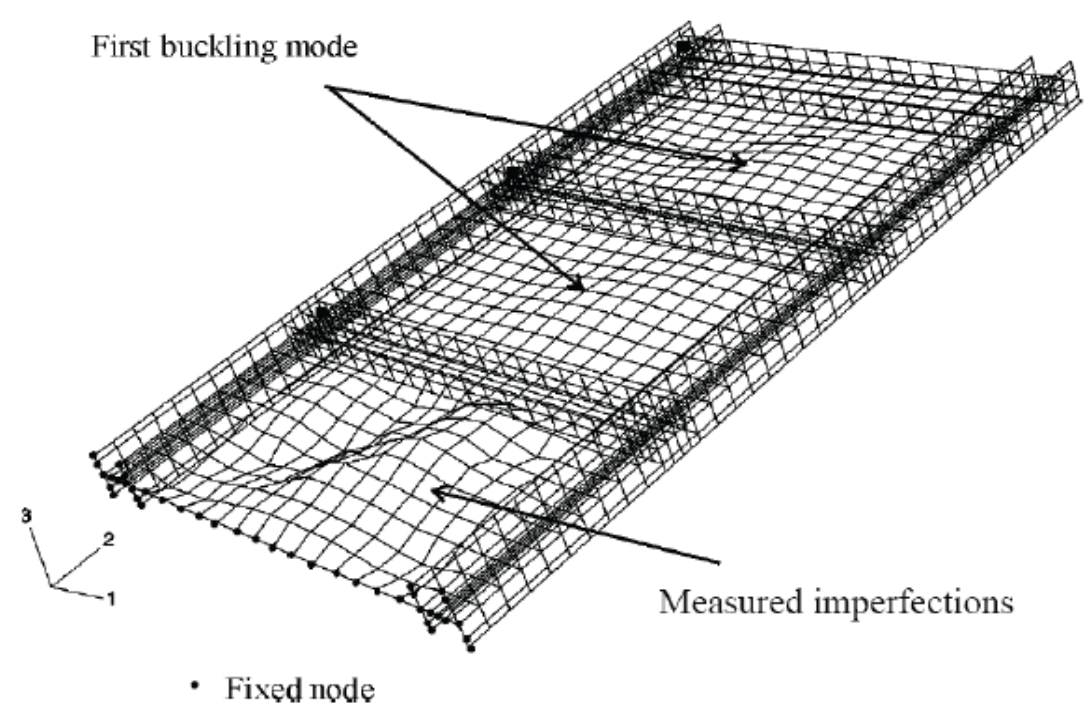

Figure 2.15: Detail FE model of the 3-storey SPSW specimen tested by Behbahanifard et al. (2003).

\subsection{Berman and Bruneau $(2003,2005,2008)$}

An analytical analysis was proposed by Berman and Bruneau (2003) considering plastic collapse mechanism as well as strip model. The primary objective of this research was to develop a design procedure for unstiffened SPSW. Prior to that, the SPSW was designed as plate girder. Single storey pin connected analytical test specimen was considered (Figure 2.16), and ultimate strength of the infill panel was derived by the Equation 2.5. The equation is almost identical to the equation of the CSA/CAN S16-01.

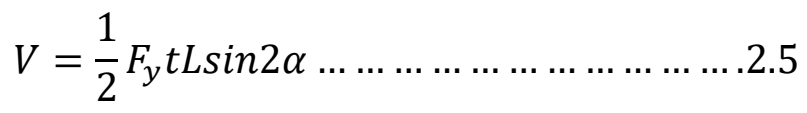


where $\mathrm{V}$ is the maximum shear taken by a steel plate, $\mathrm{F}_{y}$ is the yielding stress of steel plate and other parameters are given before.

On the other hand, for single storey rigid beam to column connection of SPSW, the researchers proposed a modified equation of 2.6. Therefore, work done by smaller plastic hinges of beam or column was included in this equation.

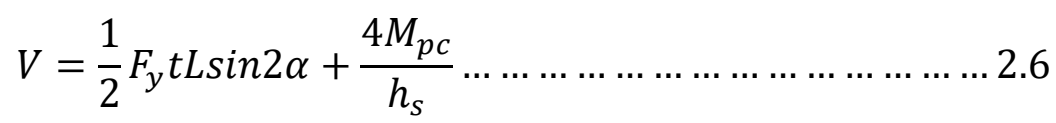

where $M_{p c}$ is the smaller plastic hinges of the beam or column, $h_{s}$ is the infill plate height, and other parameters are given previous.

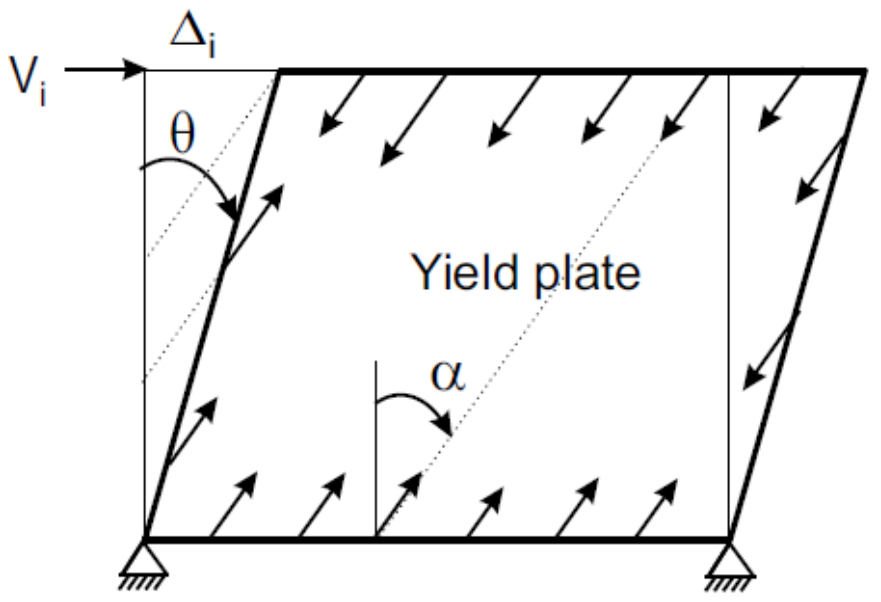

Figure 2-16: Single storey failure mechanism by Berman and Bruneau (2003).

While deriving equation for multi-storey SPSW connected with simple beam to column, the researchers took into consideration two failure mechanism, one was soft storey failure mechanism (Figure 2.16a), and another one was uniform failure mechanism (Figure 2.16b). For the soft storey failure mechanism, hinges were considered at the column where stiffness was less. So the work done by the soft storey column plastic hinges were included in Eq. 2.7. On the other hand, for 
uniform collapse mechanism, two cases were presented, one for the pin connected the beam to the column and another for moment resisting beam to column connection. For pin connected boundary members, uniform plate yielding will be governed by the ultimate strength. So they proposed Equation 2.8 for uniform plate yielding.

In addition, for moment resisting multistory SPSW, only uniform collapse mechanism was recommended, and ultimate strength of the SPSW was developed as per Equation 2.9. Therefore, infill plate will be yielded prior to forming of plastic hinges at the end of each beam. Later, plastic hinges will be formed at the bottom and top of the columns following of plastic beam hinges.

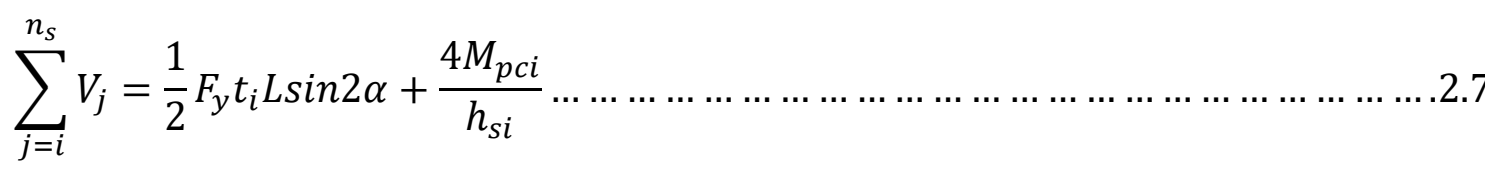

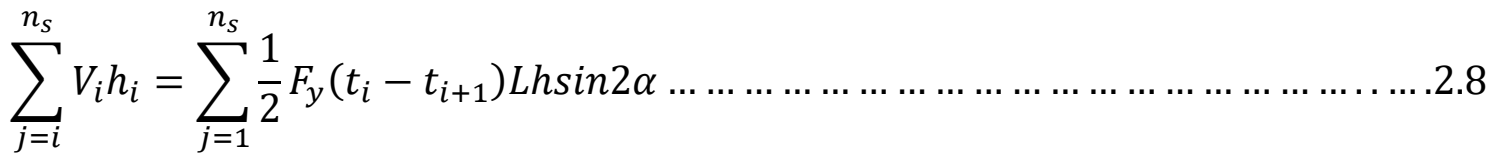

$\sum_{j=i}^{n_{s}} V_{i} h_{i}=2 M_{p c 1}+2 M_{p c n}+\sum_{j=1}^{n_{S}-1} M_{p b i}+\sum_{j=1}^{n_{s}} \frac{1}{2} F_{y}\left(t_{i}-t_{i+1}\right) L h_{j} \sin 2 \alpha \ldots \ldots \ldots \ldots 2.9$

where, $\mathrm{V}_{\mathrm{i}}$ is the applied lateral force at $\mathrm{i}^{\text {th }}$ floor, $t_{i}, t_{i+1}$ is the plate thickness at $\mathrm{i}^{\text {th }}, \mathrm{i}+1^{\text {th }}$ floor respectively $M_{p b i}$ Plastic moment capacity of $\mathrm{i}^{\text {th }}$ storey beam, $M_{p c l}$ plastic moment capacity of bottom column, $M_{p c n}$ plastic moment cpacity of top the column and other parameters are presented previous. 


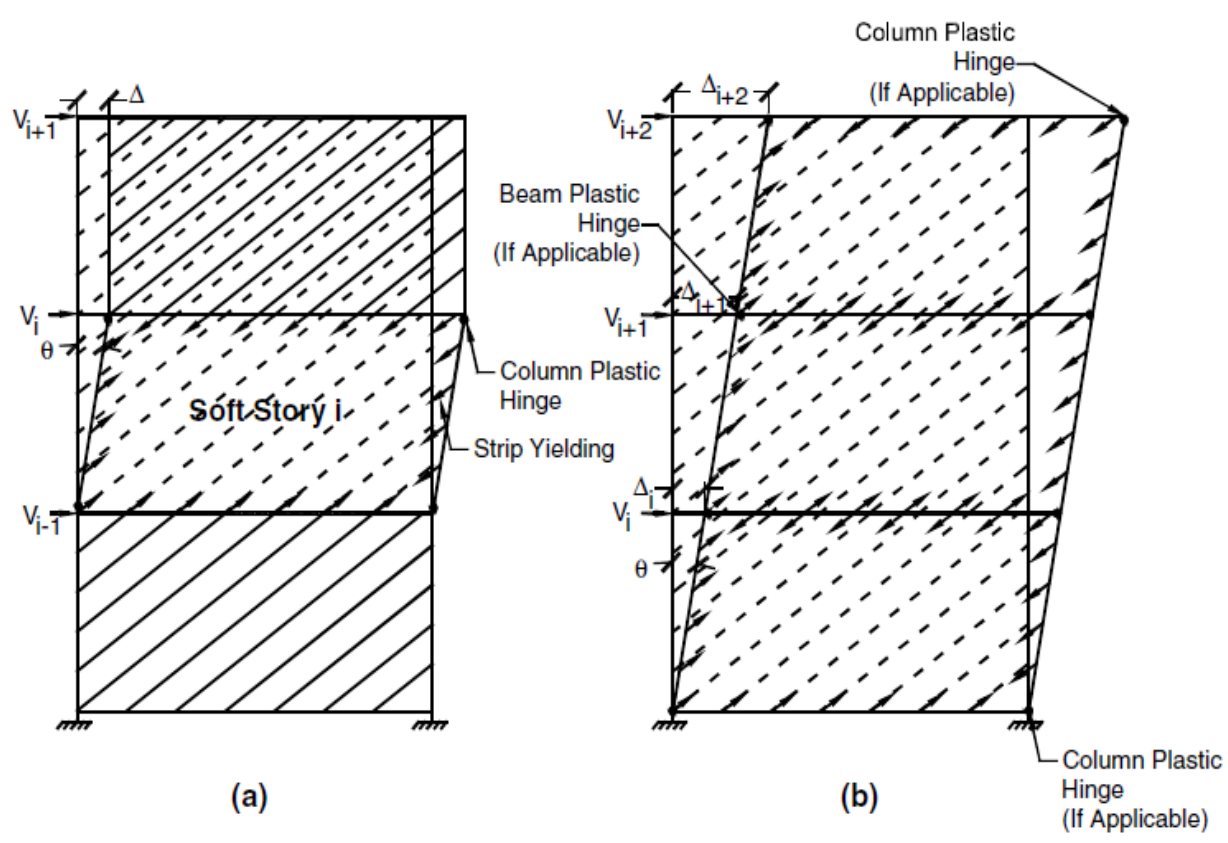

Figure 2.17: Collapse mechanism of the multi-storey SPSW: a) soft storey collapse and b) Uniform collapse mechanism.

Furthermore, the investigators validated the analytical model with experiments. Along with simple semi-rigid, rigid beam to column connections was also considered for SPSW in this study. All the analytical results underestimated the test results. As a consequence, researchers concluded that the Equation 2.5 extracted from the strip model but this approach always conservatively estimates plate thickness. So a factor $(\Omega)$ was included for determining plate thickness (Equation 2.9).

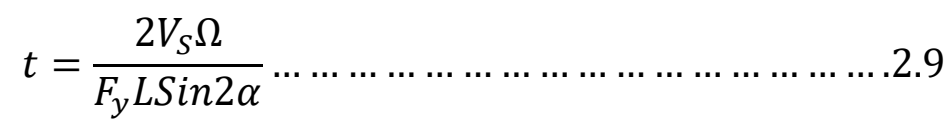

where $V s$ story shear and $\Omega=1.1-1.5$

Later, Berman and Bruneau (2005) conducted a series of SPSW test for seismic retrofitting of the hospital building. Instead of hot rolled thick steel plate, the investigators incorporated cold formed light gauge thin steel plate. So the goal of this study was to minimize the plate force over the surrounding members by using light gauge cold rolled steel plate. Flat and corrugated steel plate were used with two different connections (welded/epoxy). Half scale test specimens with the 
dimensions of $3660 \mathrm{~mm} \times 1830 \mathrm{~mm}$ were designed in such a way that boundary member will lie within elastic limit after loading. Under this circumstances, samples are divided into two types, accordingly Type A (F1-flate infill with epoxy connections and F2-flate infill with welded connections) and Type B (C1- corrugated infill with epoxy connections). Mainly 22 gauge $(0.75 \mathrm{~mm})$ corrugated infill and 20 gauge $(1 \mathrm{~mm})$ flat infill were used. Quasi-static loading scheme was maintained at the top of each steel plate as shown in Figure 2.18.

F2 test specimen exhibited excellent elasto-plastic behavior, good initial stiffness, high displacement reasonable energy dissipation. The sample reached ductility ratio up to 12 in compared to the elastic limit. On the other hand, sample F1 didn't provide reasonable behavior because of the limited shear strength of epoxy. Cyclic test for $\mathrm{C} 1$ specimen provided unsymmetrical hysteretic loop due to the orientation of corrugations only in tension field direction. Therefore, it was recommended that corrugated plate should be provided in opposite direction in a different bay.

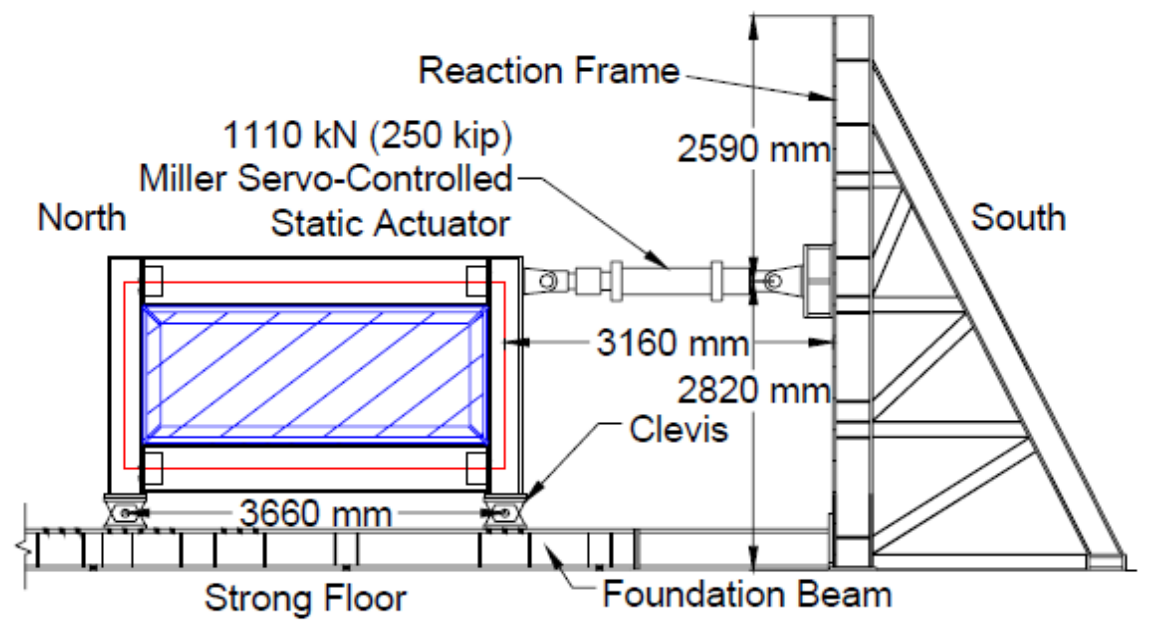

Figure 2.18: Loading frame with test specimen by Berman and Bruneau (2005) 
For vertical boundary element design, Berman and Bruneau (2008) proposed a capacity design approach. Considering fundamental plastic collapse mechanism, the researchers included plastic hinges at the bottom of each column. Prior to column hinge, plastic beam hinges will be formed at each end, and infill plate will be yielded fully. Linear beam design was incorporated, and nonlinearity was excluded during the analysis which made the design more compatible.

It was conservative to use only uniform plastic collapse mechanism, but soft story failure mechanism was ignored for this analytical procedure. The infill plates and HBEs of the SPSW were considered as a resisting factored load. The reduced plastic moment capacity for HBEs was used for calculating the moment of VBEs at each story. Where Figure 2.19 represents the free body diagram of the VBEs. Later two 4-storey SPSW were designed maintaining constant plate thickness and variable plate thickness respectively. Good agreement was reported for the proposed procedure and pushover analysis results.
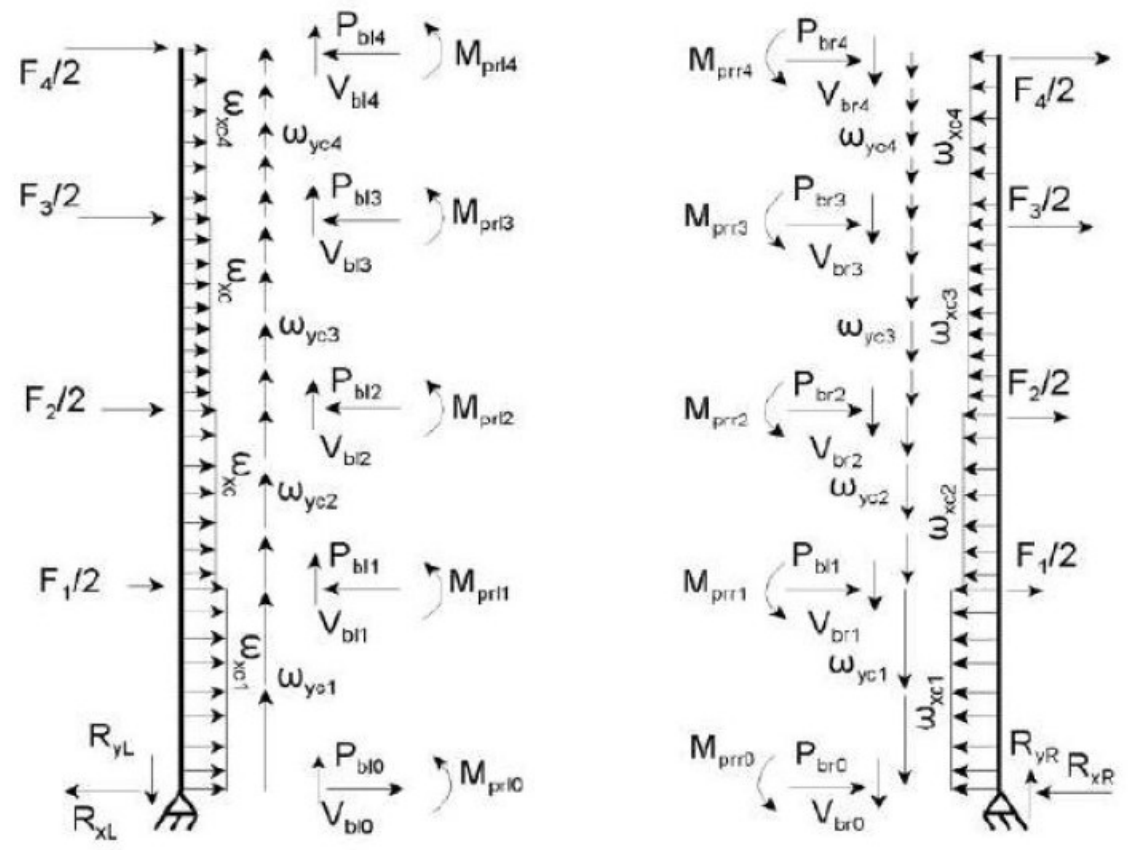

Figure 2.19: Free body diagram of the VBEs (Berman and Bruneau 2008) 


\subsection{Vian and Bruneau (2005)}

Vian et al. (2005) conducted an analytical study for the uniformly distributed perforation over the entire infill plate. Roberts et al. (1992) proposed Equation 2.4 only applicable for centrally placed single perforation. For the multiple perforations, Vian et al. (2005) considered single strip as shown in Figure 2.20 and proposed a modified Equation (2.10) corresponding to a single strip.

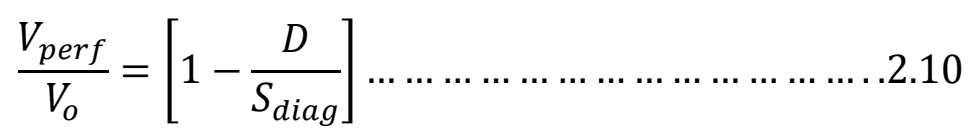

where $V_{\text {perf }}$ and $V_{o}$ are the shear strength of perforates and solid infill plate respectively, $S_{\text {diag }}$ is the perforated strip width, and other parameters are mentioned early.

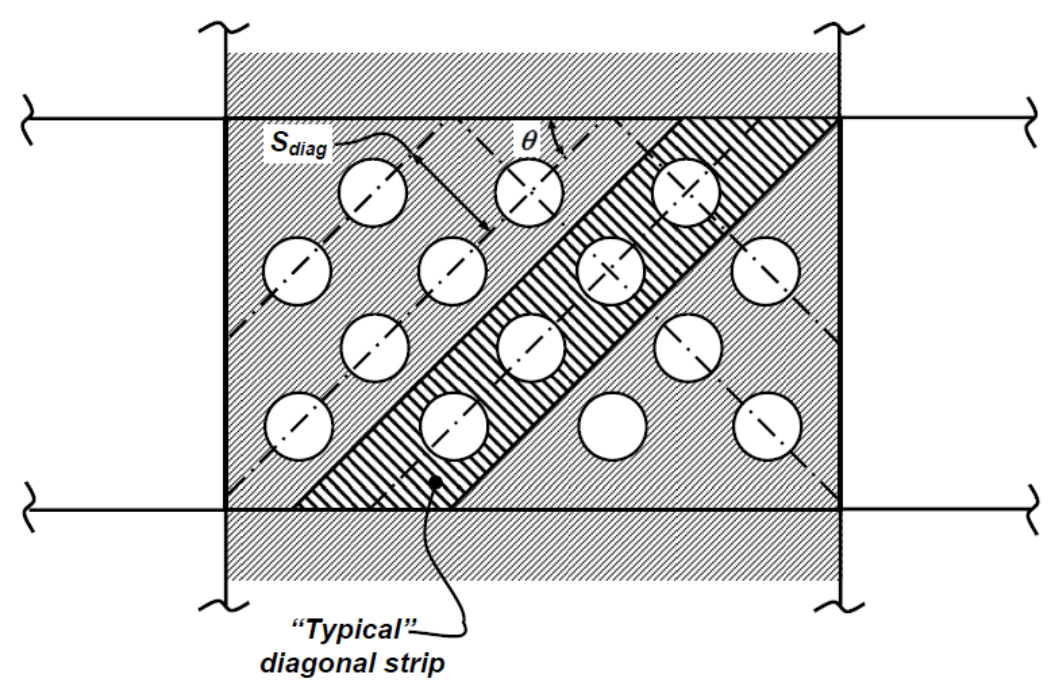

Figure 2.20: Schematic details of perforated SPSW and individual strip (Vian et al. 2005)

Openings are required to facilitate the utilities as well to reduce the force over the surrounding boundary elements. Along with one solid infill SPSW (S2) specimens, two perforated SPSW (Circular-P and corner cut -CR) test were conducted at University of Buffalo, the USA by Vian et al. (2005). Where, the Low yield steel (LYS) plate was used in infill with reduced beam section 
for the seismic retrofitting. Additional reinforcements were provided around the corner cutout (CR), on the other hand, circular perforations (P) were unreinforced.

One half scale size of the test specimen with $4000 \mathrm{~mm} \times 2000 \mathrm{~mm}$ dimension of width and height respectively. W18x65 and W18x71 (USA standard) size beam and column were selected respectively. For the circular perforated specimen (P), the diameter of the opening was $200 \mathrm{~mm}$ and a center to center distance of $300 \mathrm{~mm}$. Also, openings were oriented in $45^{\circ}$ (Figure 2.21). On the other hand, $500 \mathrm{~mm}$ radius quarter-circle corner cutout with $160 \mathrm{~mm} \times 19 \mathrm{~mm}$ reinforced was provided to reduce the stress concentration around the borders (Figure 2.21).

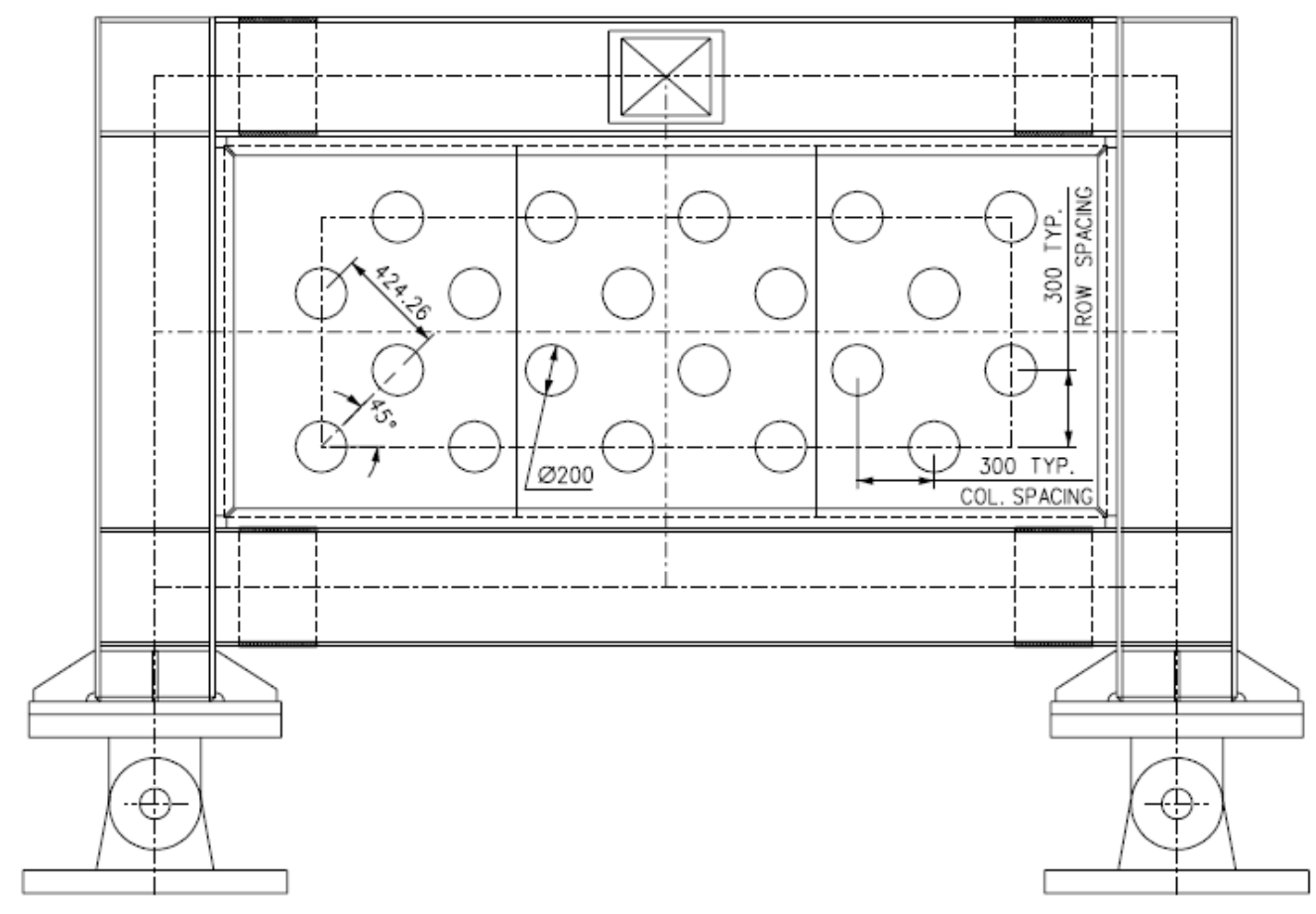

Figure 2.21 Perforated SPSW (P-specimen) (Vian et al. 2005)

Before testing three specimens (P, CR, and S2), one identical solid infill specimen (S1) was tested to gain knowledge. Thus, the midpoint of the top beam was subjected to quasi-static cyclic load 
until the attainment of 3\% inter-storey drifts both for S2 and P specimen and 4\% inter-storey drift for CR specimen.

Outstanding test results were reported for all sample, and it was recommended that no reinforcement was required around the openings for the perforated test sample (P). Moreover, it was reported that P-specimen can effectively reduce the reaction force over boundary members.

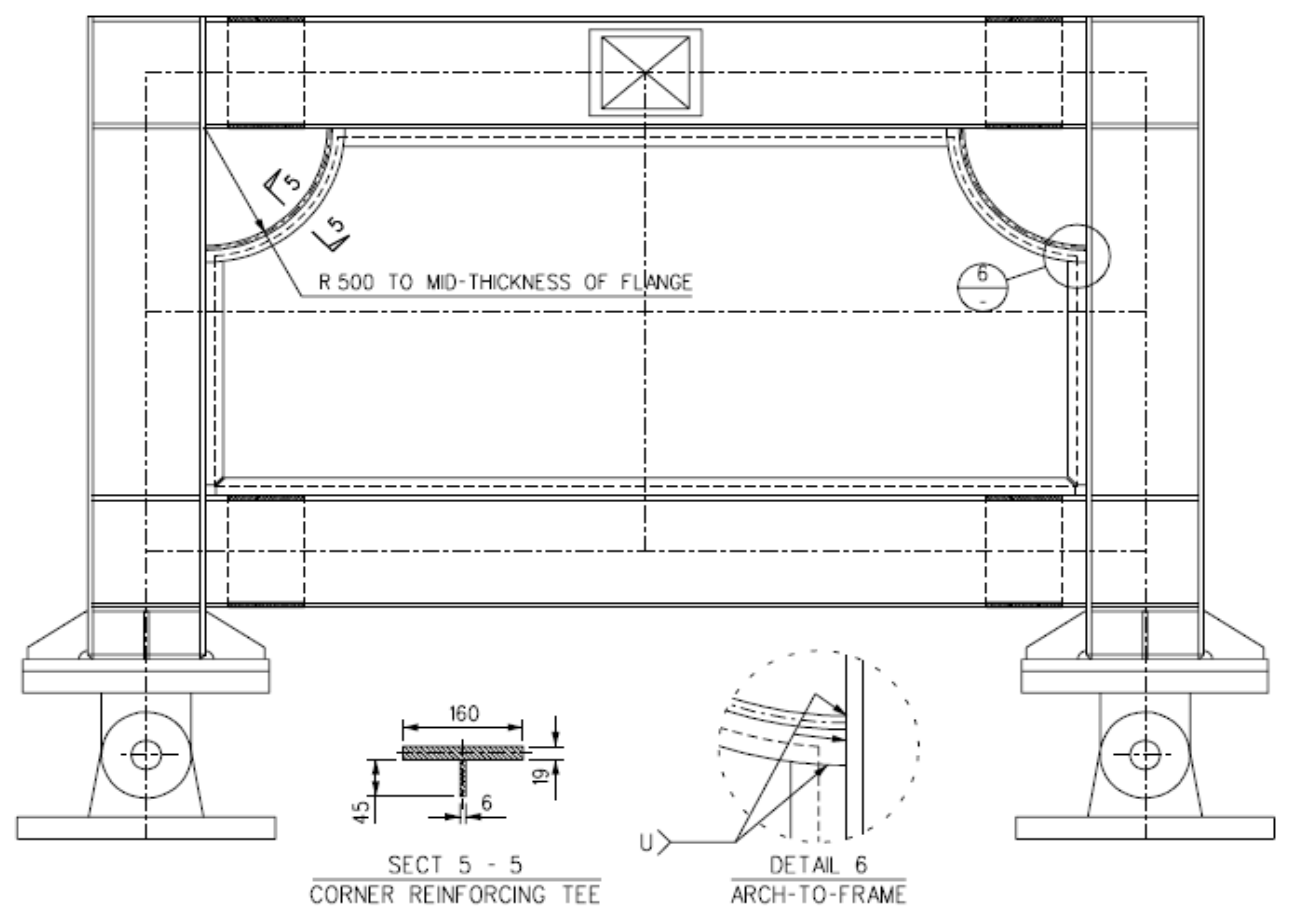

Figure 2.22: Corner cut-out test sample (CR) (Vian et al. 2005)

In addition, Vian et al. (2005) conducted a finite element analysis using four node shell element (S4R) using ABAQUS/CAE (2003). For the material properties, uniaxial tension test data was incorporated for the boundary members, but half cycle experimental data was integrated into the infill plate. Boundary condition was applied at the bottom of each column releasing the rotation perpendicular to the specimen and out of plane movement was restrained at the flange of the top beam and column joint (Figure 2.23). Displacement control analysis was done at the mid-point of 
the top beam, and the first buckling mode was incorporated as initial imperfection. Above all, a good correlation was observed for monotonic and cyclic FE analysis result with the test results.

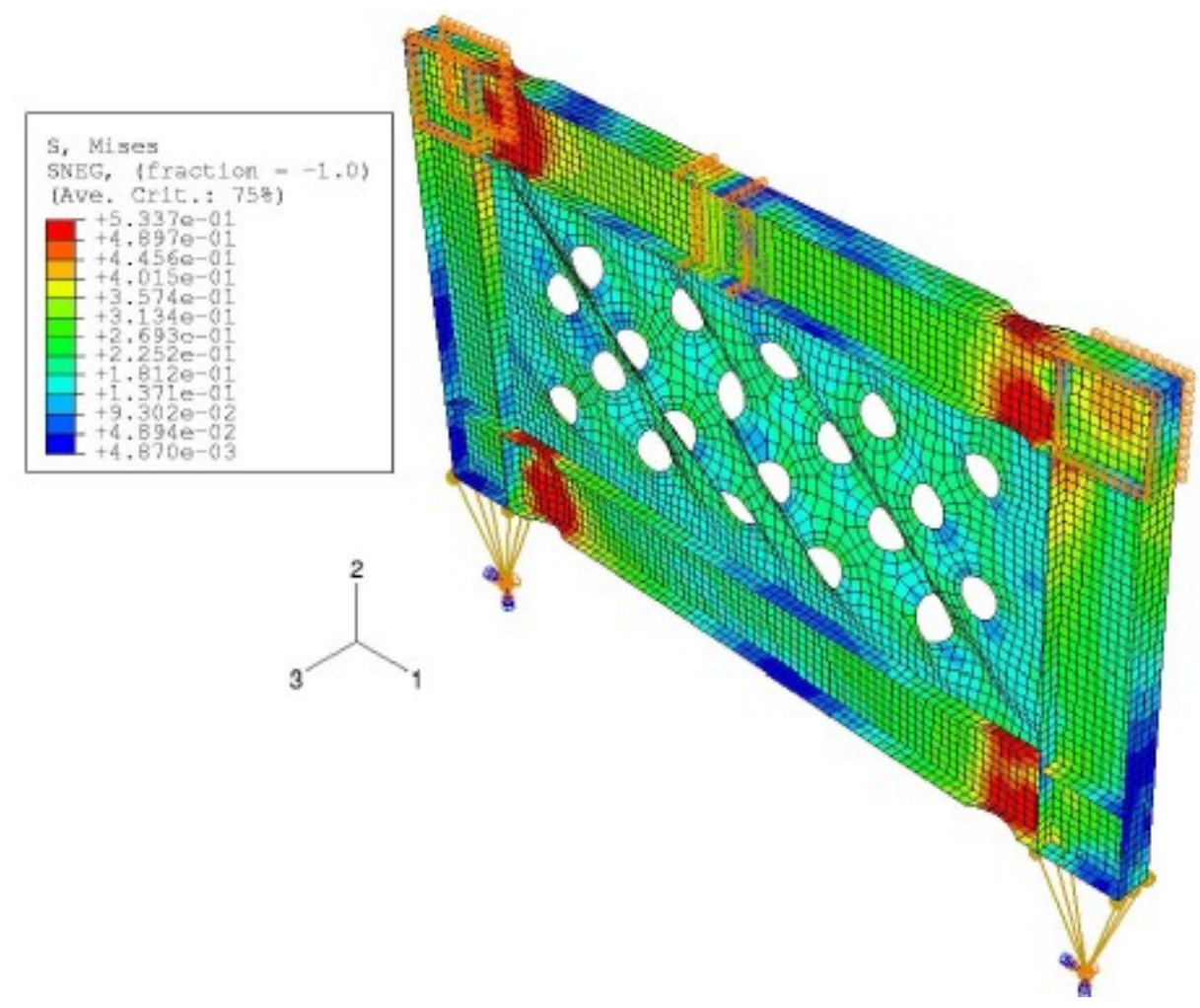

Figure 2.23: Finite element model of perforated SPSW (Vian et al. 2005)

FE modeling was extended further for the individual strip with a dimension of $2000 \mathrm{~mm} \times 400 \mathrm{~mm}$ considering different openings diameters $(100 \mathrm{~mm}, 150 \mathrm{~mm}$, and $200 \mathrm{~mm})$ to look the individual elongation carefully. Nonetheless, the discrepancy was reported between single strip analytical model and finite element model. After all, they recommended further study on single perforated strip mesh refinement and stress-strain distribution along the periphery of the hole.

\subsection{Purba and Bruneau (2006)}

To resolve individual strip perforation problems as reported by Vian et al. (2005), Purba et al. (2006) extended the research work. The objective was to investigate the individual perforated strip 
strength and get the overall strength of SPSW. Using FE, Purba et al. (2006) modeled single strip with a dimension of $2000 \mathrm{mmx} 400 \mathrm{~mm}$ with perforation diameter $\mathrm{D}=100 \mathrm{~mm}$. The model was identical with Vian et al. (2005) single strip model, however, effective mesh refinement was investigated (Figure 2.24)

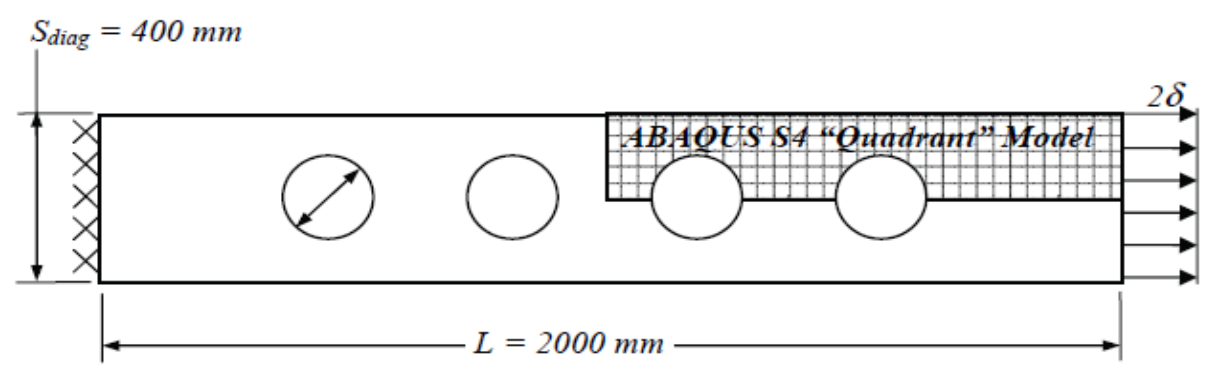

(a) Geometry of Perforated Strip

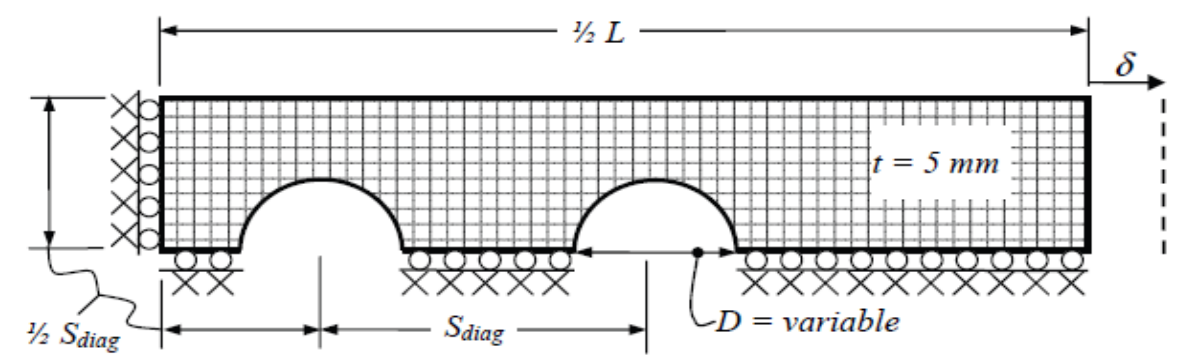

Figure 2.24: Schematic Representation of Individual Strip (Purba et al. 2006)

Based on the previous investigation for $100 \mathrm{~mm}$ diameter hole, the researchers extended similar technique for the different perforations (Diameter $10 \mathrm{~mm}-300 \mathrm{~mm}$ ) along with various boundary conditions and plate thickness. Later single storey SPSW with different perforation diameter, with modified plate thickness were evaluated. After nonlinear pushover analysis over the single-storey SPSW, the result indicated that individual perforation exhibited good agreement with full SPSW behavior. It was reported that the perforation should be less than $60 \%$ along the single strip (D/S $\left.\mathrm{S}_{\text {diag }}<0.6\right)$. At the same time, it was recommended that there was no effect between adjacent strips in stress distribution. So single perforated strip model was justified. 
Purba et al. (2006) also carefully looked at the equation proposed by Sabouri-Goumi (1992) and Vian et al. (2005). Later, he suggested a modification of Equation 2.11 for multiple perforations spaced all over in infill panel.

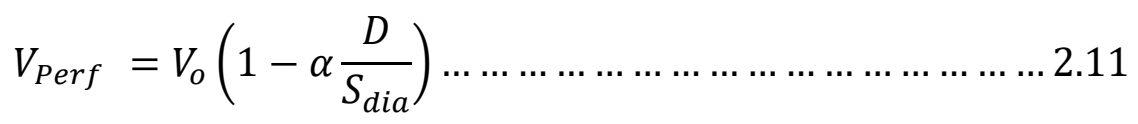

The proposed correction factor $\alpha=0.7$.

Besides, two corner cutout SPSW models were considered in this study as well. Based on the investigation, it was recommended that corner cutout can be designed considering it solid infill.

\subsection{Bhowmick et al. (2009)}

A comprehensive finite element analysis was conducted by Bhowmick et al. (2009) over SPSW. Using FE software ABAQUS/Standard (Hibbitt et al. 2007), the researchers included material, geometric non-linirities, and strain rate effects.

In this research, Ductile (Type D) and Limited Ductile (Type LD) with rigidly connected beam to a column of 4-and 8-story SPSW were designed which were compatible with Vancouver and Montreal seismic response. Therefore, for Seismic load calculation and designing beams/columns, NBCC2005, and CAN/CSA S16-01 seismic provision were considered respectively. Nonlinear Dynamic analysis was performed over two different stories for different earthquake records. As expected, Type D SPSW performed more ductile than Type LD (Figure 2.25).

Later, the researchers studied strain rate and P- $\Delta$ effect over steel plate shear wall in seismic response. 4- and 15- storey SPSW was designed according to NBCC2005 and CAN/CSA S16-01 compatible with Vancouver region. Strain rate effect was incorporated into the finite element 
model as proposed by Cowper-Symonds overstress power law (Cowper and Symonds 1957) as shown in Equation of 2.12.

$$
\dot{\varepsilon}_{p}=D\left(\frac{\sigma_{D}}{\sigma_{r}}-1\right)^{q}
$$

where $\dot{\varepsilon}_{p}$ is the plastic strain rate effect, $\sigma_{\mathrm{D}}$ is the dynamic and $\sigma \mathrm{r}$ is static yield stress. $\mathrm{D}$ and $\mathrm{q}$ are material properties which taken $40.4 \mathrm{sec}^{-1}$ and 5 respectively.

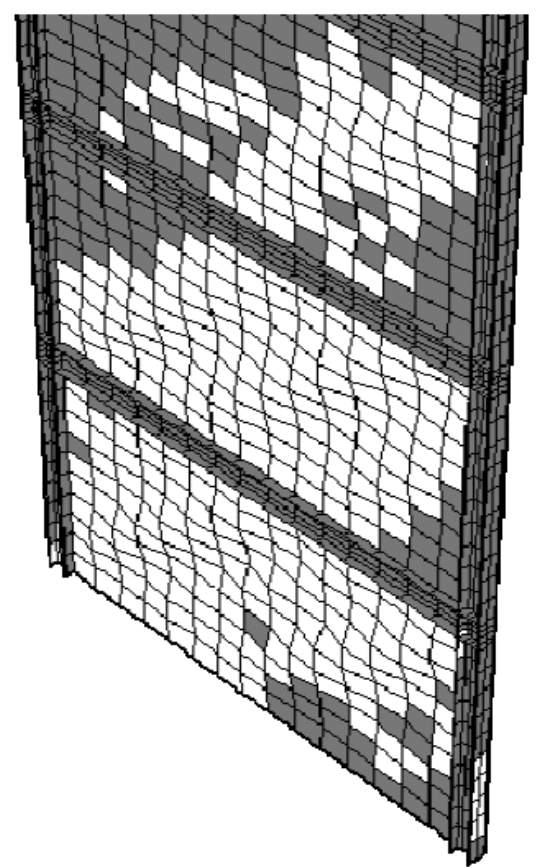

Type D SPSW

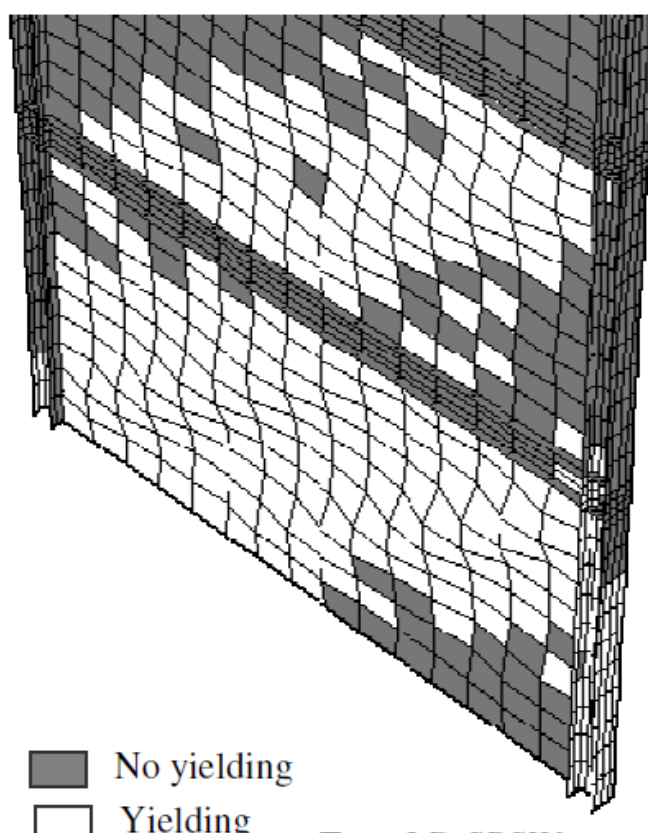

Type LD SPSW

Figure 2.25: Yielding of elements of Ductile (left) and Limited Ductile (Right) SPSW

(Bhowmick et al. 2009)

Both NBCC2005 and NEHRP2000 provision were considered for the amplification of base share to account the $\mathrm{P}-\Delta$ effect. It has been reported that, because of $\mathrm{P}-\Delta$ effect, capacity design approach of CAN/CSA S16-01 underestimates for SPSW, but the inter-storey was drift within the 2.5\% 
limit. However, NEHRP2000 approach of base shear modification was more flexible than the NBCC2005, because NEHRP2000 accounts inelastic storey drift.

Later, a series of one storey multiple perforated steel plates were modeled using FE techniques. A modification of Equation 2.11 was proposed for the perforated plate.

For perforated steel plate, Bhowmick et al. (2009) suggested the following formula.

$$
V_{\text {Perf }}=V_{o}\left(1-0.7 N_{r} \frac{D}{L \cos \alpha}\right) \ldots \ldots \ldots \ldots \ldots \ldots \ldots \ldots \ldots \ldots \ldots . .12
$$

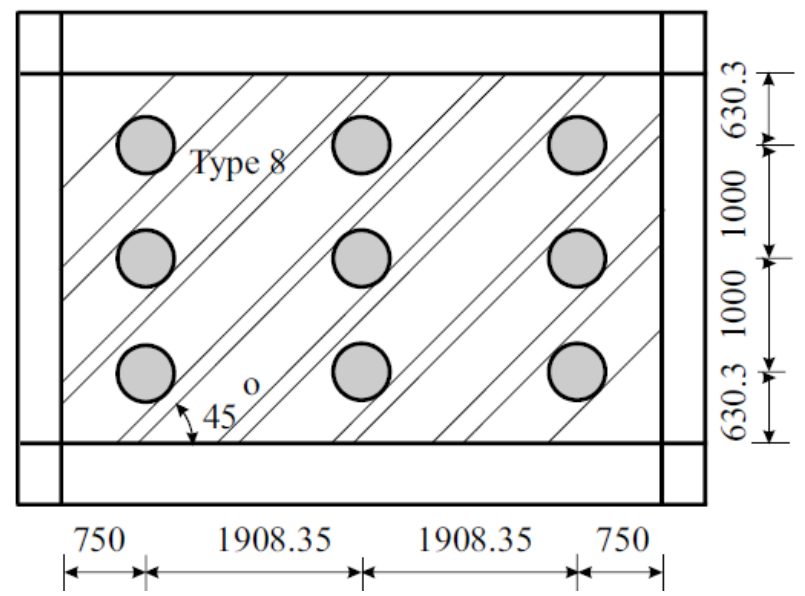

Figure 2.26 Perforated steel plate (type 8) (Bhowmick et al. 2009)

where for type 8 the $\mathrm{N}_{\mathrm{r}}$ is 7 , and other parameters are mentioned early. 


\section{Chapter 3. Finite Element (FE) Modeling and Design of Perforated Steel Plate Shear Wall (P-SPSW)}

\subsection{Introduction}

Apart from time consuming and expensive experimental procedure, finite element method (FEM) is an efficient and sustainable solution to study the behavior of any structural system. Today's industries mostly depend on finite element packages for modeling and analysis of the structural system. FE analysis is equally applicable for structural, geotechnical, mechanical, aerospace, biomedical engineering and so on. Nevertheless, to keep the techniques out of questions, before using FEM for any purpose, it is imperative that, the method should be validated with the identical test experiments.

From the very beginning, FE analysis of unstiffened SPSW was not an easy task since enormous local buckling appeared in thin infill plate. Therefore, the main challenge was to capture the postbuckling behavior of infill plate for different loading conditions. The research group of the University of Alberta was a pioneer in analytical research for unstiffened SPSW. Since 1997, extensive research works were accomplished on FE for unstiffened SPSWs at University of Alberta. Driver et al. (1997) found extreme convergence problems throughout quasi-static analysis in FEM, while validating the experiment results of 4-storey SPSW by using ABAQUS/Implicit (Hibbitt et al. 1994). However, Behbahanifard et al. (2003) reported that convergence problem can be easily achieved by using ABAQUS/Explicit.

The main objective of this chapter is to select the detailed FE techniques using comprehensive FE software ABAQUS/CAE (Hibbitt et al. 2011). Afterwards validated the chosen techniques with the experimental results. Another objective of this chapter is to design the multi-storey (4-,8- and 
12-storey) P-SPSW compatible with Vancouver response spectrum. Later, conduct the pushover analysis to check the structures performing as per design and compare the FE base shear with deign base shear as well.

\subsection{Selection of Finite Element Analysis (FEA) Techniques}

In this research, the user-friendly graphical interface of ABAQUS/CAE (Hibbitt et al. 2011) was used. ABAQUS is a very useful FE tool to solve static, quasi-static and dynamic structural problems with a high degree of accuracy. As required, 1-D, 2-D or 3-D problems both linear and non-linear can easily be implemented in ABAQUS/CAE as well. The existence of a vast number of pre-defined materials model, element library, meshing techniques, several analysis procedures and solver techniques make the package very efficient for the analysis extensive analysis purpose. An attractive feature of ABAQUS/CAE is that it has two analysis modules: ABAQUS/ Standard, also known as ABAQUS/implicit, and ABAQUS/Explicit. After creating a model in ABAQUS/CAE, one can submit the model in any of the two modules depend on requirement.

ABAQUS/Standard (Hibbitt et al. 2011) is an implicit analysis tool where the solutions were obtained by Hilber-Hughes-Taylor (HHT) time integration. In this approach, the response value of time $t$ and $t+\Delta t$ can be achieved by the value of $t$ and $t+\Delta t$ time respectively. Since HHT operator is unconditionally stable, the size of the time increment can be large for most analyses in ABAQUS/Standard. Thus, in this research project, dynamic implicit formulation has been used. On the other hand, the explicit analysis uses integration procedure of central difference method. In this approach, response values can be obtained at any time (t) based on the response on previous time at $(\mathrm{t}-\Delta \mathrm{t})$. New stiffness matrix is updated at every time increment over changed geometric and material properties. This process is conditionally stable on a small time increment. Thus, 
accurate solutions can be achieved for very small time increment, but explicit formulation often requires rigorous computational demand.

It is important to note that thin infill plate, both solid and perforated, easily buckle under a small amount of lateral force. Consequently, the whole shear wall will be subjected to a tremendous amount of geometric and material non-linarites during analysis. Therefore, material and geometric non-linarites are included to capture the actual post-buckling behavior of the unstiffened P-SPSW.

The FE model was validated for two test specimens: single storey solid infill SPSW specimen tested by Nielson et al. (2010) and single storey perforated SPSW tested by Vian et al. (2005). Monotonic pushover and quasi-static cyclic analyses results were compared with the test results in this study.

\subsubsection{Geometric Definition and Mesh Generation}

In the beginning different parts (for example beam, column, infill, etc.) were created separately in ABAQUS/CAE. After assembling respective parts, the final model was generated which consisted of the 1-D line (Example: Dummy column), 2-D shell (Infill) and 3-D shell (beam and column) element. The final model was kept as simple as possible to reduce the complexity, convergence problems as well as computational demand.

Even though fish plates are usually used to connect infill plates with boundary elements but during modeling fish plates were neglected, and it was considered that infill was directly welded with surrounding boundary members. It has been observed that neglecting fish plate in the FE model, has a very minimal effect on the global behavior of large-scale SPSW (Driver et al. 1997). In real P-SPSW, infill plate will be subjected to some degree of eccentricity due to fish plate connection. However, no eccentricity was considered in the infill plate during modeling and considered it 
connected throughout the mid sections of boundary members. Instead of welded connection, the merging technique was considered during assembling. Therefore, welding failure couldn't be captured. Besides, residual stress was not taken into account for the built up sections or welded connections.

Initial imperfection considerably reduces the initial stiffness and strength of the shear wall. It is evident that, during construction, some imperfections will be unexpectedly added in the infill. However, data is not available for the initial imperfection in the thin plate. For initial imperfection, it is common practice to use first buckling mode shape of infill plate with the appropriate scale factor. Therefore, buckling analysis was conducted to assess the different mode shape. Corresponding first buckling mode of the infill was included as initial imperfection with a scale factor of respective plate thickness.

Appropriate mesh size is an integral part of FEM. The fine mesh can lead to accurate results but also escalate the computation complexity. On the other hand, course mesh can lessen the computational demand, but not capable of providing appropriate solutions. Under these circumstances, mesh convergence study is required to select the optimum mesh size, which can lead to minimum time requirement and precise solutions. In this research project, the most complicated part was a meshing of the perforated infill plates, where multiple openings made the area very complex for meshing. Moreover, to reduce the stress concentration, the mesh should be fine and uniform around the openings as well as in the boundary members. Therefore, mesh convergence study was conducted to select the proper mesh size.

Several meshing techniques are integrated into ABAQUS/CAE for executing expected mesh orientation, for example, free mesh, structured mesh and sweep mesh techniques, etc. Among 
them, "structured mesh" technique is quite suitable for the member has geometric irregularities like openings. Thus, "structured mesh" technique was taken to get the uniform mesh in perforated plates as well as boundary members. Besides, quad type mesh size was considered along with minimized mesh transition algorithm to get uniform meshing too.

\subsubsection{Element Selection}

A wide range of pre-defined elements is included in ABAQUS/CAE, which offers freedom to select the desired element type. Driver et al. (1998a, 1998b) conducted FE modeling by using eight node shell element (S8R) for the boundary element and four node shell element (S4R) for the thin infill. The incompatible result was found in FE result over test result for the 4-storey SPSW test specimens. Instead of eight node shell element, later, Behbahanifard et at. (2003) modeled boundary members with four node shell element (S4R) along with infill and reported sufficient agreement over test results.

Therefore, in this research, shell element (S4R) was used both for infill and boundary elements. Generally, in the four node shell element (S4R), each node has six degrees of freedoms, among them three translations $\left(\mathrm{u}_{\mathrm{x}}, \mathrm{u}_{\mathrm{y}} \& \mathrm{u}_{\mathrm{z}}\right)$ and three rotations $\left(\theta_{\mathrm{x}}, \theta_{\mathrm{y}}, \theta_{\mathrm{z}}\right)$. S4R is a general purpose doubly curved shell element with reduced integration. This element uses only one integration point at the mid-surface of the element, which effectively reduces the computational time and also provide accurate results.

\subsubsection{Material Properties}

ABAQUS/CAE material library is convenient to use and give a wide range of freedom to include different properties. As no tension coupon test was conducted, so the yield stress for boundary elements and infill plates was taken as $350 \mathrm{MPa}$ and $385 \mathrm{MPa}$ respectively. Moreover, 
corresponding elastic modulus (Es) and Poison's ratio (v) were taken into consideration 200GPa and 0.3 respectively for both members as a practical point of view. For monotonic pushover analysis, the isotropic hardening model was considered. However, for seismic analysis and quasi-static cyclic analysis combined hardening model was used. For the nonlinear static analysis, 5\% Rayleigh proportional damping was considered. However, for the seismic analysis, dynamic damping factors ( $\alpha$ and $\beta$ ) was taken into account for corresponding 5\% Rayleigh proportional damping. Finally, Von Mises yield criterion was adopted for the analysis result.

\subsubsection{Boundary Condition}

Appropriate boundary conditions are an integral part of FE analysis also. During design, it was considered that the columns were pin supported. To integrate pin supports in the model, reference points (RP) were created at the bottom of each column with a certain distance. Connections between RP and base nodes of the column were obtained by connector element (CONN3D2) by restraining six degrees of freedom. Subsequently, boundary conditions (pin support) were employed at the respective RP. During seismic analysis, horizontal movement at the reference points was released. On the other hand, the out-of-plane movement was restrained in the panel zones. In this study, P-SPSW was modeled along with one dummy column for dynamic analysis. A dummy column was added here to simulate gravity columns. Similar boundary conditions were maintained for the dummy column too. The connections between the P-SPSW and the dummy column were provided by rigid links in every storey.

\subsubsection{Loading Conditions}

For pushover analysis, both force and displacement controlled scheme can be performed in ABAQUS/Standard. Displacement control analysis is very convenient and easy to implement 
however load controlled analysis is very pragmatic to use. Up to the ultimate point, the forcedisplacement curve is identical to both force and displacement controlled analysis. For validating the selected experiments, displacement control analysis was implemented for nonlinear monotonic pushover as well as quasi-static cyclic analysis. For the pushover analysis of the selected PSPSWs, force controlled analysis was conducted. On the other hand, for the seismic analysis, time accelerations data was taken into account.

\subsubsection{Analysis Types}

A series of FE analysis was performed in this research. Including buckling, monotonic pushover, quasi-static cyclic, frequency, and time history analysis. Among of them, buckling analysis was conducted to obtain the first mode of buckling in the infill plates. Where first mode shape of the respective infill was incorporated in the pushover and seismic analysis to capture the effect of initial imperfection. Load controlled nonlinear pushover analysis was performed for the selected P-SPSWs to confirm the system was working as per as design. Besides frequency analysis was conducted to estimate the actual time period since code provided Equation for fundamental period always underestimates the SPSW (Bhowmick et al. 2009). Finally, a series of seismic analysis was conducted to investigate seismic performance of the selected P-SPSWs.

\subsection{Validation of Test Specimen by Finite Element Method (FEM)}

Chosen FE techniques were validated with two experiments; among of them, one was single storey SPSW tested by Neilson et al. (2010) and another one was P- SPSW tested by Vian et al. (2005). A brief description of FE modeling for selected test specimens are given below.

\subsubsection{Validation of Neilson et al. (2010) Specimen}


Both static pushover and quasi-static cyclic analysis were performed for the Neilson et al. (2010) test specimen using detailed FE model. Similar FE techniques were executed as discussed early in this chapter, except free mesh technique was carried out as there were no geometrics irregularities in the infill plates (Fig. 3.1). Movements out of the plate were restrained similar to the test specimen. On the other hand, all bottom nodes of the specimen were modeled as fixed support suppressing all degrees of freedom. No fish plates were modeled except the lower one because it was connected directly to the base plate. An elastic-linearly plastic material model was considered here. Where, material properties of the respective element are shown Table 3.1 (a). Neither welding nor residual stress was included, as their contribution was insignificant on ultimate strength for global behaviour. For initial imperfection of the infill plate, the first mode of buckling was adopted with a scaling factor of two times of plate thickness. Displacement control nonlinear static pushover and quasi-static cyclic analysis (Fig 3.2) were conducted. For quasi-static cyclic analysis, time displacement curve considered as listed in the table 3.1 (b). The load-displacement curve for the test and FE analysis are illustrated in Fig 3.3 and 3.4 respectively for static pushover and quasistatic cyclic analysis. Sufficient correlation was found to capture the elastic to inelastic nature for static pushover and cyclic analysis. However, FE model slightly underestimated the initial stiffness as well as ultimate strength which is around 5\%.

Table 3.1 (a): Material Properties of Neilson et al. (2010) test specimen

\begin{tabular}{|c|c|c|c|}
\hline Properties & $\begin{array}{c}\text { Elastic Modulus } \\
\mathrm{E}(\mathrm{MPa})\end{array}$ & $\begin{array}{c}\text { Yield Stress } \\
\mathrm{F}_{\mathrm{y}}(\mathrm{MPa})\end{array}$ & $\begin{array}{c}\text { Ultimate stress } \\
\mathrm{F}_{\mathrm{u}}(\mathrm{MPa})\end{array}$ \\
\hline Beam \& column (W200X31) & 210,000 & 360 & 461 \\
\hline $\begin{array}{c}\text { Fish plates } \\
(\text { 6mmX100mm) }\end{array}$ & 200,000 & 300 & 450 \\
\hline Infill (A1008) & 233,000 & 173 & 288 \\
\hline
\end{tabular}


Table 3.1(b): Time dispalcement curve for Neilson et al. (2010) test specimen

\begin{tabular}{|c|c|c|c|c|c|c|c|}
\hline $\begin{array}{c}\text { Time } \\
(\mathrm{Sec})\end{array}$ & $\begin{array}{c}\text { Displa- } \\
\text { cement } \\
(\mathrm{mm})\end{array}$ & $\begin{array}{c}\text { Time } \\
(\mathrm{Sec})\end{array}$ & $\begin{array}{c}\text { Displa- } \\
\text { cement(mm) }\end{array}$ & $\begin{array}{c}\text { Time } \\
(\mathrm{Sec})\end{array}$ & $\begin{array}{c}\text { Displa- } \\
\text { cement(mm) }\end{array}$ & $\begin{array}{c}\text { Time } \\
(\mathrm{Sec})\end{array}$ & $\begin{array}{c}\text { Displa- } \\
\text { cement(mm })\end{array}$ \\
\hline 0 & 0 & 3 & 10.2 & 12 & -14.6 & 36 & 43.8 \\
\hline 0.1 & 2.8 & 4 & -11.9 & 14 & 28.9 & 40 & -43.8 \\
\hline 0.2 & -3.6 & 5 & 10.2 & 16 & -29.26 & 44 & 43.5 \\
\hline 0.3 & 2.5 & 6 & -12 & 18 & 29 & 48 & -43.67 \\
\hline 0.4 & -3.7 & 7 & 14.5 & 20 & -29.12 & 53 & 66 \\
\hline 0.6 & 2.6 & 8 & -14.6 & 22 & 29.1 & 58 & -66 \\
\hline 0.8 & -3.8 & 9 & 14.6 & 24 & -29.1 & 63 & 65.9 \\
\hline 1 & 11.6 & 10 & -14.5 & 28 & 43.6 & 68 & -65.8 \\
\hline 2 & -12 & 11 & 14.6 & 32 & -43.8 & 80 & 54.8 \\
\hline
\end{tabular}

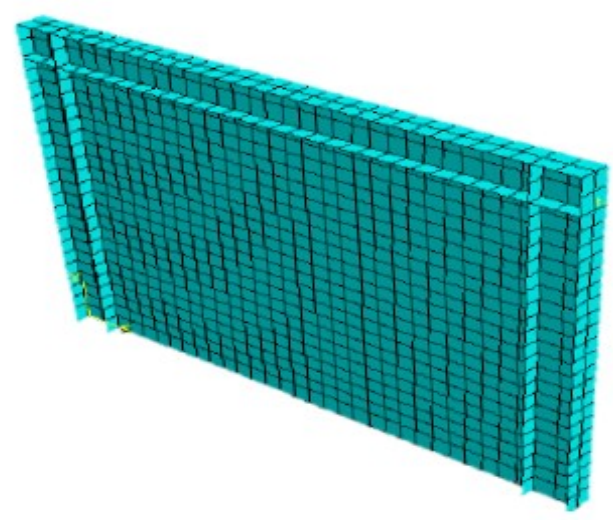

Figure 3.1: Validation of Neilson et al. (2005) test specimen: FE model

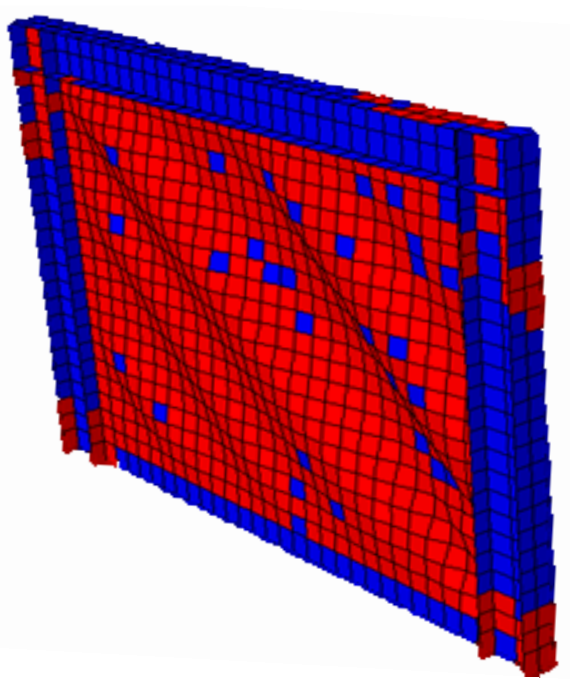

Figure 3.2: Cyclic analysis of Neilson et al. (2005) test: yielding of element (red color) 


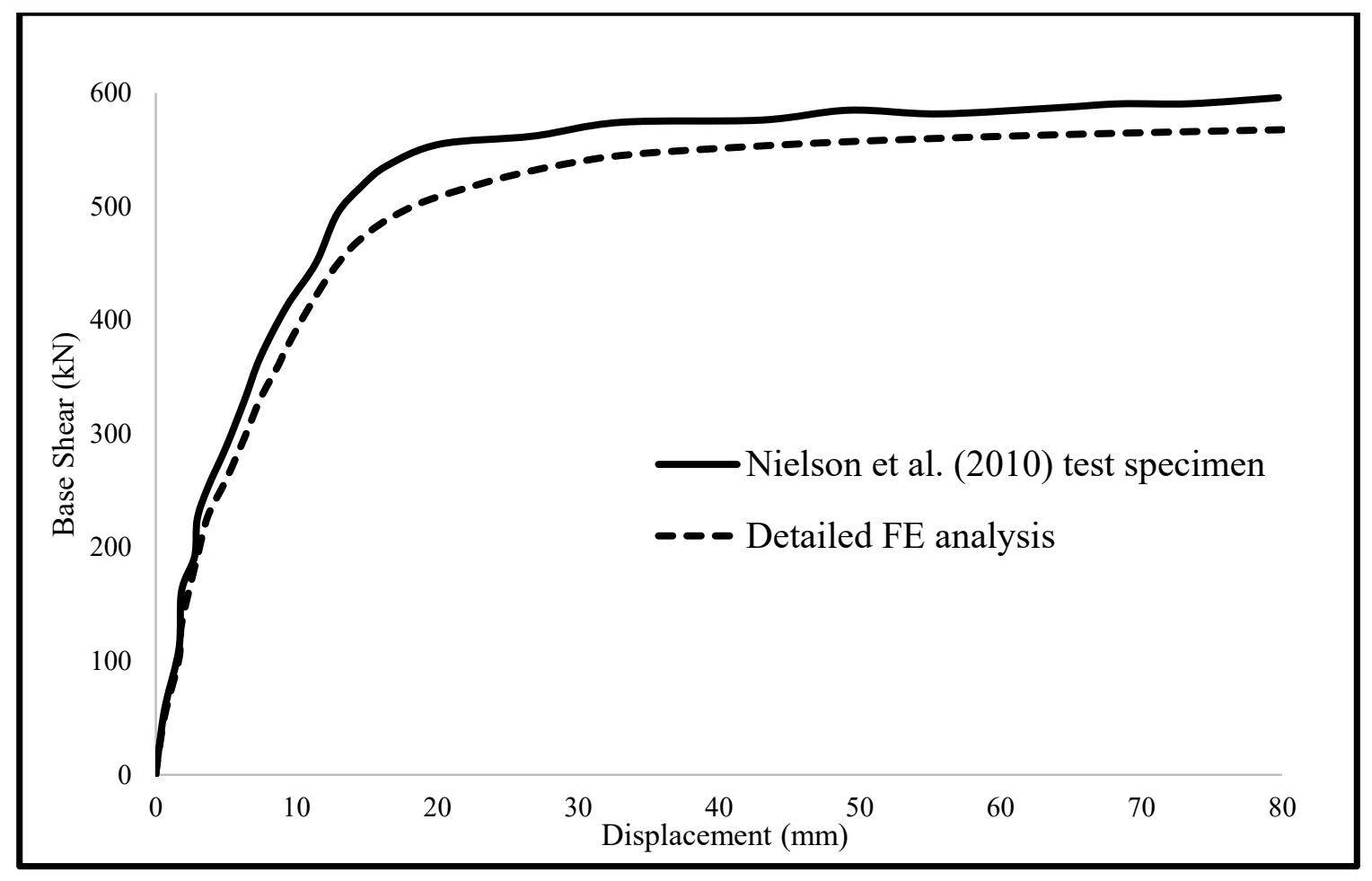

Figure 3.3: Base Shear vs. Floor Displacement Curve (Neilson et al. 2005)

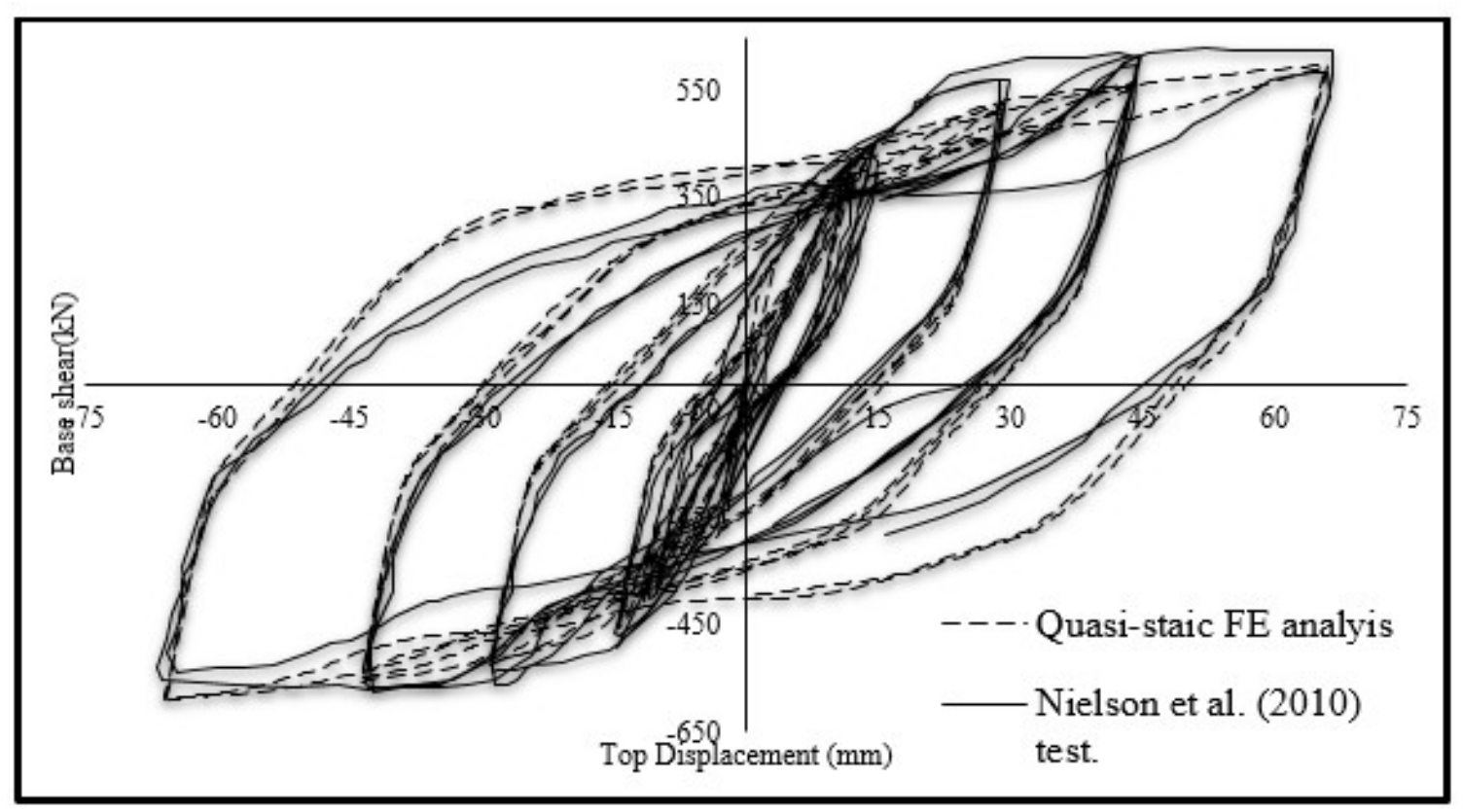

Figure 3.4: Hysteric curves of Neilson et al. (2005) test and finite element model 


\subsubsection{Validation of Vian et al. (2005) Experiment}

FE analysis was also performed for Vian et al. (2005) P-SPSW test specimen. Similar FE techniques were implemented as discussed early in this chapter. Instead of modeling fish plate or tab, it was considered that infill plate was connected directly in the mid-section with the boundary members. Reported tension coupon test data by Vian et al. (2005) was incorporated as material properties. Besides, "structured mesh" technique was taken into account for boundary elements as well as infill plate. Similar to the test specimen, movement out of the plate was restrained at the panel zones. Moreover, the base of each column was modeled as pin supported allowing rotation perpendicular to the P-SPSW direction. Here also displacement controlled monotonic pushover, and quasi-static cyclic analysis was performed. Distributing coupling constraint was used to distribute the displacement/load from controlling point to slave points uniformly. The slave points were positioned $300 \mathrm{~mm}$ apart from the center of the top beam. The time displacement curve was considered at the slave point for the quasi-static cyclic curve given in table 3.1(c).

The pushover curve is illustrated in Figure 3.6, which depicts that sufficient agreement was obtained with test results. Even though initial stiffness exactly matched with experiment but slightly undermine the ultimate strength, and it was around 3\%. The hysteresis behavior from the cyclic analysis is shown in Figure 3.7 and was found a good correlation with experimental results (Figure 3.13). Therefore, it can be concluded that developed FE model techniques were capable of predicting the post-yielding behavior of large-scale P-SPSW. 


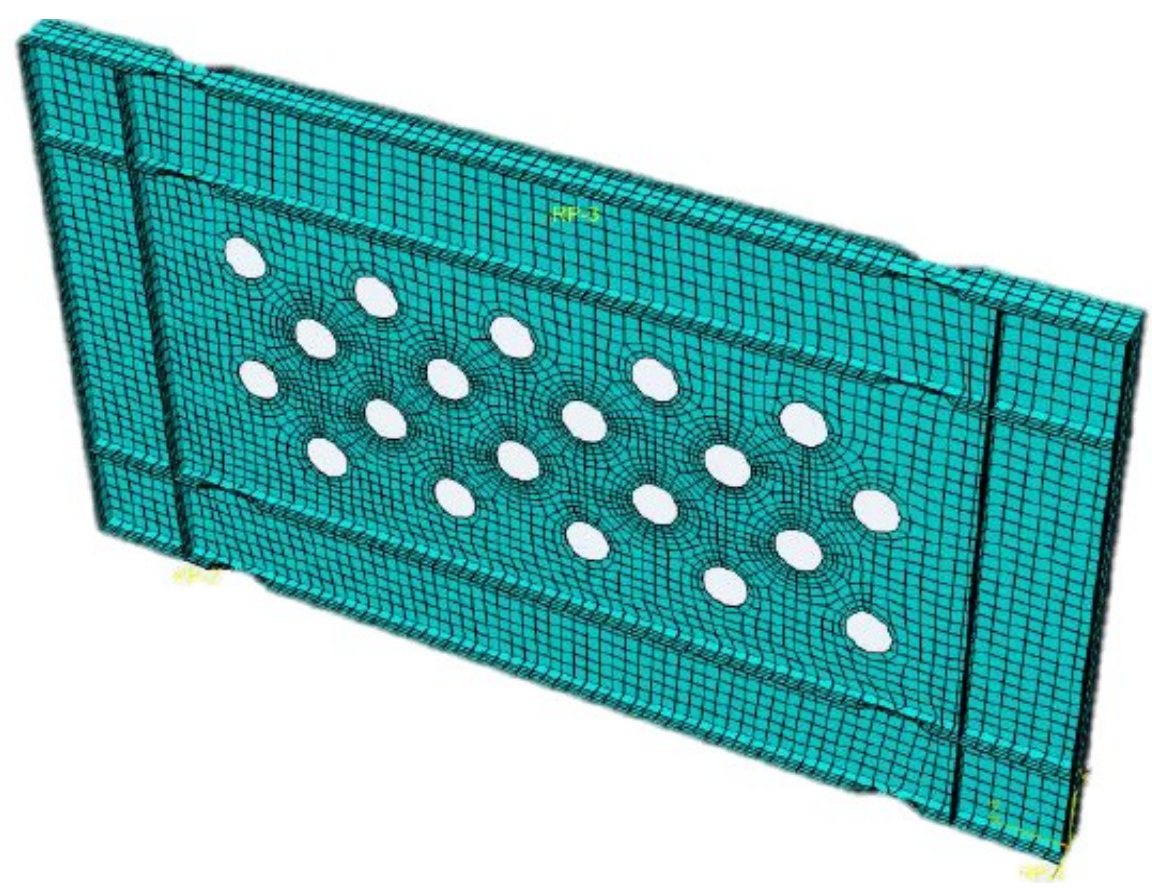

Figure 3.5 : Detailed FE model of Vian et al.(2005) test specimen

Table 3.1(c): Time displacement data for the Vian et al. (2005) cyclic test

\begin{tabular}{|c|c|c|}
\hline Time(Sec) & Cycle (number) & $\begin{array}{c}\text { Average Tested } \\
\text { Top Displacement } \\
(\mathrm{mm})\end{array}$ \\
\hline 2 & 1 & 3.52 \\
\hline 4 & 1 & 6.82 \\
\hline 9 & 1 & 9.97 \\
\hline 13 & 1 & 19.01 \\
\hline 18 & 1 & 28.03 \\
\hline 26 & 1 & 37.05 \\
\hline 36 & 1 & 45.92 \\
\hline 48 & 1 & 60.72 \\
\hline 56 & 1 & 75.48 \\
\hline 65 & 1 & 89.73 \\
\hline
\end{tabular}




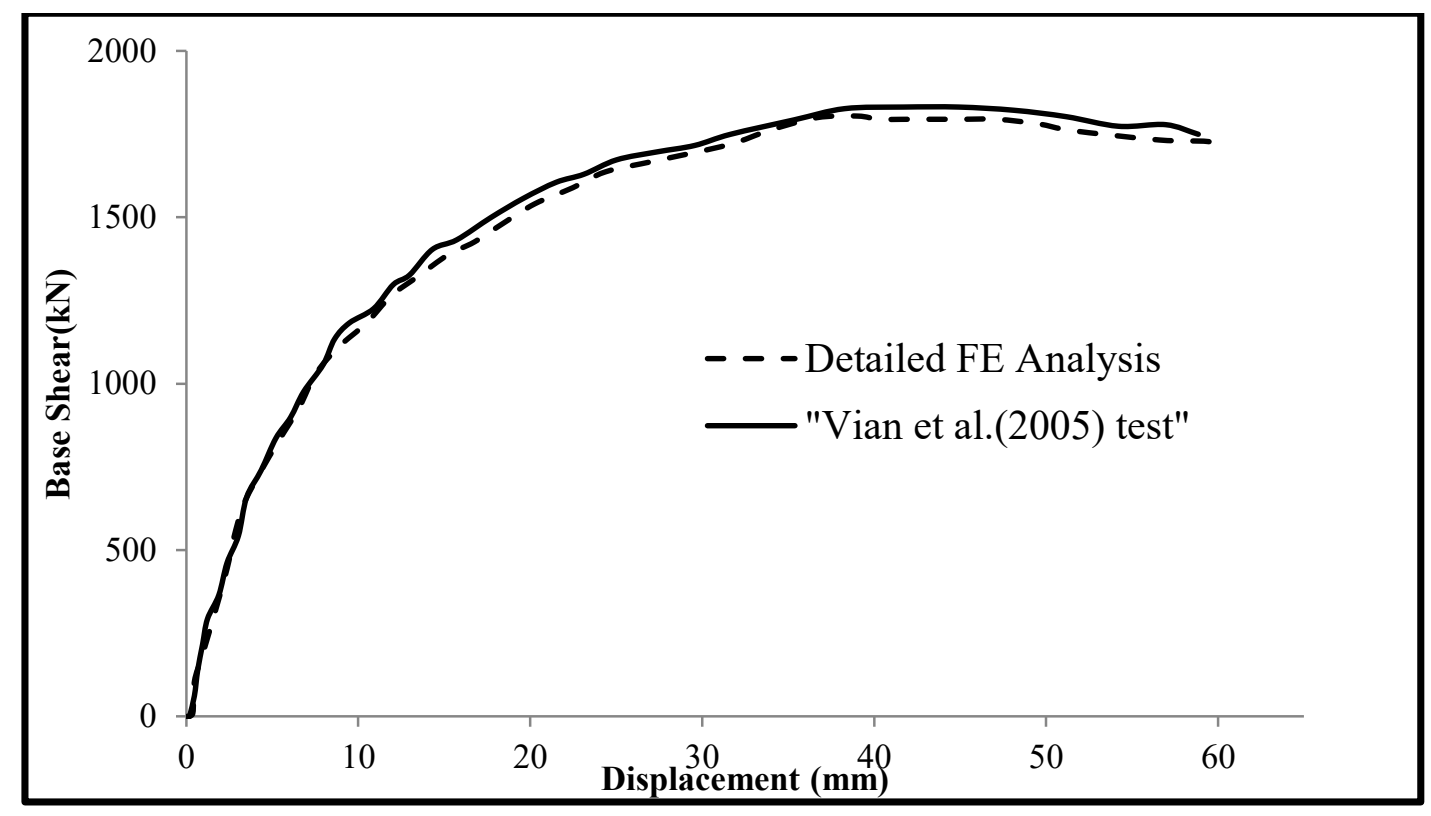

Figure 3.6 : Force-displacement curves of the Vian et al.(2005) test and finite element result.

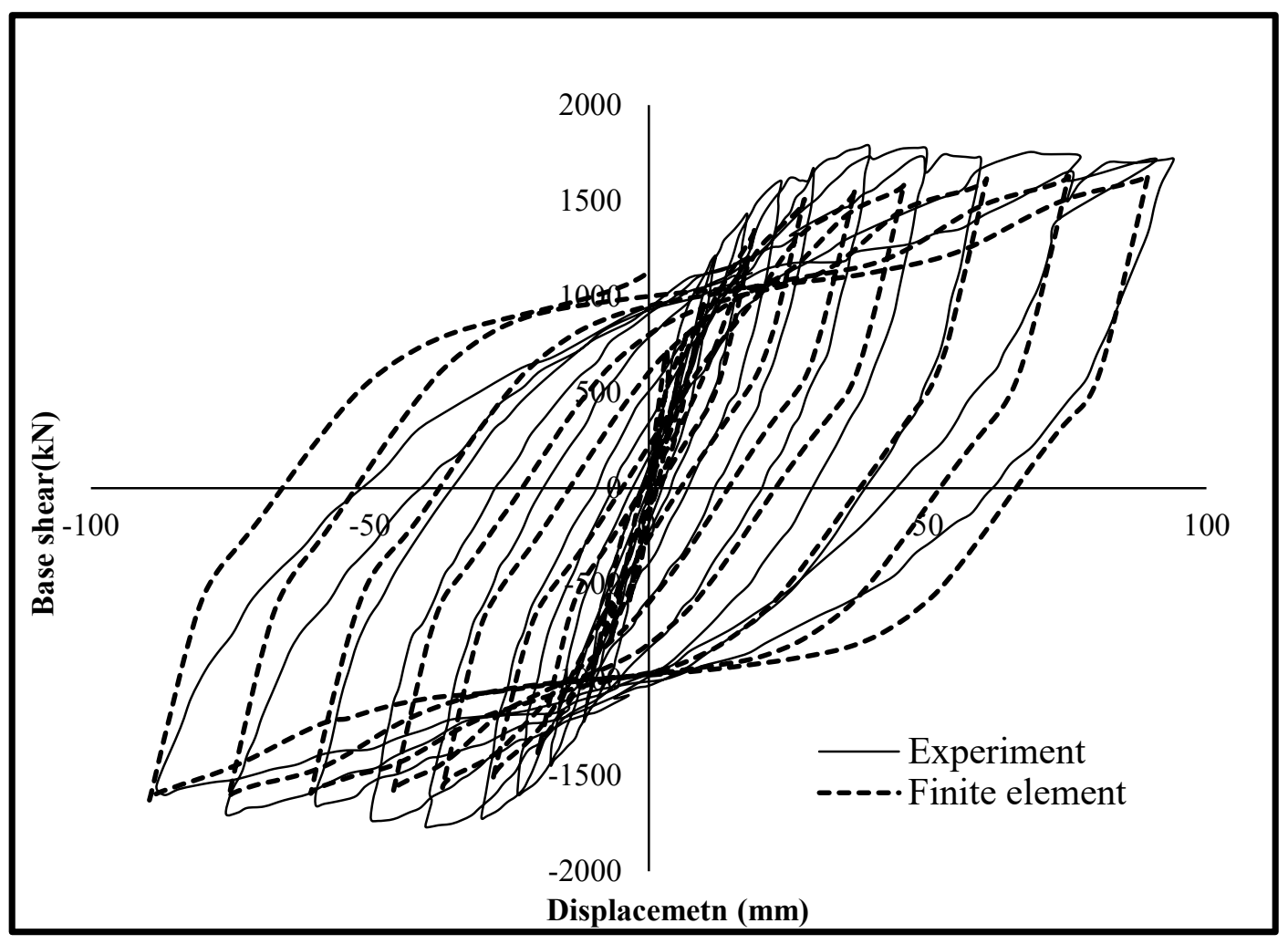

Figure 3.7: Hysteresis curves of the test specimen and finite element analysis. 


\subsection{Design of Multi-Storey Perforated Steel Plate Shear Wall (P-SPSW)}

\subsubsection{Building Geometry and Loading}

A hypothetical office building with regular plan view was considered in this research. The building was assumed to be located in Canada's most active seismic zone, Vancouver, BC. The building plan was identical for 4-,8-\& 12-storey, along with two identical and ductile perforated SPSW in both directions (N-S, E-W). According to NBCC 2010, at any particular direction, the entire lateral load resisting system should be designed in such a way that it may carry $100 \%$ of the lateral load. Thus, half of the total seismic force in one particular direction will be carried by one P-SPSW. Even though the building was symmetric over the height as well as in plan, it was expected that no torsion will be induced during seismic events. However, accidental torsion was considered during load calculation.

The typical plan and elevation view of the selected P-SPSWs are shown in Figures 3.8 and 3.9 respectively. The chosen building had equal storey height of $3.8 \mathrm{~m}$ and same bay width of $5.7 \mathrm{~m}$ in all directions. Therefore, it was maintained 1.5 aspect ratio for all selected P-SPSWs. Besides, total floor plan area was $2631.7 \mathrm{~m}^{2}$. The building foundations were assumed to be on very dense soil or soft rock (site class C according to NBCC 2010). For every floor along with 4.2 KPa dead load, a live load of 2.4 KPa was considered. However, for roof level $1.5 \mathrm{KPa}$ dead load and $1.12 \mathrm{KPa}$ snow load were considered.

During seismic load calculation, full dead load with $25 \%$ snow load was considered. The load combinations of $1.0 \mathrm{D}+0.5 \mathrm{LL}+1.0 \mathrm{E}$ and $1.0 \mathrm{D}+0.25 \mathrm{~S}+1.0 \mathrm{E}$ were used for designing beams and columns at floor and roof level respectively. 
Rigidly connected beam and column with fully welded infill is considered in this research. Where elastic modulus for all members was $200 \mathrm{GPa}$. Though yield strength of the beam and column material was taken as $350 \mathrm{MPa}(\mathrm{G} 40.21-350 \mathrm{~W})$ but for infill plate, it was considered as $385 \mathrm{MPa}$.

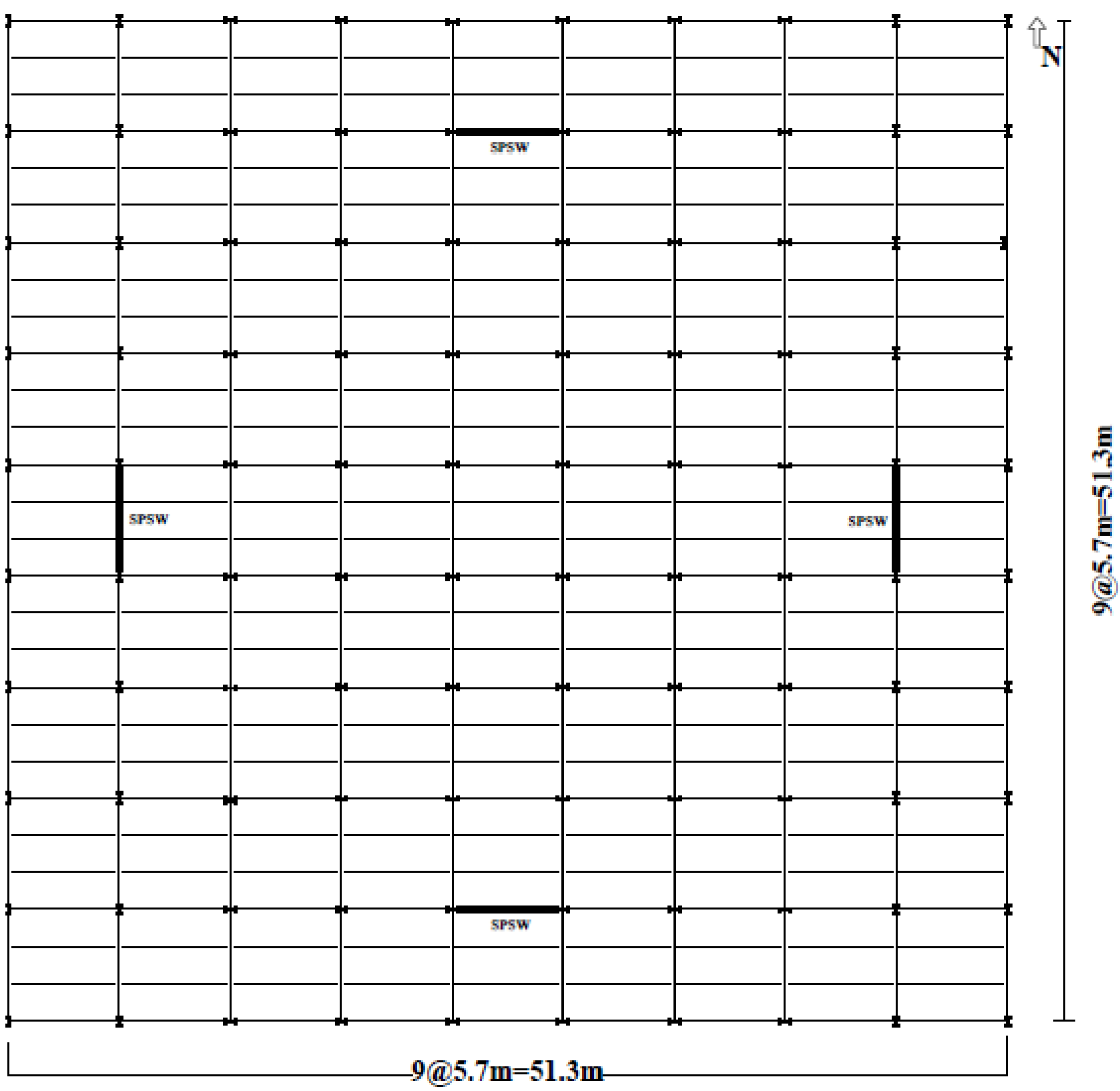

Figure 3.8: Typical Floor Plan of the Hypothetical Office Building (Gravity System and two SPSW in each direction) 


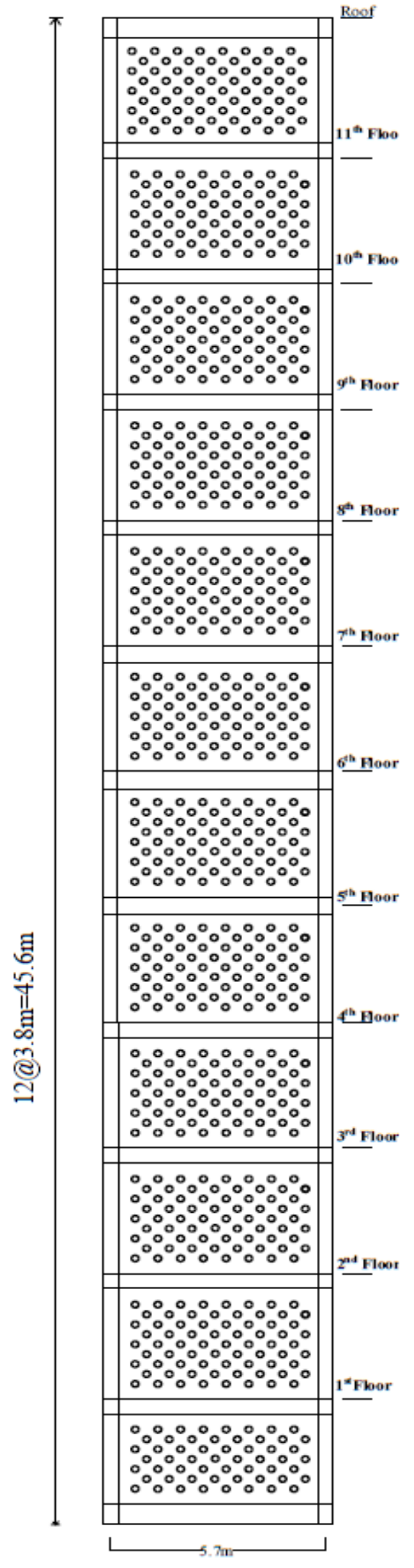

(a)

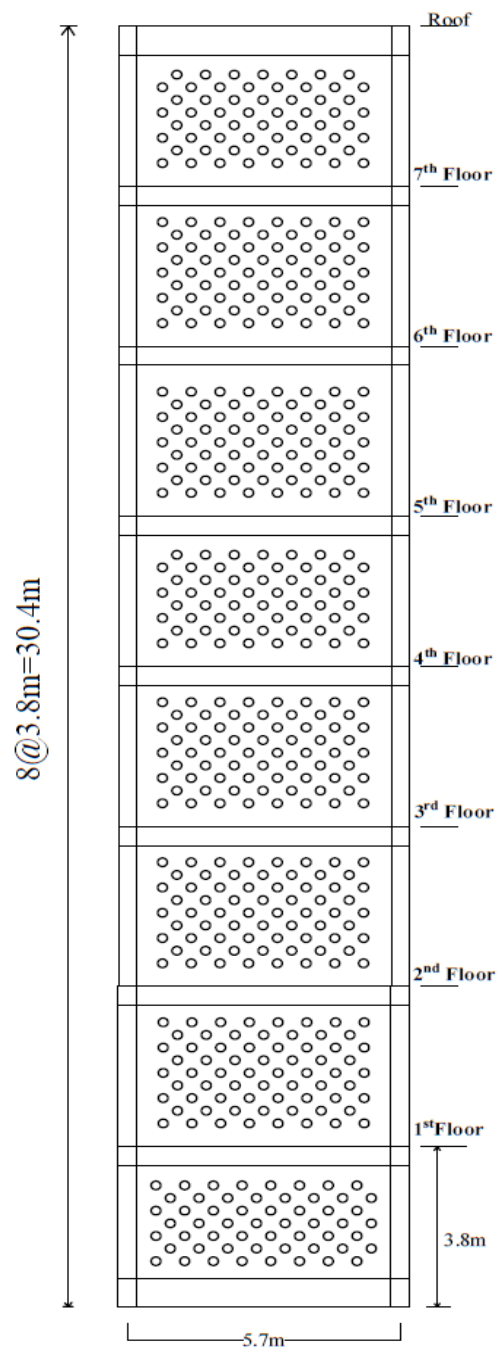

(b)

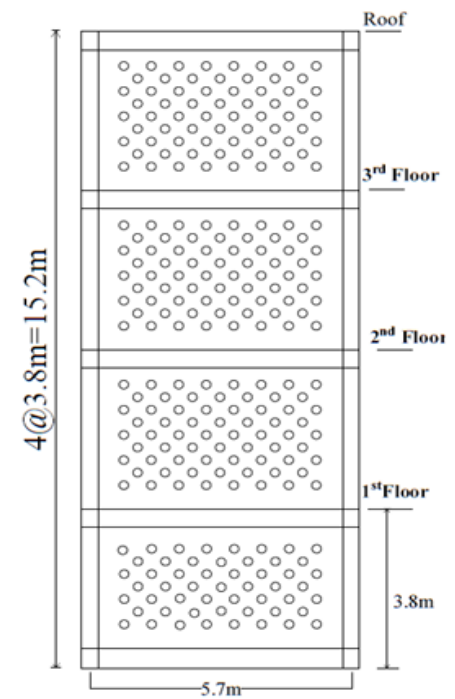

(c)

Figure 3.9: Elevation view of the P-SPSW (a) 12-storey (b) 8-storey and (c) 4-storey 


\subsubsection{Calculation of Design Base Shear}

It is required to calculate the seismic load to design the infill plate as well as beam/column. Seismic base shear was estimated according to the equivalent lateral load method. To determine the base shear, at the first fundamental period of SPSW was calculated by code provided Eq.3.1.

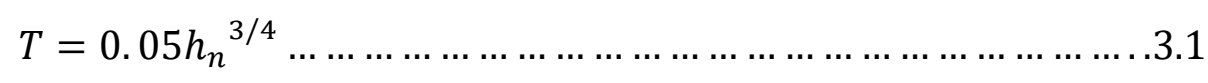

where $h_{n}$ is the total height of the building in the meter.

Total base shear $\left(\mathrm{V}_{\mathrm{b}}\right)$ can be calculated by the Eq. 3.2.

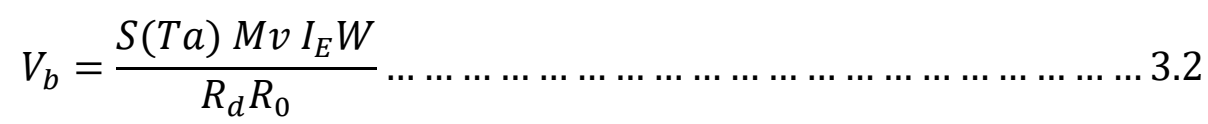

All the parameters were taken from NBCC 2010,

where, $\mathrm{S}(\mathrm{Ta})$ is the pseudo-acceleration corresponding to the time period which was calculated from Eq. 3.1, $\mathrm{M}_{\mathrm{v}}$ is the velocity related soil factor to account higher mode effect, $\mathrm{I}_{\mathrm{E}}$ is the importance factor of the structure, $\mathrm{W}$ is the weight of the building which can be calculated by $100 \%$ of dead load, $25 \%$ snow load and $60 \%$ of storage load, where no storage was considered in this study. $R_{d}$ is the ductility related force modification factor (for ductile SPSW the factor is 5.0), Ro is the over strength related force modification factor (for the ductile SPSW Ro is 1.6).

The calculated total static base shear was compared with the maximum and minimum requirement of base shear. Where maximum base shear $\left(\mathrm{V}_{\max }\right)$ is calculated from Eq.3.3.

$$
V_{\text {max }}=\frac{2}{3} \frac{S(0.2) M v I_{E} W}{R_{d} R_{0}}
$$


where, $S(0.2)$ is the pseudo-acceleration corresponding to the time period of $0.2 \mathrm{sec}$, and other parameters are same as earlier.

and minimum base shear $\left(\mathrm{V}_{\min }\right)$ can be calculated by the Eq. 3.4.

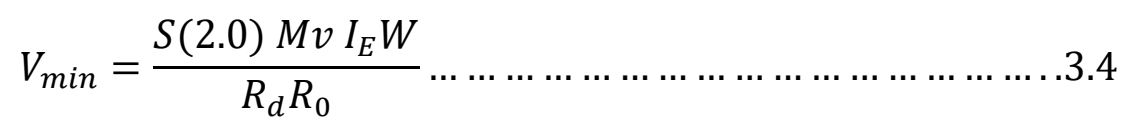

where S (2.0) is the pseudo-acceleration corresponding to the time period of $2.0 \mathrm{sec}$, and other parameters are same as earlier.

Therefore, the calculated static base shear was checked by the Eq.3.5 that was in between maximum and minimum limit of base shear.

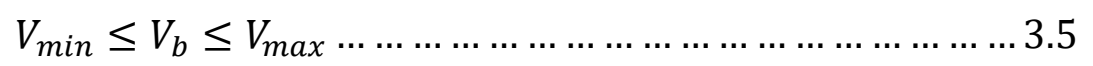

According to NBCC 2010, an equivalent lateral force method is applicable only when the height and time period of the structure is less than $60 \mathrm{~m}$ and $2.0 \mathrm{sec}$ respectively. In this research, all the structures are within the limit. Therefore, equivalent lateral load procedure was carried out.

\subsubsection{Distribution of Lateral Force}

The calculated total base shear (Eq. 3.2) was distributed over the height of the SPSW building

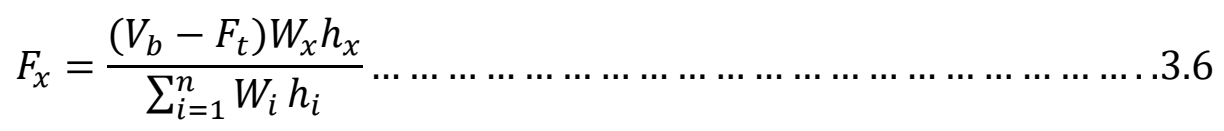

where $\mathrm{F}_{\mathrm{x}}$ is the lateral force on the particular floor at a height of $\mathrm{hx}, \mathrm{V}_{\mathrm{b}}$ is total seismic base shear, $\mathrm{W}_{\mathrm{x}}$ is the seismic weight of the $\mathrm{x}$ floor, $\mathrm{W}_{\mathrm{i}}$ and $\mathrm{h}_{\mathrm{i}}$ are weight and height at the $\mathrm{i}^{\text {th }}$ floor, $\mathrm{F}_{\mathrm{t}}$ is the concentrated force at the topmost floor to account for higher mode effect. $F_{t}$ can be calculated by the Eq. 3.7. 


$$
F_{t}=0.07 T_{a} V_{b} \leq 0.25 V_{b}
$$

Even though the building was regular in plan and height, accidental torsion can be induced during the seismic event. NBCC 2010 recommends some accidental torsional force while calculating equivalent static force.

Added torsional load in every floor can be calculated by the Eq. 3.8.

$$
T x=\left( \pm 0.1 D_{n x}\right) F_{x}
$$

where $\mathrm{D}_{\mathrm{nx}}$ is plan dimension perpendicular to the seismic loading and $\mathrm{F}_{\mathrm{x}}$ is the loading at any particular floor calculated from the Eq. 3.6

Table 3.2: Equivalent Static Lateral force and Storey Shear force for the 4-storey P-SPSW

\begin{tabular}{|c|c|c|}
\hline \multicolumn{3}{|c|}{ 4-storey Perforated SPSW } \\
\hline Floor Level & $\begin{array}{c}\text { Equivalent Static lateral load } \\
(\mathrm{kN})\end{array}$ & Static Storey Shear (kN) \\
\hline Roof & 225 & 225 \\
\hline Floor-3 & 640 & 865 \\
\hline Floor-2 & 428 & 1293 \\
\hline Floor-1 & 215 & 1508 \\
\hline
\end{tabular}

Table 3.3: Equivalent Static Lateral force and Storey Shear force for the 8-storey P- SPSW

\begin{tabular}{|c|c|c|}
\hline \multicolumn{3}{|c|}{ 8-Sotrey Perforated SPSW } \\
\hline Floor Level & $\begin{array}{c}\text { Equivalent Static lateral load } \\
(\mathrm{kN})\end{array}$ & $\begin{array}{c}\text { Static Storey Shear } \\
(\mathrm{kN})\end{array}$ \\
\hline Roof & 275 & 275 \\
\hline Floor-7 & 674 & 949 \\
\hline Floor-6 & 578 & 1527 \\
\hline Floor-5 & 480 & 2007 \\
\hline Floor-4 & 385 & 2392 \\
\hline Floor-3 & 288 & 2680 \\
\hline Floor-2 & 194 & 2874 \\
\hline Floor-1 & 96 & 2970 \\
\hline
\end{tabular}


Table 3.4: Equivalent Static Lateral force and Storey Shear force for the 12-storey P- SPSW

\begin{tabular}{|c|c|c|}
\hline \multicolumn{3}{|c|}{ 12-Sotrey Perforated SPSW } \\
\hline Floor Level & $\begin{array}{c}\text { Equivalent Static lateral load } \\
(\mathrm{kN})\end{array}$ & $\begin{array}{c}\text { Static Storey Shear } \\
(\mathrm{kN})\end{array}$ \\
\hline Roof & $144+196(\mathrm{Ft})$ & 340 \\
\hline Floor-11 & 502 & 842 \\
\hline Floor-10 & 465 & 1299 \\
\hline Floor-9 & 411 & 1710 \\
\hline Floor-8 & 365 & 2075 \\
\hline Floor-7 & 320 & 2395 \\
\hline Floor-6 & 274 & 2669 \\
\hline Floor-5 & 228 & 2897 \\
\hline Floor-4 & 187 & 3080 \\
\hline Floor-3 & 137 & 3216 \\
\hline Floor-2 & 91 & 3308 \\
\hline Floor-1 & 45 & 3354 \\
\hline
\end{tabular}

\subsubsection{Infill Plate Design}

The capacity design concept was used for the design of P-SPSW where fully yielding of infill was considered to design the boundary frame. To carefully look at the perforation effect over the boundary members, instead of openings, the boundary members were designed as a solid infill SPSW. Where the thickness of the infill calculated as per Eq. 3.9 provided by CSA/CAN-S01-09

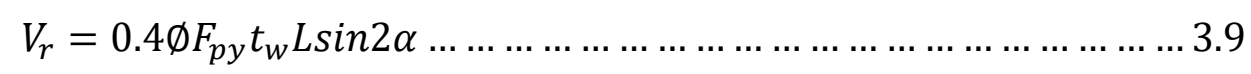

where $V_{r}=$ is the storey shear, $\alpha=$ the angle of inclination of the tension field, the $t_{w}=$ thickness of the infill plate, $\mathrm{L}=$ plate width, $\emptyset=$ resistance factor, equal to 0.9 .

It is important to mention that for low-rise (4-storey) to mid-rise building (8-storey), the thickness requirement for the plate is insignificant compared to available, hot rolled plate thickness (minimum plate thickness is $3 \mathrm{~mm}$ ). Thus, either light gauge or low yield steel (LYS) plate can be a good alternative instead of thick hot rolled plate. However, for the light gauge plate, welding 
connection is very difficult to achieve, on the other hand, low yield steel (LYS) plates are not commercially available yet in the market. Therefore, considering practical availability, welding and handling requirements, a minimum plate thickness of $3 \mathrm{~mm}$ was selected. The plate thicknesses for 4-, 8- and 12-storey P-SPSWs are given in tables 3.4, $3.5 \& 3.6$ respectively.

\subsubsection{Perforation Layout}

To formed appropriate tension field action in infill plates, the holes' positions are very critical for any perforated SPSW. For multiple openings, it is recommended by CSA/CAN-S01-09 that the openings should be uniformly scattered over the entire plate with staggered position. The openings of $200 \mathrm{~mm}$ diameters along with $300 \mathrm{~mm} \mathrm{C} / \mathrm{C}$ distance were considered. So the diagonal strip width $\left(\mathrm{S}_{\text {diag }}\right)$ of $424.24 \mathrm{~mm}\left(\mathrm{D} / \mathrm{S}_{\text {diag }}=0.47\right)$ was considered in this study. The perforations were uniformly distributed over the entire infill with the staggered position which is illustrated in the elevation view of Figure 3.15.

Also, an edge distance of e (Eq. 3.10) was maintained from the boundary members to a perforation in between diameter $(\mathrm{D})$ and $\mathrm{D}+0.7 \mathrm{~S}_{\text {diag }}$.

$$
D<e<(\mathrm{D}+0.7 \text { Sdiag })
$$

\subsubsection{Boundary Member Design}

For designing vertical boundary members, Burman \& Bruneau (2008) capacity design procedure was followed. Even though Burman and Bruneau (2008) proposed the procedure for solid infill, it is equally applicable to perforated one. Fully yielded infill plates with plastic hinges at the ends of each beam were considered during uniform collapse mechanism. The beams and columns were designed to carry the yielding forces of the infill plates. 
The distributed load components applied at the beam from yielding of plate of ith storey plate can be calculated by Eq. $3.11 \& 3.12$

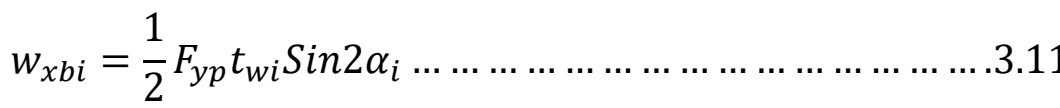

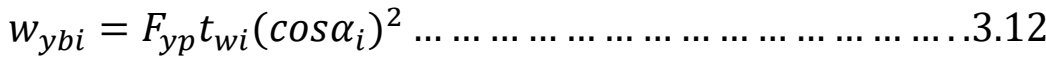

Distribution force over the column for the yielding of infill plate can be calculated by Eqs. 3.13 and 3.14.

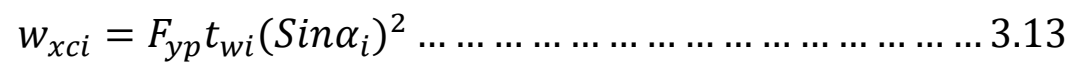

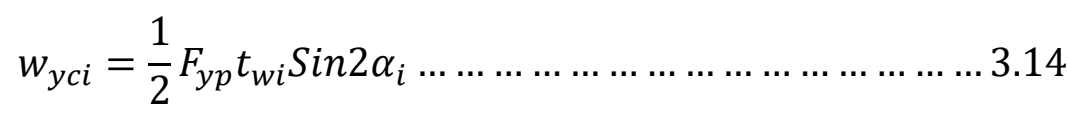

where $t_{w i}$ is the plate thickness, $F_{y p}$ is the plate yielding stress, $\alpha_{i}$ is the angle of inclination tension field action, $w_{\mathrm{xbi}}$ and $w_{\mathrm{ybi}}$ are the infills yielding forces acting on the beam, $w_{\mathrm{cbi}}$ and $w_{\mathrm{cbi}}$ are the infills yielding forces at the column.

Axial forces in the beams come from two sources: (i) the inward force applied to the columns by the infill plate $\left(\mathrm{P}_{\mathrm{si}}\right)$, and (ii) force from the difference in the effects of the infill plates above and below the beam. The inward force applied to the columns by the infill plate at the $\mathrm{i}^{\text {th }}$ floor $\left(\mathrm{P}_{\mathrm{si}}\right)$ can be obtained from Eq. 3.15

$$
P_{s i}=w_{x c i} \frac{h_{i}}{2}+w_{x c i+1} \frac{h_{i+1}}{2}
$$

Total axial forces applied to beam at $\mathrm{i}^{\text {th }}$ was calculated by the Eq. 3.16 and 3.17

$$
P_{b l i}=-\left(w_{x b i}-w_{x b i+1}\right) \frac{L}{2}+P_{s i}
$$




$$
P_{b r i}=-\left(w_{x b i}-w_{x b i+1}\right) \frac{L}{2}+P_{s i}
$$

where $\mathrm{P}_{\text {bli }}$ and $\mathrm{P}_{\text {bri }}$ were the total plate yield force over beam from the left and right side respectively.

Bottom beam axial force was calculated by Eqs. 3.18 and 3.19

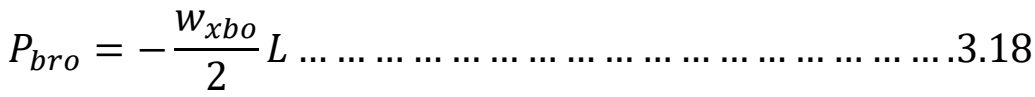

$$
\begin{aligned}
& P_{b l o}=\frac{w_{x b o}}{2} L
\end{aligned}
$$

\subsubsection{Horizontal Boundary Element (HBE-Beam) and Vertical Boundary Element (VBE- Column) Design}

Horizontal boundary elements (beams) were designed for dead loads and live loads as per code requirement combination of DL $+0.5 \mathrm{LL}$. In addition, the beams were subjected to net web yielding vertical force $\left(w_{\mathrm{ybi}}-w_{\mathrm{ybi}+1}\right)$,

Plastic moments developed at beam ends were reduced due to the presence of an axial load. Therefore, reduced plastic moment was calculated either by Eq. 3.20 or by Eq. 3.21

$$
\begin{aligned}
& M_{p r l i}=1.18\left(1-\frac{\left|P_{b l i}\right|}{F_{y b} A_{b i}}\right) Z_{x b i} \quad \text { if } 1.18\left(1-\frac{\left|P_{b l i}\right|}{F_{y b} A_{b i}}\right) \leq 1.0 \ldots \ldots \ldots \ldots \ldots \ldots .20 \\
& M_{p r l i}=Z_{x b i} F_{y b} \quad \text { if } 1.18\left(1-\frac{\left|P_{b l i}\right|}{F_{y b} A_{b i}}\right)>1.0 \ldots \ldots \ldots \ldots \ldots \ldots \ldots \ldots \ldots \ldots \ldots \ldots \ldots \ldots \ldots \ldots \ldots \ldots \ldots \ldots \ldots \ldots \ldots \\
&
\end{aligned}
$$

where, $F_{y b}=H B E$ yield strength, $A_{b i}=$ cross sectional area of $H B E$ at the $i^{\text {th }}$ floor and $Z_{x b i}=H B E$ plastic modulus at the storey $\mathrm{i}^{\text {th }}$.

Corresponding beam shear forces were calculated by Eq. 3.22 and 3.23, 


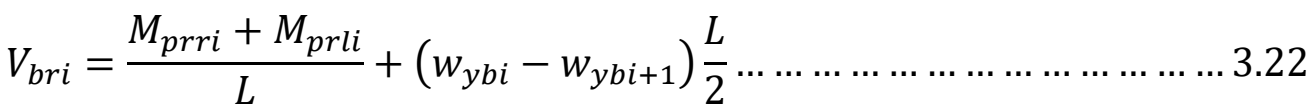

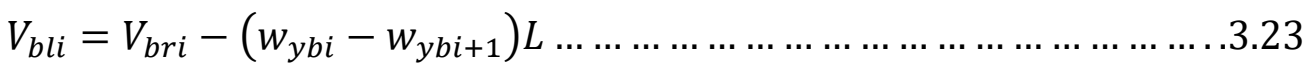

where, $\mathrm{V}_{\text {bri }}$ and $\mathrm{V}_{\text {bli }}$ are the calculated beam shear forces on the left and right side of the beam respectively. $\mathrm{M}_{\text {prri }}$ and $\mathrm{M}_{\text {prli }}$ are the reduced beam plastic moments on the left and right side of the beam respectively, and other parameters are presented earlier.

For the top and bottom beams fully developed tension field action in the infill plate is assumed. Thus, according to CAN/CSA S16-09, Eq. 3.24 and 3.25 should be satisfied for top and bottom beams respectively.

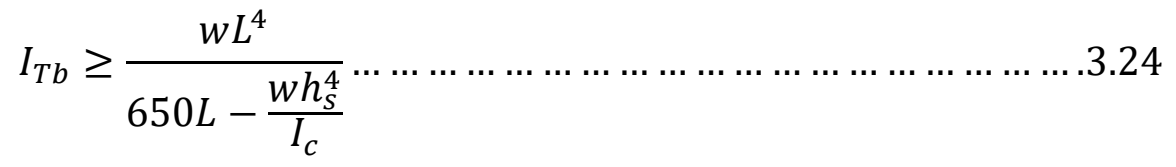

where $\mathrm{I}_{\mathrm{tb}}$ is the moment of inertia of the top beam cross-section, $\mathrm{I}_{\mathrm{c}}$ is the column moment of inertia on the top floor; $w$ is the plate thickness, $\mathrm{h}_{\mathrm{s}}$, and $\mathrm{L}$ are the bay height and width respectively.

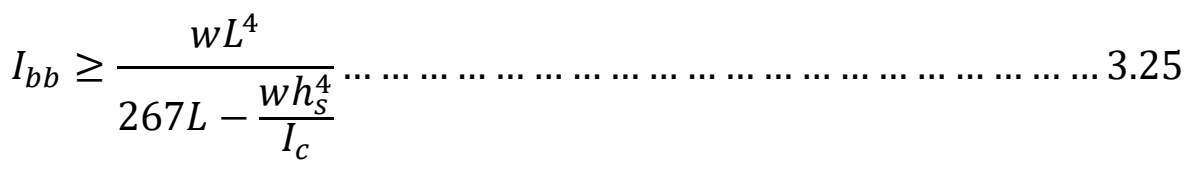

where $\mathrm{I}_{b b}$ is, the moment of inertia of the bottom beam and other parameters are mentioned before.

The governing equation for the collapse mechanism

$$
\sum_{i=1}^{n_{i}} F_{i} H_{i}=\sum_{i=0}^{n_{i}} M_{p r l i}+\sum_{i=0}^{n_{i}} M_{p r r i}+\sum_{i=1}^{n_{i}} \frac{1}{2}\left(t_{w i}-t_{w i+1}\right) F_{y p} L H_{i} \sin 2 \alpha_{i} \ldots \ldots \ldots .2 .26
$$

Where $\mathrm{F}_{\mathrm{i}}=$ applied the lateral load at each storey, $\mathrm{H}_{\mathrm{i}}=$ height of the storey. 
Once the force required to cause collapse mechanism is determined to free body diagrams can be developed for beams and columns, from which the design loads for beams and columns are calculated. Beam and column sections are designed as beam-column. The selected beams and columns for the perforated SPSWs are given below in Table 3.5, $3.6 \& 3.7$ respectively.

Above all, columns sections have been checked (Eq. 3.27) according to CAN/CSA S16-09 for fully developing tension field actions in infill plate.

$$
I_{c} \geq \frac{0.0031 w h_{s}^{4}}{L} .
$$

where $I_{c}$ is the column moment of inertia, and other parameters are presented early

Table 3.5: Plate thickness, openings diameter, and beam, column sections for the 4-storey.

\begin{tabular}{|c|c|c|c|c|}
\hline \multicolumn{5}{|c|}{ 4-storey P-SPSW } \\
\hline Floor Level & $\begin{array}{c}\text { Plate thickness } \\
(\mathrm{mm})\end{array}$ & $\begin{array}{c}\text { Openings } \\
\text { Diameter }(\mathrm{mm})\end{array}$ & Beam section & Column section \\
\hline Roof & 3 & 200 & W460X315 & W360X314 \\
\hline Floor-3 & 3 & 200 & W460X144 & W360X314 \\
\hline Floor-2 & 3 & 200 & W460X144 & W360X509 \\
\hline Floor-1 & 3 & 200 & W460X144 & W360X509 \\
\hline Bottom & & & W460X315 & W360X509 \\
\hline
\end{tabular}


Table 3.6: Plate thickness, openings diameter, and beam, column sections for the 8 -storey.

\begin{tabular}{|c|c|c|c|c|}
\hline \multicolumn{5}{|c|}{ 8-Sotrey P-SPSW } \\
\hline Floor Level & $\begin{array}{c}\text { Plate } \\
\text { thickness } \\
(\mathrm{mm})\end{array}$ & $\begin{array}{c}\text { Openings } \\
\text { Diameter } \\
(\mathrm{mm})\end{array}$ & Beam section & $\begin{array}{c}\text { Column } \\
\text { section }\end{array}$ \\
\hline Roof & 3 & 200 & W610X415 & W360X463 \\
\hline Floor-7 & 3 & 200 & W460X144 & W360X463 \\
\hline Floor-6 & 3 & 200 & W460X144 & W360X634 \\
\hline Floor-5 & 3 & 200 & W460X144 & W360X634 \\
\hline Floor-4 & 3 & 200 & W460X144 & W360X634 \\
\hline Floor-3 & 4.8 & 200 & W460X144 & W360X634 \\
\hline Floor-2 & 4.8 & 200 & W460X260 & W360X900 \\
\hline Floor-1 & 4.8 & 200 & W460X260 & W360X900 \\
\hline Bottom & & & W610X415 & W360X900 \\
\hline
\end{tabular}

Table 3.7: Plate thickness, openings diameter, and beam, column sections for the 12-storey.

\begin{tabular}{|c|c|c|c|c|}
\hline \multicolumn{5}{|c|}{ 12-Sotrey P-SPSW } \\
\hline Floor Level & $\begin{array}{c}\text { Plate } \\
\text { thickness } \\
(\mathrm{mm})\end{array}$ & $\begin{array}{c}\text { Openings } \\
\text { Diameter } \\
(\mathrm{mm})\end{array}$ & Beam section & $\begin{array}{c}\text { Column } \\
\text { section }\end{array}$ \\
\hline Roof & 3 & 200 & W610X341 & W360X421 \\
\hline Floor-11 & 3 & 200 & W460X144 & W360X421 \\
\hline Floor-10 & 3 & 200 & W460X144 & W360X421 \\
\hline Floor-9 & 3 & 200 & W460X144 & W360X421 \\
\hline Floor-8 & 3 & 200 & W460X158 & W360X634 \\
\hline Floor-7 & 3 & 200 & W460X158 & W360X634 \\
\hline Floor-6 & 3 & 200 & W460X213 & W360X634 \\
\hline Floor-5 & 4.8 & 200 & W460X213 & W360X634 \\
\hline Floor-4 & 4.8 & 200 & W460X260 & W360X1086 \\
\hline Floor-3 & 4.8 & 200 & W460X260 & W360X1086 \\
\hline Floor-2 & 4.8 & 200 & W460X384 & W360X1086 \\
\hline Floor-1 & 4.8 & 200 & W460X384 & W360X1086 \\
\hline Bottom & & & W610X415 & W360X1086 \\
\hline
\end{tabular}




\subsection{Finite Element Modeling (FEM) of 4-, 8 - and 12-storey P-SPSW for Pushover}

\section{Analysis}

Seismic analysis is very time-consuming, complex procedure and requires several earthquake records to assess the performance of any lateral load resisting system. In comparison, pushover analysis is very convenient and simple investigation tool to study seismic performance of structure under lateral loads. Pushover is commonly used nonlinear static analysis procedure to check the adequacy of design as well. Thus, before seismic analysis, nonlinear pushover analysis was conducted for each of the selected P-SPSWs. For the pushover analysis, no dummy column was added. However, gravity loads were applied at the respective floor level. Before performing pushover analysis, linear perturbation "Buckle analysis" was performed to incorporate the initial imperfection in the respective infill plate. First mode buckling of selected P-SPSW with a scale factor of respective plate thickness was incorporated as an initial imperfection. Load controlled monotonic pushover analysis was performed for the selected P-SPSWs. Therefore, monotonically applied equivalent static loads were considered at the respective floor level. The lateral loads were increased monotonically during the pushover analysis. For the P-SPSW, tension field action fully developed before yielding of the infill. The hinges formed at the end of the beams after yielding in infill. At the end column, plastic hinges formed at the base of the columns. After all, 4-, 8- and 12-storey P-SPSW performed as per capacity design manner. Figure 3.10(b) shows the extent of yielding in 4-storey perforated SPSW. Table 3.8 presents the comparison of FE base shear and static base shear calculated as per NBCC 2010. The obtained base shear from pushover analyses was higher than designed value for all the selected P-SPSWs. For the 4-,8- and 12-storey P-SPSWs the FE base shear was $172 \%, 67 \%$, and $140 \%$ respectively. One of the main reasons for the additional base shear was the over-strength of the steel plate. 


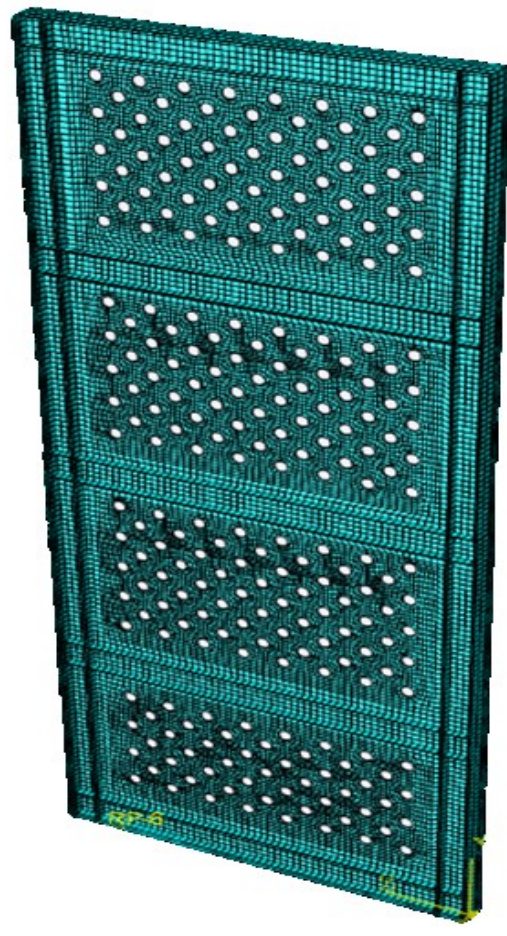

(a)

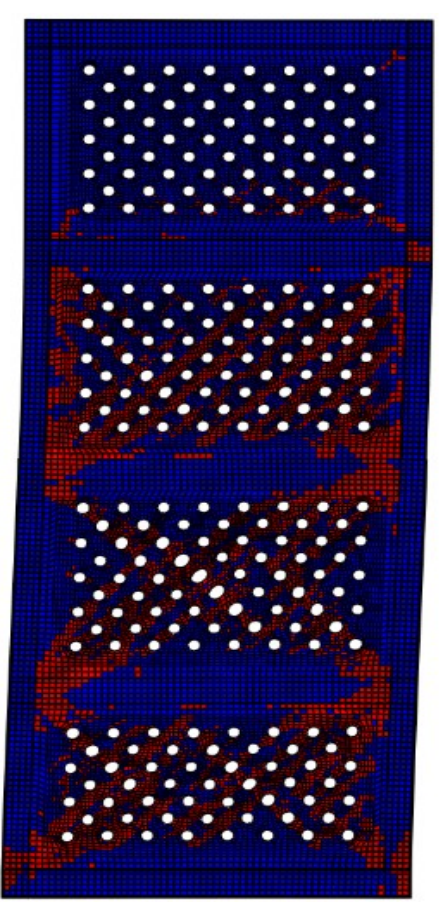

(b)

Figure 3.10: Four sotrey P-SPSW (a) Meshing (b) yield at ultimate load (red color)

According to CAN/CSA S16-09 the plate thickness requirement was very small but for the practical applicability, the plates were provided in higher thickness. Subsequently, the boundary members provided with high sections. Therefore, it increased the overall strength of the steel plate shear wall and increased the resisting base shear too.

Table 3.8: Comparison of Base shear for static NBCC 2010 and monotonic pushover Analysis

\begin{tabular}{|c|c|c|c|}
\hline \multirow{2}{*}{ P-SPSW } & \multicolumn{2}{|c|}{ Base shear (kN) } & \\
\cline { 2 - 4 } & From NBCC 2010 & $\begin{array}{c}\text { From Pushover } \\
\text { analysis }\end{array}$ & Variation in \% \\
\hline 4-storey & 1508 & 4110 & $172 \%$ \\
\hline 8-Storey & 2970 & 4950 & $67 \%$ \\
\hline 12-storey & 3354 & 8076 & $140 \%$ \\
\hline
\end{tabular}




\subsection{Summary}

In this chapter, initially, finite element modeling and analysis techniques were described. Afterwards, the chosen FE model was validated with two test specimens both for monotonic pushover and quasi-static cyclic analysis. It was observed that the developed FE techniques can accurately predict the experimental results. Finally, to investigate seismic performance of perforated steel plate shear walls, three multi-storey (4-, 8-, and 12-storey) P-SPSWs were designed as per Canadian standard. The seismic loads were calculated according to NBCC 2010. The infill plates, beam, and columns were designed according to the design provisions of CAN/CSA S16-09. Consequently, pushover analysis was performed for 4-, 8- \& 12- story PSPSWs to investigate the behavior of selected P-SPSWs under quasi-static loading conditions. 


\section{Chapter 4. Seismic Response of Perforated Steel Plate Shear Wall (P-SPSW)}

\subsection{Introduction}

Buildings that are located in the active seismic zone are usually vulnerable for strong ground motions. Buildings codes require that all the buildings situated in earthquake zones be considered for earthquake loads. However, the seismic analysis is quite complicated and time-consuming compared with other conventional analysis procedures. According to NBCC 2010, dynamic time history analysis is mandatory when the buildings have height more than $60 \mathrm{~m}$ or for structures with fundamental time periods more than 2 seconds. The objective of dynamic time history analysis is to assess the performance during the earthquake. For normal category building (for example office building), the expectation will be life safety so that some structural damages can be allowed, but it should withstand after designed level of earthquakes. As the P-SPSWs were designed to take the $100 \%$ of lateral in a particular direction, the desired level of performance will be some amount of structural damage but survive structurally. For capacity based design, usually, performance level checks with the inter-storey drift. NBCC 2010 requires that inter-storey drifts remain below $2.5 \%$ of the respective storey height.

In this chapter, dynamic (frequency and nonlinear time history) analysis were performed for three multi-storey (4-, 8-, and 12-storey) P-SPSWs to assess the seismic performance. A set of ground motions were chosen and scaled to match the response spectrum (RS) of Vancouver region. Finally, seismic responses were compared with recommended limits proposed by NBCC 2010 and CAN/CSA S16-09. 


\subsection{Nonlinear Dynamic Analysis of Perforated Steel Plate Shear Wall (P-SPSW)}

\subsubsection{Frequency Analysis}

For scaling of the time history data and estimation of damping factors $(\alpha$ and $\beta$ ) for nonlinear dynamic analysis, time periods are required. The code recommended empirical equation (Eq. 3.1) usually underestimates the actual period for a particular structure. Thus, frequency analysis of the selected three perforated SPSWs was conducted. The FE model used for the frequency analysis is similar to the one utilized in the previous chapter for pushover analysis. Only a dummy column was added parallel to the P-SPSW. The dummy column (leaning column) was used to account for the P- $\Delta$ effect of the surrounding gravity columns. The column was modeled in such a way that it could maintain a certain horizontal distance from the wall and ensure that no lateral stiffness was being added in the system. Thus, two node 3D truss element (ABAQUS T2D3) was used with a link connection between the stories to dummy column. Besides, half of the buildings gravity columns area (probable) was taken as the area of the truss element. The material properties of the dummy column were considered similar to the material properties of boundary element. Moreover, half of the building's lumped masses was added in the dummy column at their respective storey level. For P-SPSW, the lumped masses were applied at the top of each column.

\subsubsection{Frequency Analysis Result}

Frequency analysis was conducted for 4-, 8-, and 12-storey P-SPSWs and corresponding first two modes of vibrations were estimated. Frequencies of the first and second mode of vibration are given in Table 4.1. The corresponding period (T) was calculated by the Eq. 4.1 from the frequency $\left(\omega_{\mathrm{n}}\right)$. In addition, the Raleigh proportional damping coefficients $\alpha$ and $\beta$ have been computed by 
the Eq. 4.2 and 4.3 respectively. While calculating damping factors, 5\% Raleigh proportional damping factor $(\xi)$ was considered.

$$
\begin{aligned}
& T=\frac{2 \pi}{\omega_{n}} \ldots \ldots \ldots \ldots \ldots \ldots \ldots \ldots \ldots \ldots . . . \ldots \ldots \ldots \\
& \alpha=\xi \frac{2 \omega_{1} \omega_{2}}{\omega_{1}+\omega_{2}} \ldots \ldots \ldots \ldots \ldots \ldots \ldots \ldots . . . \ldots .2 \\
& \beta=\xi \frac{2}{\omega_{1}+\omega_{2}} \ldots \ldots \ldots \ldots \ldots \ldots \ldots \ldots . . . \ldots \ldots
\end{aligned}
$$

where $\omega_{1}$ and $\omega_{2}$ are the circular frequency of the $1^{\text {st }}$ mode and $2^{\text {nd }}$ mode of vibration respectively.

Table 4.1: Frequency and corresponding time periods of the 4-, 8- and 12-storey P-SPSWs.

\begin{tabular}{|c|c|c|c|}
\hline \multicolumn{2}{|c|}{ P-SPSW } & Circular frequency $(\omega)$ in rad/sec & Time period (T) in sec \\
\hline \multirow{2}{*}{ 4-storey } & $1^{\text {st }}$ mode & 6.20 & 1.01 \\
\cline { 2 - 4 } & $2^{\text {nd }}$ mode & 17.16 & 0.37 \\
\hline \multirow{2}{*}{ 8-storey } & $1^{\text {st }}$ mode & 2.97 & 2.10 \\
\cline { 2 - 4 } & $2^{\text {nd }}$ mode & 9.39 & 0.67 \\
\hline \multirow{2}{*}{ 12-storey } & $1^{\text {st }}$ mode & 1.92 & 3.27 \\
\cline { 2 - 4 } & $2^{\text {nd }}$ mode & 6.58 & 0.95 \\
\hline
\end{tabular}

\subsection{Selection of Ground Motion Records}

West coast of Canada is the most active seismic region; maximum seismic events were recorded in this area. The most active fault line, "Ring of Fire" stretches parallel to the west coast of Canada within $50 \mathrm{Km}$ from shore. In this research, Vancouver was considered for the location of the hypothetical building. Therefore, the response spectrum (RS) of the Vancouver region was taken from the uniform hazardous spectrum of NBCC 2010. 
While selecting a number of ground motions record, ASCE 7-10 guideline was considered, as there are no guidelines in Canada. As per ASCE 7-10, at least three earthquakes are required when a maximum response will be checked off a structure. On the other hand, minimum seven earthquake records must be considered when the average response will be checked. Besides, it is common practice to take an equal amount of simulated earthquakes with real seismic events, to predict the real behavior in future.

To investigate seismic performance of P-SPSWs designed for Vancouver, the selected ground motions data must be compatible with response spectrum (RS) of the Vancouver region. Real ground accelerations data were taken from Pacific Earthquake Engineering Research Center (PEER 2010), on the other hand, site dependent artificial ground motions data were taken from Engineering Seismology toolbox website (Atkinson et al. 2009).

While selecting real ground motions data, the geology, the fault line, distance from fault, etc. of the selected records should be identical to Vancouver, BC. Taking into account all the factors, USA west coast (California) is the utmost choice. Therefore, most of the real ground motions data were considered from California area. Initially, a set of strong motions data were taken into account. However, few of them were considered which fulfill the two criteria are given below.

- Firstly, from $1600-2006$, over 400 years' period of time, almost $60 \%$ of the earthquakes struck nearby the west coast of Canada in compare to the whole country. Among them, highest ranges of earthquakes were 6-7 magnitude Richter scale (Lamontagne et al. 2008).

- Secondly, earthquake magnitude also depends on the soil class. Therefore, acceleration (A) and the velocity (V) of the earthquakes change with soil quality. It was reported that for Vancouver, the A/V ratio is in between 0.8-1.2 (Naumoski et al. 2004). 
Under these circumstances, while selecting ground motions records, finally the events were nominated for the time history analysis which was the magnitude in between M6-M7 and A/V ratio within the range 0.8-1.2. In addition, Kobe 1995 was considered as it matches with geology and fault line with Vancouver.

Moreover, simulated earthquakes were taken into consideration for the seismic responses evaluation for the selected P-SPSWs. Both types of simulated earthquakes like near field and far field were considered. For the soil class $\mathrm{C}$ only four simulate earthquakes were found in the Engineering Seismology toolbox website (Atkinson et al. 2009). Where, for the west side of Canada only 6.5 and 7.5 magnitude Richter scale earthquakes data were taken.

Therefore, four simulated earthquakes and six real earthquakes were carefully chosen for nonlinear time history analysis. Selected seismic events are given below in table 4.3, and table 4.4 for the real and synthetic ground motions records respectively.

Table 4.2: Selected real time ground motions records from PEER database

\begin{tabular}{|l|c|c|c|c|c|c|}
\hline \multicolumn{1}{|c|}{ Event } & Year & Station & M & $\begin{array}{c}\text { PGA } \\
(\mathrm{g})\end{array}$ & $\begin{array}{c}\text { PGV } \\
(\mathrm{m} / \mathrm{s})\end{array}$ & A/V \\
\hline $\begin{array}{l}\text { Imperial Valley- } \\
\text { 6,California,USA }\end{array}$ & 1979 & 183 El Centro & 6.53 & 0.525 & 0.502 & 1.04 \\
\hline $\begin{array}{l}\text { Kern County, } \\
\text { California, USA }\end{array}$ & 1952 & Taft Lincoln School & 7.3 & 0.156 & 0.153 & 1.02 \\
\hline Kobe city, Japan & 1995 & 1105 HIK & 6.6 & 0.143 & 0.147 & 0.97 \\
\hline Loma Prieto, USA & 1989 & $\begin{array}{c}\text { 739AndersonDam } \\
\text { (Downstream) }\end{array}$ & 6.93 & 0.233 & 0.221 & 1.05 \\
\hline Northridge-I,USA & 1994 & $\begin{array}{c}\text { 68 LA-Hollywood Stor } \\
\text { FF }\end{array}$ & 6.7 & 0.231 & 0.183 & 1.20 \\
\hline $\begin{array}{l}\text { San Fernando, USA } \\
\text { California, USA }\end{array}$ & 1972 & $\begin{array}{c}\text { 68 LA-Hollywood } \\
\text { Stor FF }\end{array}$ & 6.6 & 0.188 & 0.179 & 1.05 \\
\hline
\end{tabular}


Table 4.3: Selected Simulated ground motions records from Eng. Seismology toolbox website

\begin{tabular}{|c|c|c|c|}
\hline Event name & Magnitude(M) & Distance $(\mathrm{Km})$ & $\begin{array}{c}\text { Peak acceleration } \\
(\mathrm{cm} / \mathrm{s} 2)\end{array}$ \\
\hline $6 \mathrm{C} 1$ & 6.5 & 8.8 & 487 \\
\hline $6 \mathrm{C} 2$ & 6.5 & 14.6 & 265 \\
\hline $7 \mathrm{C} 1$ & 7.5 & 15.2 & 509 \\
\hline $7 \mathrm{C} 2$ & 7.5 & 45.7 & 248 \\
\hline
\end{tabular}

\subsection{Time Period Selection for the Scaling of Ground Motion:}

The time period of the FE analysis overestimates over code provided equation (Bhowmick et al. 2011). So, as a practical point of view, the fundamental period of the finite element analysis was taken for scaling. Chosen fundamental time period (T1) for the code equation and FE analysis of the 4-,8- and 12-storey P-SPSW is presented in Table 4.4.

Table 4.4: Comparison of Time period from code equation and FE modeling

\begin{tabular}{|c|c|c|}
\hline P-SPSW & $\begin{array}{c}\text { NBCC 2010 time period } \\
\text { in Sec }\end{array}$ & $\begin{array}{c}\text { Time period from FE } \\
\text { analysis } \mathrm{T}_{1}(\mathrm{sec})\end{array}$ \\
\hline 4-storey & 0.385 & 1.01 \\
\hline 8-storey & 0.647 & 2.01 \\
\hline 12-storey & 0.87 & 3.20 \\
\hline
\end{tabular}

\subsection{Scaling of Ground Motion Data:}

Seismic records must be scaled with design response spectrum. In this research, the design response spectrum was taken from the NBCC 2010 for the 5\% of critically damped of single degree of freedom system (SDOF) for soil class $\mathrm{C}$. The chosen records were converted as pseudo response spectrum by using SeismoMatch software (V.2.1.2). Later, pseudo-response spectrum of a particular record was plotted against designed response spectrum which is shown in Figure 4.1. If 
the record was well-matched with the reference response spectrum, then it was selected finally for scaling.

There are several scaling methods for seismic data; every method has some merits as well demerits. In Canada, there is no guideline for the scaling of ground motion records. In this research partial area method of ground motion scaling was taken into consideration. According to EC8 (European Committee Standardization, 2004), for partial area method the lower and higher limit of target response spectrum is $0.2 \mathrm{~T}_{1} \& 2.0 \mathrm{~T}_{1}\left(\mathrm{~T}_{1}=\right.$ fundamental time period) respectively. On the other hand, U.S. standard (American Society of Civil Engineers, 2007) recommended partial area method by allowing range 0.2 times to 1.5 times of the time period in the response spectrum. Similar to ASCE07 , the lower and higher limit was taken $0.2 \mathrm{~T}_{1}$ and $1.5 \mathrm{~T}_{1}$ respectively in the target response spectrum ( $T_{1}$ is the fundamental period from the Table 4.4). The Total area bounded by the lower and upper limit in the respective response spectrum was calculated separately for the both case, respectively designed (A1) and selected ground motions (A2). Afterwards, the scale factor (SF) was calculated from the ratio of design RS (A1) and ground motion RS (A2) area.

The scale factor of the selected ground motions was maintained such a way that it should be neither more than two nor less than 0.5 , if so, the record was discarded. If scaling factor is more than 2, the earthquake is too small for the area, on the other hand, if the SF is less than 0.5 , the quake is too big to evaluate the seismic response for selected P-SPSWs. Table 4.5 present the scale factor for selected grounds motions. Finally, scaled response spectrums were established by multiply the scaling factor with the raw (unscaled) RS.

As the input data in the FE modeling was time history data (acceleration verse real time), hence, the RS of the chosen records were converted as a time history data. Figure 4.1 illustrates the 
unscaled and Figure 4.2, $4.3 \& 4.4$ represent the scaled response spectrum data of selected earthquakes for 4-,8- and 12-storey P-SPSWs respectively. In addition, Figure 4.5 to 4.14 are the in unscaled and scaled time history data for the selected P-SPSWs.

Table 4.5: Scaling factors of the selected ground motions for selected P-SPSWs

\begin{tabular}{|l|c|c|c|}
\hline \multirow{2}{*}{ Events } & \multicolumn{3}{c|}{ Scaling Factor(SF) } \\
\cline { 2 - 4 } & 4-storey & 8-storey & 12-storey \\
\hline Imperial Valley-II, (IV) & 0.99 & 1.04 & 1.01 \\
\hline Kern County, California, (KC) & 1.86 & 1.81 & 1.89 \\
\hline Kobe City, Japan & 1.71 & 1.57 & 1.61 \\
\hline Loma Prieto(LP), USA & 1.31 & 1.38 & 1.47 \\
\hline Northridge-I(NR),USA & 1.38 & 1.34 & 1.42 \\
\hline San Fernando(SF), California & 1.61 & 1.64 & 1.68 \\
\hline Simulated 6C1 & 0.70 & 0.78 & 0.88 \\
\hline Simulated 6C2 & 1.30 & 1.48 & 1.64 \\
\hline Simulated 7C1 & 0.83 & 0.91 & 0.97 \\
\hline Simulated 7C2 & 1.66 & 1.45 & 1.83 \\
\hline
\end{tabular}




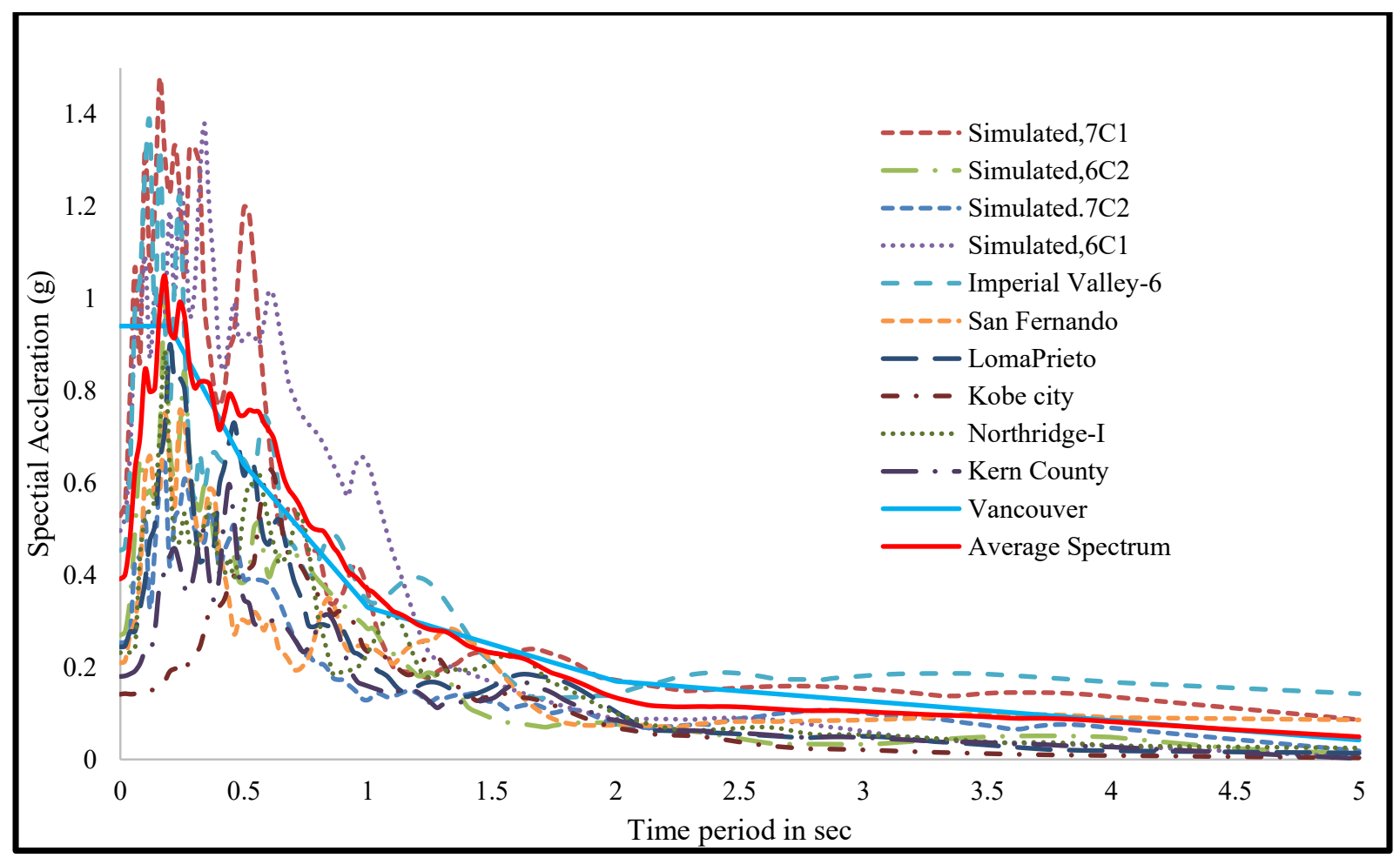

Figure 4.1: Unscaled Acceleration spectra for selected ground motions and Vancouver design spectra

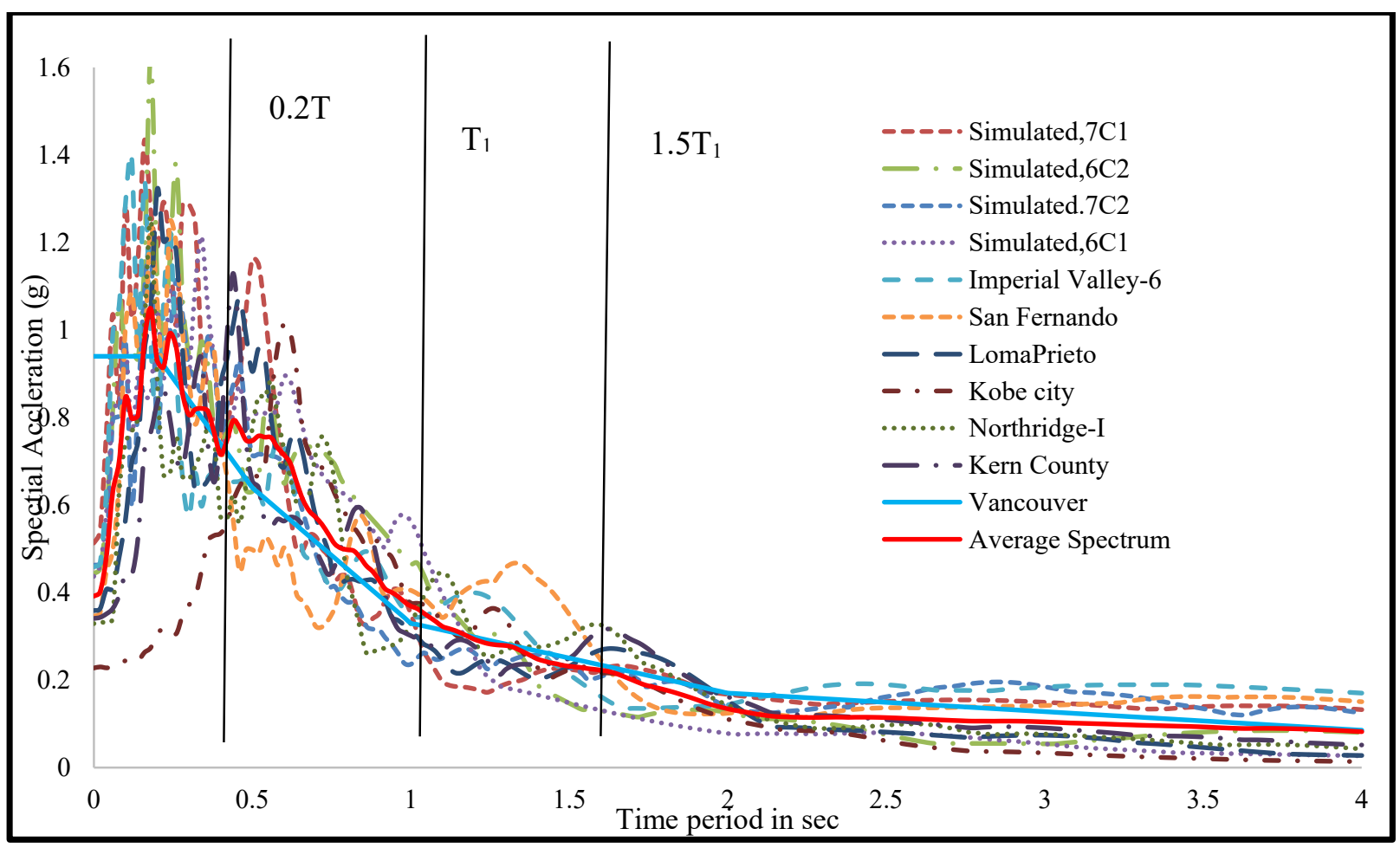

Figure 4.2: Scaled Acceleration spectra for the ground motions \& Vancouver design spectra for 4-storey P-SPSW 


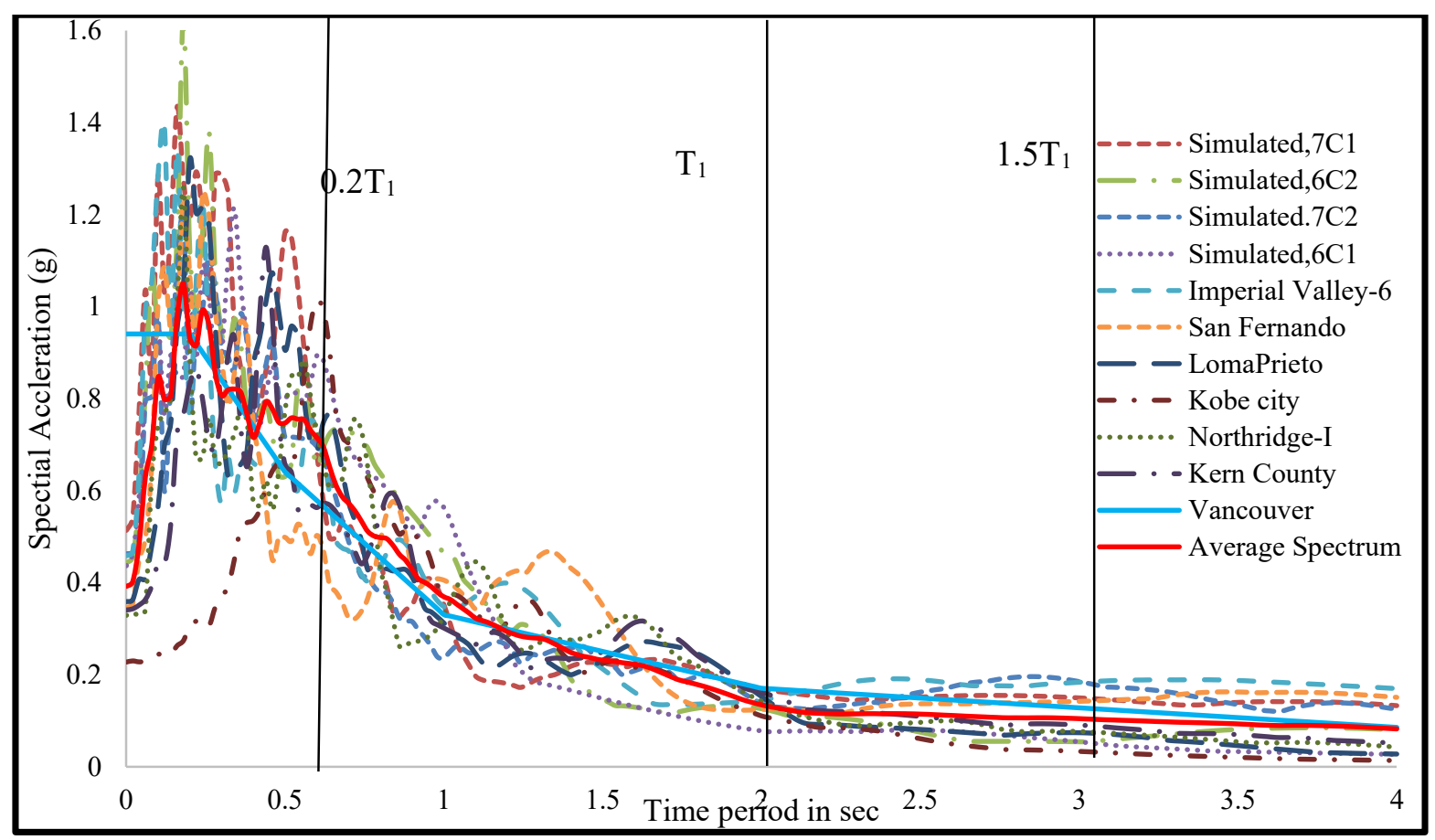

Figure 4.3: Scaled Acceleration spectra for the ground motions \& Vancouver design spectra for 8-storey P-SPSW

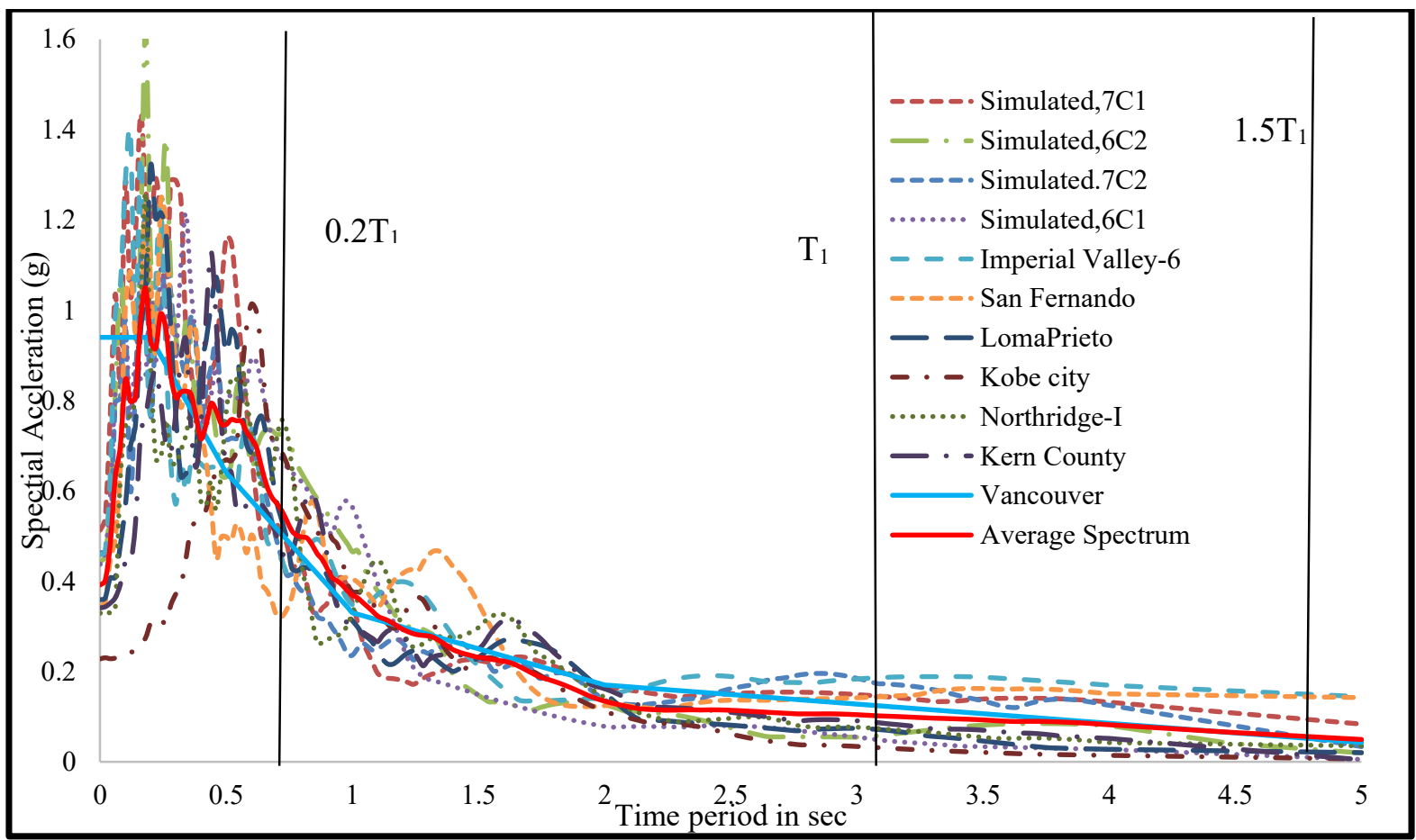

Figure 4.4: Scaled Acceleration spectra for the ground motions \& Vancouver design spectra for 12-storey P-SPSW 

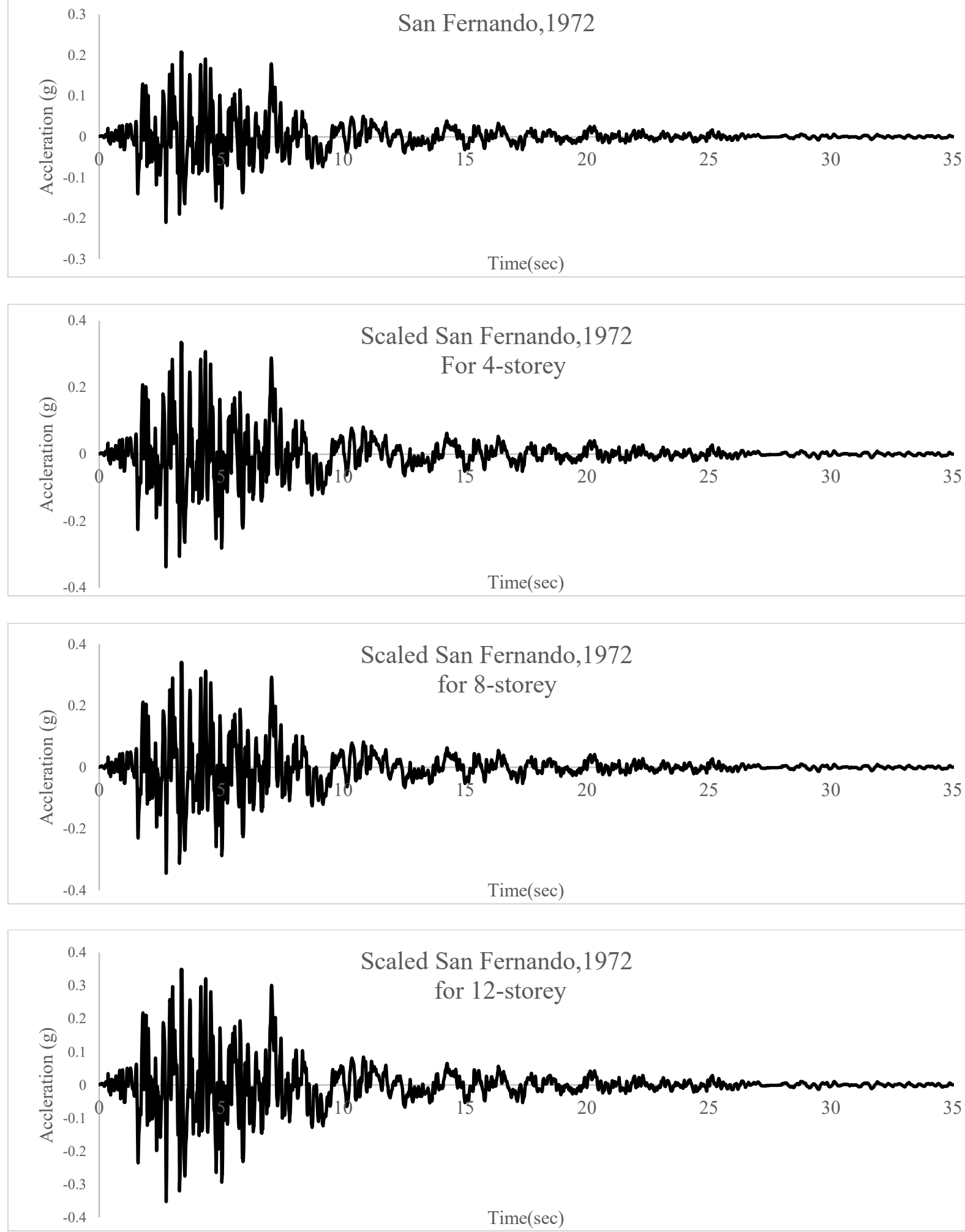

Figure 4.5: Unscaled San Fernando, 1972 earthquake and scaled for 4, 8 \& 12-storey P-SPSW

78 

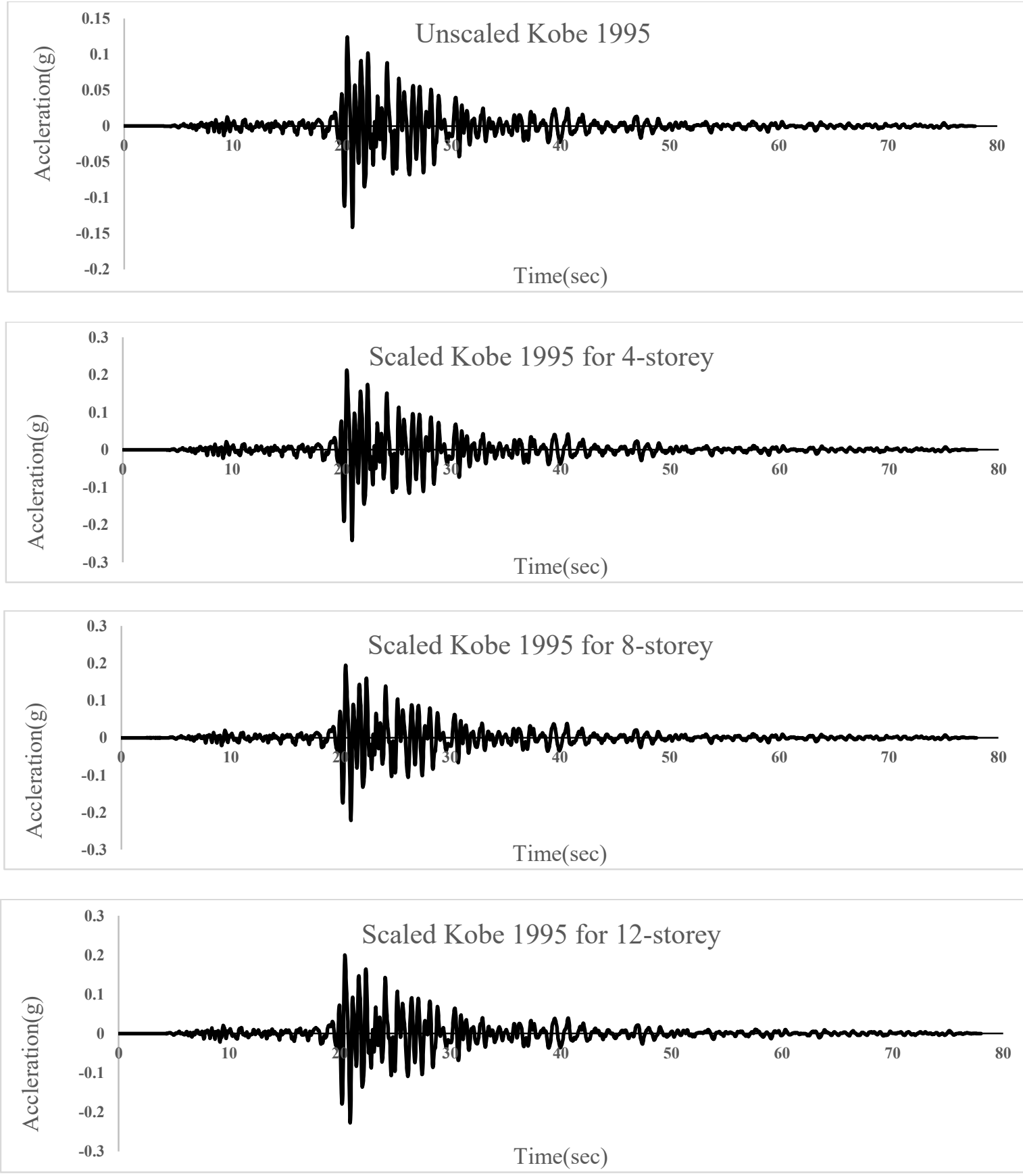

Figure 4.6: Unscaled Kobe, 1975 earthquake and scaled for 4, 8 \& 12-storey P-SPSW 

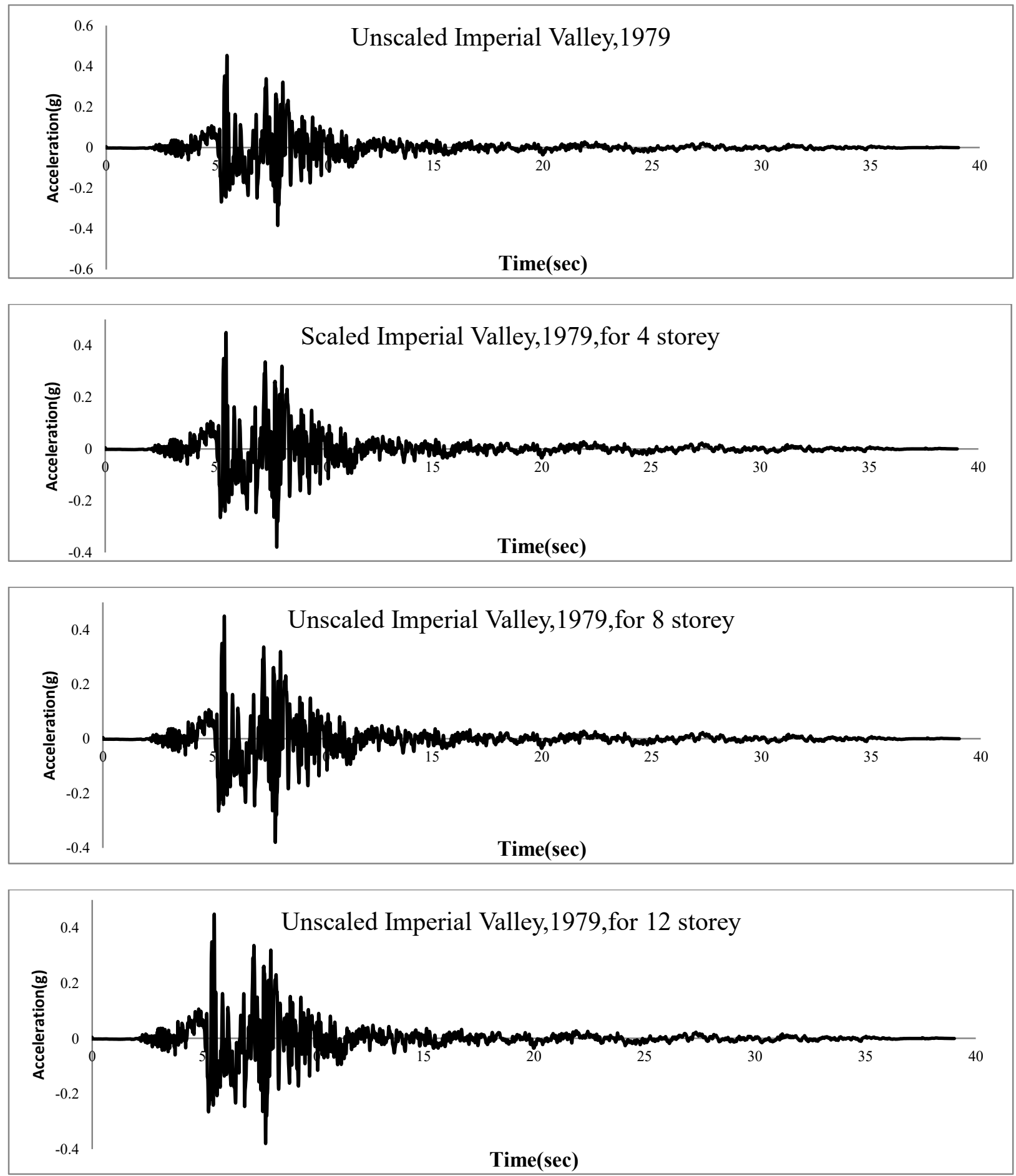

Figure 4.7: Unscaled Imperial Valley, 1979 earthquake and scaled for 4, 8 \& 12-storey P-SPSW 

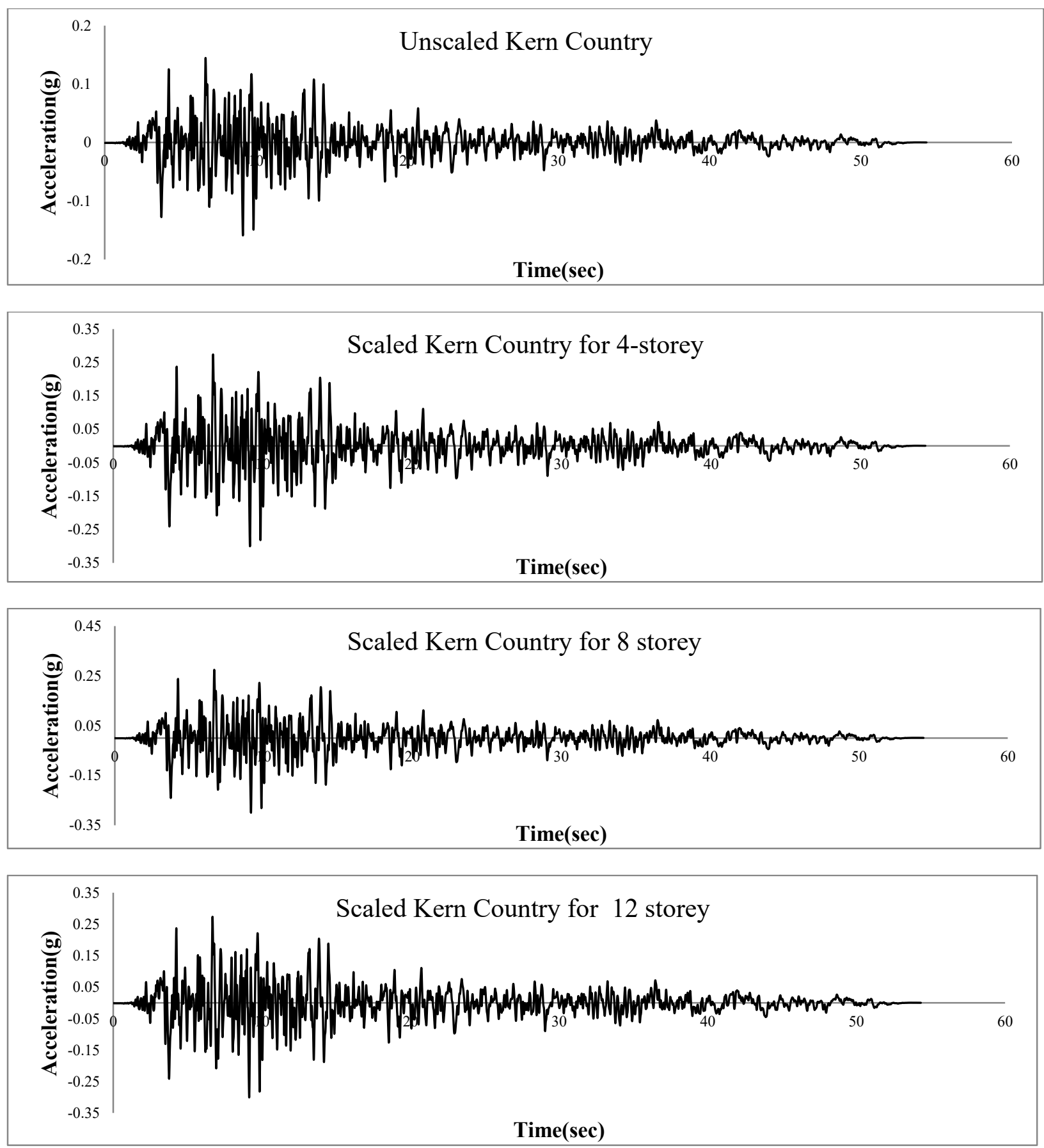

Figure 4.8: Unscaled Kern Country earthquake and scaled for 4, 8 \& 12-storey P-SPSW 

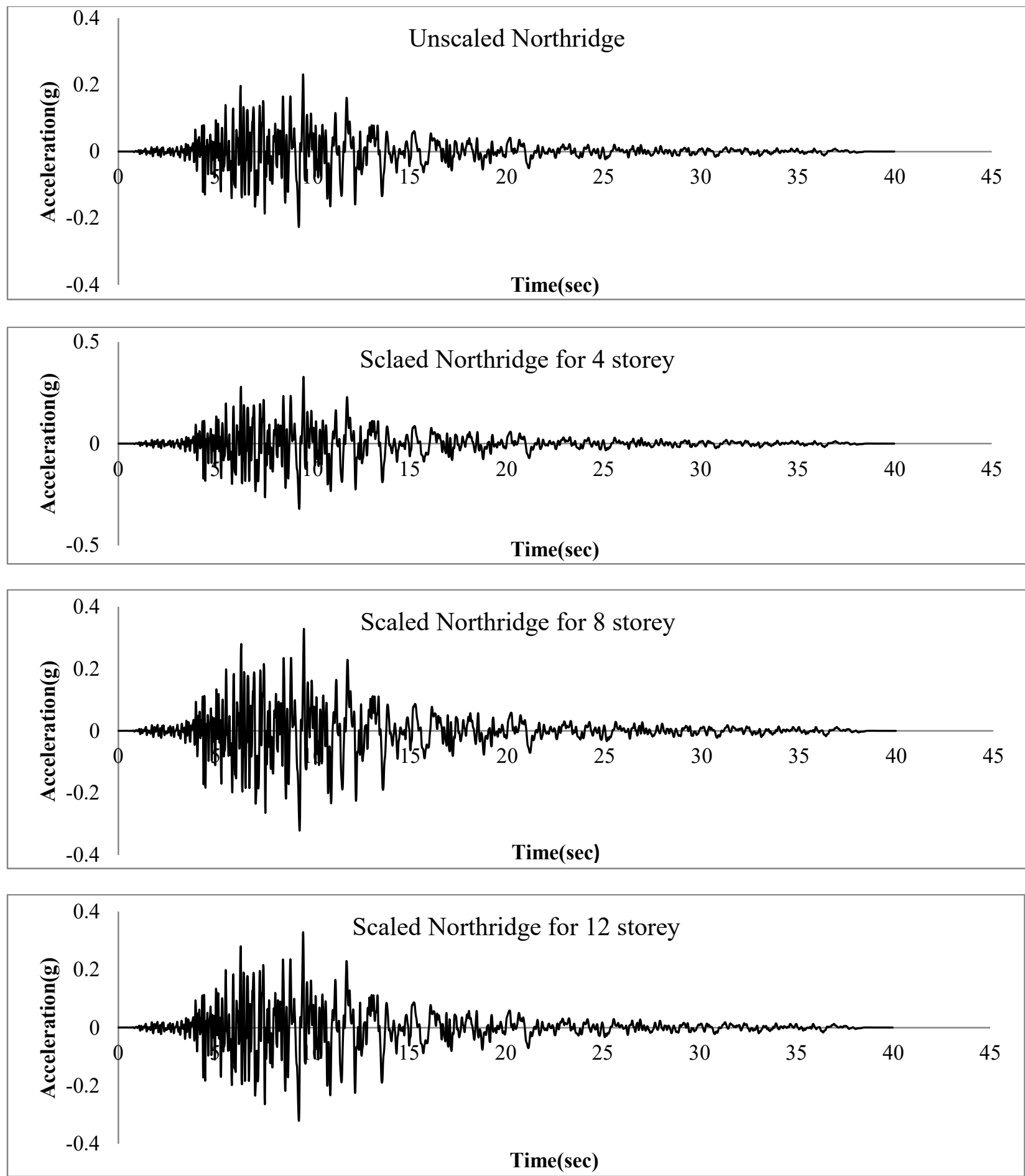

Figure 4.9: Unscaled Northridge earthquake and scaled for 4, 8 \& 12-storey P-SPSW 

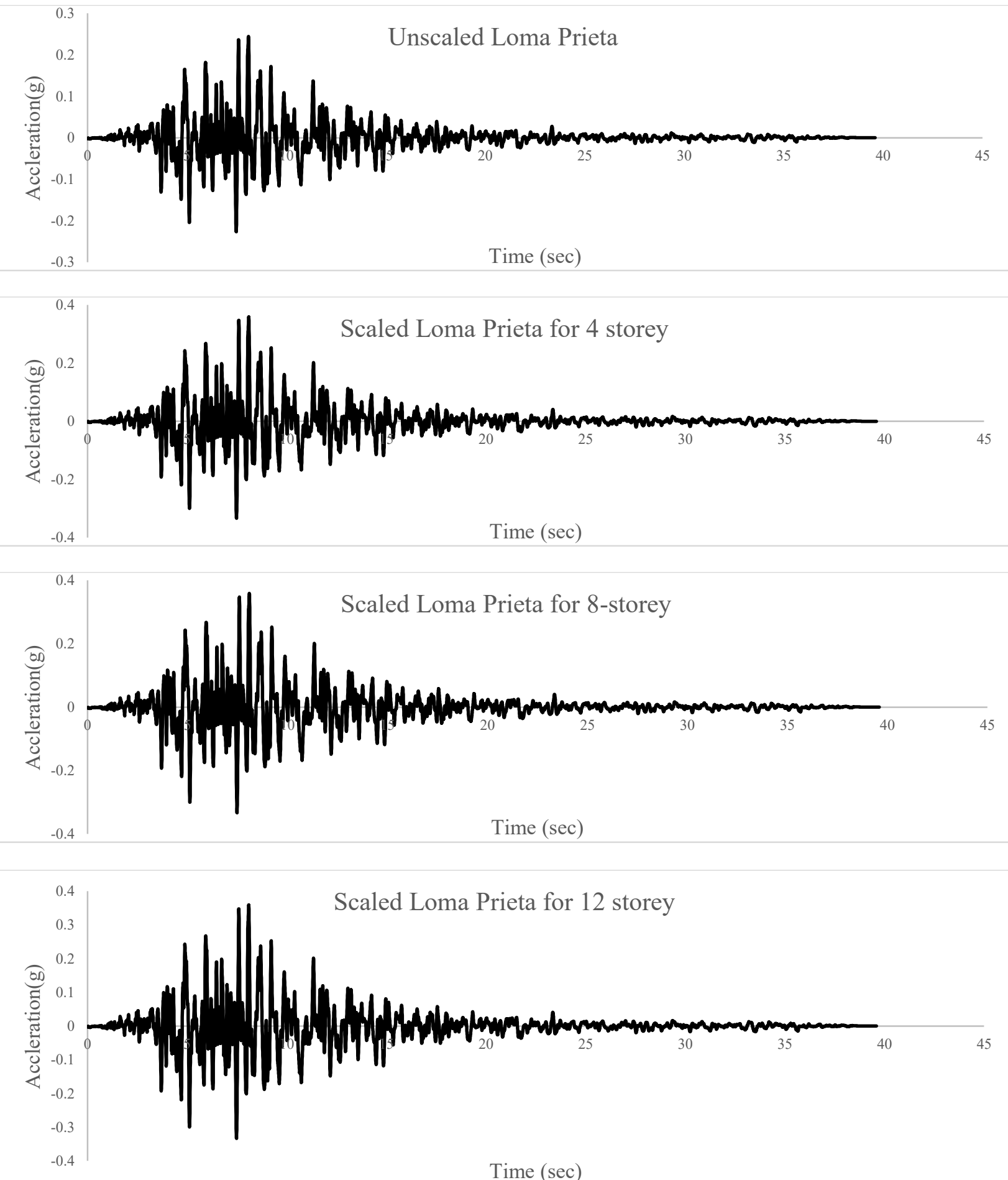

Figure 4.10: Unscaled Loma Prieta earthquake and scaled for 4, 8 \& 12-storey P-SPSW 

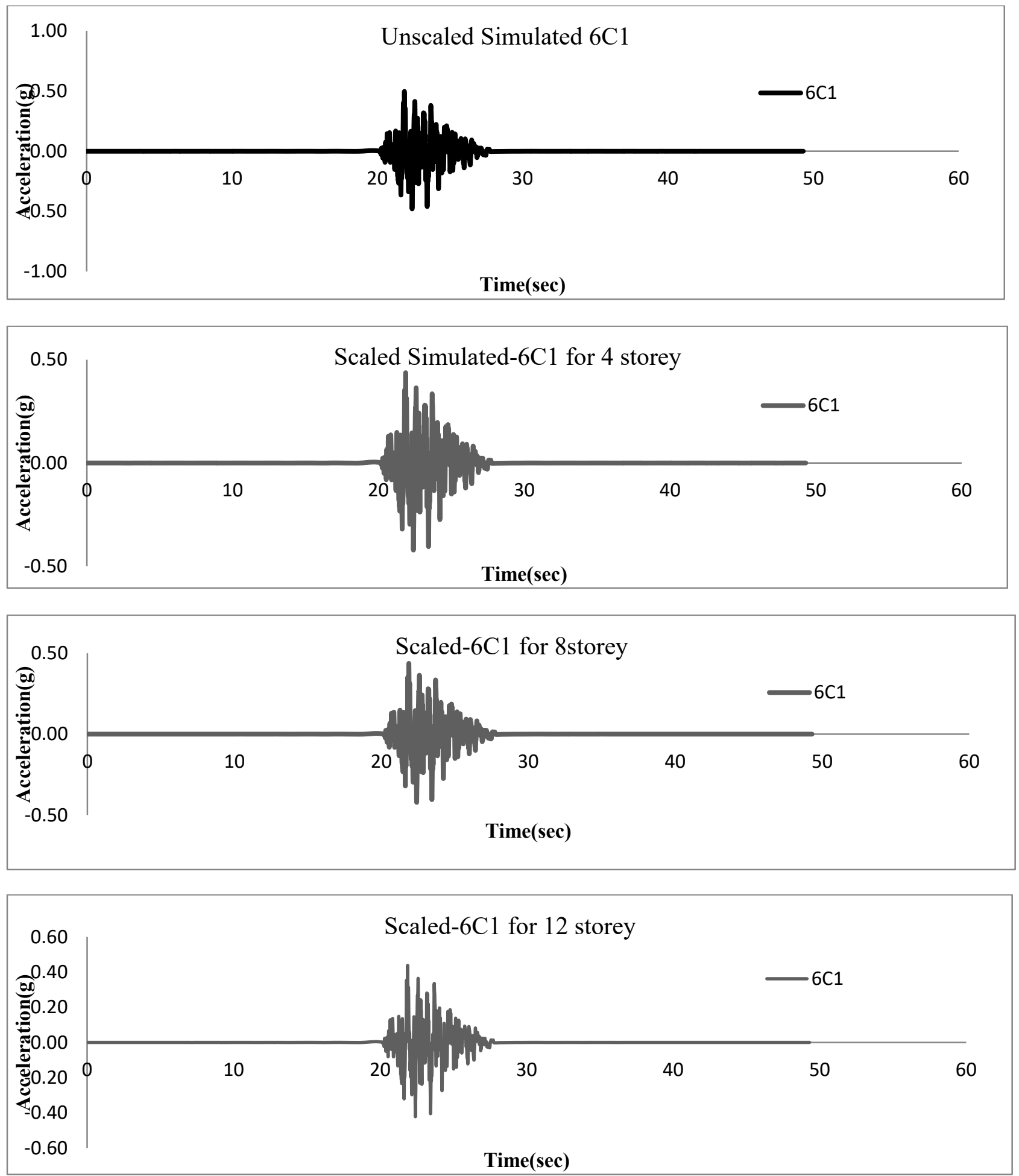

Figure 4.11: Unscaled Simulated 6C1 earthquake and scaled for 4, 8 \& 12-storey P-SPSW 

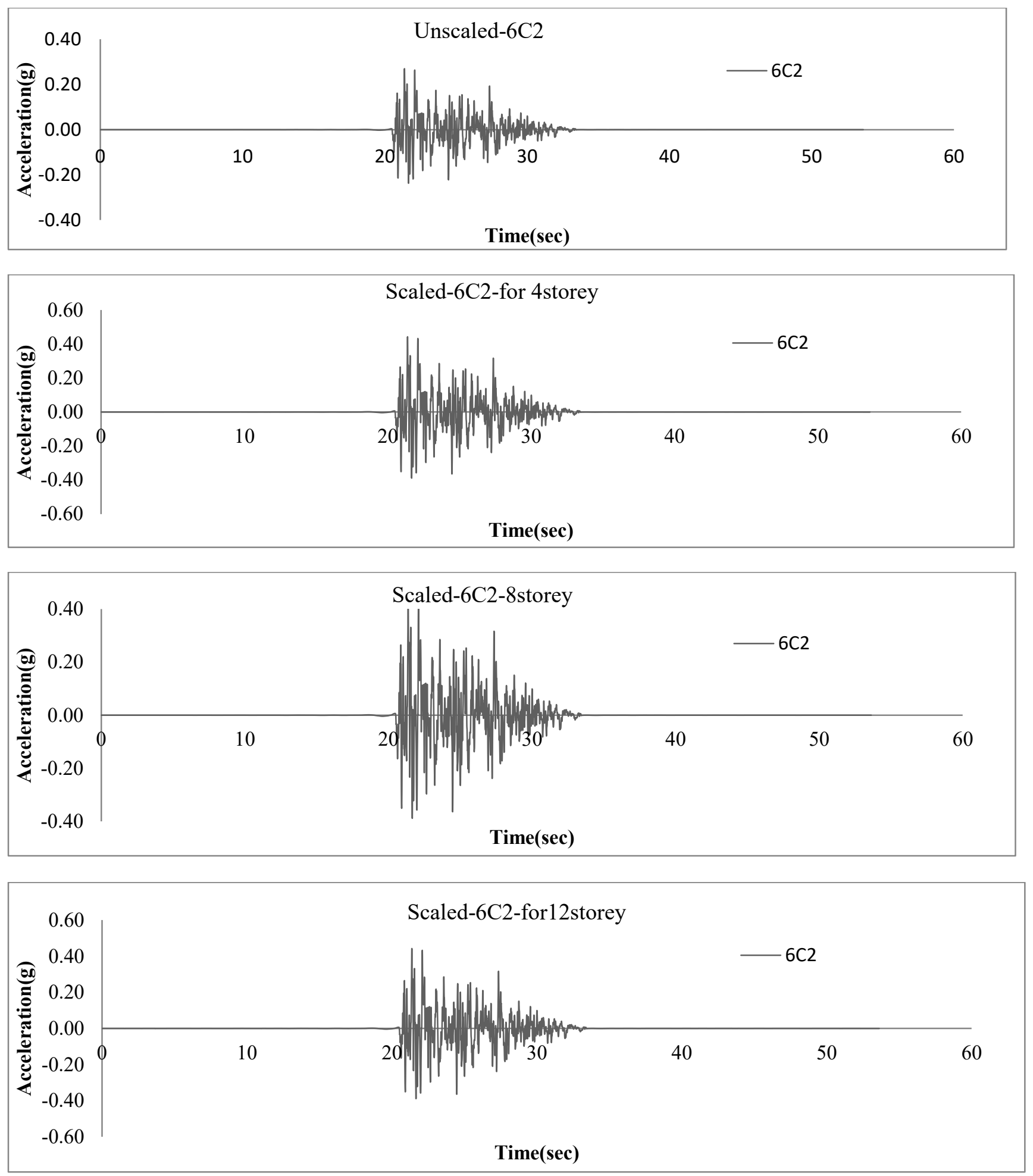

Figure 4.12: Unscaled Simulated 6C2 earthquake and scaled for 4, 8 \& 12-storey P-SPSW 

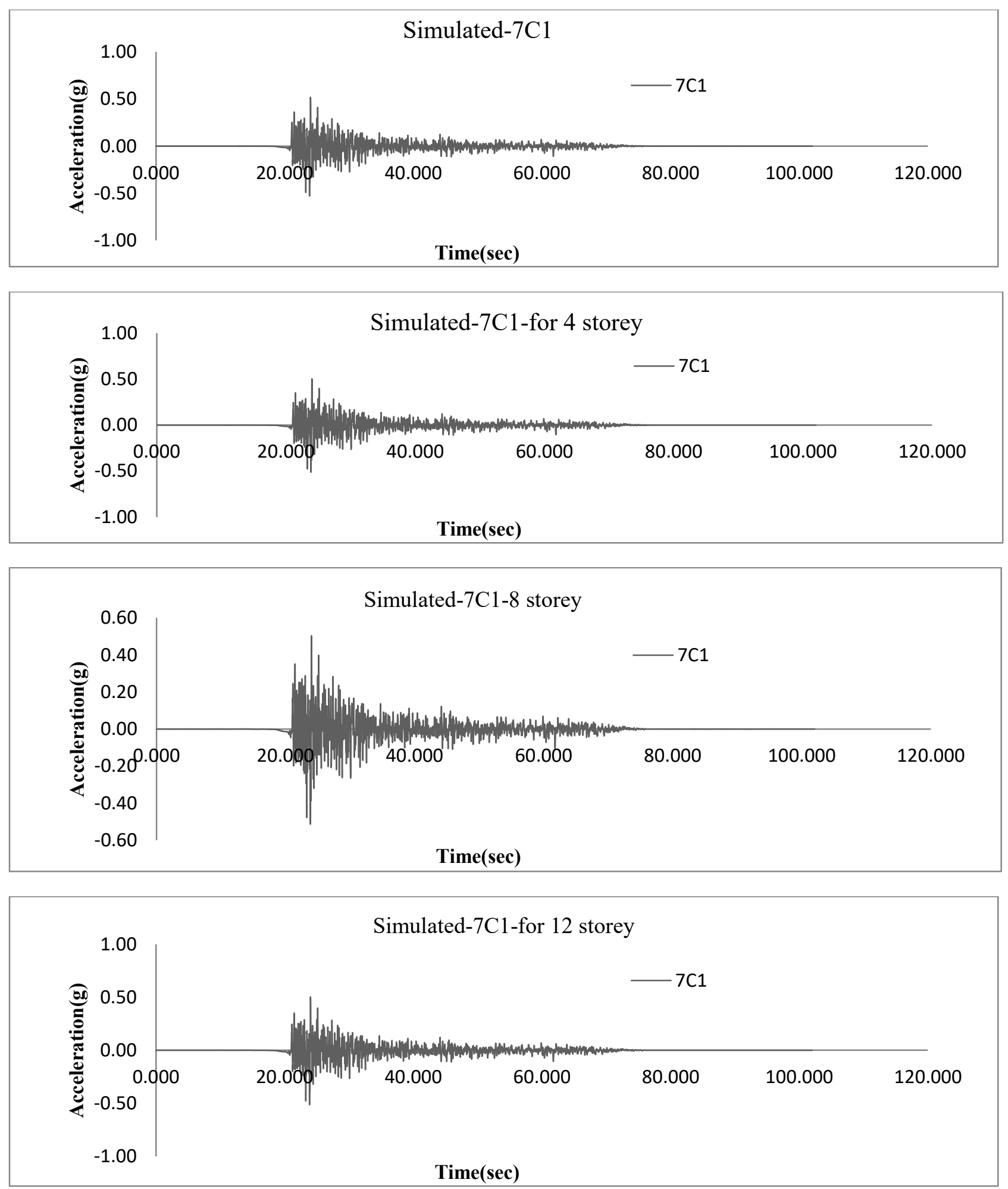

Figure 4.13: Unscaled Simulated 7C1 earthquake scaled for 4, 8 \& 12-storey P-SPSW 

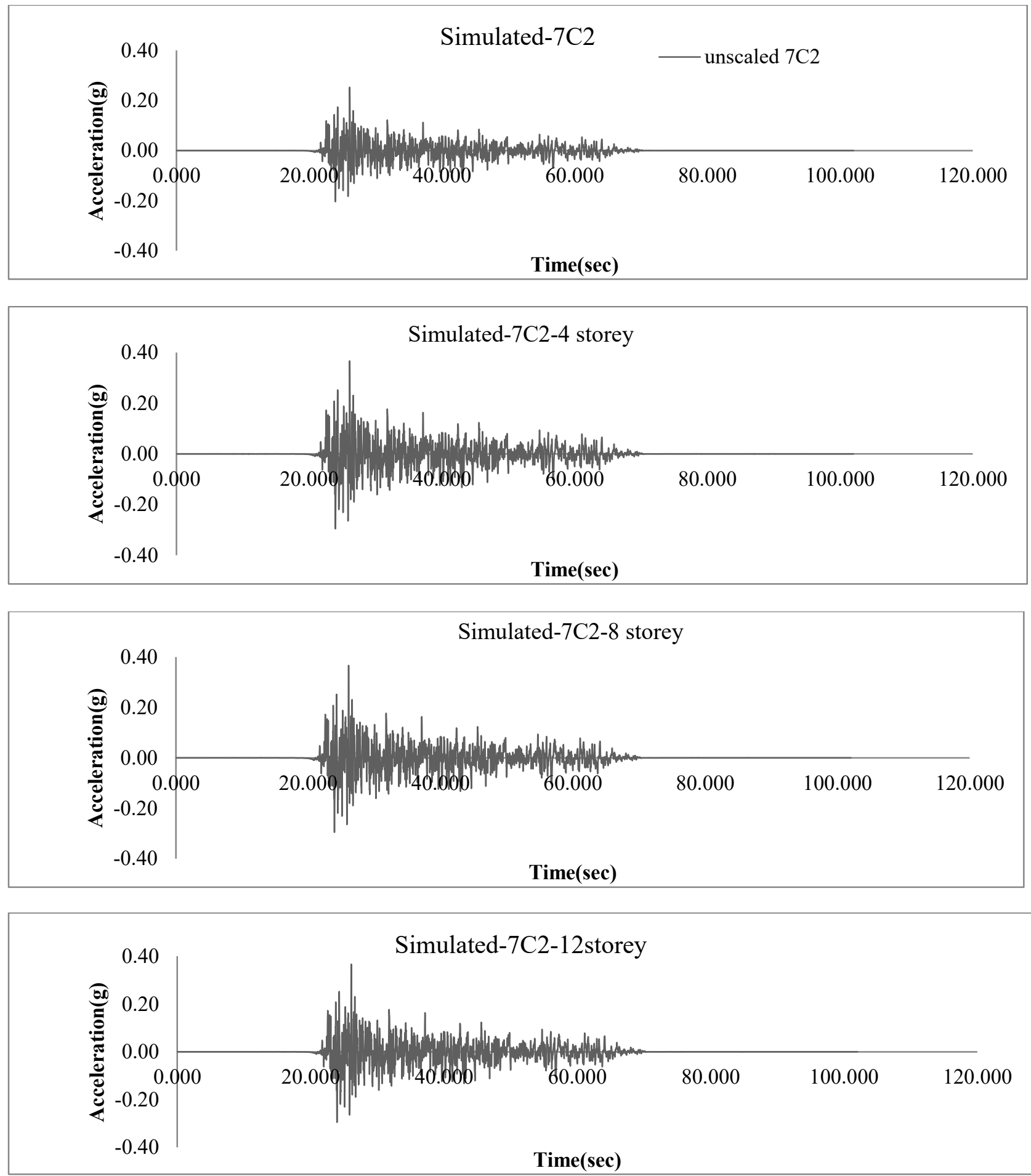

Figure 4.14: Unscaled Simulated 7C2 earthquake and scaled for 4, 8 \& 12-storey P-SPSW 


\subsection{Seismic Responses of 4-, 8-, and 12-storey P-SPSWs}

The nonlinear seismic analysis was performed for 4-, 8- and 12-storey P-SPSW for the selected ground motions. Six historic and four simulated ground motions were considered in this study. To fulfill the ASCE7-10 criteria, more than seven earthquakes were considered to take the average responses.

Among the selected earthquakes, simulated 7C1 and 7C2 were high in magnitude which was M7.5. On the other hand, other selected ground motions records were in between the range of M6.0M7.0. Therefore, peak responses were higher for the two simulated earthquakes (7C1 \& 7C2) compare to the other ground motions.

As per NBCC 2010, for capacity-based design, inter-storey drift is most important criteria to assess the performance of structure during an earthquake. Thus, the maximum inter-storey drift must be less than $2.5 \%$ of the height of the respected storey. It was observed that average inter-storey drift was less than code limit. For the simulated earthquakes 7C1 and 7C2, the first-floor inter-storey drift was much higher than the other ground motions.

During the design of P-SPSW, only fist mode collapse mechanism was considered. Thus, from the non-linear time history analysis, it was observed that for the 4- and 8-storey P-SPSW, the first mode of vibration was also dominating mode. So the lower storeys experienced high drift compared to upper stories. At the same time, lower few stories perforated plate participate energy dissipation by yielding the material and upper stories plates were elastic (Table 4.6 and 4.7). However, for the 12-storey P-SPSW, higher mode effect was induced during the earthquake. Thus, with the lower stories, higher stories steel plates contributed during the earthquakes by yielding action which can be found from Table 4.8 
Therefore, for the low-rise (4-storey P-SPSW) to mid-rise (8-storey P-SPSW) structure, the point of interest was the first floor due to its high inter-storey drift. For the 4-storey P-SPSW, the firstfloor drift was $1.01 \%$ which was lower than code limit of $0.025 \mathrm{hs}$ (hs is the storey height). In contrast, for the 8 -storey P-SPSW, average inter-storey drift was $1.45 \%$ of storey height, which was still high compared to other P-SPSW but less than the code limit. For 12-storey P-SPSW, due to the higher mode effect in the high-rise structure, the drift was distributed over the height which can be found in the Figure 4.15(c).

Dynamic base shear is also an important criterion to check the seismic performance. Static base shear calculated as per NBCC 2010 was compared with FE analysis base shear for selected ground motions as shown in figure 4.17. The average base shear for the selected ground motions were $110 \%, 230 \%$ and $150 \%$ higher for the 4-, 8- and 12-storey P-SPSW respectively in compared to NBCC 2010 static base shear. One of the main reasons for the additional base shear was the overstrength of the steel plate. According to CAN/CSA S16-09 the plate thickness requirement was very small but for the practical applicability, the plates were provided in higher thickness. Subsequently, the boundary members provided with high sections. Therefore, it increased the overall strength of the steel plate shear wall and increased the resisting base shear.

The average dynamic storey shear force was compared with the NBCC2010 static storey force. For 4-, 8-, and 12-storey P-SPSWs the average seismic force on every floor was higher than the design one. During design, the column shear contribution was neglected but in practice, a considerable amount shear is taken by the columns, which lead to the higher shear force on every floor. It was also observed that for the 4-storey and 8-storey P-SPSW, the lower storeys have higher shear force because of high drift but for the 12-storey, the maximum storey force was found in the second or third storey. 
Dynamic shear in the mid-section of the perforated plate was compared with CAN/CSA S16-09 provided equation (2.11) for perforated steel plate. The shear forces in the perforated plates for 4, 8- and 12 -storey P-SPSWs are presented in Tables 4.6, 4.7 and 4.8 respectively. It was observed that the standard equation always overestimates the average section force for selected earthquakes. Therefore, the standard equation (2.11) is safe to use in the design of P-SPSW. The percentage of variation increases with the rise of the floor level for the selected P-SPSWs. For the 12-storey PSPSW, the variation was close to the higher floor compared to $4 \& 8$-storey P-SPSW, due to higher mode effect in the high-rise structure (12-storey P-SPSW).

Later, columns' axial forces were compared with Berman and Bruneau (2008) designed procedure. The average axial forces obtained from the dynamic analysis of the selected ground motions were less than the designed one which can be found in the figure 4.19, 4.20 and 4.21 for the 4-, 8- and 12-storey P-SPSW respectively. During design, the column shear contribution was neglected, but it was found that considerable amount of shear force was contributing by both of the columns.

The P-SPSW was designed as per as capacity design. The expected performance is that during an earthquake the infill plates as well as both ends of each beam will act like a ductile fuse. Moreover, the columns will perform elastically during earthquakes and remain with stand after earthquakes. For the 4- and 8-storey P-SPSW, initially, the lower two stories infill yielded than plastic hinges formed at the both end of the beams (figure 4.25). In the upper floor of the 4-and 8-storey P-SPSW, there was no yielding in the infill plates. On the other hand, for 12-storey P-SPSW, bottom to top floor infill plate yielded during seismic analysis (figure 4.26) because of higher mode contribution during vibration. Nevertheless, for all the structures, both columns were performed elastically during the dynamic analysis. 


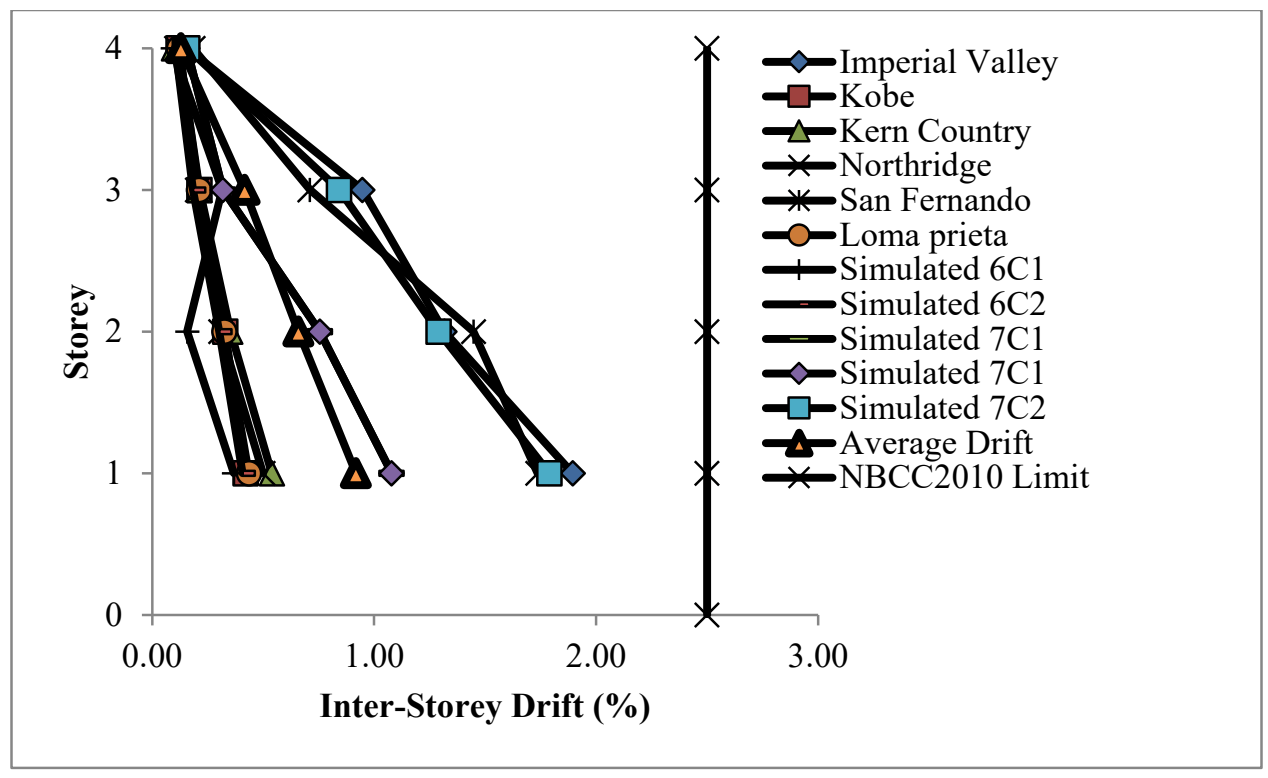

(a)

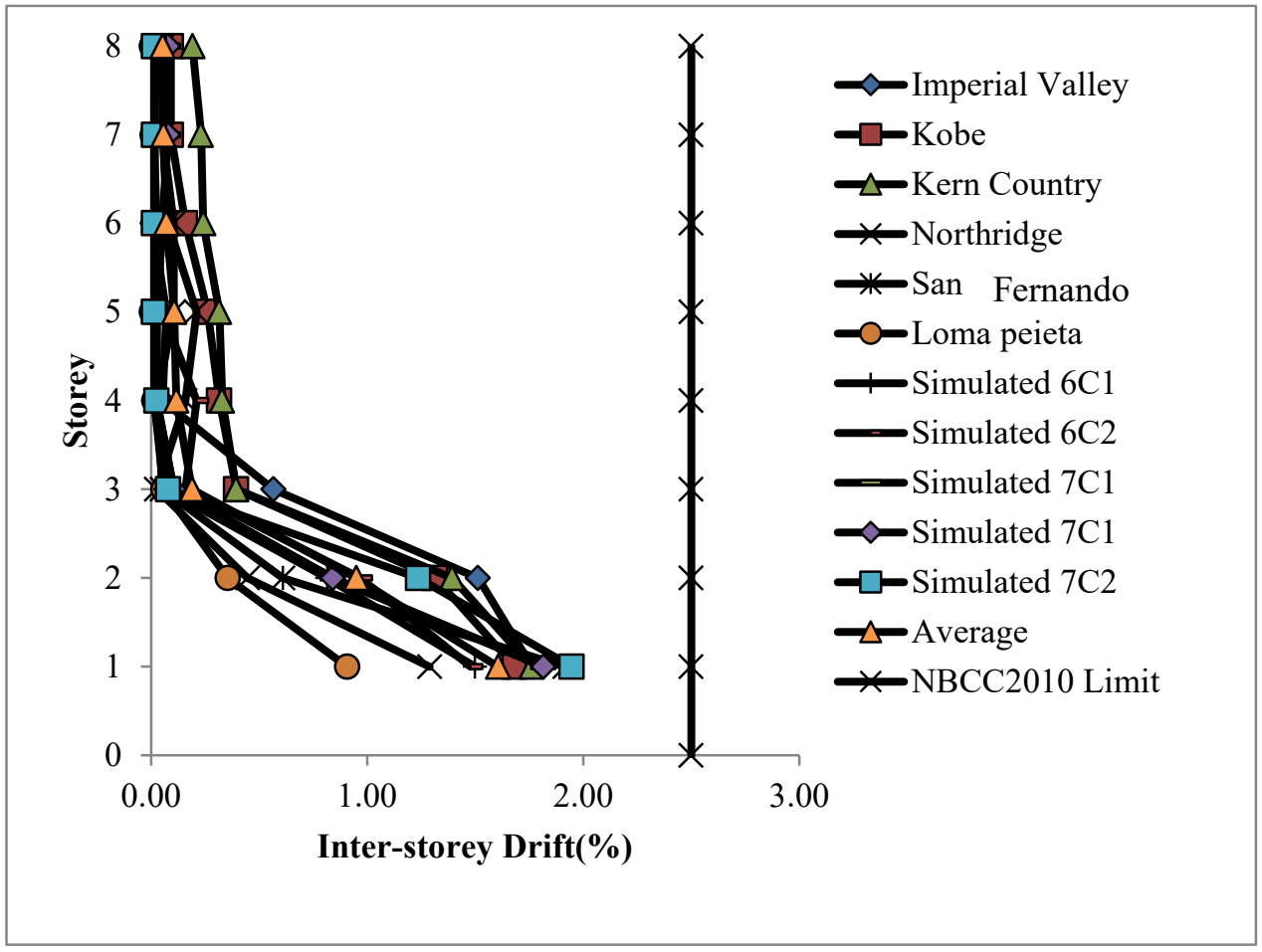

(b) 


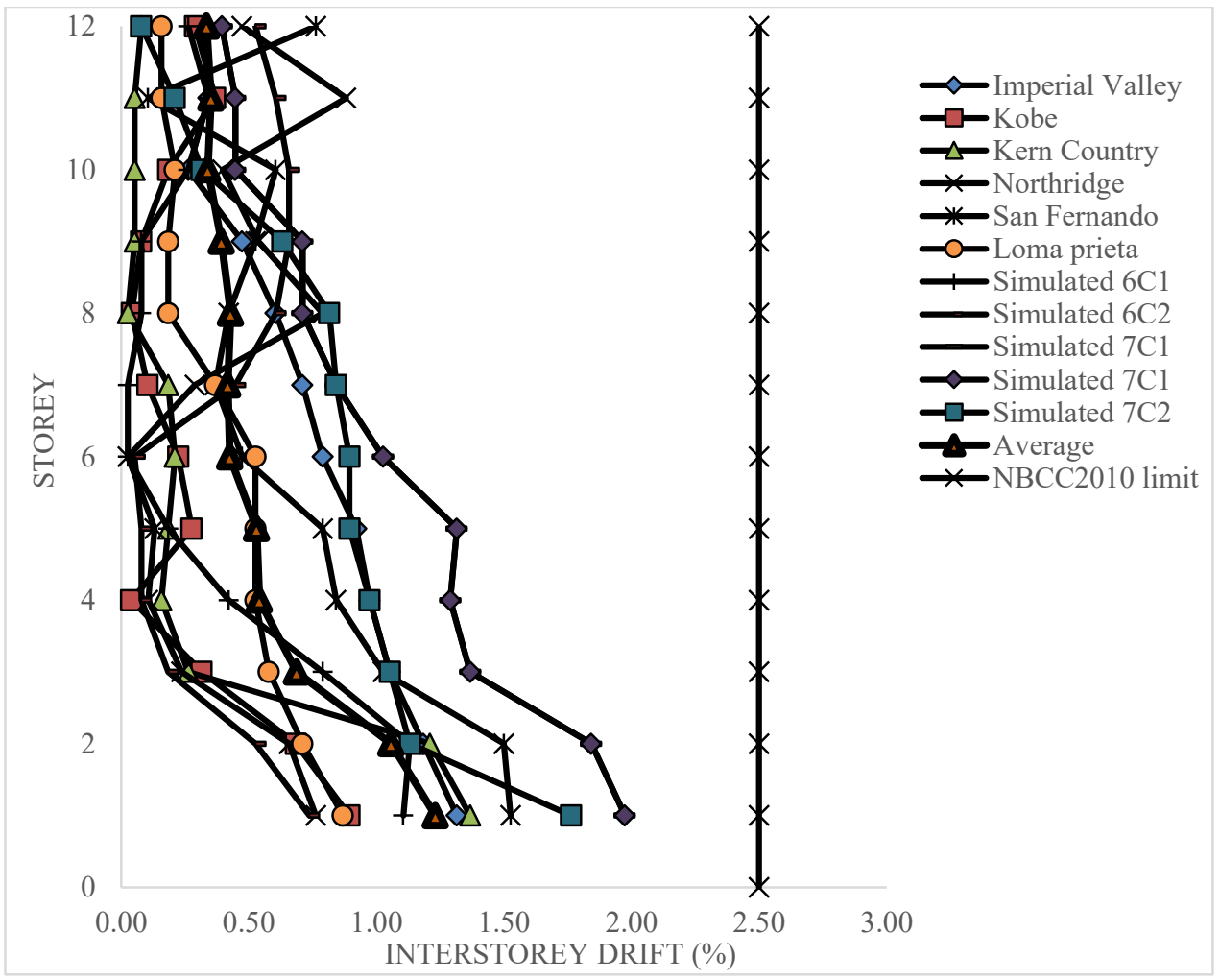

(C)

Figure 4.15: Inter-storey drift for a) 4-storey b) 8-storey and c) 12-storey P-SPSW

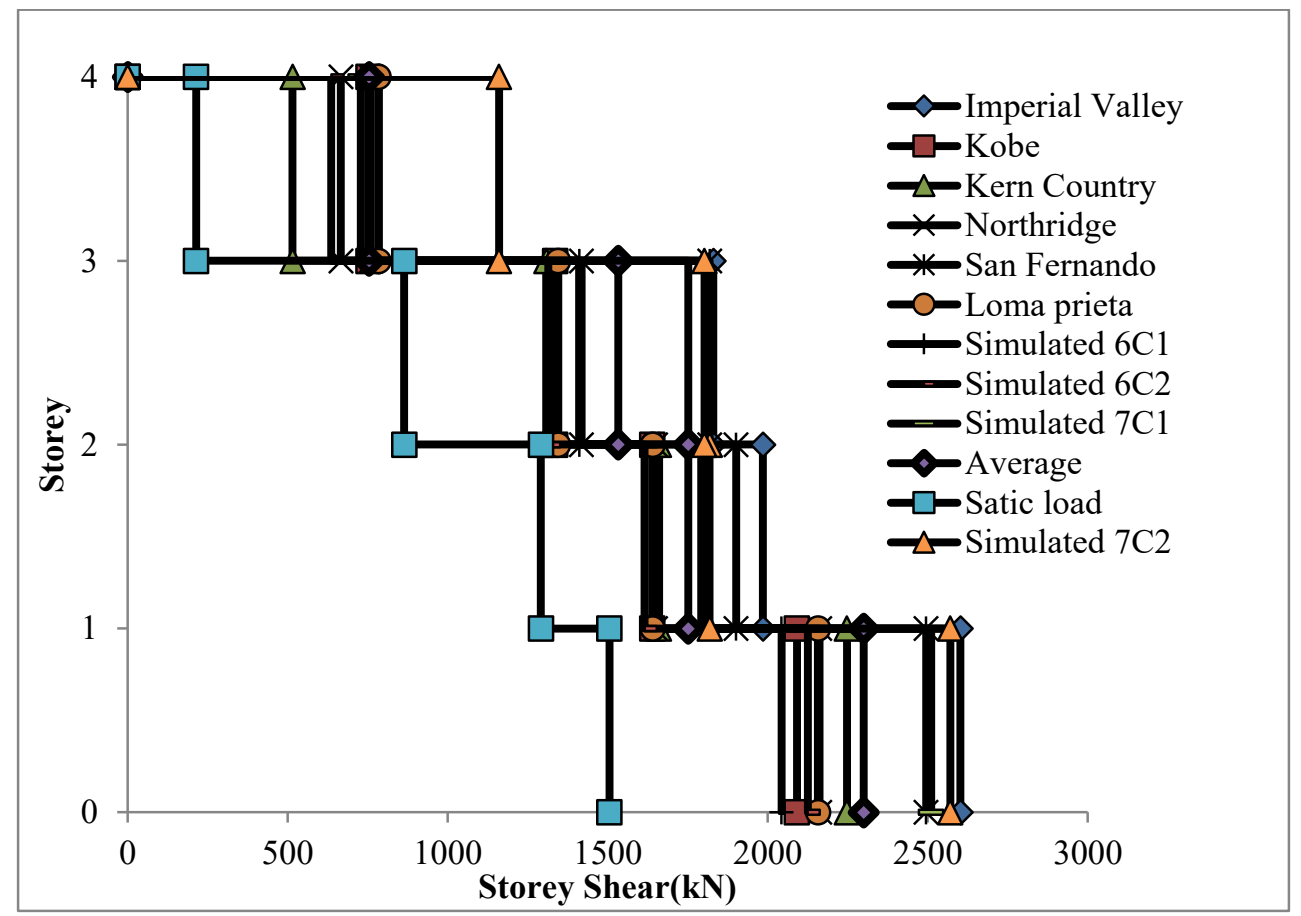

(a) 


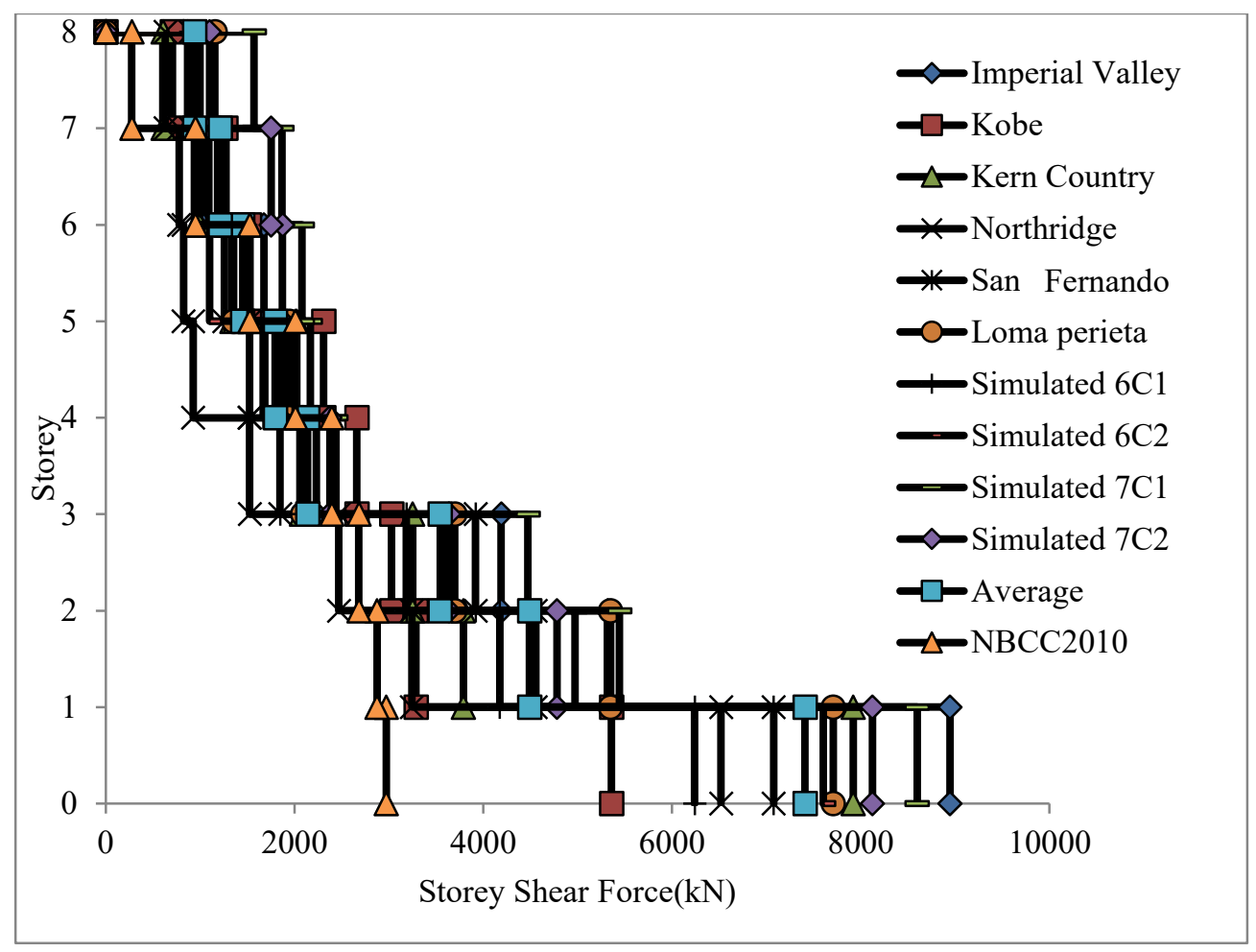

(b)

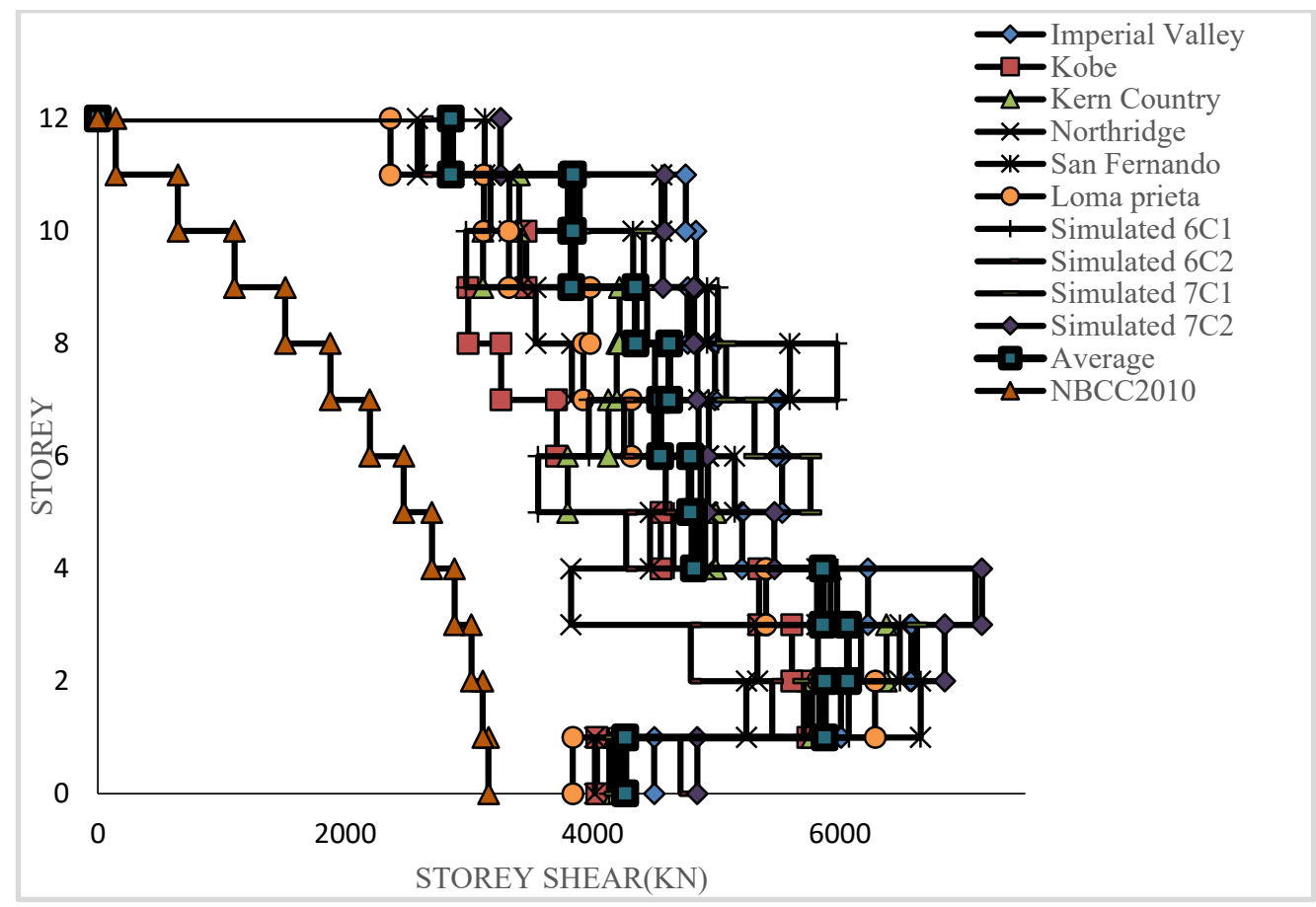

(c)

Figure 4.16: Storey Shear force for a) 4-storey b) 8-storey and c) 12-storey P-SPSW 


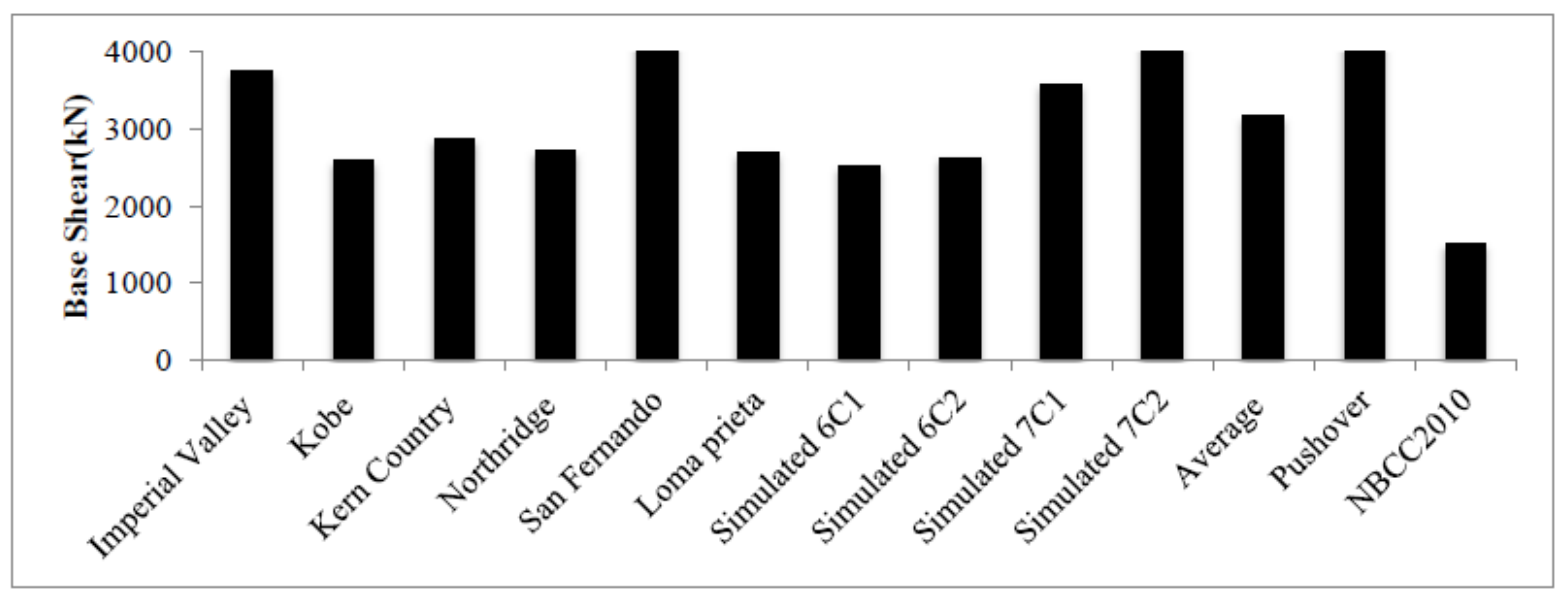

(a)

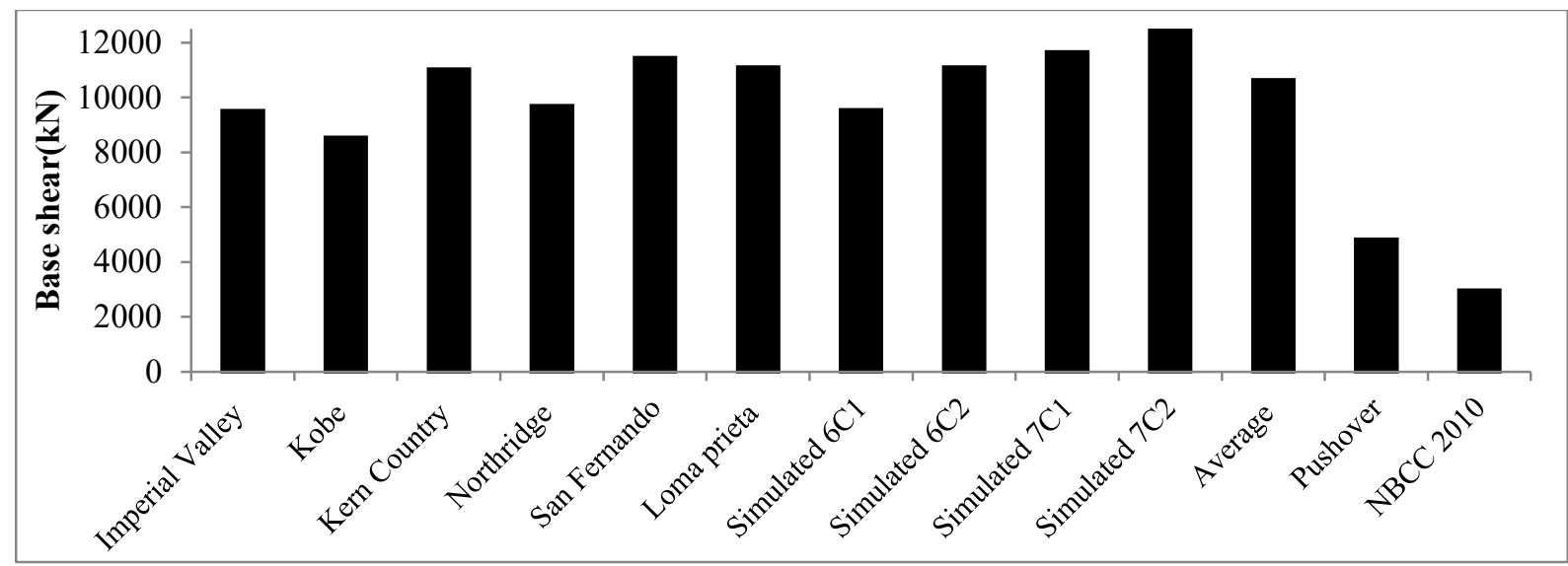

(b)

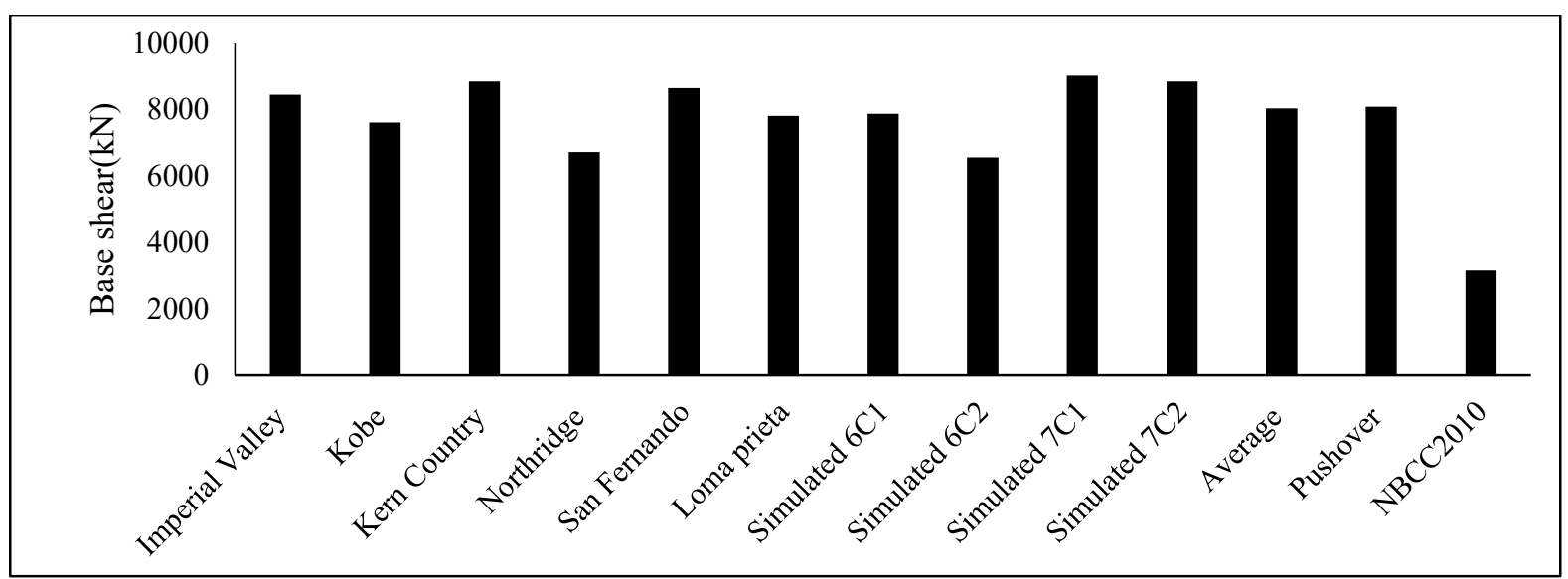

(c)

Figure 4.17: Base shear for a) 4-storey b) 8-storey and c) 12-storey P-SPSW 
Table4.6: Shear force $(\mathrm{kN})$ in the perforated steel plate for the 4-storey

\begin{tabular}{|l|c|c|c|c|}
\hline & Level-1 & Level-2 & Level-3 & Level-4 \\
\hline Imperial Valley & 1626 & 1538 & 1361 & 490 \\
\hline Kobe & 1644 & 1552 & 1057 & 857 \\
\hline Kern Country & 1416 & 1184 & 712 & 345 \\
\hline Northridge & 1647 & 1534 & 1088 & 411 \\
\hline San Fernando & 1715 & 1594 & 1005 & 365 \\
\hline Loma Prieta & 1705 & 1526 & 1067 & 438 \\
\hline Simulated 6C1 & 1486 & 1439 & 1067 & 565 \\
\hline Simulated 6C2 & 1728 & 1516 & 1046 & 415 \\
\hline Simulated 7C1 & 1762 & 1748 & 1384 & 514 \\
\hline Simulated 7C2 & 1838 & 1790 & 1271 & 1008 \\
\hline Average & 1656.7 & 1542.1 & 1105.8 & 540.8 \\
\hline Equation 2.11 & 2050 & 2050 & 2050 & 2050 \\
\hline \% of variation & 19 & 25 & 46 & 74 \\
\hline
\end{tabular}

Table 4.7: Shear force $(\mathrm{kN})$ in the perforated steel plate for 8 -storey

\begin{tabular}{|l|r|r|r|r|r|r|r|r|}
\hline & \multicolumn{1}{|l|}{ L-1 } & L-2 & L-3 & L-4 & L-5 & L-6 & L-7 & \multicolumn{1}{l|}{ L-8 } \\
\hline Imperial Valley & 3131 & 2874 & 2859 & 1788 & 1556 & 1350 & 850 & 553 \\
\hline Kobe & 2948 & 2614 & 2668 & 1721 & 1648 & 1032 & 864 & 404 \\
\hline Kern Country & 3113 & 2740 & 2847 & 1708 & 1406 & 1699 & 1554 & 725 \\
\hline Northridge & 3372 & 2516 & 2038 & 1376 & 1112 & 863 & 667 & 502 \\
\hline San Fernando & 3436 & 2984 & 2783 & 1637 & 940 & 704 & 641 & 413 \\
\hline Loma Prieta & 3374 & 3113 & 2840 & 1799 & 1566 & 1114 & 1200 & 730 \\
\hline Simulated 6C1 & 3430 & 2774 & 2411 & 1622 & 1181 & 1070 & 1415 & 841 \\
\hline Simulated 6C2 & 3376 & 3024 & 2877 & 1603 & 1297 & 960 & 995 & 508 \\
\hline Simulated 7C1 & 3343 & 2722 & 2678 & 1749 & 1661 & 1701 & 1697 & 1052 \\
\hline Simulated 7C2 & 3383 & 2840 & 2655 & 1845 & 1725 & 1739 & 1626 & 1106 \\
\hline Average & 3291 & 2820 & 2666 & 1685 & 1409 & 1223 & 1151 & 683 \\
\hline Equation 2.11 & 3275 & 3275 & 3275 & 2050 & 2050 & 2050 & 2050 & 2050 \\
\hline \% of variation & -0.5 & 13.9 & 18.6 & 17.8 & 31.3 & 40.3 & 43.9 & 66.7 \\
\hline
\end{tabular}


Table 4.8: Shear force $(\mathrm{kN})$ in the perforated steel plate for the 12 storey

\begin{tabular}{|l|c|c|c|c|c|c|c|c|c|c|c|c|}
\hline & L-1 & Ll-2 & L-3 & L-4 & L-5 & L-6 & L-7 & L-8 & L-9 & L-10 & L-11 & L-12 \\
\hline IV & 2993 & 3237 & 3078 & 2982 & 2984 & 1850 & 1833 & 1860 & 1870 & 1910 & 1820 & 924 \\
\hline Kobe & 3169 & 3064 & 3005 & 3055 & 3120 & 1752 & 1573 & 1735 & 1521 & 1496 & 1422 & 882 \\
\hline KC & 3224 & 3295 & 3155 & 3006 & 2831 & 1773 & 1843 & 1792 & 1587 & 1660 & 1690 & 947 \\
\hline NR & 2883 & 3017 & 3042 & 2901 & 2909 & 1880 & 1792 & 1648 & 1754 & 1782 & 1677 & 892 \\
\hline SF & 3155 & 3274 & 2915 & 2957 & 3139 & 1792 & 1831 & 1838 & 1802 & 1710 & 1686 & 975 \\
\hline LP & 3109 & 3257 & 3143 & 2988 & 2968 & 1790 & 1863 & 1874 & 1799 & 1586 & 1516 & 728 \\
\hline 6C1 & 3294 & 3083 & 2990 & 2878 & 2769 & 1777 & 1929 & 1967 & 1468 & 1620 & 1645 & 873 \\
\hline 6C2 & 3142 & 3059 & 2934 & 2880 & 2964 & 1876 & 1998 & 1872 & 1859 & 1807 & 1886 & 929 \\
\hline 7C1 & 3254 & 3104 & 2983 & 3016 & 3021 & 1883 & 1814 & 1904 & 1866 & 1784 & 1674 & 1650 \\
\hline 7C2 & 3068 & 3239 & 3147 & 2942 & 2857 & 1885 & 1892 & 1897 & 1878 & 1852 & 1745 & 1650 \\
\hline Avg & 3129 & 3163 & 3039 & 2961 & 2956 & 1825 & 1836 & 1838 & 1740 & 1720 & 1676 & 1045 \\
\hline Eq. 2.11 & 3275 & 3275 & 3275 & 3275 & 3275 & 2050 & 2050 & 2050 & 2050 & 2050 & 2050 & 2050 \\
\hline Variation(\%) & 4.5 & 3.4 & 7.2 & 9.6 & 9.7 & 10.9 & 10.4 & 10.3 & 15.1 & 16.1 & 18.2 & 49 \\
\hline
\end{tabular}

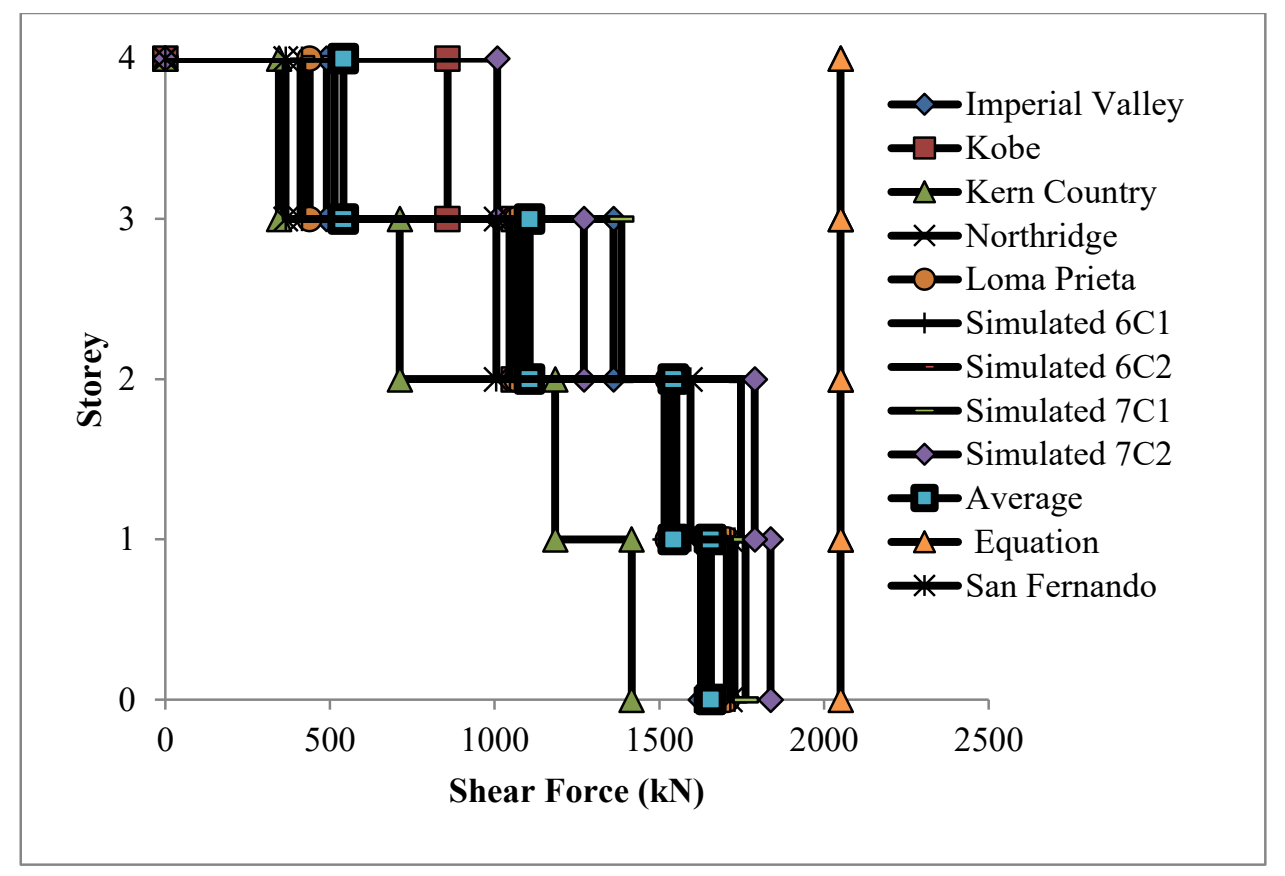

(a) 


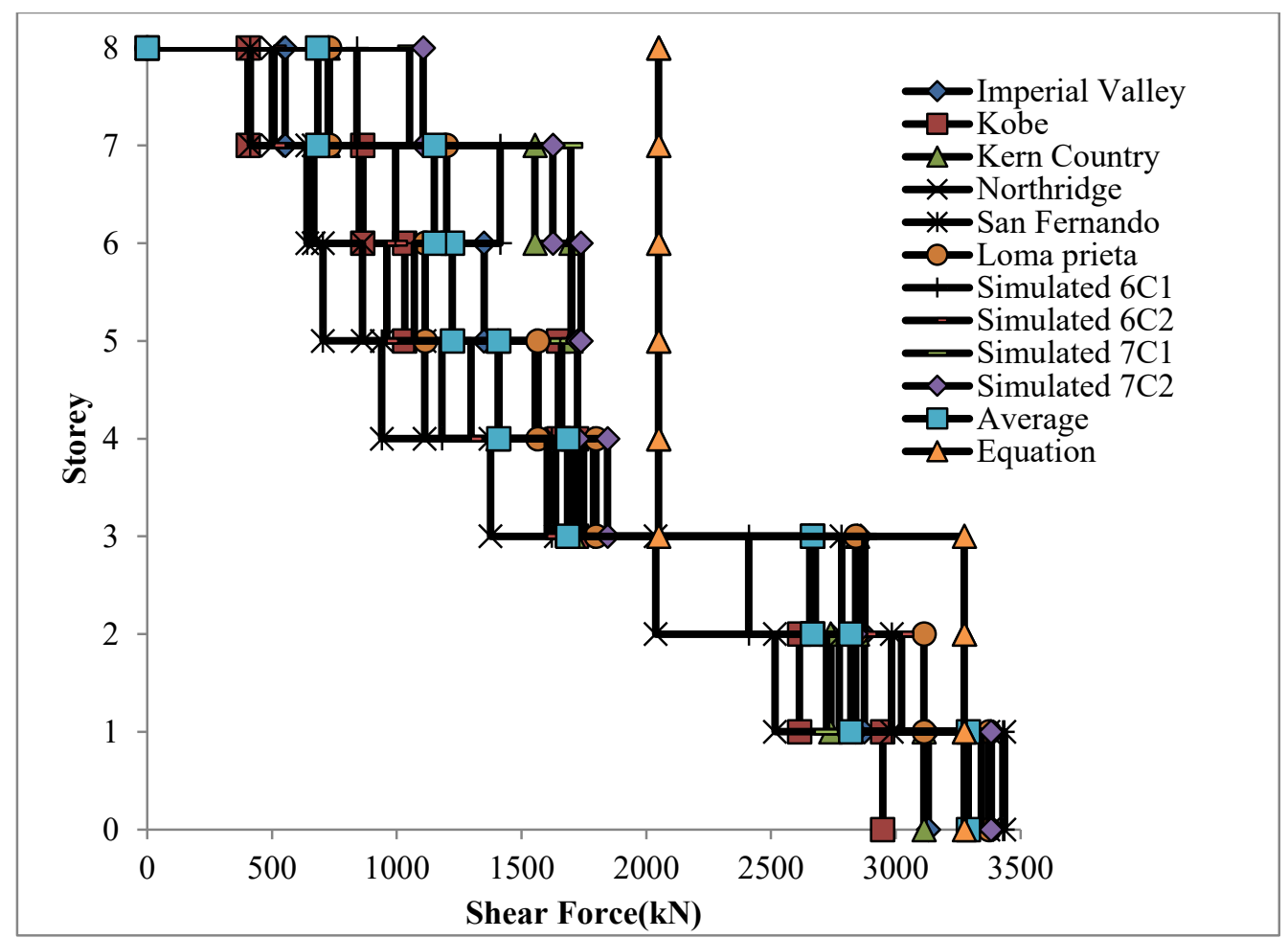

(b)

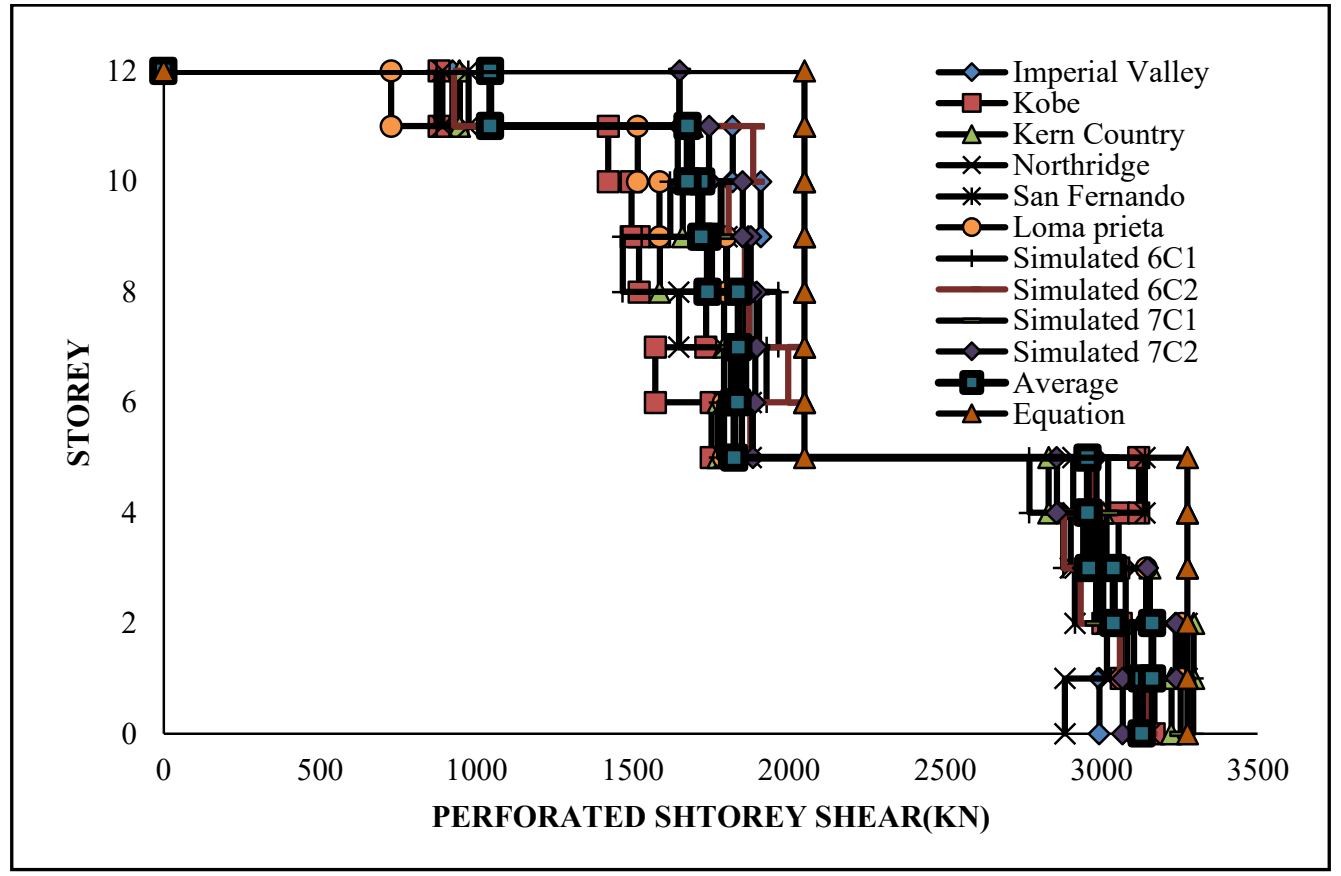

(c)

Figure 4.18: Mid-section force of the perforated steel plate for a) 4-storey b) 8-storey \& c) 12storey 


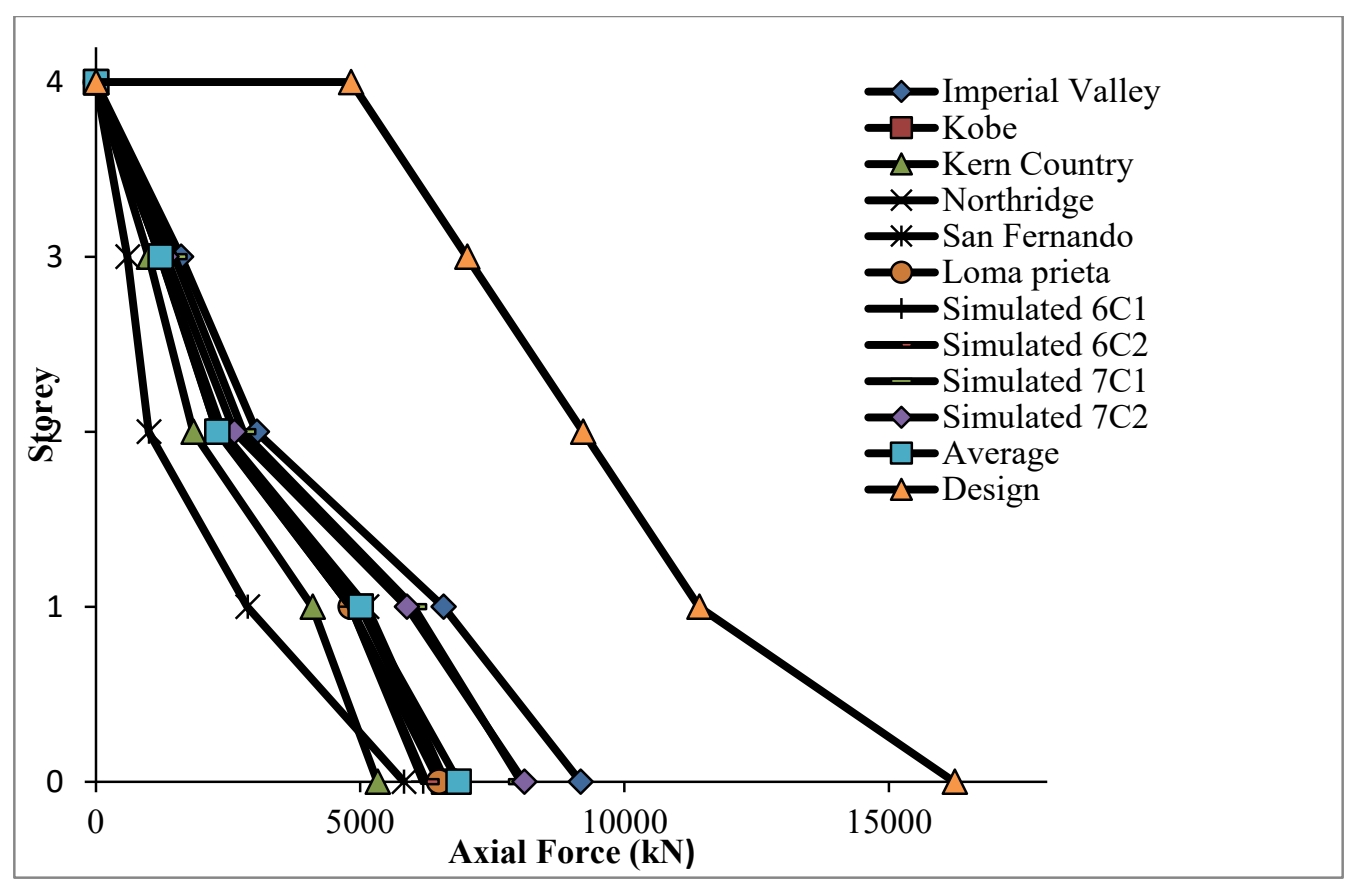

(a)

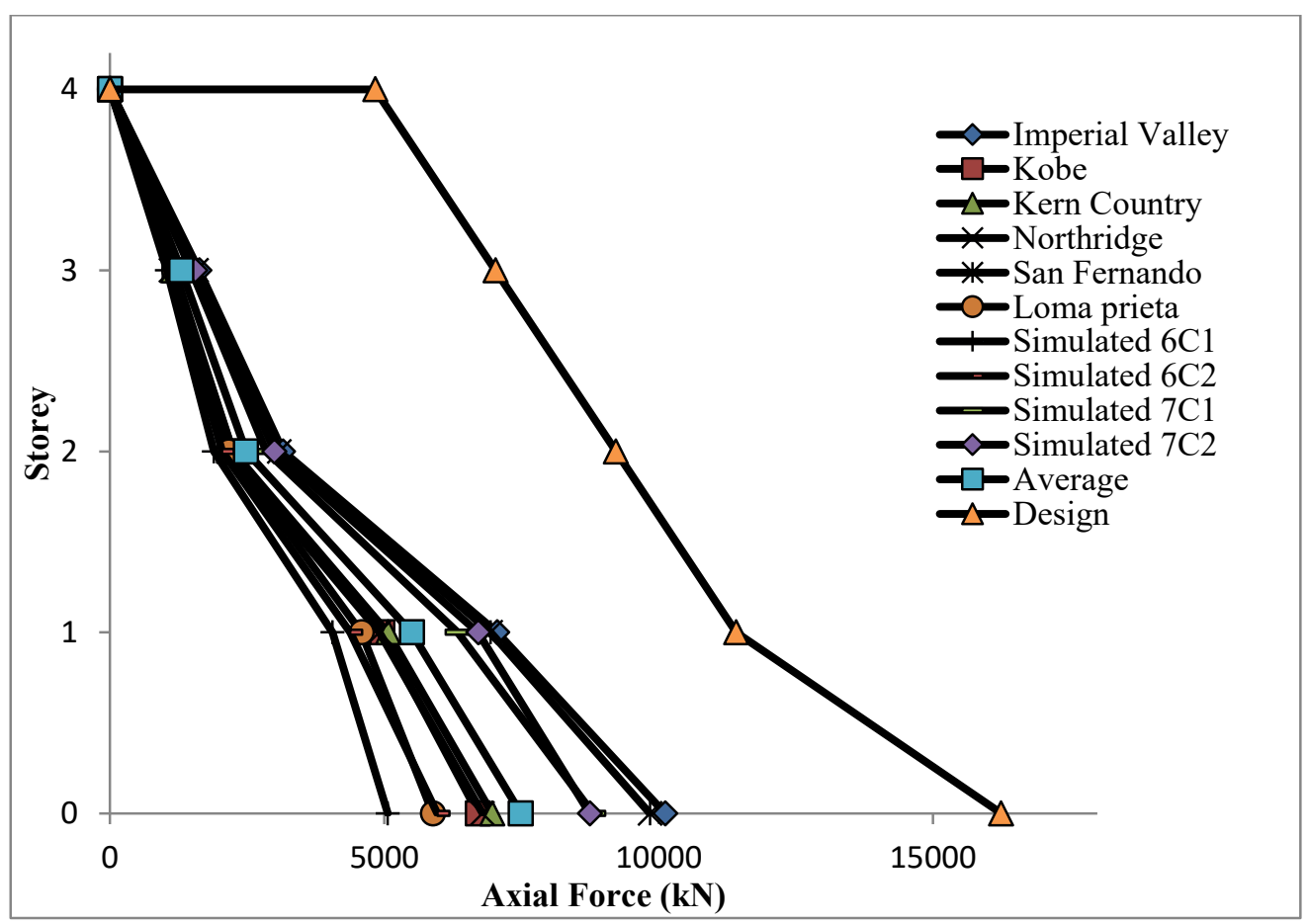

(b)

Figure 4.19: Peak column axial force for 4-storey P- SPSW a) Left column \& b) Right column 


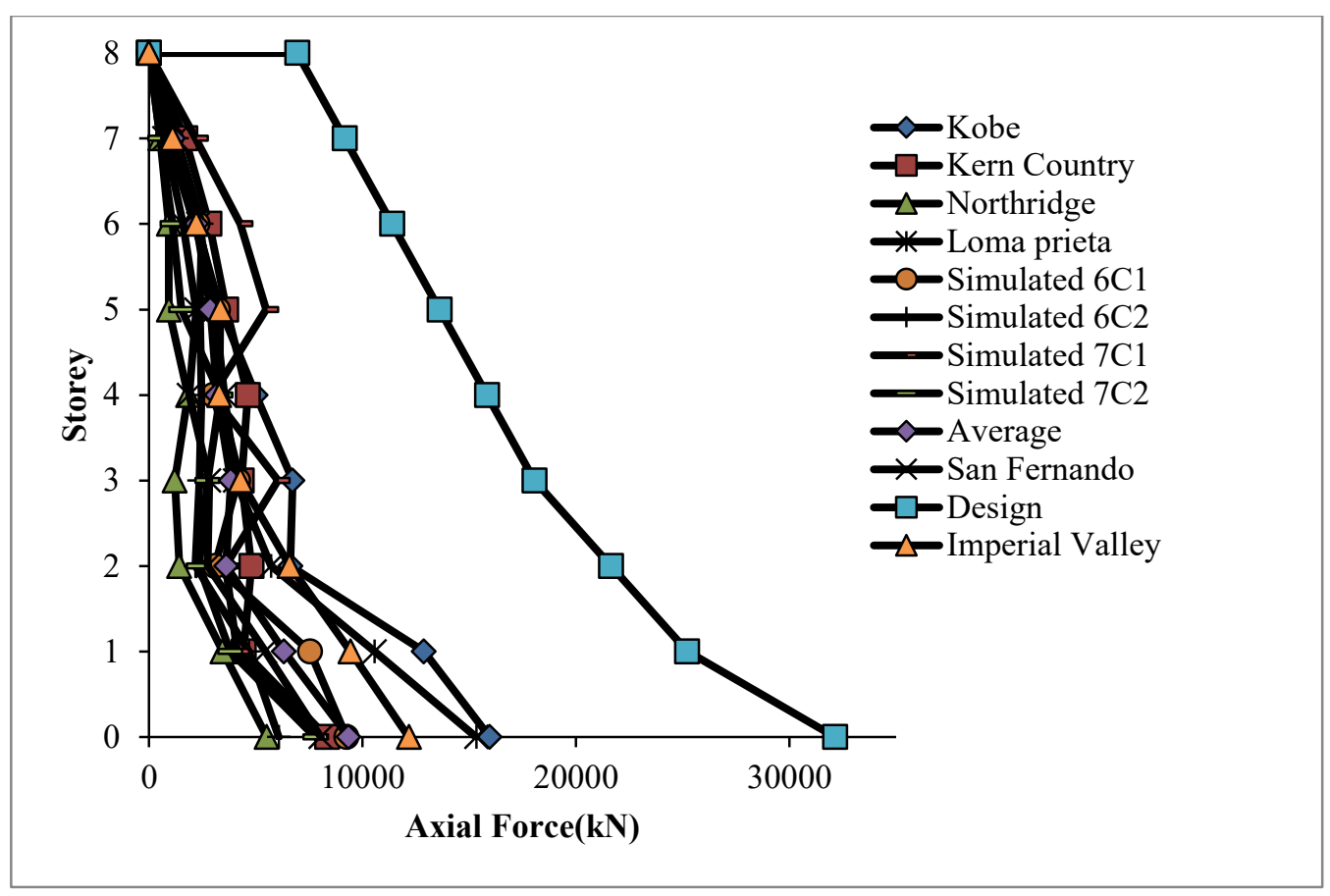

(a)

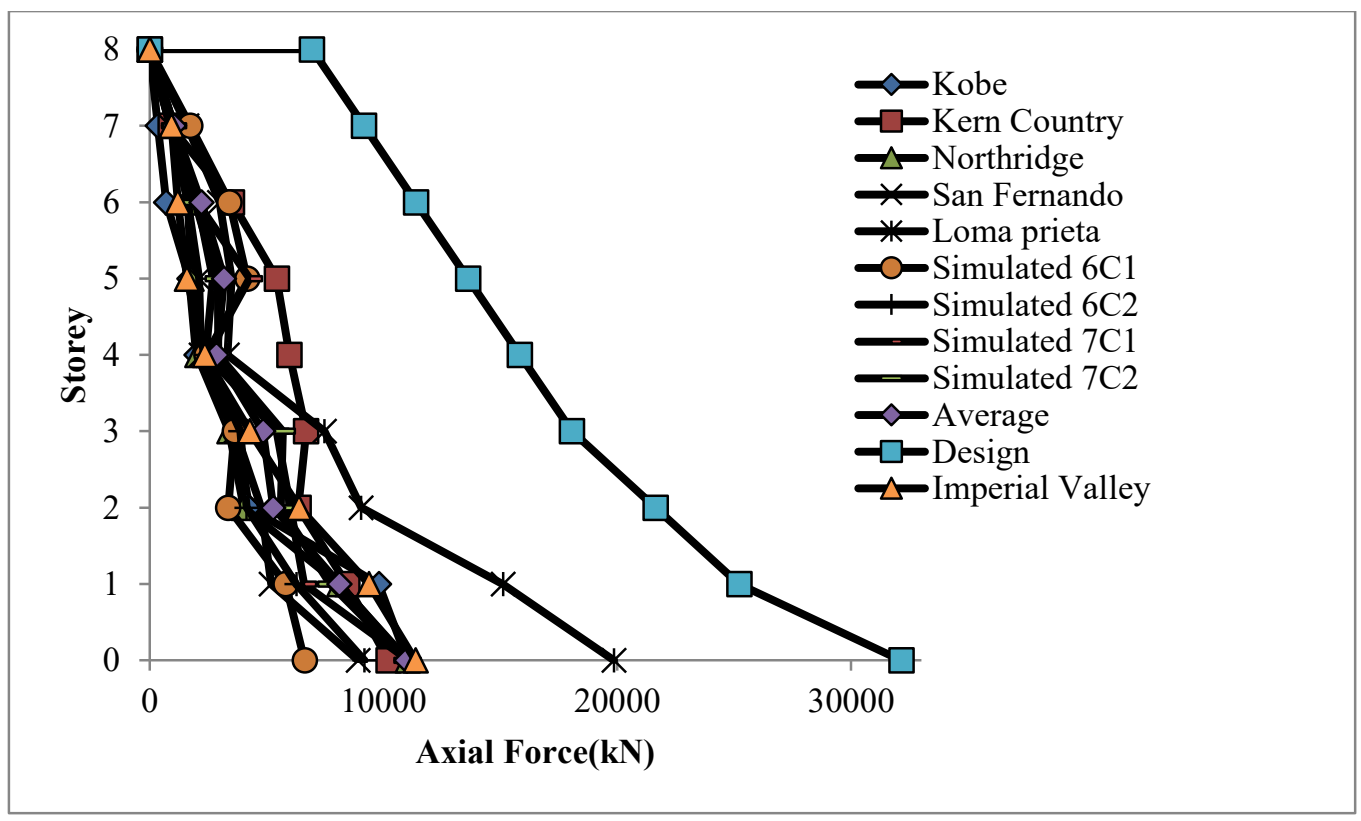

(b)

Figure 4.20: Peak column axial force for 8-storey P-SPSW a) Left column \& b) Right column 


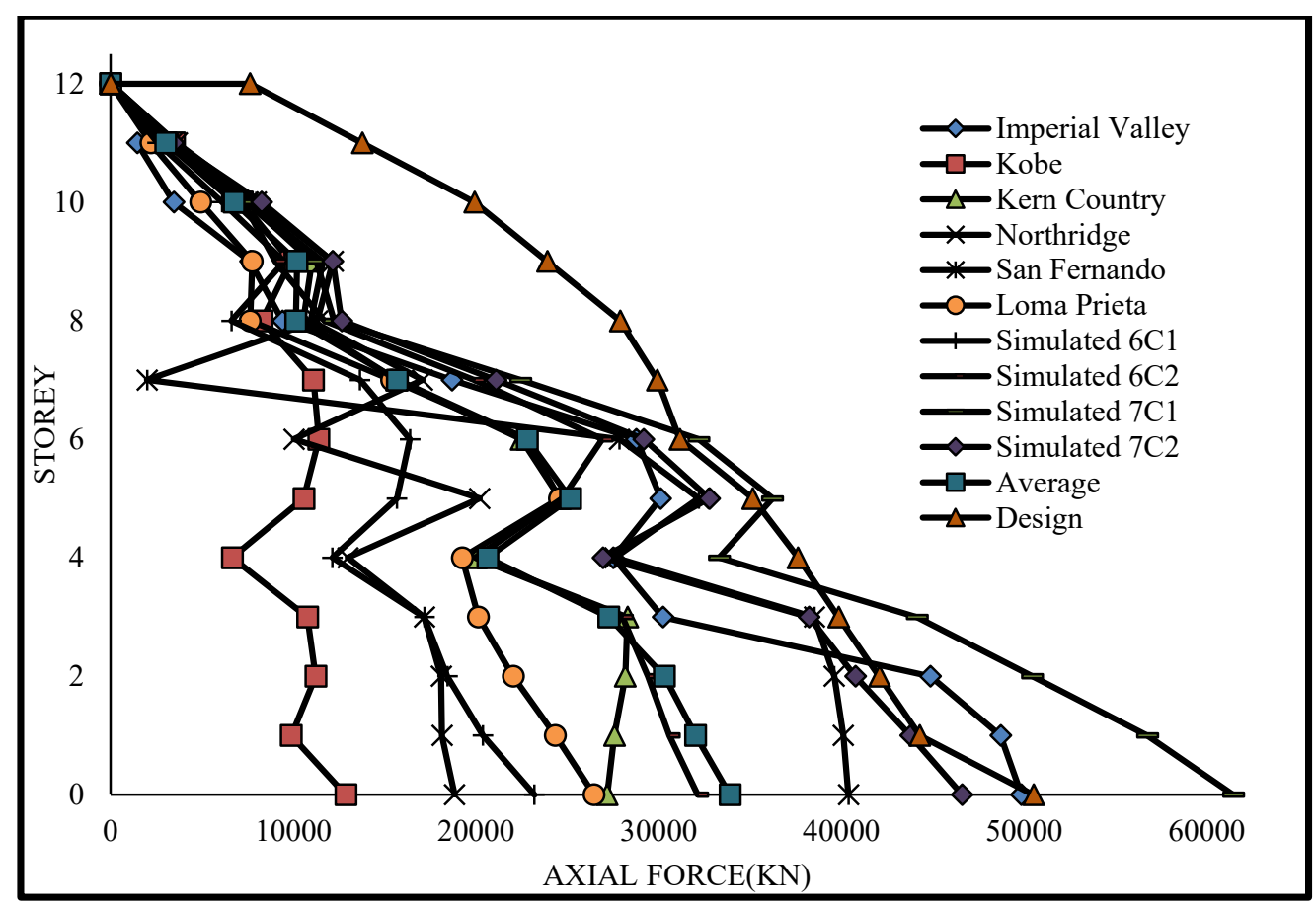

(a)

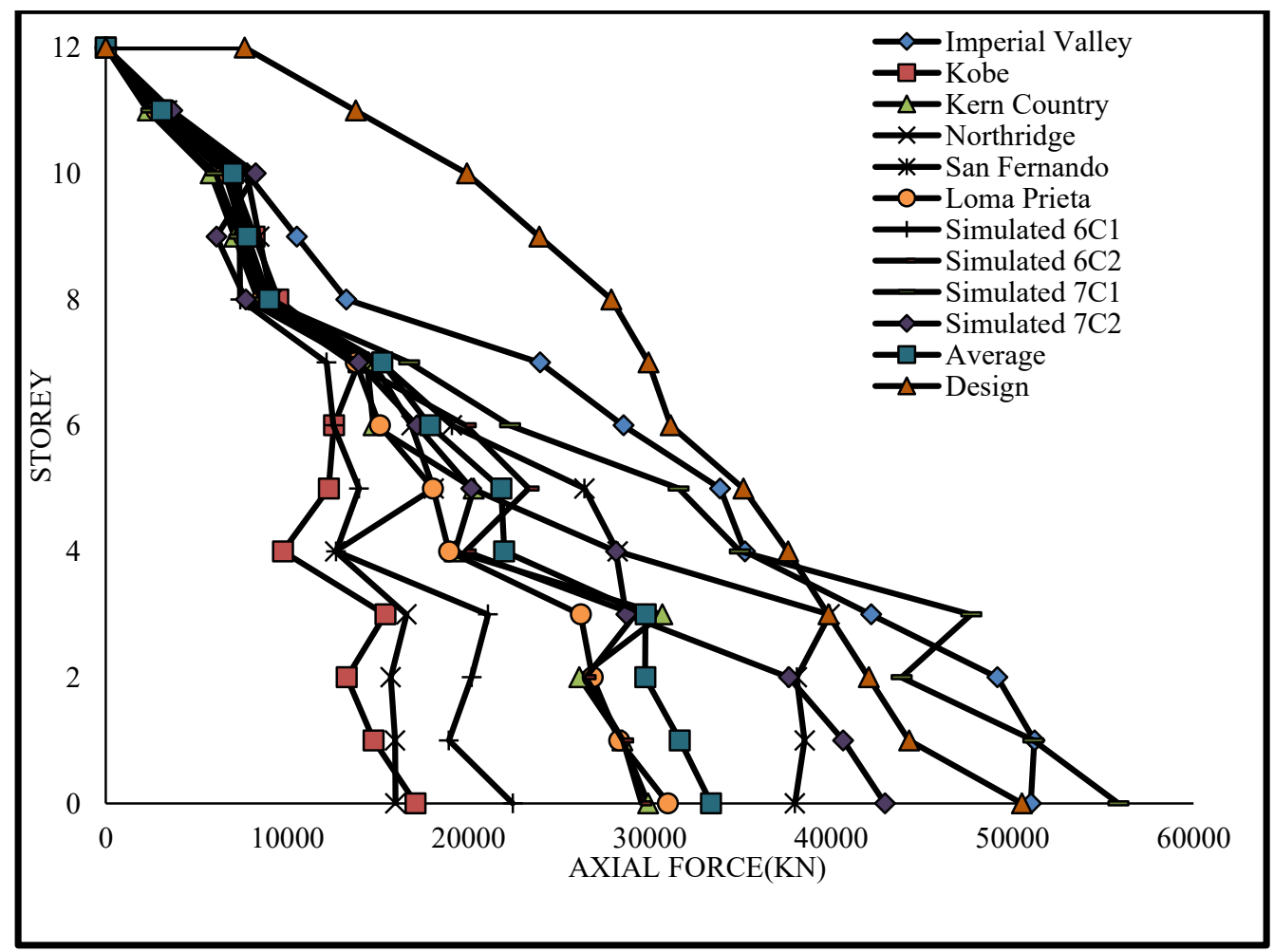

(b)

Figure 4.21: Peak column axial force in 12-storey P-SPSW 


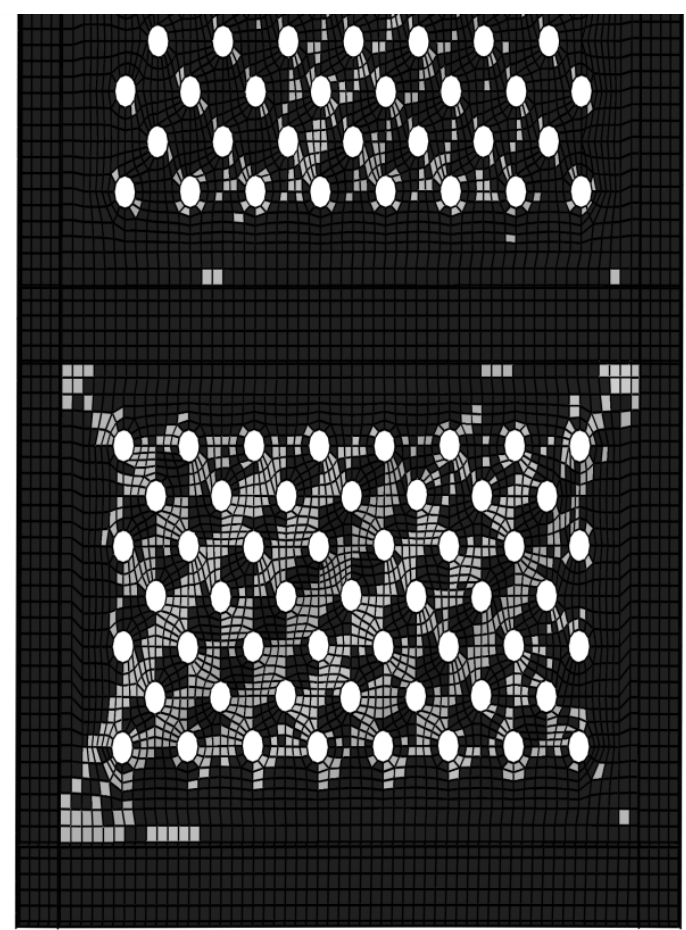

(a)

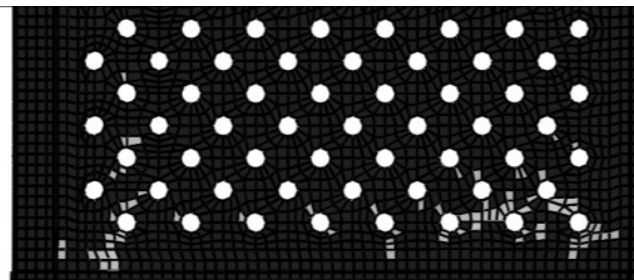

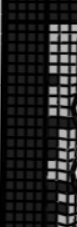

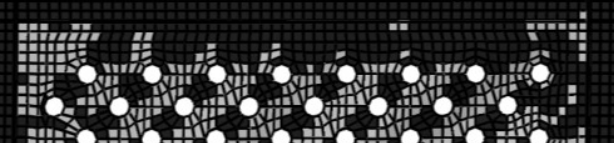

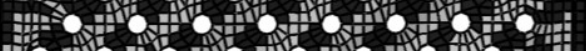
Ho b o o o . .

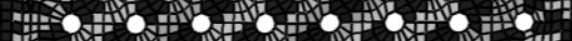
To 0 o 0 o 0 . O ( ) 䉼 (1) 睡 皮

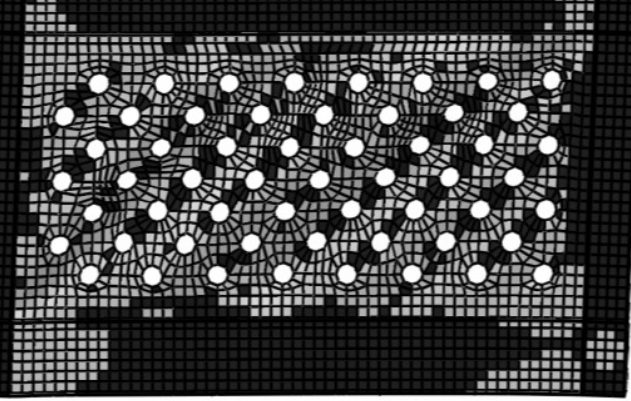

(b)

Figure 4.25: Yeilding pattern of the plate in the lower two stories a) the 4-storey P-SPSW for the Northridge earthquake b) the 8-storey P-SPSW for the Loma Prieta earthquake 

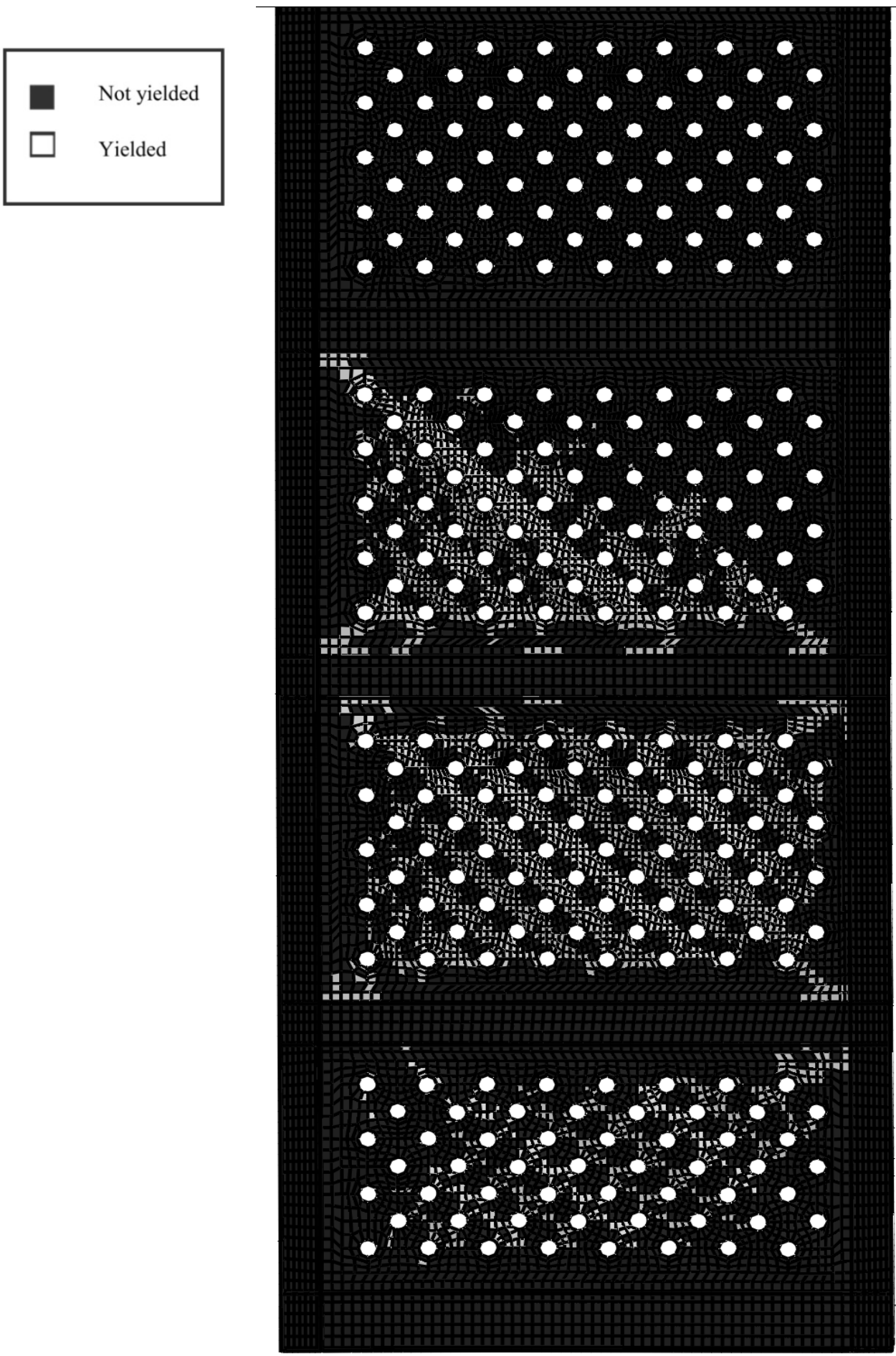

Figure 4.26: Yielding pattern of the plate in the lower stories of the 12 storey P-SPSW for the Kobe City 1995 earthquake 


\subsection{Summary}

Frequency analysis was performed to assess the natural period of the structure. Besides, damping factors $(\alpha$ and $\beta$ ) were evaluated from the first and second mode of vibration as well. Later the factors were incorporated in the material properties for the dynamic time history analysis.

To assess the seismic performance, in this research project a series of historical and synthetic ground motions records were selected which were compatible with Vancouver response spectrum. In total ten ground motions data (six historical and four simulated) were chosen. While selecting records, it was kept in mind; the records were in between 6-7 magnitude and $\mathrm{A} / \mathrm{V}$ ratio in a range of 0.8-1.2 as well. The natural period found from frequency analysis were considered for scaling of the time history data. Using partial area method within a range of 0.2 times to 1.5 times of the period in the target response spectrum was considered for the scaling factor

The records were applied as an acceleration versus real time in the finite element model of 4-, 8-, and 12-storey P-SPSWs. The non-linear dynamic implicit analysis was performed in ABAQUS. Seismic analysis showed that the perforated SPSW designed according to the capacity design approach behaved in a ductile and stable manner. The peak responses were estimated for all the selected ground motions. The average inter-storey drift of the selected P-SPSWs was less than NBCC 2010 drift limit. Moreover, average base shear and story shear has been compared with NBCC 2010 static shear. The shear force in the infill was calculated for each floor. It was observed that the code designed perforated plate Eq. (2.11) Overestimated the average shear force which depicts that the equation is safe to use in design. 


\section{Chapter 5. N2 Method for the Perforated Steel Plate Shear Wall (P-SPSW)}

\subsection{Introduction}

Seismic performance evaluation is a common practice for the new as well as existing structure. Often, at the preliminary design stage, it is required to estimate seismic response parameters to check the adequacy of design. There are several simplified methods for seismic performance evaluation of structures, for example Capacity-demand-diagram (CDD) Method (Chopra and Goel 1999), nonlinear analysis (N2) method (Fajfar 1999), Yield point spectra (YPS) method (Aschheim 2000), Displacement-based seismic design (DBSD) method (Humar and GhorbanieAsl 2005). Among all these simplified methods N2 method has become very popular among the engineers for its effectiveness and easiness to use for seismic performance evaluation of existing buildings as well as for new construction.N2 method was proposed by Fajfar (1999), which is based on constant ductility demand suggested by Vidic et al. (1994). Eurocode8 embraced this approach which is commonly known as N2 method (Fajfar 1999). The N2 method is a nonlinear static analysis procedure. Moreover, using an equivalent damped spectrum of the location, ductility demand of the building can be assessed. The N2 method is a final product of two curves, among them one is capacity response curve and another one is the site-specific constant ductility demand curve. When both curves superimpose, the expected responses of the structure can be evaluated easily. The first mode pushover curve (base shear versus top displacement) of a multi-degree of freedom system (MDOF) is transferred into capacity spectrum curve for a single equivalent degree of freedom (ESDOF) system. On the other hand, site specific acceleration response spectrum can be converted into constant ductility demand spectrum which is known as an acceleration displacement response spectrum (ADRS) format. 
The objective of this chapter is to assess the inelastic seismic response of 4-, 8- and 12-storey PSPSW by N2 method. The selected P-SPSWs designed and modeled in Chapter 3 were considered in this study. The pushover curves of the selected buildings were converted into a capacity response spectrum curve. Then, acceleration response spectrum of the Vancouver region was modified as an ADRS format. Finally, inelastic seismic responses were estimated for the selected structures; subsequently, comparisons between non-linear time history responses (from chapter 4) and N2 method were made.

\subsection{N2 Method by Fajfar (1999)}

The N2 method proposed by Fajfar (1999) as follows:

\subsubsection{Development of Capacity Curve of Equivalent Single Degree of Freedom (ESDF)} System

Initially, natural frequency $\left(\omega_{n}\right)$ and corresponding mode shape $\left(\varphi_{n}\right)$ of the multi-degree of freedom system were calculated from frequency analysis. The lateral force $\left(\mathrm{p}_{\mathrm{i}}\right)$ at any floor $\left(\mathrm{i}^{\mathrm{th}}\right)$ calculated by using following equation.

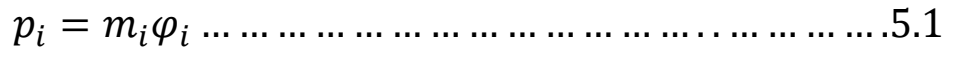

where $m_{i}=$ floor mass in the $\mathrm{i}^{\text {th }}$ floor.

Then, modal participation factor was determined from the Eq. 5.2

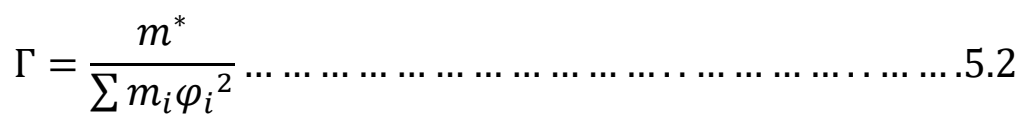

where $m^{*}=$ the total mass of the ESDF system for the fundamental mode and calculated by Eq. 5.3 .

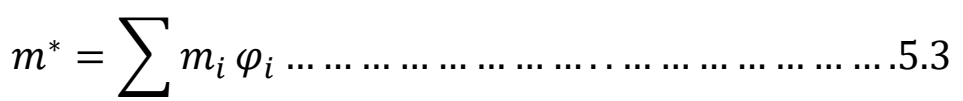


After getting $\mathrm{m}^{*}$, pushover curve of the MDOFs was transformed into the capacity curve of ESDOFs. Where, base shear $\left(V_{b}\right)$ was modified as force $\left(F^{*}\right)$ by Eq. 5.4 and top displacement $\left(D_{t}\right)$ was transformed to $D^{*}$ by Eq. 5.5 .

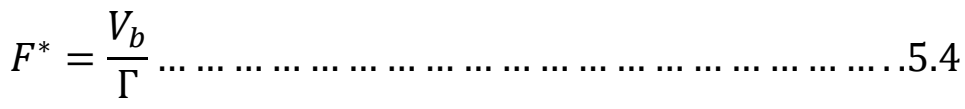

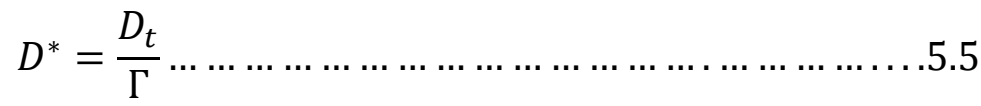

Finally, the capacity curve of the ESDOF was transformed into elastic perfectly plastic format considering energy conservation of FEMA-273 and converted into spectral acceleration at the yielding point by Eq. by 5.6.

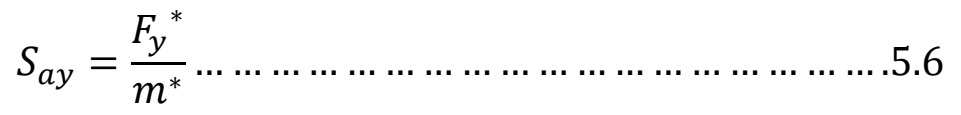

Where $\mathrm{F}_{\mathrm{y}}=$ the yield strength in the elastic perfectly plastic curve of the ESDOFs.

The elastic time period $\left(\mathrm{T}^{*}\right)$ for the bilinear curve was determined from the Eq. 5.7

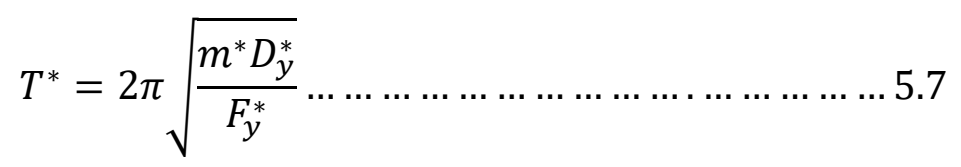

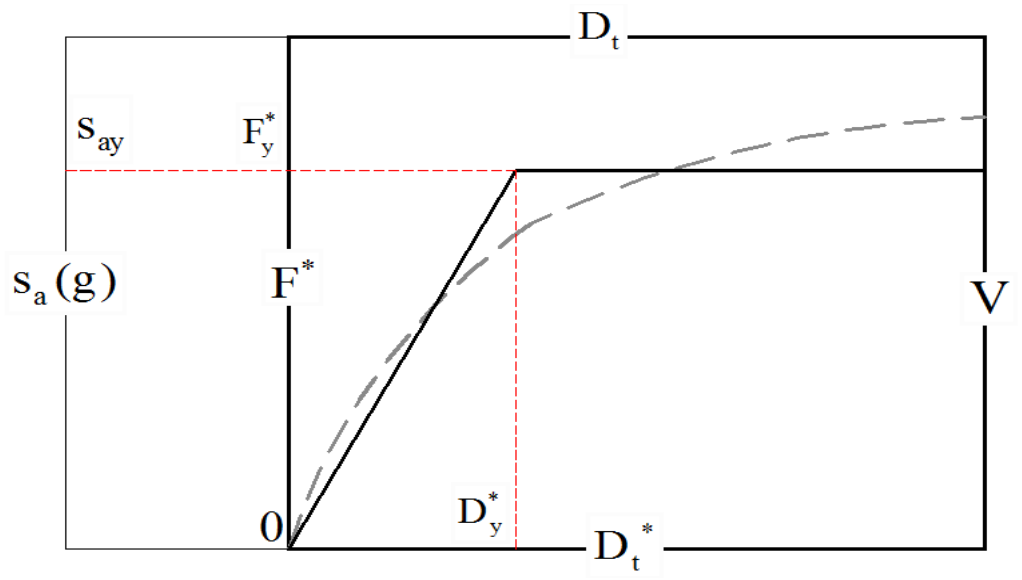

Figure 5.1 Development of the capacity spectrum of an equivalent SDOF system by Fajfar (1999). 


\subsubsection{Determination of Seismic Demand for a Particular Location}

The site specific response spectrum (RS) was taken from the uniform hazard response spectrum of NBCC2010. The response spectrum consists of acceleration $(\mathrm{Sa})$ versus time period $(\mathrm{T})$ of single degree freedom system (SDOF). Response spectrum was transformed into acceleration displacement response spectrum format (ADRS) to get the seismic demand. In this format, the time periods were in radial lines. The steps of seismic demand are enumerated below.

Firstly, the pseudo-acceleration of the single degree of freedom system was converted into an elastic displacement response spectrum by the Eq. 5.8.

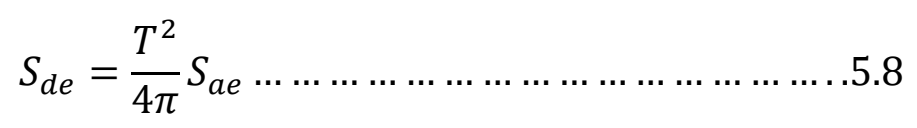

where $\mathrm{S}_{\mathrm{ae}}$ and $\mathrm{S}_{\mathrm{de}}$ were the elastic pseudo acceleration and pseudo-displacement respectively for the SDOFs corresponding any period $(\mathrm{T})$ and constant damping of $5 \%$.

Secondly, elastic acceleration and displacement RS were transformed into an inelastic RS by the Eq. 5.9 and 5.10 respectively.

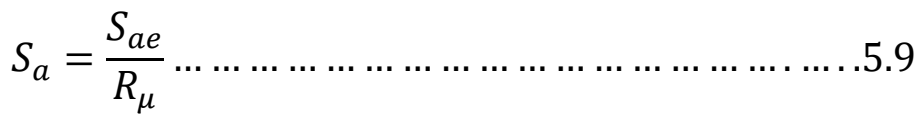

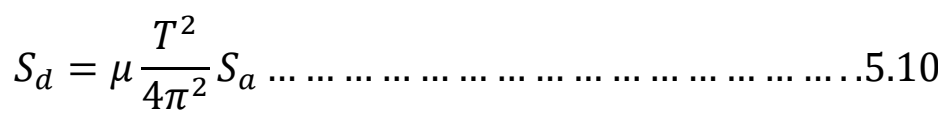

where $S_{a}$ and $S_{d}$ were the inelastic response for the SDOF. R $\mu$ was the strength reduction factor proposed by Vidic et al. (1994). The ratio between elastic strength over the inelastic strength of SDOFs is termed as strength reduction factors $(\mathrm{R} \mu)$. On the other hand, $\mu$ was the ductility factor, where ductility factor was defined as the ratio of the maximum displacement to yield displacement. 
For force reduction factor $(\mathrm{R} \mu)$, either 5.11 or $5.12 \mathrm{Eq}$. was used.

$$
\begin{aligned}
& \mathrm{R} \mu=(\mu-1) \frac{T}{T_{0}}+1 \ldots \ldots \ldots \ldots \ldots \ldots \ldots \ldots \ldots \ldots \ldots \ldots \ldots \ldots \ldots \text { for } T \leq T_{o}
\end{aligned}
$$

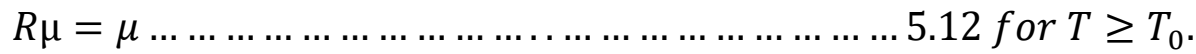

where $T_{o}$ was the transition period which depends on structural ductility, calculated by the following equation.

$$
T_{0}=0.65 \mu^{0.3} T_{c} \quad \leq T_{c} \ldots \ldots \ldots \ldots \ldots \ldots \ldots \ldots \ldots \ldots \ldots \ldots \ldots .5 .13
$$

where $T_{c}$ was the characteristic time period, defined as the transition time period of the constant acceleration to constant velocity response. Moreover, corresponding time period (Tc) can be obtained when largest force was applied in the structure.

For simplicity, Fajfar (1999) considered transition period (To) and characteristic time period (Tc) were equal.

$$
T_{o}=T_{c}
$$

Constant ductility demand spectrum can be found once ductility and seismic force reduction factor obtained. Figure 5.2 is the schematic ductility demand spectrum for the ductility $\mu=1$ to ductility $\mu=6$.

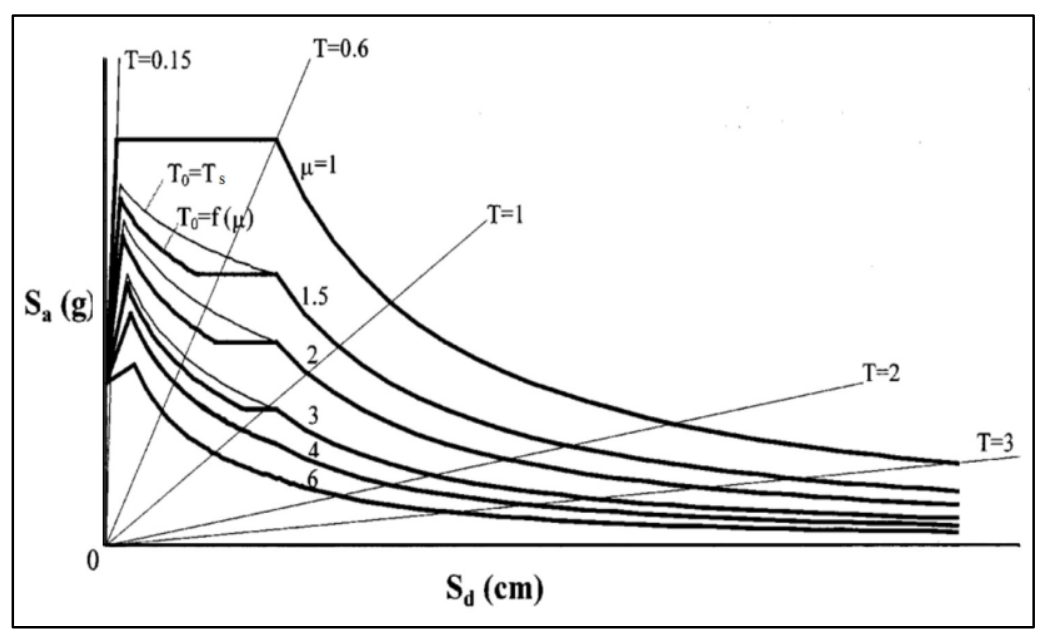

Figure 5.2: Schematic figure of a seismic demand spectrum (constant ductility response spectrum in ADRS format) by Fajfar (1999). 


\subsection{Application of N2 Method for Selected P-SPSWs}

Selected P-SPSWs (4-, 8- and 12-storey) were considered for the seismic demand evaluation by the N2 method. The 4-, 8- and 12-storey P-SPSWs were designed as per as NBCC 2010 and CAN/CSA S16-09 and at the same time modeled in ABAQUS as presented in chapter 3.

\subsubsection{Capacity Curves for Selected P-SPSWs}

Frequency analysis performed for the 4-, 8- and 12-storey P-SPSW in chapter 4 was considered for the capacity spectrum. Corresponding first mode shape has been estimated for the selected PSPSWs. For the pushover analysis Eq. 5.1 was considered for the monotonic lateral load. Pushover curves (base shear versus top displacement) for 4-, 8- and 12-storey P-SPSW has been illustrating in Figure 5.3. Consequently, a force-displacement idealized curve, as well as spectral acceleration vs. spectral displacement curve of equivalent SDOF system, has been assessed which is shown in Figure 5.4 for 4-, 8-, and 12-storey P-SPSWs.

Once the force-displacement idealized curve was obtained, yield strength, yield displacement and elastic time period were calculated easily. The effective masses, mass participation factors, the yield strengths, yield displacements and elastic time periods for the selected 4-, 8-, and 12-storey P-SPSWs are tabulated for the equivalent SDOFs in Table 5.1. 


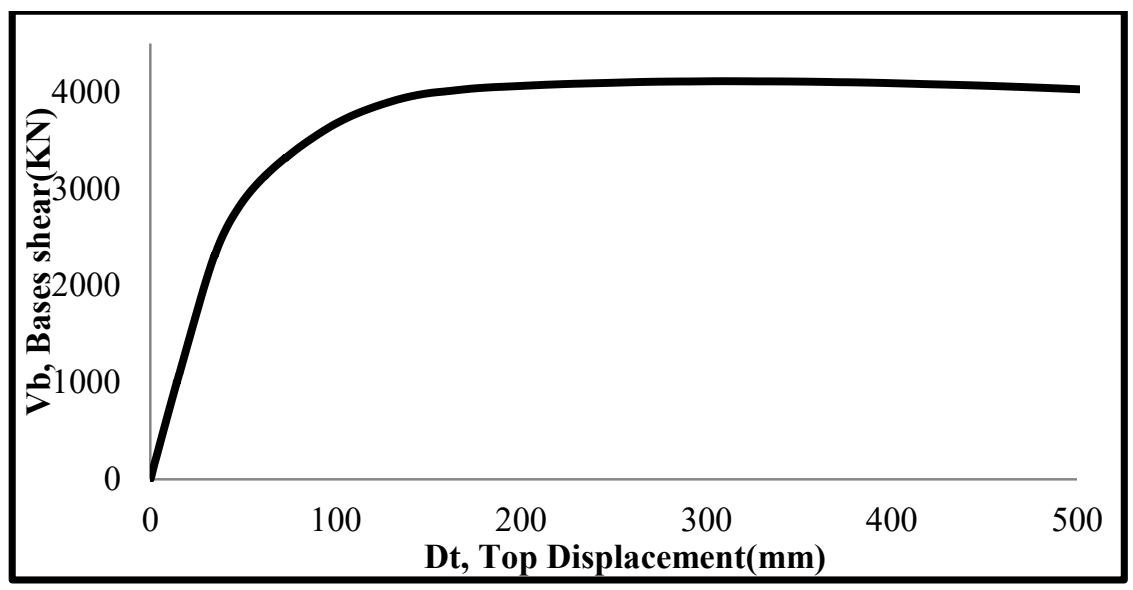

(a)

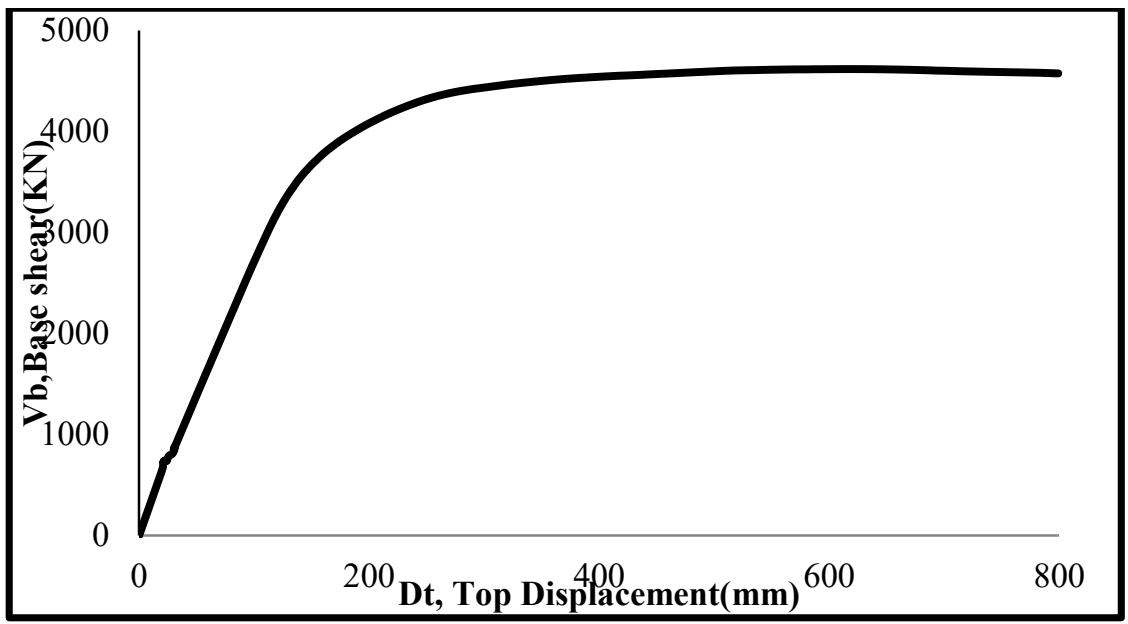

(b)

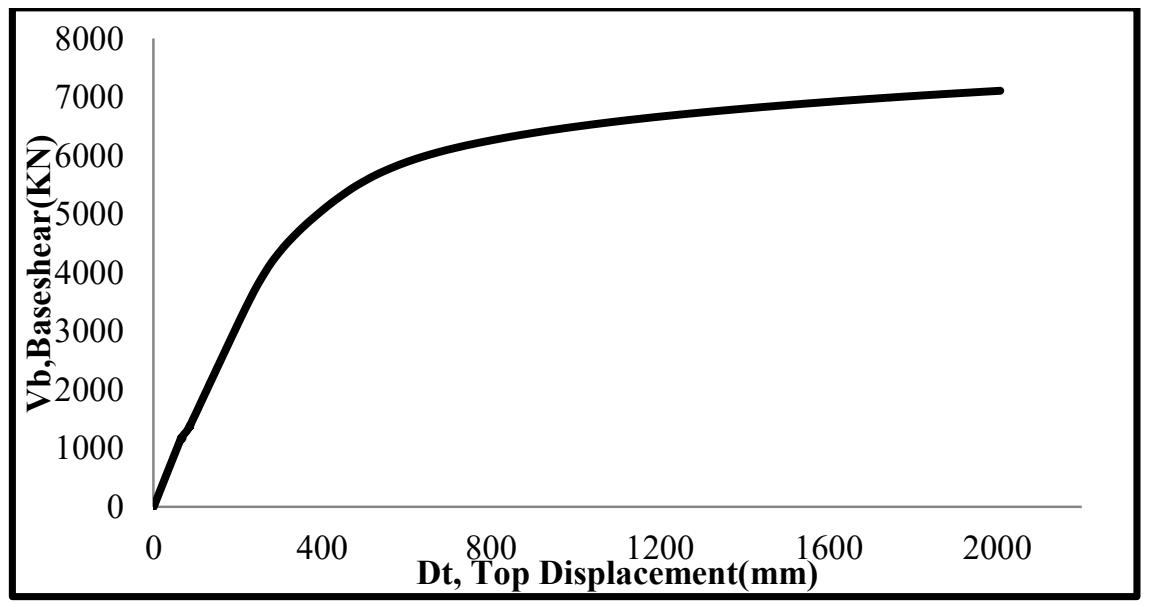

(c)

Figure 5.3: First mode pushover curve for a) 4-storey (Top), b) 8-storey (Middle) and c) 12storey (bottom) P-SPSW 


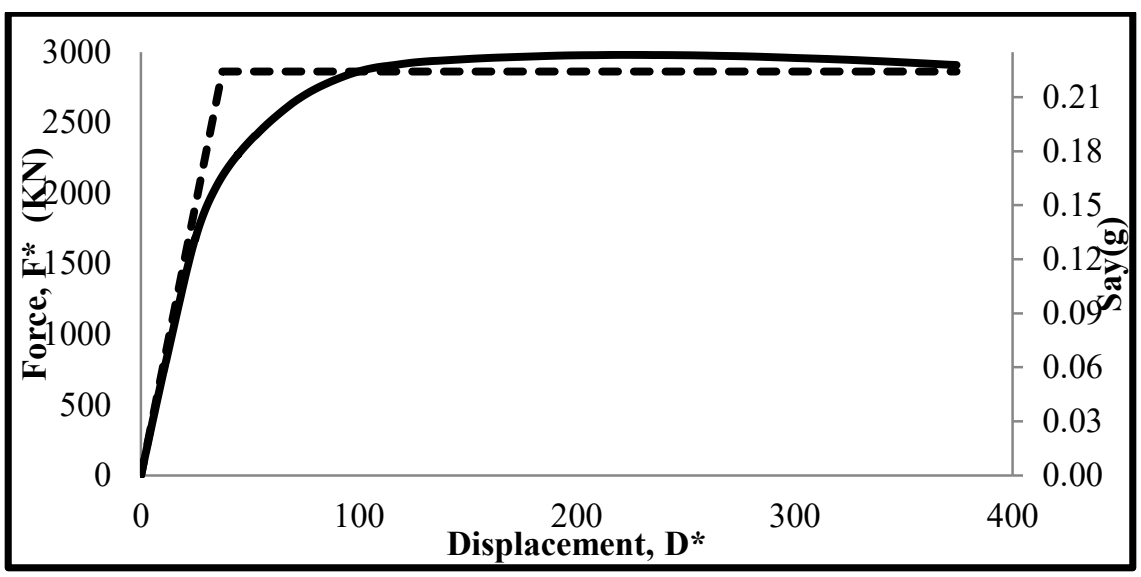

(a)

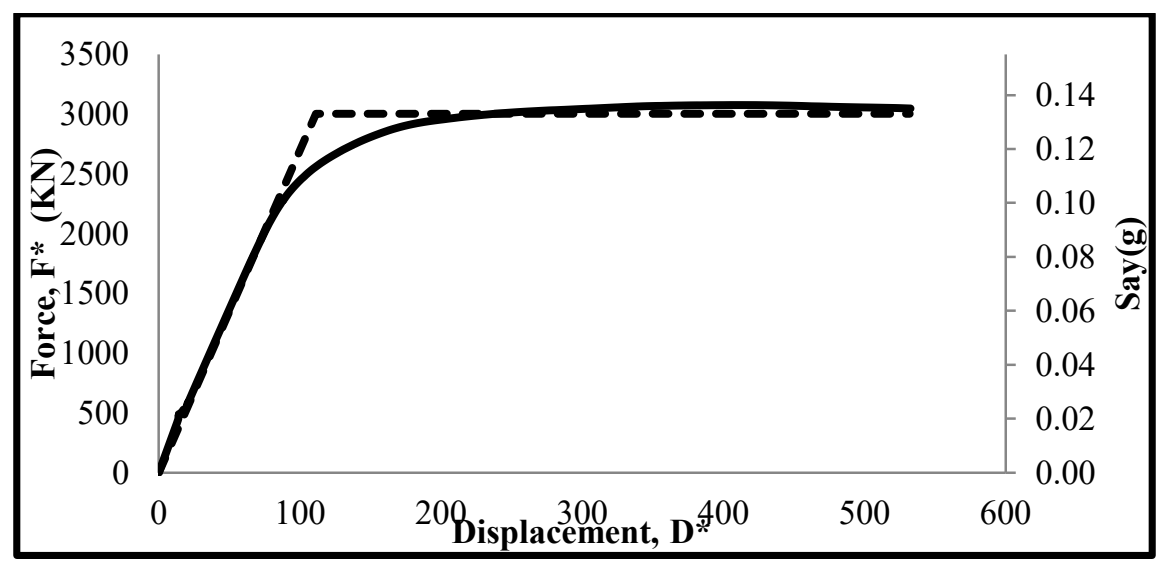

(b)

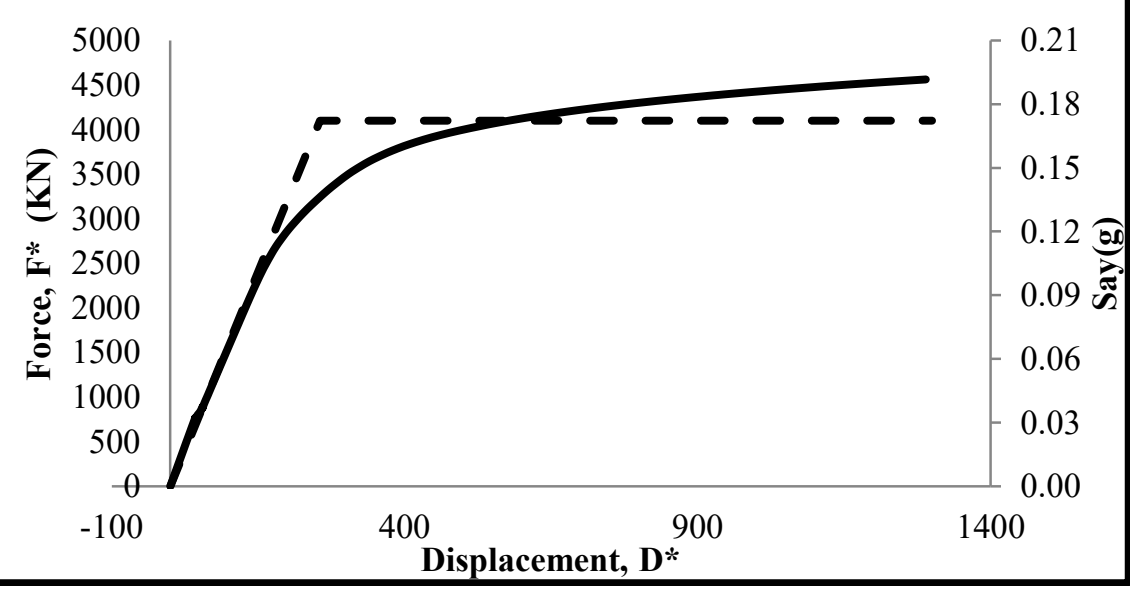

(c)

Figure 5.4: Force-Displacement Idealized Curve as well as Spectral Acceleration vs. Spectral Displacement Curve of Equivalent SDOF System for 4-Storey (top), 8-Storey (middle), and 14Storey (bottom) for P-SPSW. 
Table 5.1: Structural Properties of Equivalent SODF system

\begin{tabular}{|c|c|c|c|c|c|}
\hline P-SPSW & $\begin{array}{c}\text { Effective } \\
\text { mass m* } \\
\text { (ton) }\end{array}$ & $\begin{array}{c}\text { Modal } \\
\text { Participation } \\
\text { Factor } \Gamma\end{array}$ & $\begin{array}{c}\text { Yield } \\
\text { Strength } \\
\mathrm{F}_{\mathrm{y}}{ }^{*} \\
(\mathrm{kN})\end{array}$ & $\begin{array}{c}\text { Yield } \\
\text { Displacement } \\
\mathrm{D}_{\mathrm{y}}{ }^{*} \\
(\mathrm{~mm})\end{array}$ & $\begin{array}{c}\text { Elastic } \\
\text { Period } \\
\mathrm{T}^{*} \\
(\mathrm{sec})\end{array}$ \\
\hline 4-storey & 1308 & 1.39 & 2860 & 37.4 & 0.82 \\
\hline 8-storey & 2302 & 1.49 & 3000 & 111 & 1.84 \\
\hline 12-storey & 3035 & 1.56 & 3900 & 255 & 2.80 \\
\hline
\end{tabular}

\subsubsection{Demand Spectrum for the Vancouver Area}

The site specific response spectrum (RS) of the Vancouver has been taken from uniform hazard response spectrum of NBCC 2010. The response spectrum consists of the spatial acceleration ( $\mathrm{Sa}$ ) versus time period $(\mathrm{T})$ for the single degree freedom system (SDOF) for $5 \%$ critical damping with the soil class C. Then elastic response spectrum (RS) was transformed into elastic displacement response spectrum by Eq. 5.8, which is shown in Figure 5.5. From the response spectrum the characteristic time period, $\mathrm{T}_{\mathfrak{c}}$, for the Vancouver region has been selected as $0.2 \mathrm{sec}$.

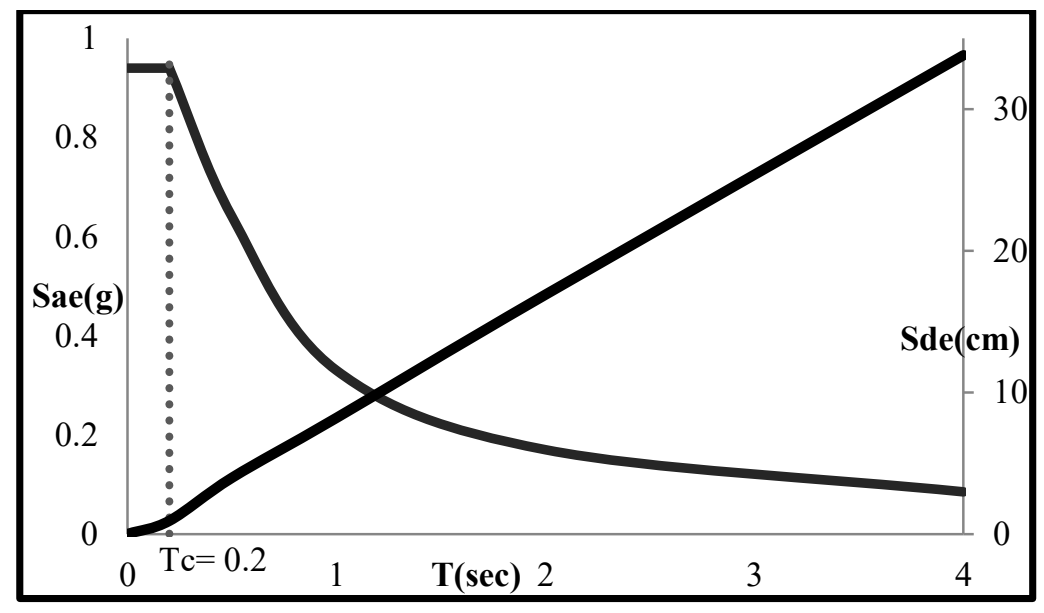

Figure 5.5: Elastic Acceleration $\left(\mathrm{S}_{\mathrm{ae}}\right)$ \& Displacement $\left(\mathrm{S}_{\mathrm{de}}\right)$ Response Spectrum for the Vancouver.

Later, elastic response spectrum was shifted into an acceleration displacement response spectrum (ADRS) format for constant ductility as shown in Figure 5.6. In this diagram, the radial lines were 
represented the elastic time periods for the SDOF. Finally, the elastic response was converted into inelastic responses (acceleration and displacement) by using the Eq. 5.9 and 5.10. The elastic $(\mu=1.0)$ and inelastic $(\mu=5.0)$ seismic demand spectrum (constant ductility response spectrum in ADRS format) for the Vancouver are illustrated in Figure 5.6.

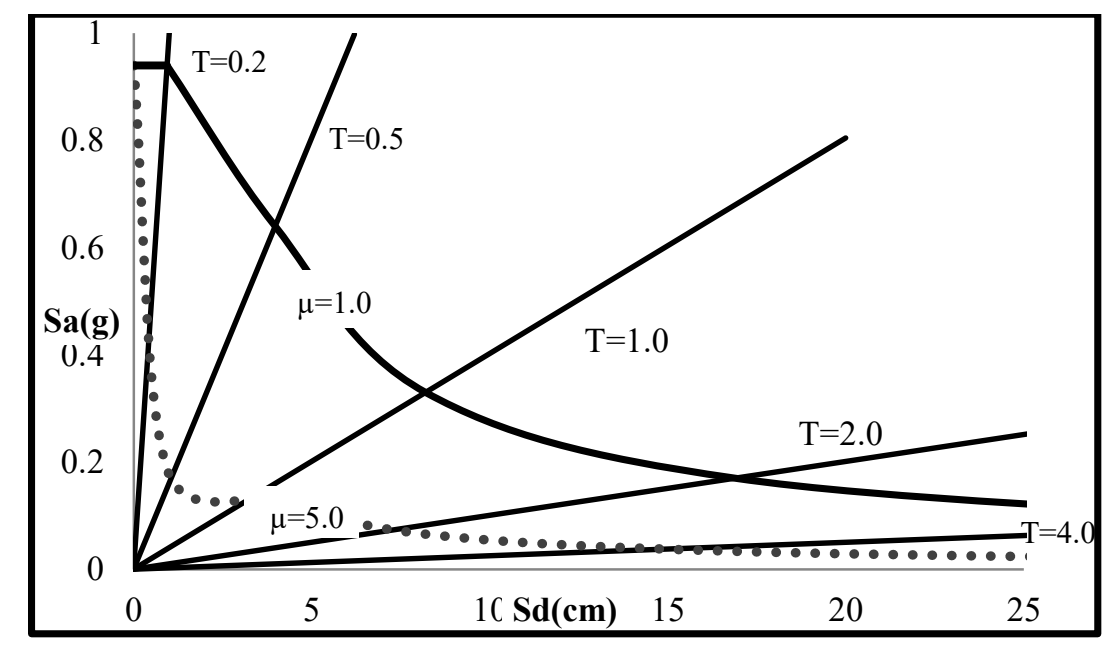

Figure 5.6: Seismic demand spectrum (constant ductility response spectrum in ADRS format) for the Vancouver.

\subsection{Seismic Demand of P-SPSWs Using N2 method}

Once the demand spectra (Vancouver area) and the capacity spectra of the selected P-SPSWs (4-, 8-, and 12-storey P-SPSWs) obtained, the two curves were plotted in the same graph. The plots are shown in Figures 5.7-5.9. The elastic time periods $\left(\mathrm{T}^{*}\right)$ are shown in dash line. Once elastic time period line (radial line) intersects with the elastic ADRS line $(\mu=1)$, the corresponding elastic displacement and acceleration spectra are obtained. On the other hand, spectral acceleration at the yielding point $\left(\mathrm{S}_{\mathrm{ay}}\right)$ is calculated from the bi-linear capacity spectrum of the corresponding yield force $\left(\mathrm{F}^{*}\right)$ by Eq. 5.6. For the selected P-SPSWs strength reduction factors $(\mathrm{R} \mu)$ are obtained by the ratio of the Eq. 5.9. Once force reduction factor is found, ductility $(\mu)$ can be calculated by using Eq. 5.11 or 5.12 . 
According to NBCC 2010, the design ductility of the P-SPSW is 5 and overstrength factor is 1.6. Therefore, in the demand spectrum of the ADRS format, in addition to the ductility of $\mu=1$, the ductility of $\mu=5$ was plotted to distinguish the ductility of selected P-SPSWs. From N2 method, it has been found that ductility is less than design ductility. Thus, for 4-, 8-, and 12-storey P-SPSWs the structural ductilities are calculated as 1.8, 1.4 and 1.0 respectively. For ductility value, it is easily evaluated that, the high rise P-SPSW (12-storey) work more elastically than the low rise PSPSW.

As the fundamental period (elastic time period, $\mathrm{T}^{*}$ ) of the selected P-SPSWs were more than the characteristic time period $\left(T_{c}\right)$. Hence, the equal displacement rule is appropriate. By using this rule, it is considered that inelastic displacement demand is equal to elastic displacement demand. Displacement demand is obtained from the intersection point of the bi-linear capacity curve and the calculated ductility of the selected P-SPSWs. The intersection point is the "Performance Point" for the particular structure.

The displacement demands of the ESDOF systems for the 4-, 8- and 12-storey P-SPSWs are 68 $\mathrm{mm}, 153 \mathrm{~mm}$ and $215 \mathrm{~mm}$ respectively (Figure 5.7, $5.8 \& 5.9$ ). The displacement demands of the ESDOFs were then converted to MDOFs by model participation factor. The displacement demands are $95 \mathrm{~mm}, 228 \mathrm{~mm}$, and $335 \mathrm{~mm}$ for the 4-, 8- and 12-storey P-SPSW respectively.

The average top displacements from nonlinear time history analysis were compared with displacement demands obtained from the $\mathrm{N} 2$ method and is presented in Table 5.2. The difference has been found $12 \%$ and $18.5 \%$ for the 4 -, 8 -storey P-SPSW respectively, however for the 12 storey, the difference is quite high which is $23 \%$. From, NTH analysis it was observed that for the 4- and 8-storey P-SPSW, the first mode of vibration was dominated for the selected earthquakes. 
In contrast, for the 12-storey, the higher mode effect was induced for the selected earthquakes. In N2 method, Fajfar (1999) considered only fundamental mode shape to estimate modal participation factor.

Inter -storey drifts also evaluated for the N2 method and found quite less than code limit. The comparison of drift between N2 method and average NTH analysis are illustrated in the figure 5.10 for the 4-,8- and 12 -storey respectively.

Table 5.2: Seismic demand for 4-, 8- and 12-storey P-SPSW.

\begin{tabular}{|l|c|c|c|}
\hline & 4-storey & 8 -storey & 12-storey \\
\hline Ductility from N2 method & 1.8 & 1.4 & 1.0 \\
\hline Displacement demand N2 method (mm) & 95 & 228 & 335 \\
\hline Average displacement by NTH analysis (mm) & 84.5 & 185 & 272 \\
\hline \% of variation & $12 \%$ & $18.5 \%$ & $23 \%$ \\
\hline
\end{tabular}

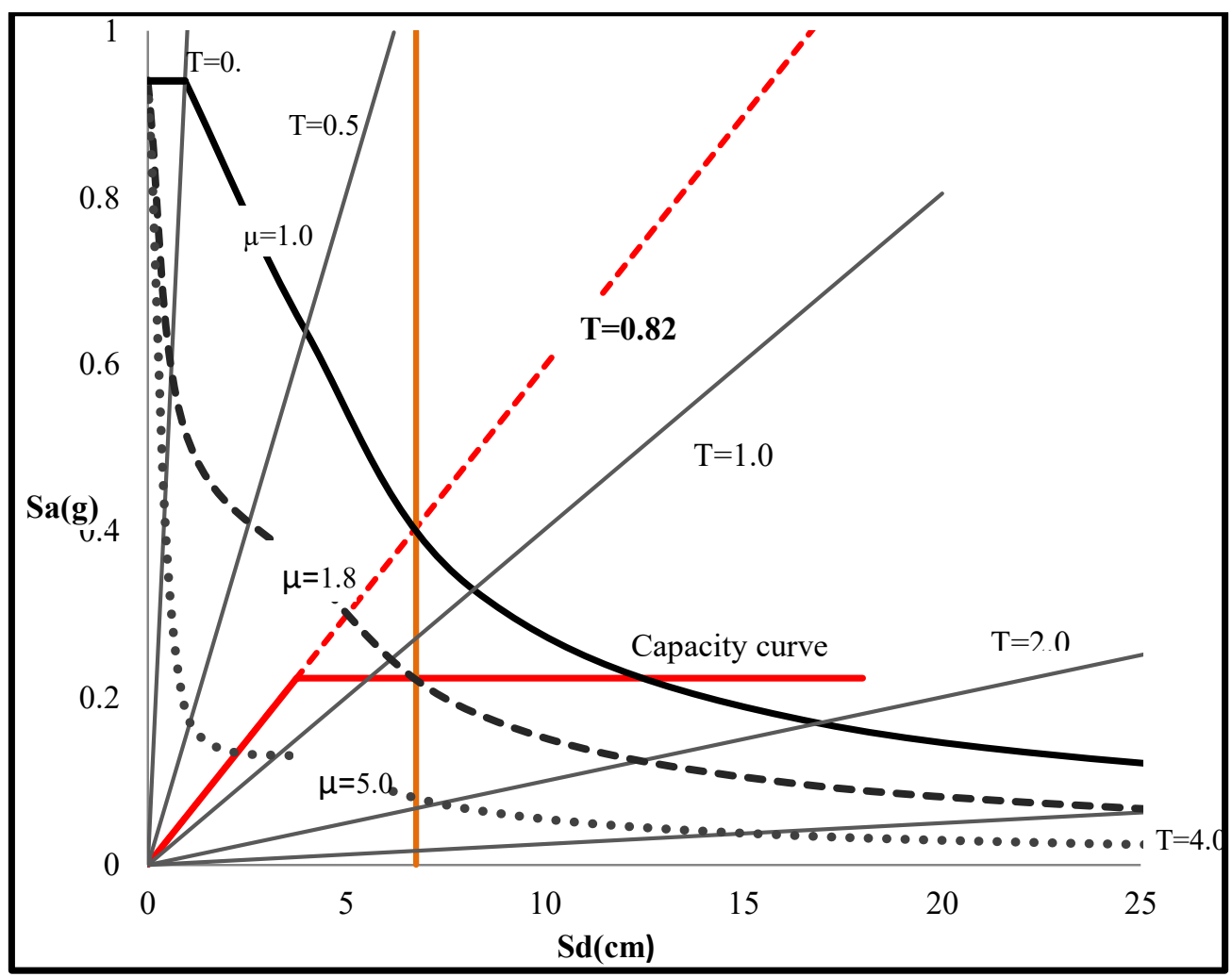

Figure 5.7: Graphical Representation of N2 method for 4-Storey P-SPSW in ADRS format. 


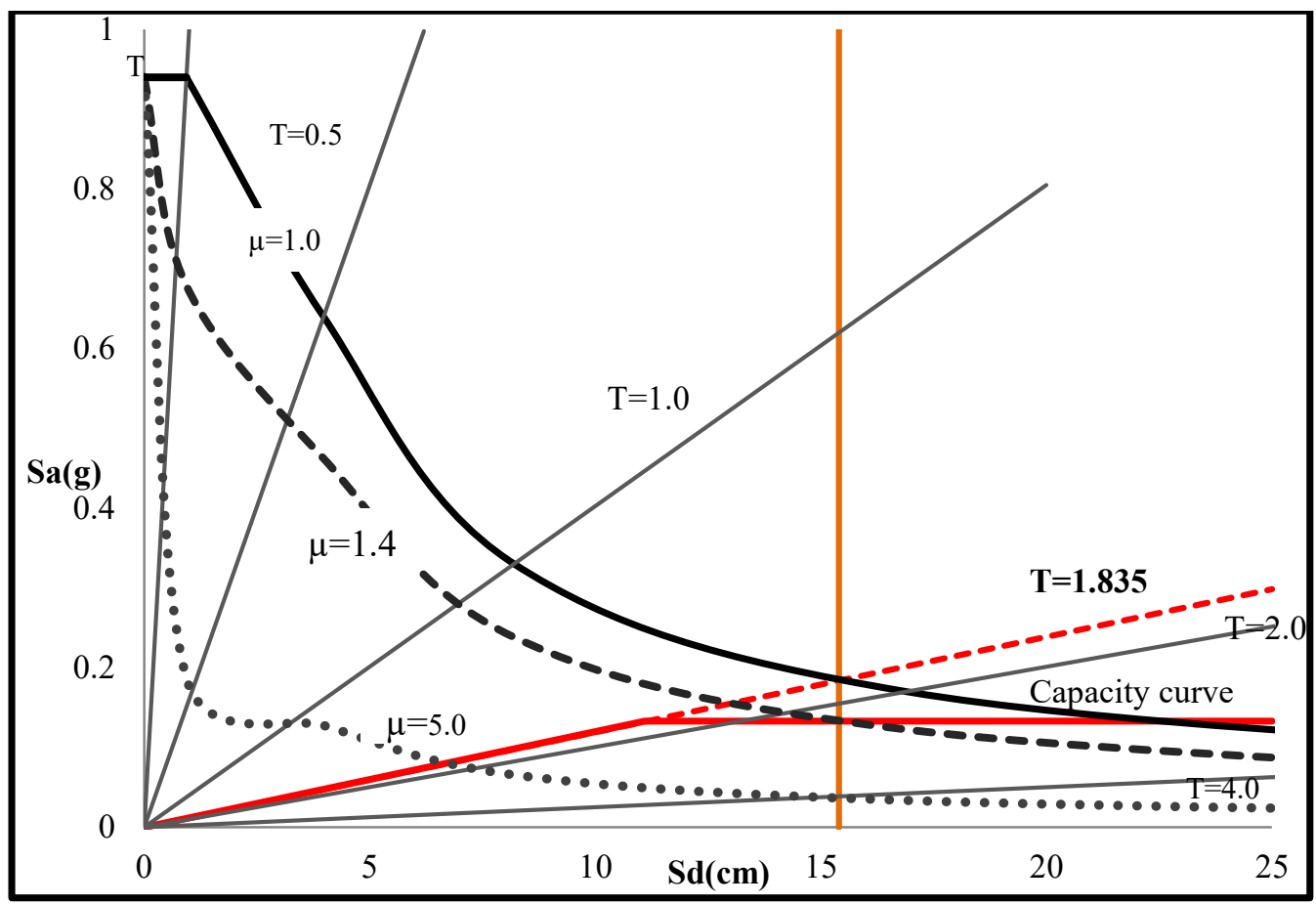

Figure 5.8: Graphical Representation of N2 method for 8-Storey P-SPSW in ADRS format

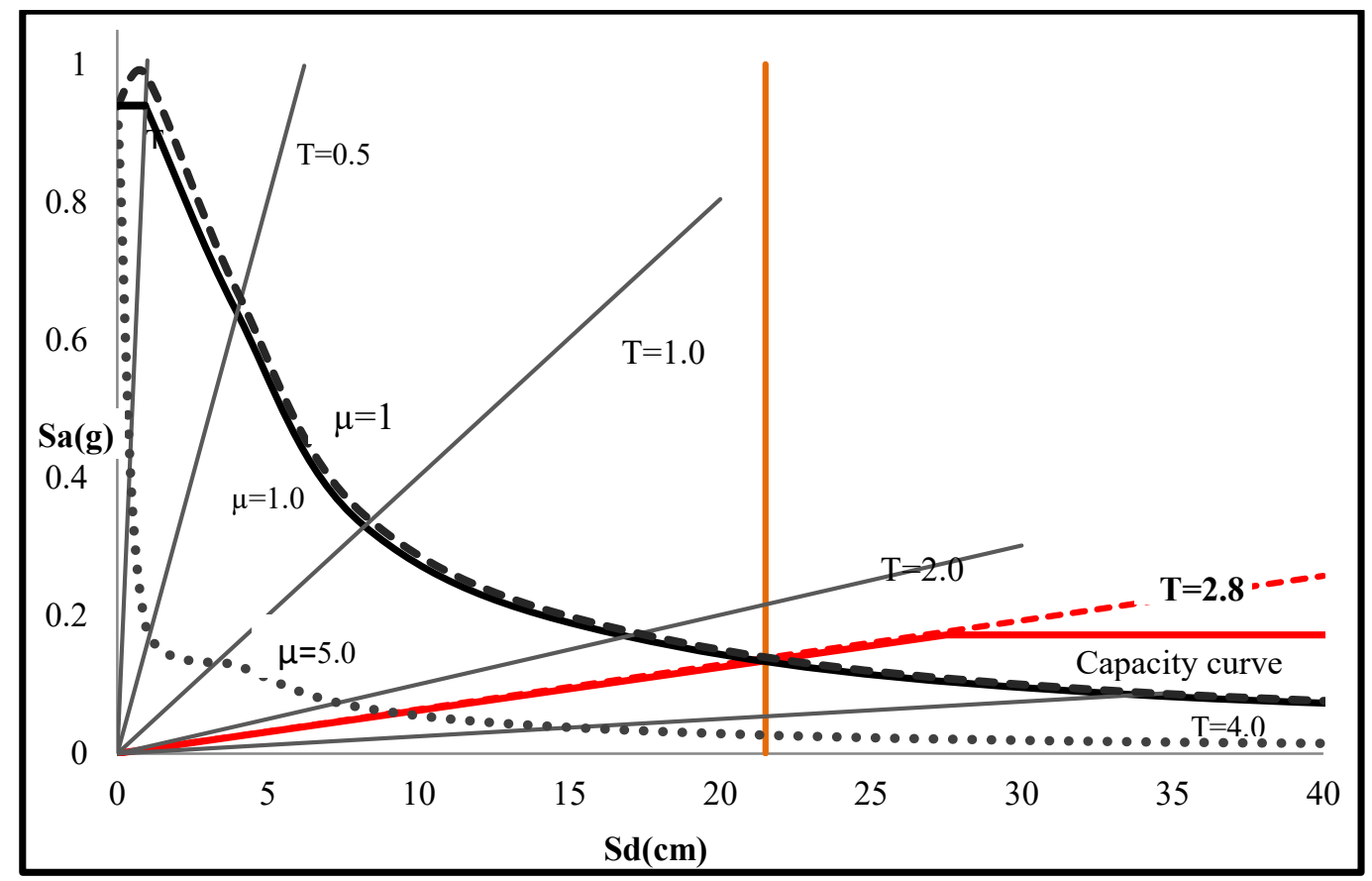

Figure 5.9: Graphical Representation of N2 method for 12-Storey P-SPSW in ADRS format. 


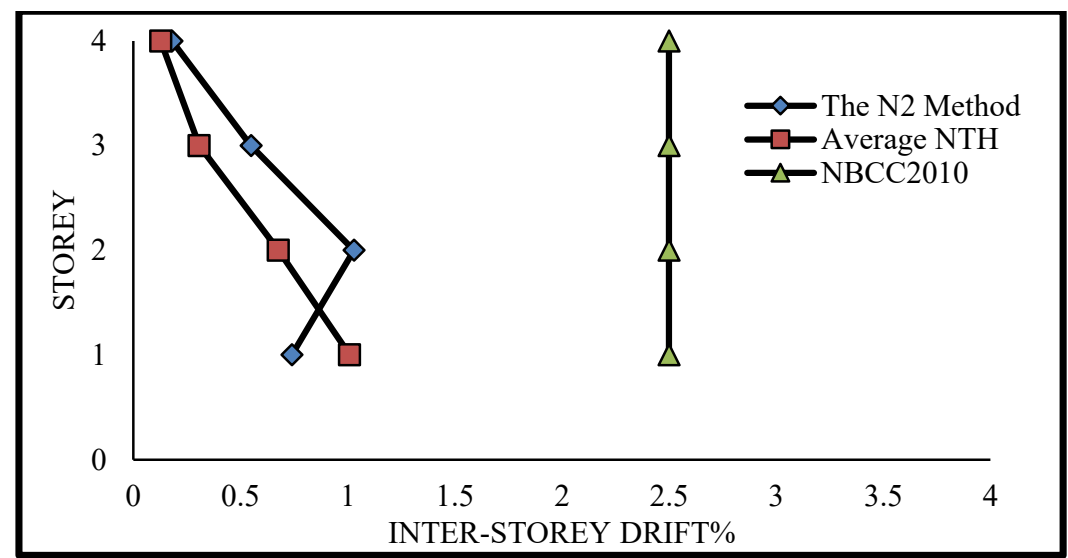

(a)

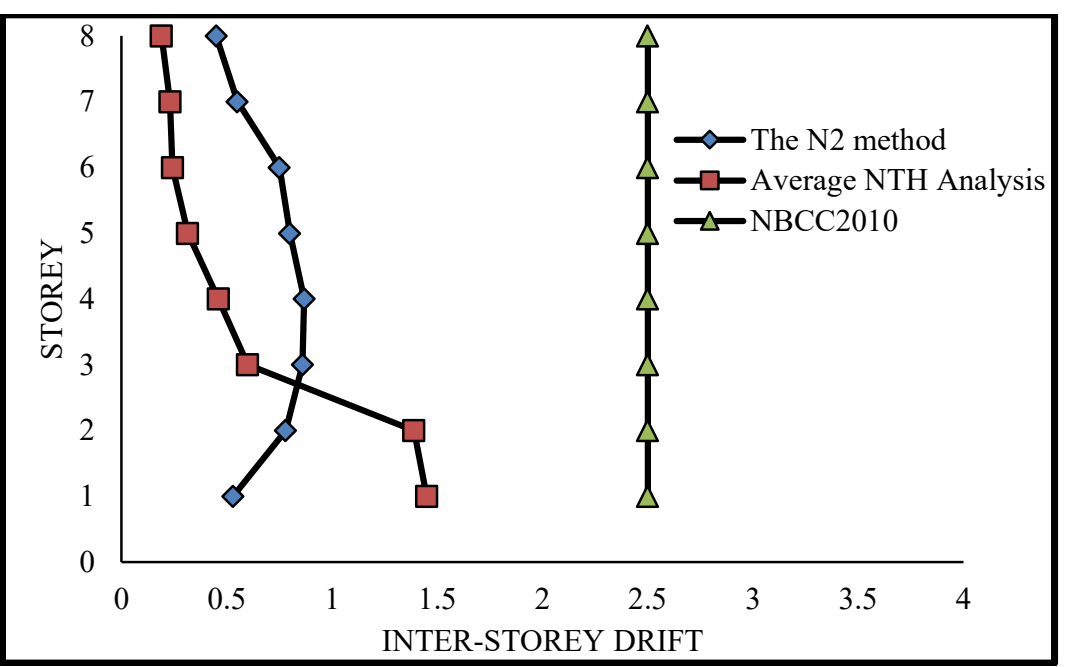

(b)

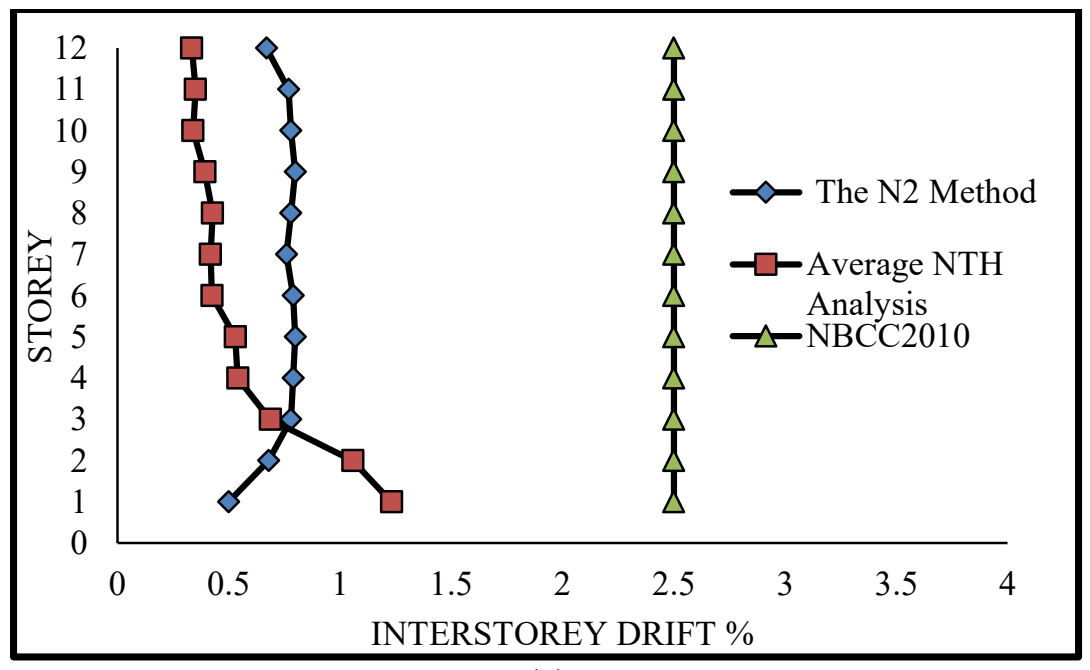

(c)

Figure 5.10: Comparison of the N2 method Inter-storey Drift with NTH analysis a) 4-storey, b) 8-storey and c) 12-storey P-SPSW. 


\subsection{Summary}

Seismic performance in terms of roof displacement and inter-storey drifts are estimated using the N2 method in this chapter. From frequency analysis, the first mode of vibration has been determined to calculate the equivalent mass of SDOFs and mass participation factor for MDOFs (4, 8 \& 12-storey P-SPSW). Later, nonlinear pushover curves have been plotted for the 4, 8 and 12-storey P-SPSW. The pushover curves of the MODFs have been converted into spectrum capacity curves of ESDOF systems. Response spectrum (RS) of the Vancouver region has been converted to ADRS format for constant ductility. Once capacity and demand spectrum has been found, then both were drawn in the same plot. The crossing point of capacity curve and demand curve is the displacement demand for the ESDOF system. Finally, using modal participation factor, the displacement demand of ESDOF has been converted to demands for MDOFs. The nonlinear seismic demand and capacity demand spectrum has been compared here. The variation of displacement demand is higher for 12-storey compared to other two P-SPSWs because of higher mode effect in the high rise structure. The N2 method is suitable for the structures which have a fundamental mode of vibration is governing mode. The N2 method is equally applicable to different site specifics response spectrum. 


\section{Chapter 6. Modified Strip Model (MSM) for the Perforated Steel Plate Shear Walls (P-SPSW)}

\subsection{Introduction}

Strip model, first proposed by Thorburn et al. (1983), is a simple method and is widely used for analysis of unstiffened SPSW. In unstiffened SPSW, infill plate buckles with a small amount of lateral load and diagonal tension field forms in the infill plate. In this strip model, they are oriented at an average angle of inclination in the principal stress direction of the infill. At least ten strips are required to predict the overall behavior. The area of the single strip is taken as the thickness of the infill time's width of the individual strip. Thus, strip model can be considered as a very simple and effective tool to predict the overall behavior of unstiffened SPSW. Both Canadian and American steel design standard have adopted the strip method for designing of unstiffened SPSW.

In order to get inelastic behavior in unstiffened SPSW, along with elasto-plastic material behavior in the tension stripes, Driver et al. (1998b) incorporated plastic hinges in the frame members. Even though this approach provided a reasonable estimation of large scale SPSW's responses, but this approach was unable to predict the initial stiffness and ultimate strength accurately. Moreover, this refinement was not capable of capturing the deterioration in strength in the pushover analysis. It was also observed that replacing the number of strips with ten to twenty in the infill; the responses changed slightly.

To make a better prediction of the experiment results, Shishkin et al. (2005) proposed "modified strip model." In this modification, load displacement hinge was provided in the tension strip to estimate post-buckling strength. On the other hand, for precise prediction of initial stiffness, a compression strut was also contained in the opposite direction of the tension strips. Area of the 
compression strut was taken from the equivalent bracing model (Eq. 2.2) proposed by Thorburn et al. (1983). Besides, material properties were considered as similar as tension strips, and maximum strength was taken as $8 \%$ of the tension strip. An axial hinge was incorporated to simulate buckling as well in the strut. Instead of the same axial hinge, in the corner tension strip, a deterioration hinge (axial hinge) was incorporated to consider the effect of tearing and welding failure in the corner of the infill plate.

For detailed modified strip model (MSM), material properties were modeled as multilinear elastoplastic including strain hardening effect. Infill plate was substituted by a pin connected tension only strips (ten) with actual angle of inclination ( $42.4^{\circ}$ regarding column). Moreover, infinitely stiff panel zones were incorporated in the beam column junctions' points to simulate elastic behavior. At the same time, multi-linear plastic hinges were modeled for the frames (beams and columns) and the strips (tension and compression) as well. For corner tension strip, a deterioration hinge was modeled separately. So, 4-sotey test specimen by Driver et al. (1997) was validated for the detailed MSM. Using simple structural analysis software SAP2000 (CSI2000), the researchers established that, the MSM was capable of providing excellent agreement with experiment results with sufficient degree of accuracy to provide elastic to post yielding behavior.

Due to the complexity of the detailed model, Shishkin et al. (2005) later offered simplified MSM, where actual strips orientation was replaced by crosshatch layout with adjacent two stories shear the same nodes. Material properties were modeled as bi-linear elasto-plastic without strain hardening effect. No panel zones were provided separately. In addition, multi-linear plastic hinges were replaced by bi-linear hinges. To assess the efficiency of the proposed simplified model, again Driver et al. (1997) test specimen was considered. For simplified MSM, it was also found that the techniques were efficient to provide sufficient agreement with experiment. 
The aim of this chapter is to implement the modified strip model for the 4-,8- and 12-storey perforated steel plate shear wall (P-SPSW). Widely used commercial structural analysis software SAP2000 (CSI 2014) was considered to conduct the pushover analysis. The chosen package is very familiar in industries, and most of the engineers are aware of it. On the other hand, comprehensive finite element modeling using ABAQUS (2011) was very complex and timeconsuming analysis procedure. However, in SAP2000, inelastic behavior can be evaluated easily by incorporating plastic hinges.

\subsection{Modeling Techniques of Modified Strip Method for the Selected P-SPSWs}

\subsubsection{Frame Joint Agreement}

The geometry, material properties of the panel zone and hinges location are collectively described as frame joint agreement. In the moment resisting frame, energy is dissipated by yielding action of the panel zone. On the other hand, infill panel acts as a fuse element for the SPSW. During the large scale four-storey SPSW test, Driver et al. $(1997 ;$ 1998a) reported that panel zones acted like infinitely elastic. Therefore, Shishkin et al. (2005) incorporated a very high (thousand times more) elastic modulus (E) for panel zone with reference to boundary element. However, the researchers did not consider extra panel zones for the simplified MSM. In this study, same elastic modulus of the column was taken into consideration for the panel zone. Besides, the plastic hinges were placed at a distance of one-half depth of the particular frame which is shown in figure 6.1 of frame joint agreement, where $d_{b}$ and $d_{c}$ are the beam and column depth respectively. 


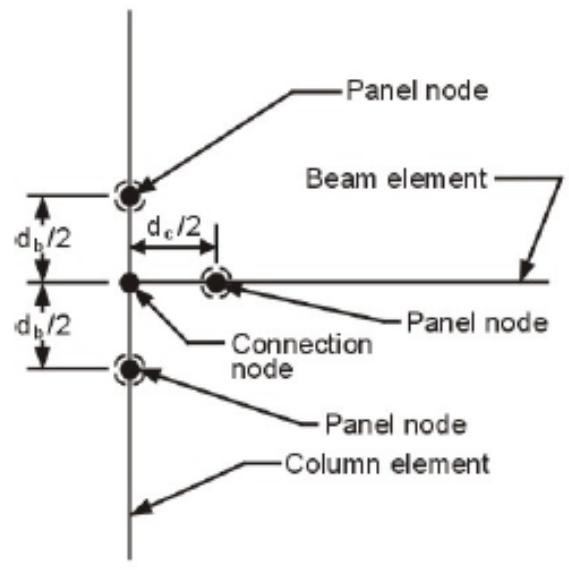

() Hode

Figure 6.1: Frame joint agreement, hinges at panel node by Shishkin et al. (2005)

\subsubsection{Tension Strips}

Pin connected tension only truss elements were modeled to simulate the infill plate buckling action. The orientation of the tension strips was taken in the direction of the principal stress direction of the infill plate. Besides, the angle of inclination $(\alpha)$ of the truss element was taken as same as openings orientation angle (in this study $\alpha=45^{\circ}$ ). Driver at al. (1998b) observed that, by changing angle of inclination between $42^{\circ}$ to $50^{\circ}$, overall responses changed only slightly. Even though minimum ten stripes were required for solid infill but for perforated infill, the number of strips for 4-,8-and 12-storey P-SPSW were taken as twelve since there were eleven diagonal openings. In addition, two types of strip width were taken into account. Among of them, one was from edge to edge (E/E) (Figure 6.2a), and another one was from center to center $(\mathrm{C} / \mathrm{C})$ from the opening (Figure 6.2b). The stripes were assigned as zero compressive capacity, to take only tensile strength. 


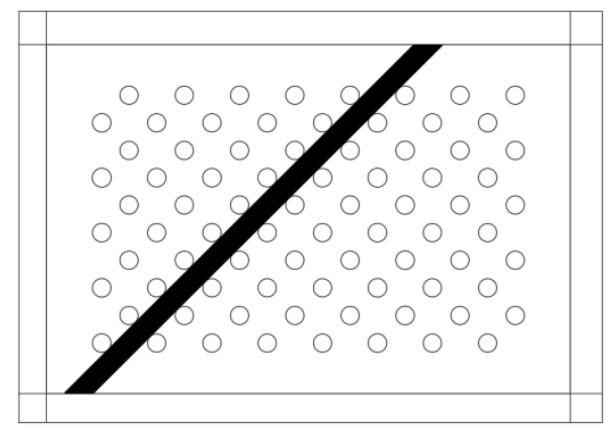

(a)

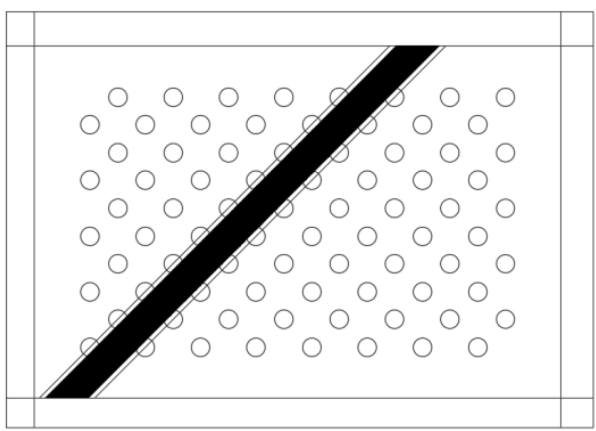

(b)

Figure 6.2: Tension strips width from a)edge to edge $(\mathrm{E} / \mathrm{E})$ and $\mathrm{b})$ center to center $(\mathrm{C} / \mathrm{C})$

\subsubsection{Compression Strut}

In basic strip model, strength contribution before plate buckling was neglected by Thorburn et al. (1983). While validating basic strip model, Driver et al. (1998 b) reported that the loaddisplacement curve underestimates the initial stiffness too. To eliminate this discrepancy, Shishkin et al. (2005) added a compression strut opposite to the tension strips. The area of the compression strut was taken from the equivalent brace model (Eq. 2.2) recommended by Thorburn et al. (1983). The pin ended compression strut was modeled by connecting two opposite corners, and zero tension capacity was assigned to it.

\subsubsection{Strip Arrangement}

Two different strip layouts were considered to look at the behavior of perforated plates. Among them, one was exact layout (Figure 6.3a), and another one was crosshatch layout (Figure 6.3b). The crosshatch layout was very easy to implement in compared to exact one. In crosshatch layout, the upper and lower strips share the same node, whereas, in the exact layout, strips are connected in the actual position of the frame. 


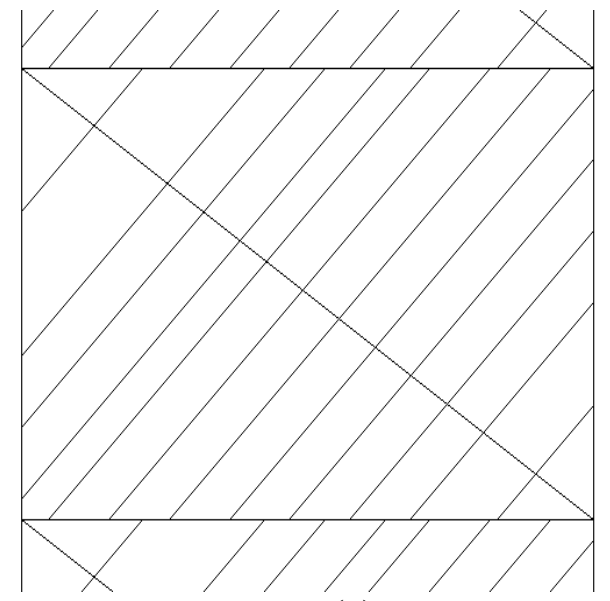

(a)

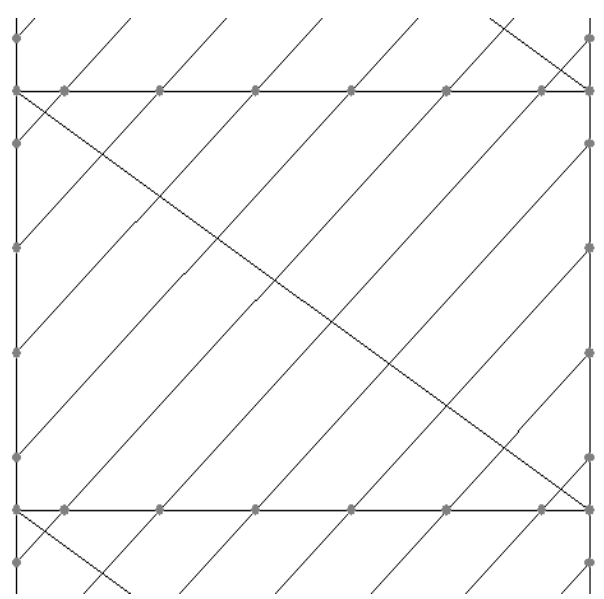

(b)

Figure 6.3: tension strips layout a) Exact layout b) Crosshatch layout

\subsubsection{Material Properties}

True stress-strain material properties transformed into as multi-linear elasto-plastic curve in detailed MSM. It was observed that there was small strain hardening effect in the forcedisplacement curve, by Shishkin et al. (2005). Therefore, in this study, material properties were modeled as bilinear elasto-plastic. Material properties of the tension strips and boundary frames were taken similar to infill panel and beams/columns respectively in the detailed finite element model. As compression strut will be buckled due to the application of the small amount of lateral load, so the material strength of the compression strip was taken $15 \%$ of tension strips. The strength was obtained from a sensitivity analysis of the strength of compression strut.

\subsubsection{Plastic Hinge Properties}

Plastic hinges were incorporated both in frame elements and strips to simulate the inelastic behavior in unstiffened P-SPSW. Even though plastic hinges are integrated into the discrete point of the frame but it has finite length, usually it is taken as equal to the member depth. As panel zones are infinitely elastic, plastic hinges were placed in a one-half depth of member, starting from beam column connection point. The hinge properties are showing in Figure 6.1. For the flexure 
hinges, user defined moment vs. rotation curves was considered in the beams and columns, where beam plastic hinge was purely flexural (M3), and columns one was axial load interacted flexure hinges (P-M3). The axial force interaction was defined according to FEMA 356 Eq. 6.1.

$$
M_{p c}=1.18 Z F_{y}\left(1-\frac{P}{A_{C} F_{y}}\right) \leq Z F_{y} \ldots \ldots \ldots \ldots \ldots \ldots \ldots \ldots \ldots .6 .1
$$

where $\mathrm{P}$ is the axial force, $\mathrm{A}_{\mathrm{c}}$ is column cross-section area; $\mathrm{F}_{\mathrm{y}}$ is the material yield stress, and $\mathrm{Z}$ are the plastic modulus.

On the other hand, user defined load displacement (axial) hinges were modeled for both tension strips and compression strut. The axial hinges $(\mathrm{P})$ were placed at mid-point of the individual strip to replicate the yielding in infill plate. Moreover, the SPSW overall strength was reduced due to tearing and welding failure in the corner of the infill. A deterioration hinge was modeled for nearest strips of the corner to predict this inelastic behavior in the corner infill plate as well. Further, an axial hinge was modeled separately for compression strut. Besides, an axial hinge was placed at discreet mid-point in the compression strut.

It was found that multi-linear plastic hinge has negligible effect in predicting the inelastic behavior of unstiffened SPSW (Shishkin et al. (2005)). Therefore, similar to Shishkin et al. (2005), bi-linear plastic hinge properties were considered for all members. Moreover, hinge properties were taken in such a manner that it could act as a perfectly rigid until yielding. The properties of the plastic hinges are given in Tables 6.1 and 6.2. The flexural hinges (M3 \& P-M3) in the beams and columns were symmetric under moment reversal. A small post yielding slope $(0.0002: 1)$ was incorporated in the column hinges to attain convergence. 
For deterioration hinges, ten times yielding force of the axial hinge was assigned to simulate $t$ quick yielding of deterioration strips. The axial hinge properties were symmetric as well and during nonlinear pushover analysis load carrying capacity was extrapolated beyond point $\mathrm{E}$ (Table 6.2). However, for flexural hinges, the load carrying capacity were taken zero while they moved beyond E point.

Table 6.1: Bi-linear Flexure Hinges Properties by Shishkin et al. (2005)

\begin{tabular}{|l|l|l|l|l|l|l|l|l|l|c|}
\hline \multirow{3}{*}{ Hinge } & \multicolumn{2}{|c|}{$\mathrm{A}$} & \multicolumn{2}{c|}{$\mathrm{B}$} & \multicolumn{2}{c|}{$\mathrm{C}$} & \multicolumn{2}{c|}{$\mathrm{D}$} & \multicolumn{2}{c|}{$\mathrm{E}$} \\
\cline { 2 - 11 } & $\mathrm{M} / \mathrm{Mp}$ & $\begin{array}{c}\theta \\
(\mathrm{rad})\end{array}$ & $\mathrm{M} / \mathrm{Mp}$ & $\begin{array}{c}\theta \\
(\mathrm{rad})\end{array}$ & $\mathrm{M} / \mathrm{Mp}$ & $\begin{array}{c}\theta \\
(\mathrm{rad})\end{array}$ & $\mathrm{M} / \mathrm{Mp}$ & $\begin{array}{c}\theta \\
(\mathrm{rad})\end{array}$ & $\mathrm{M} / \mathrm{Mp}$ & $\begin{array}{c}\theta \\
(\mathrm{rad})\end{array}$ \\
\hline Column & 0 & 0 & 1 & 0 & 1.02 & 0.10 & 1.10 & 0.5 & 1.20 & 1.00 \\
\hline Beam & 0 & 0 & 1 & 0 & 1.00 & 0.01 & 1.00 & 0.10 & 1.00 & 1.00 \\
\hline
\end{tabular}

Table 6.2: Bi-linear Axial Hinges Properties by Shishkin et al. (2005)

\begin{tabular}{|l|l|l|l|l|l|l|l|l|l|l|}
\hline \multirow{2}{*}{ Hinge } & \multicolumn{2}{|c|}{$\mathrm{A}$} & \multicolumn{2}{c|}{$\mathrm{B}$} & \multicolumn{2}{c|}{$\mathrm{C}$} & \multicolumn{2}{c|}{$\mathrm{D}$} & \multicolumn{2}{c|}{$\mathrm{E}$} \\
\cline { 2 - 12 } & $\mathrm{P} / \mathrm{P}_{\mathrm{y}}$ & $\Delta / \Delta_{\mathrm{y}}$ & $\mathrm{P} / \mathrm{P}_{\mathrm{y}}$ & $\Delta / \Delta_{\mathrm{y}}$ & $\mathrm{P} / \mathrm{P}_{\mathrm{y}}$ & $\Delta / \Delta_{\mathrm{y}}$ & $\mathrm{P} / \mathrm{P}_{\mathrm{y}}$ & $\Delta / \Delta_{\mathrm{y}}$ & $\mathrm{P} / \mathrm{P}_{\mathrm{y}}$ & $\Delta / \Delta_{\mathrm{y}}$ \\
\hline Tension strip & 0 & 0 & 1.0 & 0 & 1.0 & 16.4 & 1.0 & 50.0 & 1.0 & 100.0 \\
\hline Compression strip & 0 & 0 & 0.0 & -1.00 & -1.00 & -5.0 & -1.00 & -20.0 & -1.00 & -500.0 \\
\hline
\end{tabular}

\subsubsection{Boundary Condition}

Pin support condition was considered at the bottom of each column during design and modeling of selected P-SPSW in chapter 3. Bottom beam doesn't contribute during analysis if boundary conditions were applied at the base point of each column. On the other hand, plastic hinges were formed at the end of the bottom beam while detailed finite element pushover analysis by ABAQUS. Therefore, each column was extended to a certain height (h) toward the end. If the height (h) is increased more than certain dimension, overall strength has increased considerably. In contrast, if the height was less than the particular dimension, no plastic hinge was formed in the 
bottom beam. After all, each column was extended to a height of $800 \mathrm{~mm}$ and pin support condition was applied at the bottom of each column. The schematic diagram of boundary condition is shown in Figure 6.4. As SAP2000 can analyze the model in a 2D plane, so out of plane restraint was not considered in the model.

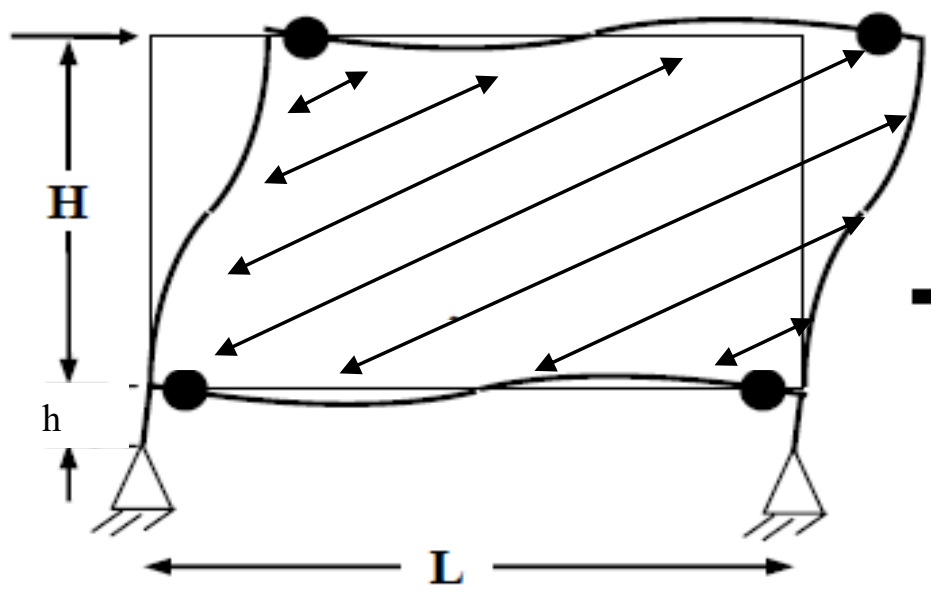

Figure 6.4: Schematic diagram of the base support for pin connection

\subsubsection{Loading Condition}

To incorporate P- $\Delta$ effect gravity loads were applied at the top of each column. The gravity loads were calculated according to NBCC 2010 for each column. On the other hand, lateral loads obtained from equivalent lateral force method was considered for the pushover analysis. Therefore, static load distribution was applied at the beam-column joint. The equivalent static load distribution was taken from the Tables 3.2 and 3.4 for the 4- and 8-storey respectively. As it was expected, ultimate strength will be more than the static base shear (as per as NBCC 2010). Before applying lateral loads, dead loads were also applied to simulate the real condition.

\subsubsection{Pushover Analysis Overview}


Pushover is widely used a non-linear static analysis procedure for seismically designed structure. This analysis can effectively predict the elastic to post yielding behavior of the structure by incorporating material nonlinearities. Also, geometric nonlinearities can be integrated by P- $\Delta$ effect when the large lateral displacement is induced for gravity loads. Besides, the inelastic behavior of P-SPSW was modeled by the pre-defined plastic hinges in several discreet points where plastic hinges will be expected to form.

In this study, material and geometric nonlinearities were taken into consideration during nonlinear static pushover analysis. With user specified increment, base shear versus top-storey displacement was recorded during pushover analysis. Displacement control load application was performed along with displacement was monitored at the top point of the P-SPSW. Only positive increments were saved during the analysis.

"Unload Entire structure" was carried out by hinges uploading method. In this method, the strain may increase or decrease when hinges move in the negative stiffness region. The load increases while increasing strain. On the other hand, load continues to decline when strain decreases. The load is partially removed from structure until it reaches at the end of the hinges negative stiffness curve. Then, at this point, the load is reapplied over the structure.

\subsection{Validation of Modified Strip Model (MSM)}

\subsubsection{Driver et al. $(1997,1998 a)$ Test Specimen}

Large scale 4-storey test specimen by Driver et al. (1997, 1998a) was chosen for validating modified strip model. The modeling was implemented as described early in this chapter using structural analysis software SAP2000 (CSI2014). Where equally spaced pin connected tension only, truss elements were molded to replicate the infill plate. Among all the strips, two corner 
strips were considered as deterioration strips. There was no bottom beam; therefore, the lower plate was directly connected with the testing floor. On the other hand, the columns were fixedly connected to the floor. Therefore, each column was connected directly to the base by fix support without extension. Flexure and axial hinges were incorporated in the frames and strips as described in Tables 6.1 and 6.2 respectively.

The gravity loads of $720 \mathrm{kN}$ were applied at the top of each column and only for the top floor. Besides, an equal amount of lateral loads $(1000 \mathrm{kN})$ were applied monotonically at the top flange of each beam in the corresponding panel zone. However, the lateral loads were applied in such a manner that to simulate actual floor loading during the earthquake. The first storey displacement up to $78 \mathrm{~mm}$ was monitored relative to base shear in pushover curve. The envelope curve of the cyclic test by Driver et al. (1998a) was compared with pushover curve of the SAP2000 (CSI 2014) model. Figure 6.5 represents the geometric and loading arrangement of Driver et al. (1997) test specimen for the MSM.

From the pushover curve (Figure 6.6) it can be easily observed that the model efficiently captured the inelastic behavior of overall SPSW. From the modified strip model, ultimate strength was found $2810 \mathrm{kN}$. Even though initial stiffness of the modified strip model perfectly matched, but the ultimate strength slightly underestimates the test result, which was around $8 \%$. Nevertheless, modified strip model is a very effective procedure to capture the elastic to inelastic nature of the large scale SPSW. 


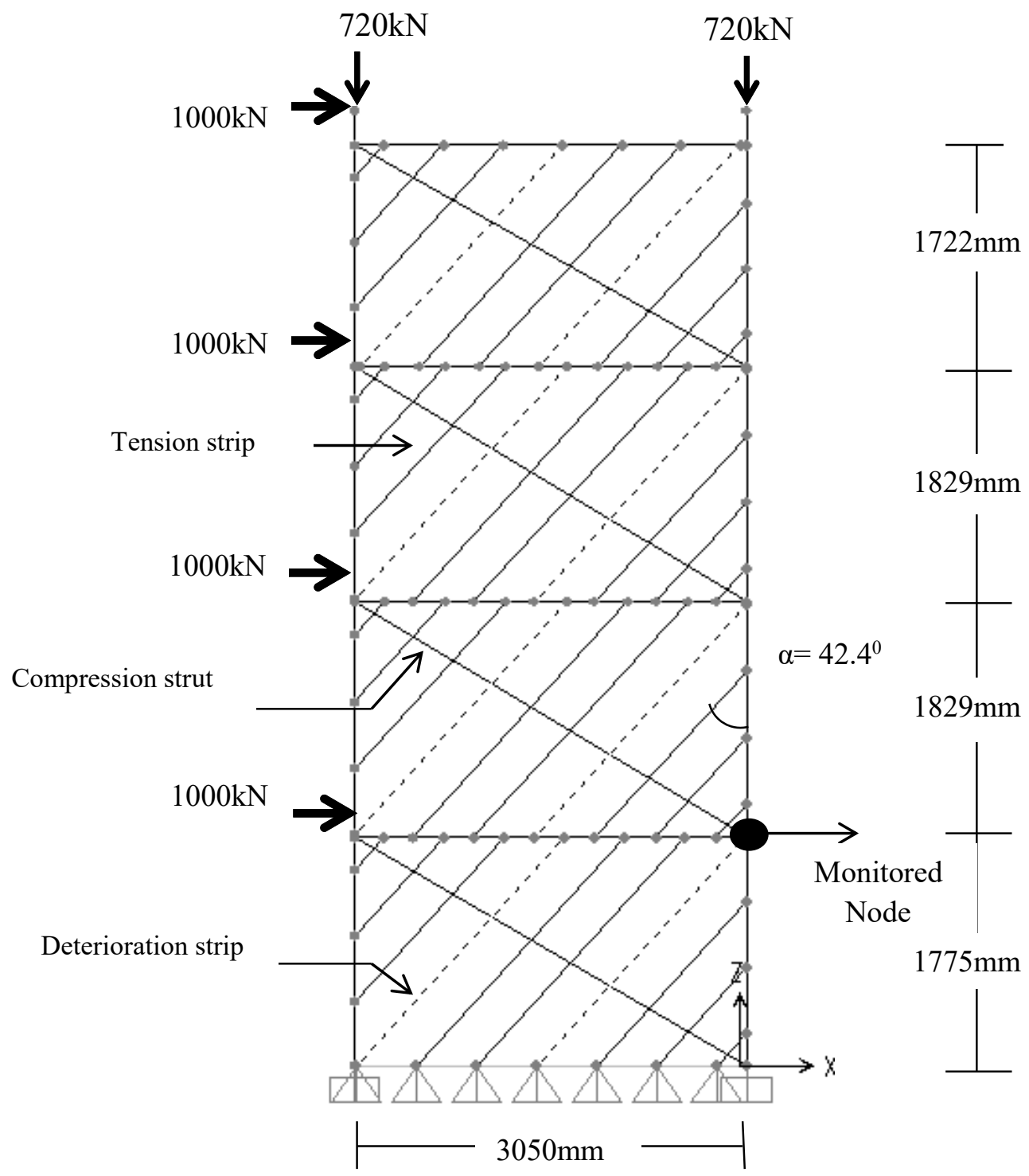

Figure 6.5: Geometry arrangement of Driver et al. (1997) test specimen for the MSM. 


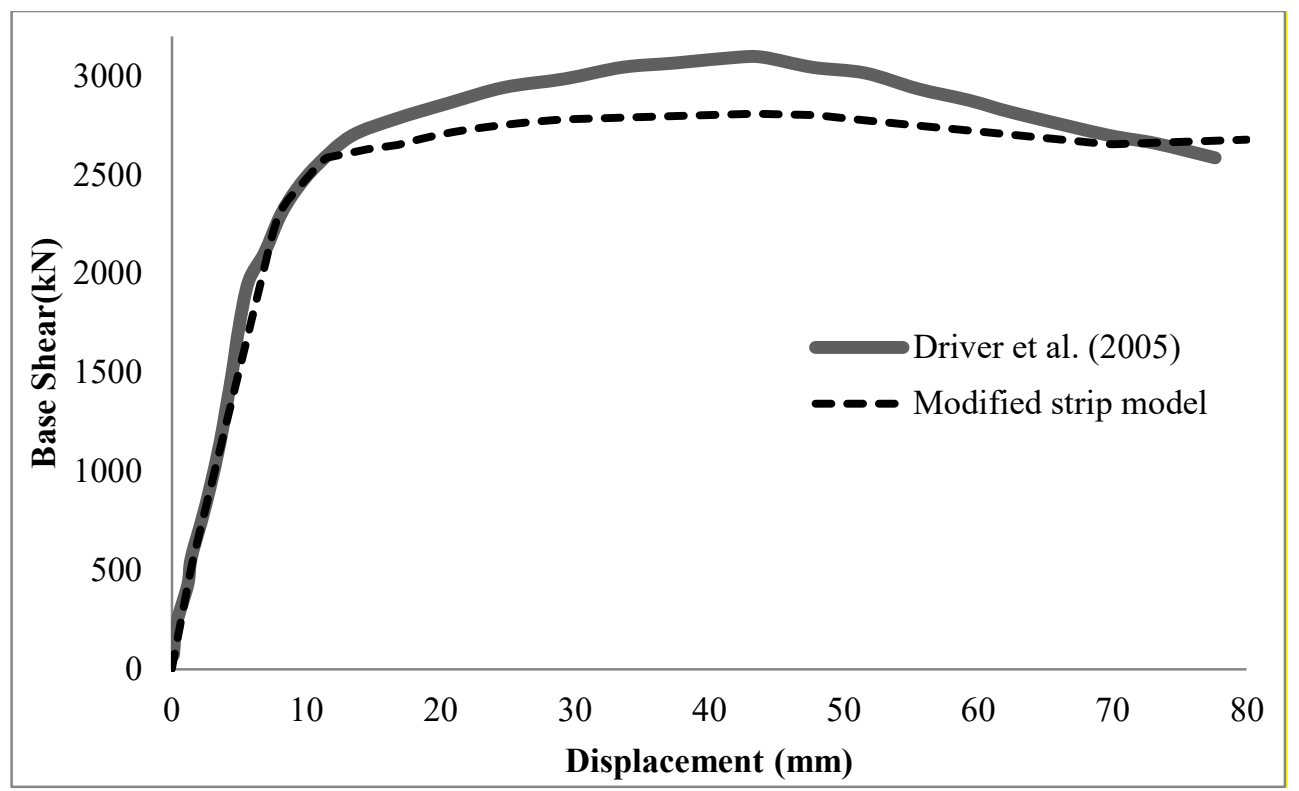

Figure 6.6: Comparisons of base shear vs. displacement curve for the Driver et al. (1998a) and modified strip model.

\subsubsection{Vian et al. (2005) Test Specimen}

As the main objective of this chapter is to implement the modified model for P-PSW, a perforated test specimen was taken into account. The test sample for seismic retrofitting by Vian et al. (2005) was considered to implement the modified strip model in this study. Columns were pin connected at the base, so each column was extended to $800 \mathrm{~mm}$ respectively and incorporated the pin connection at the bottom. Hinges properties were combined as described in Table 6.1 and 6.2. No gravity load was considered in the model because such kind of load was not applied; however, the lateral load was applied at the mid-point of the top beam. Mid-point displacement was monitored with corresponding base shear in the pushover curve. Figure 6.7 shows the geometric and loading arrangement of Vain et al. (2005) test specimen for the MSM.

From the nonlinear pushover analysis, it was found that the MSM pushover curve for C/C strip was sufficient to predict the elastic to post yielding behavior for the P-SPSW. Initial stiffness was 
slightly underestimated and ultimate strength to some extent was over-predicted the test specimen in this case (Fig. 6.8). The variation of ultimate strength was around 5\%. On the other hand, E/E stripe model considerably underestimated both initial stiffness and strength for the loaddisplacement curve for the test specimen (Fig. 6.8). Above all, the modified strip model (C/C) was a very effective tool to evaluate the inelastic behavior of P-SPSW. Therefore, for predicting overall behavior, the selected P-SPSWs were taken into account for the same modeling technique.

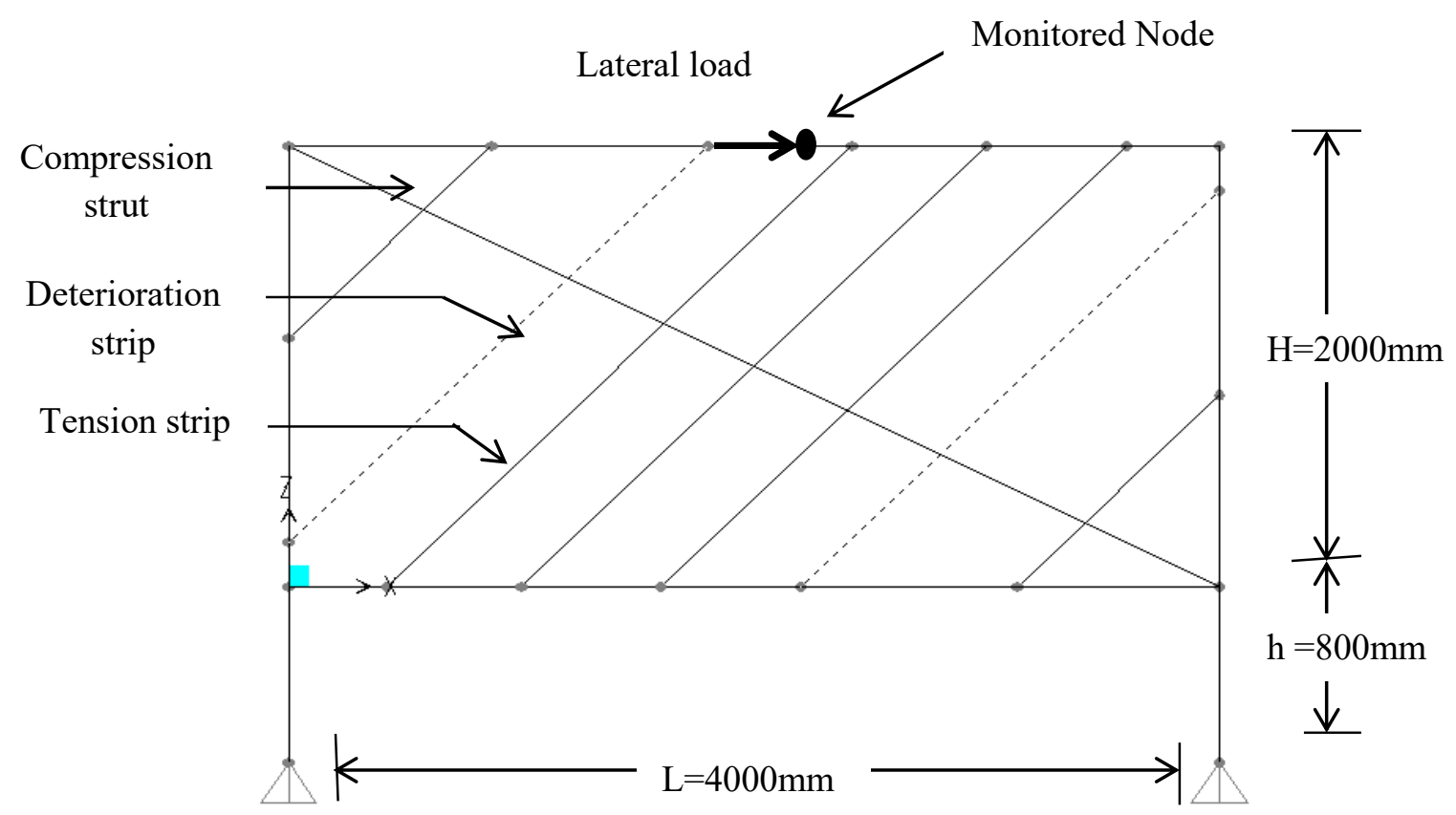

Figure 6.7: Geometry arrangement and loading condition of Vian et al. (2005) test specimen for the modified strip model. 


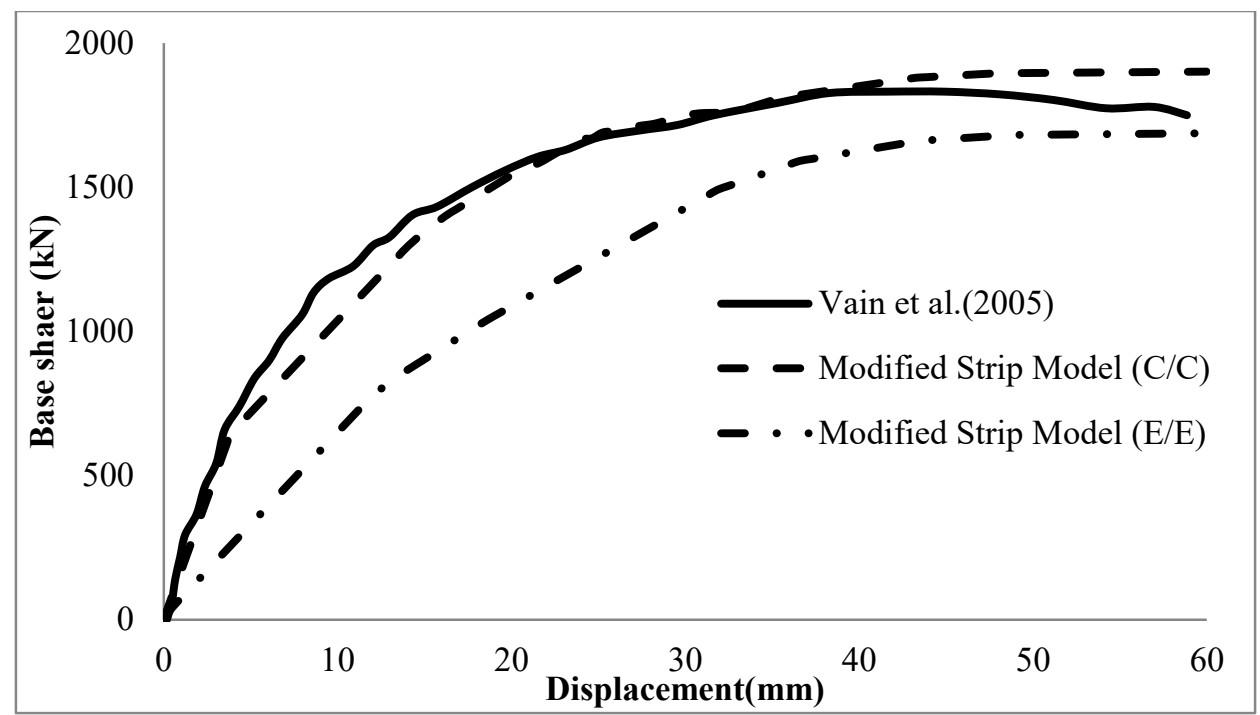

Figure 6.8: Comparison of Pushover curve of Vian et al. (2005) test and MSM.

\subsection{Modified Strip Model (MSM) for the Selected P-SPSWs (4-, 8- and 12-Storey)}

The main objective of this chapter is to evaluate the effectiveness of the modified strip model for perforated SPSW. The selected 4-, 8- and 12-storey P-SPSWs, as designed in chapter 3, were considered here. In order to check the effectiveness, pushover responses of the MSM were compared with detailed finite element model by ABAQUS (2011). In this study, two types of the strip were considered to look closely at the responses, among of them one was an edge to edge (Figure 6.2a), and another one was center to center (Figure 6.2b) from the opening. The boundary condition was applied as described in the section 6.2.7. The flexural plastic hinges in the beams and columns were assigned as shown in Table 6.1; however, for the tension strips and compression struts, the axial hinges properties were assigned as presented in Table 6.2. The gravity loads were applied at the top of each column to capture $\mathrm{P}-\Delta$ effect. Besides, static storey forces were applied monotonically at the beam-column joints. Figure 6.9 represents the geometric and loading arrangement of the Modified strip model for 4-storey P-SPSW. Top storey displacement was monitored with respect to base shear. 


\subsection{Pushover Analysis Results for the Modified Strip Model for P-SPSWs}

From nonlinear pushover analysis, it was found that the strip model performed very well to capture the elastic to inelastic behavior for selected P-SPSWs. The pushover curves for 4-, 8-and 12-storey P-SPSW are shown in the Figures 6.10, 6.12 and 6.13 respectively. Even though, the initial stiffness slightly underestimates but almost exactly predicted the ultimate strength for 4-storey PSPSW. The model was capable of predicting strength reduction in pushover curve because of distinct modeling of deterioration strip from tension strips. Neither welding failure nor tearing was considered during modeling in the detailed finite element by ABAQUS.

The analysis has been conducted separately concerning center to center $(\mathrm{C} / \mathrm{C})$, and edge to edge (E/E) strips for the 4-storey P-SPSW. From the pushover curve 6.10, it can be easily observed that $\mathrm{C} / \mathrm{C}$ strip model was performed very well compared to $\mathrm{E} / \mathrm{E}$ strip model. Where, E/E model substantially undermined the initial stiffness and ultimate strength compared to advanced finite element model. Considering $\mathrm{C} / \mathrm{C}$ strip width, later the performance of the cross-hatch strip layout for the 4-storey P-SPSW was evaluated as well. Form pushover analysis it was found that both stiffness and strength were underestimated considerably compared to detailed finite element model.

Above all, considering exact strip layout along with $\mathrm{C} / \mathrm{C}$ strip, the modified strip model showed good agreement with extensive finite element analysis by ABAQUS for 8-storey as well. Similar as 4-storey P-SPSW, for 8- and 12-storey P-SPSW the ultimate strength almost matched but slightly under-estimated initial stiffness with regards to ABAQUS analysis (Figure 6.11). The main reason was that the initial stiffness before plate buckling was neglected in strip model. In this chapter, columns axial forces, moments and shear forces were assessed for the 4-, 8-and 12- 
storey P-SPSW and compared it with designed. From the analysis, it was found that columns axial forces at each floor were far less than the design axial force (Figure 6.14 - 6.16).

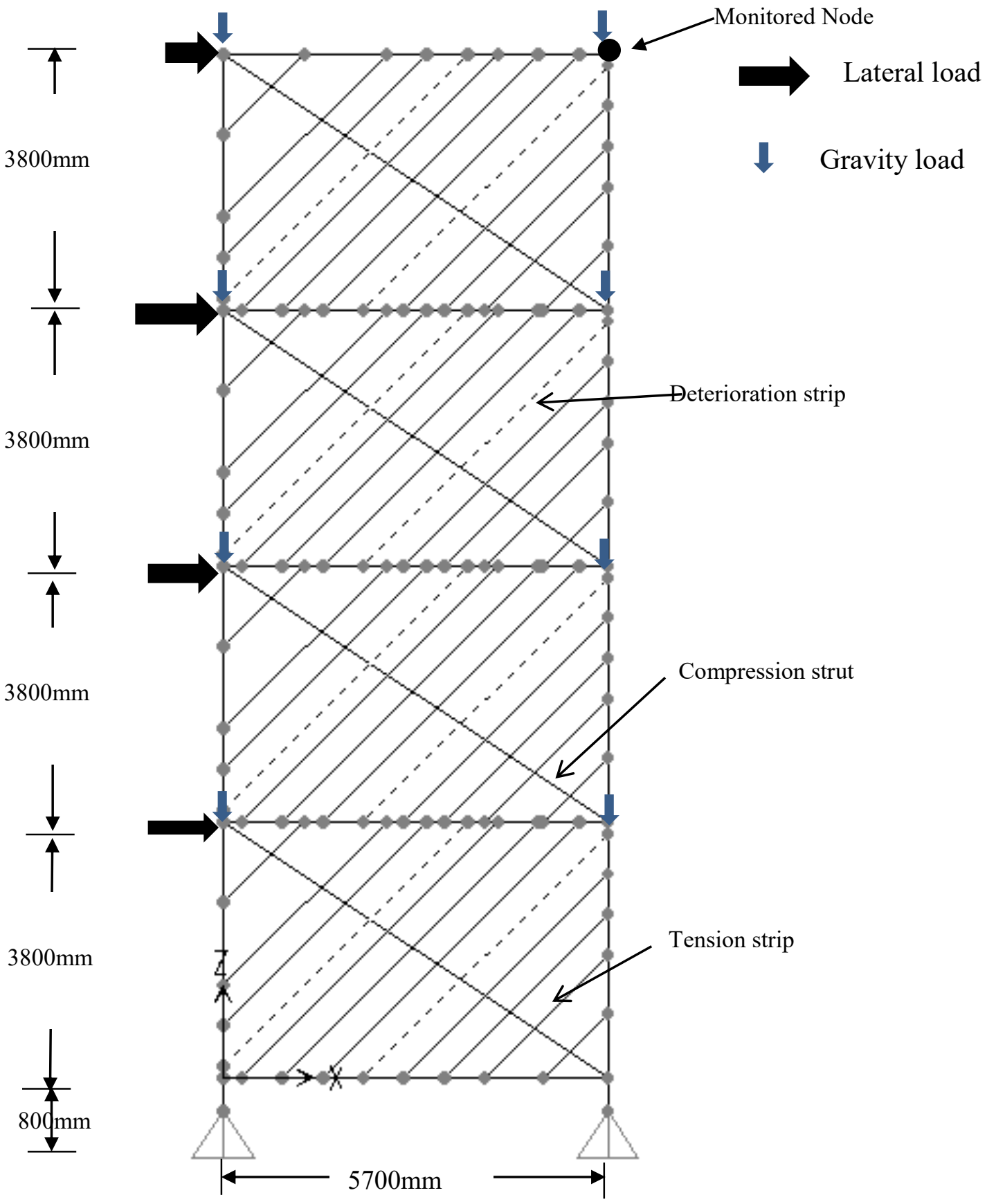

Figure 6.9: Geometric and loading arraignment of the Modified strip model for 4-storey P-SPSW 


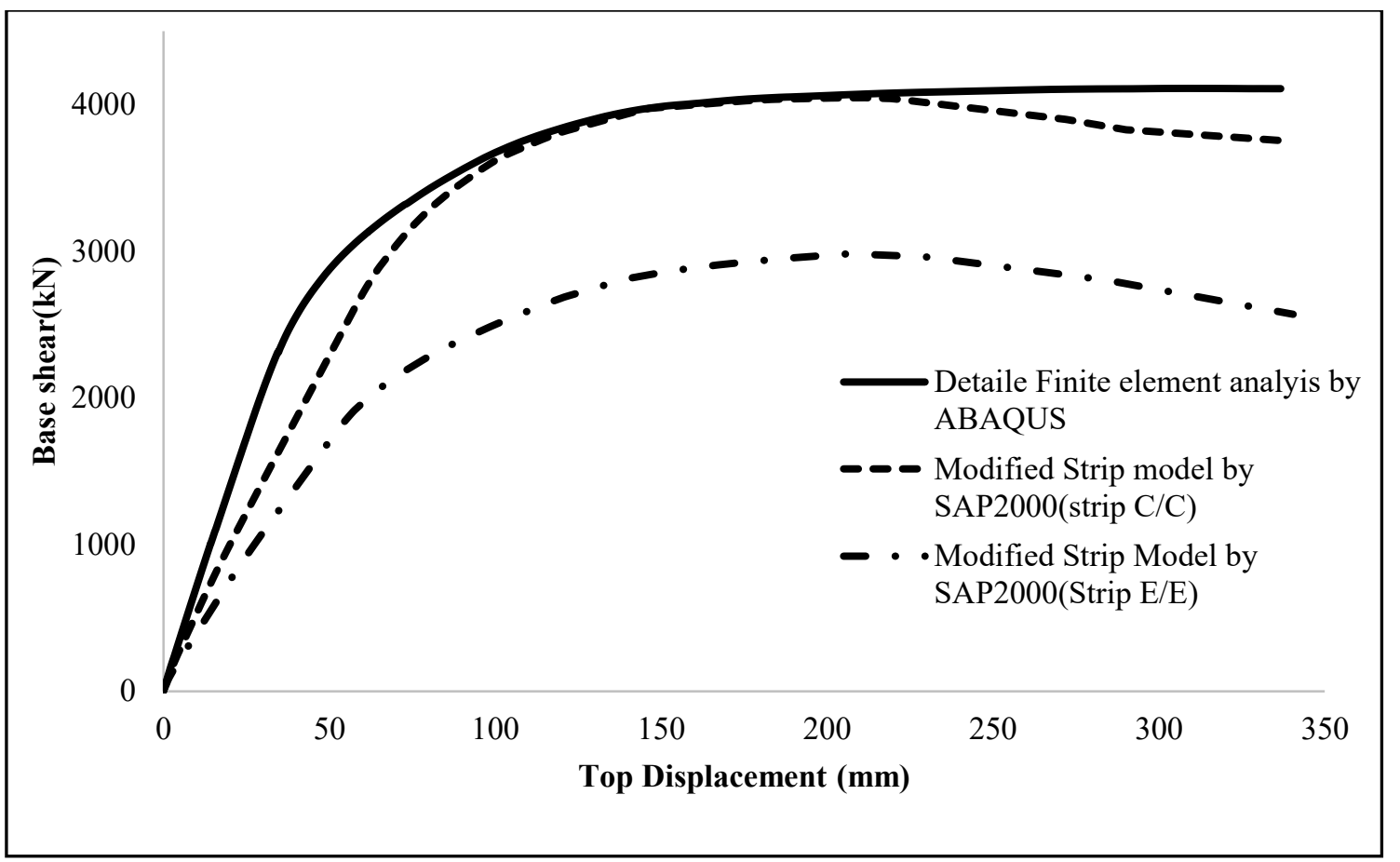

Figure 6.10: Base shear versus top displacement curve for the 4-storey P-SPSW for detailed finite element and MSM exact layout.

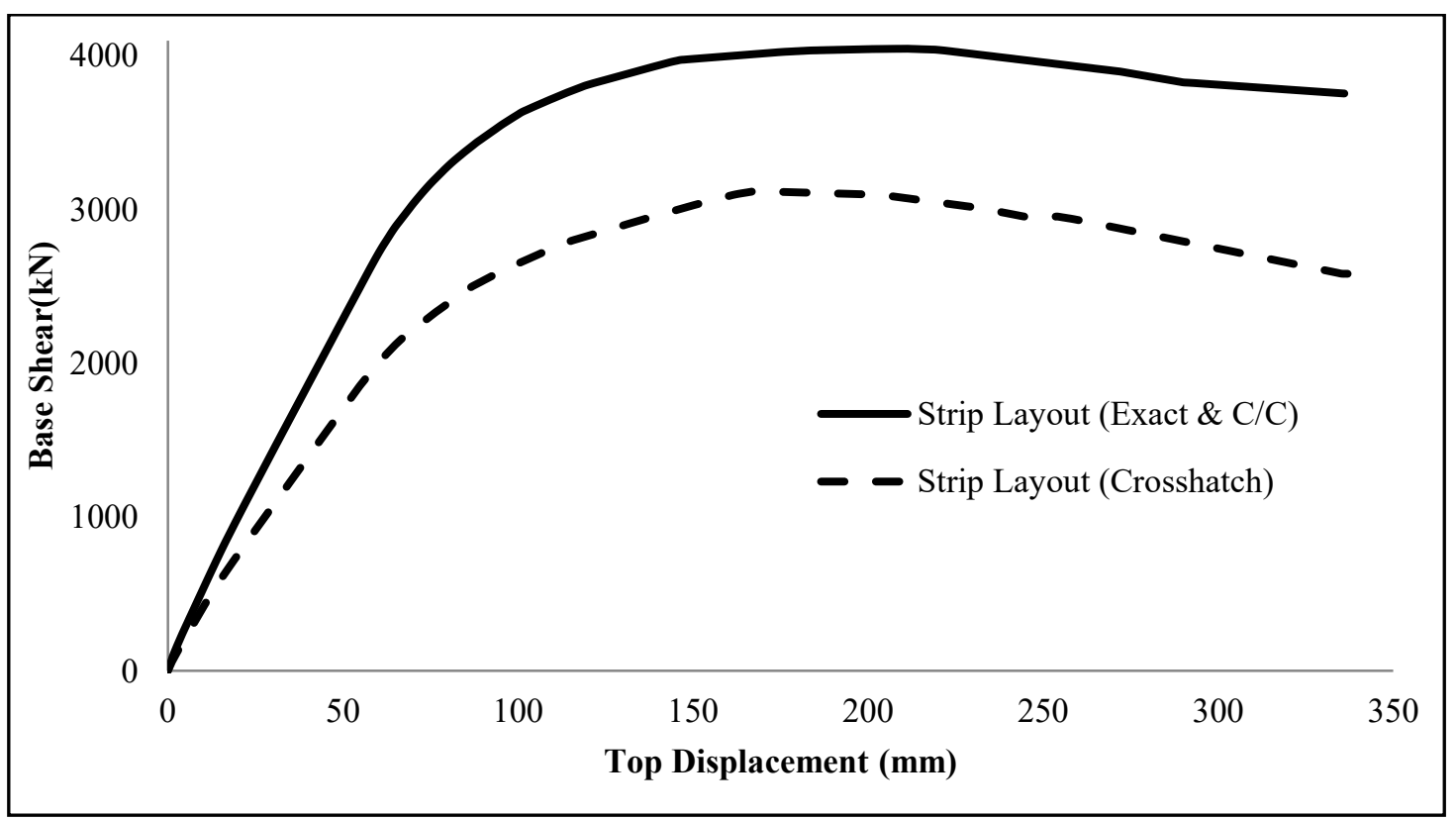

Figure 6.11: Base shear versus top displacement curve for different layout of the tension strips for the 4-storey P-SPSW. 


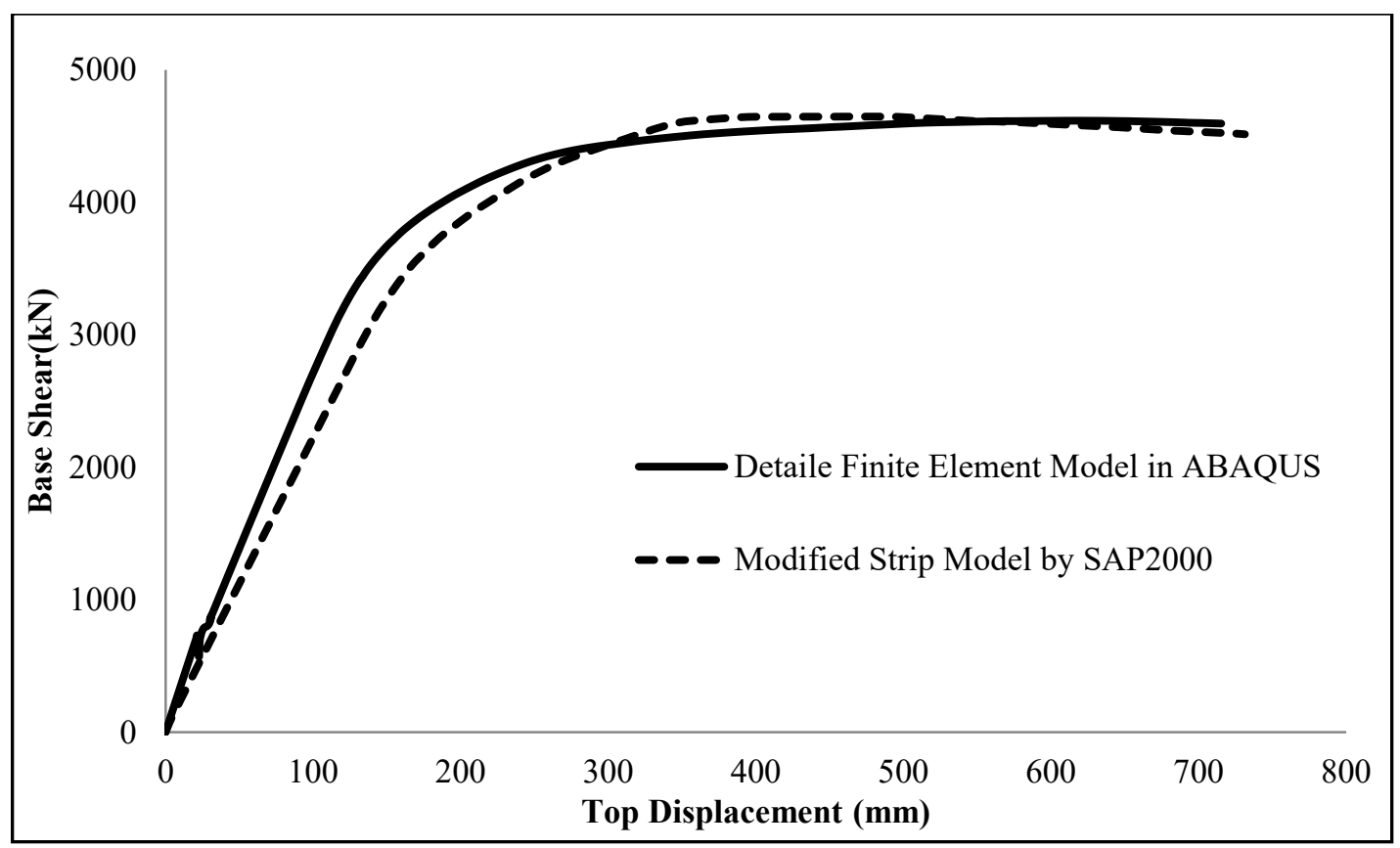

Figure 6.12: Base shear versus top displacement curve for the 8-storey P-SPSW.

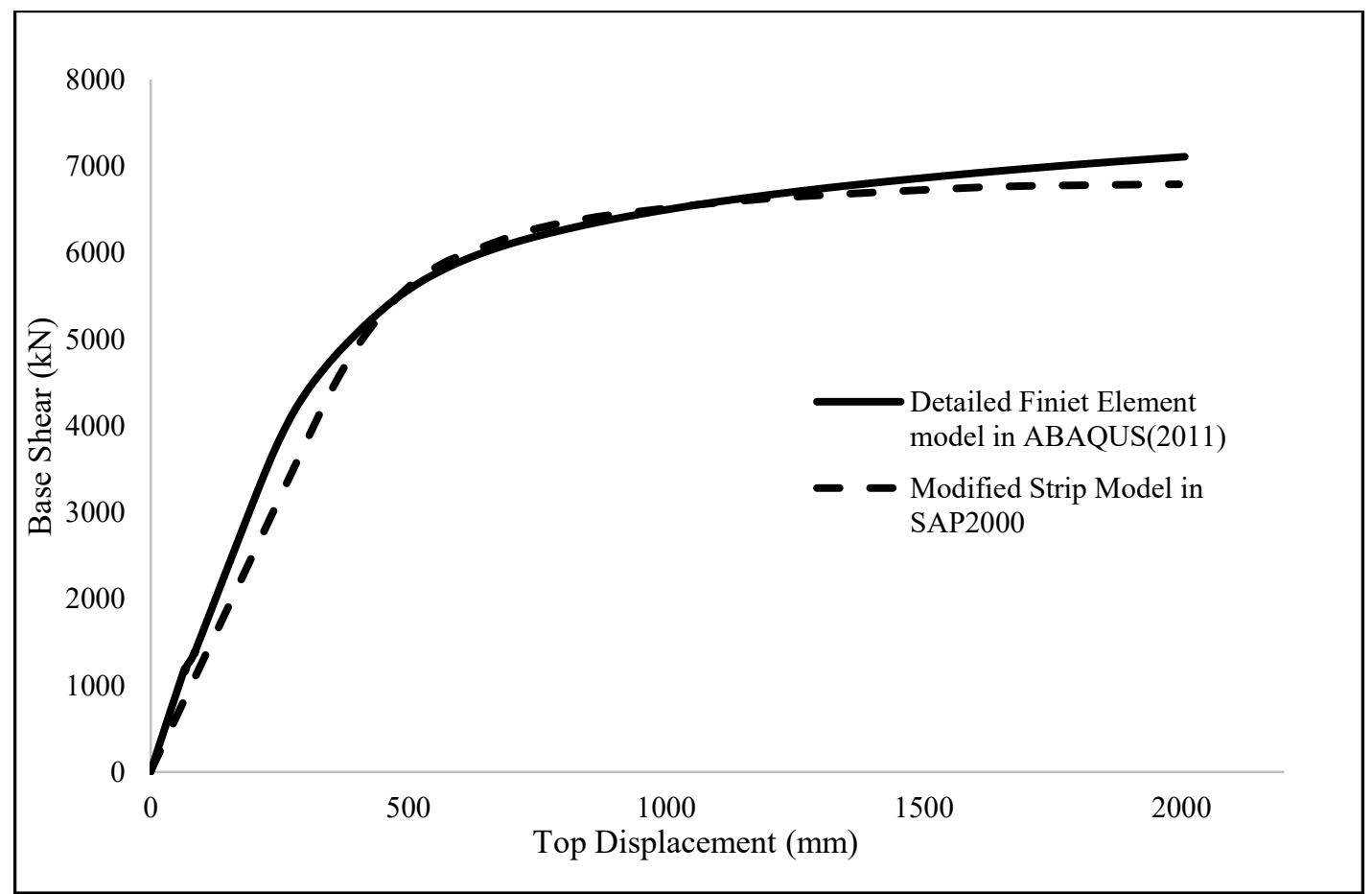

Figure 6.13: Base shear versus top displacement curve for the 12-storey P-SPSW 


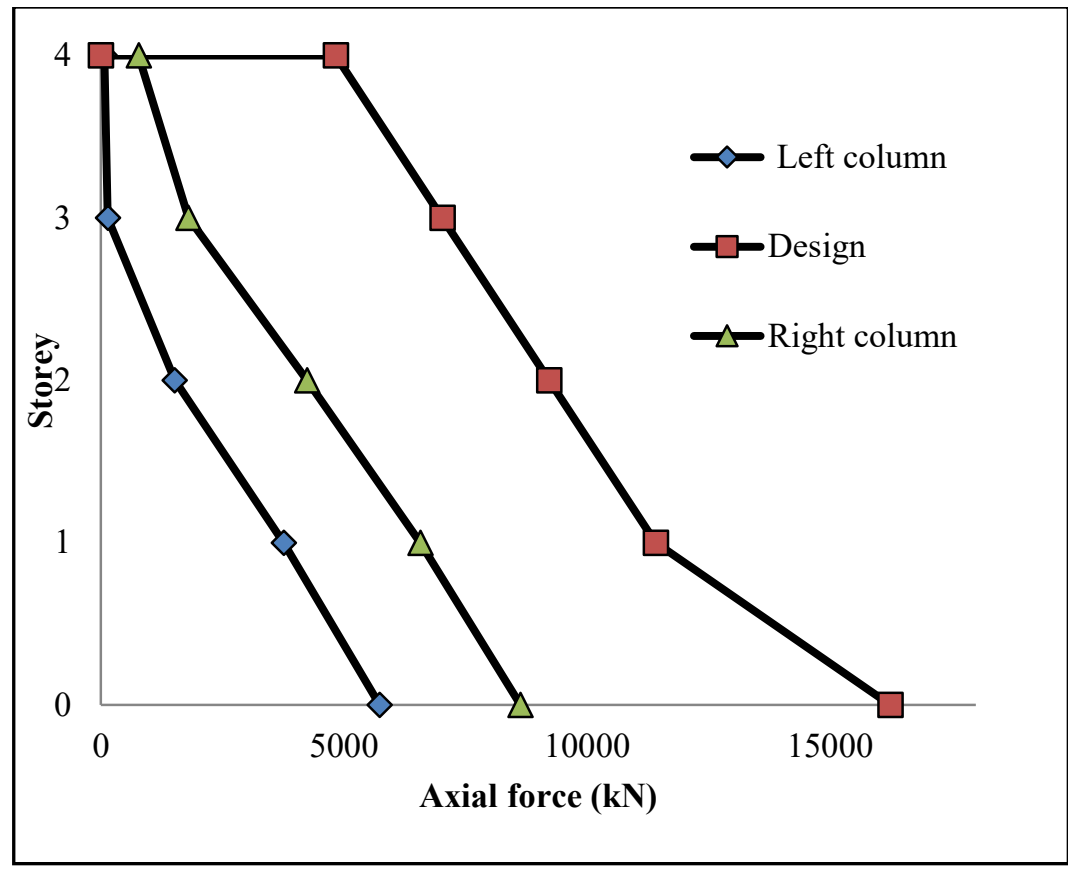

Figure 6.14: Axial force from MSM and design for 4-storey P-SPSW

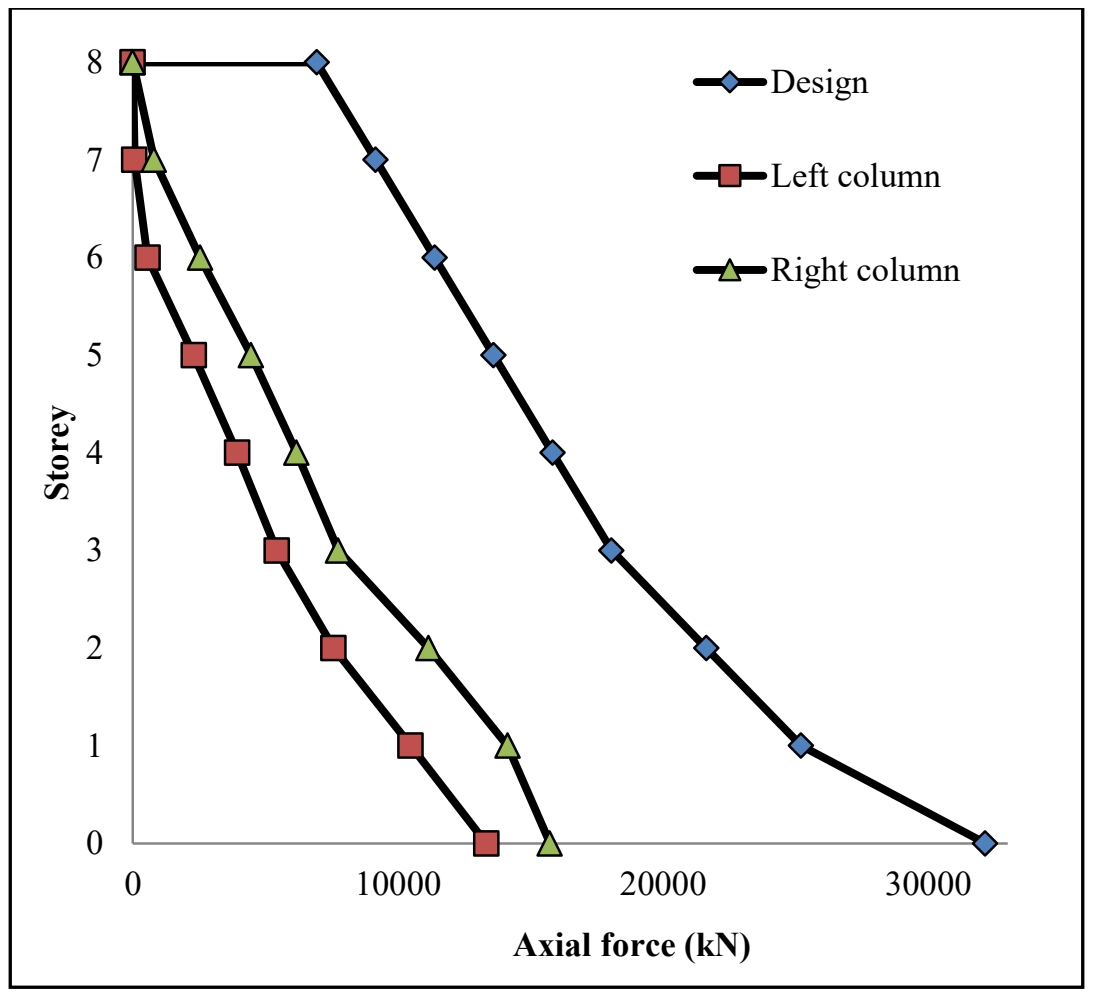

Figure 6.15: Axial force from MSM and design for 8-storey P-SPSW 


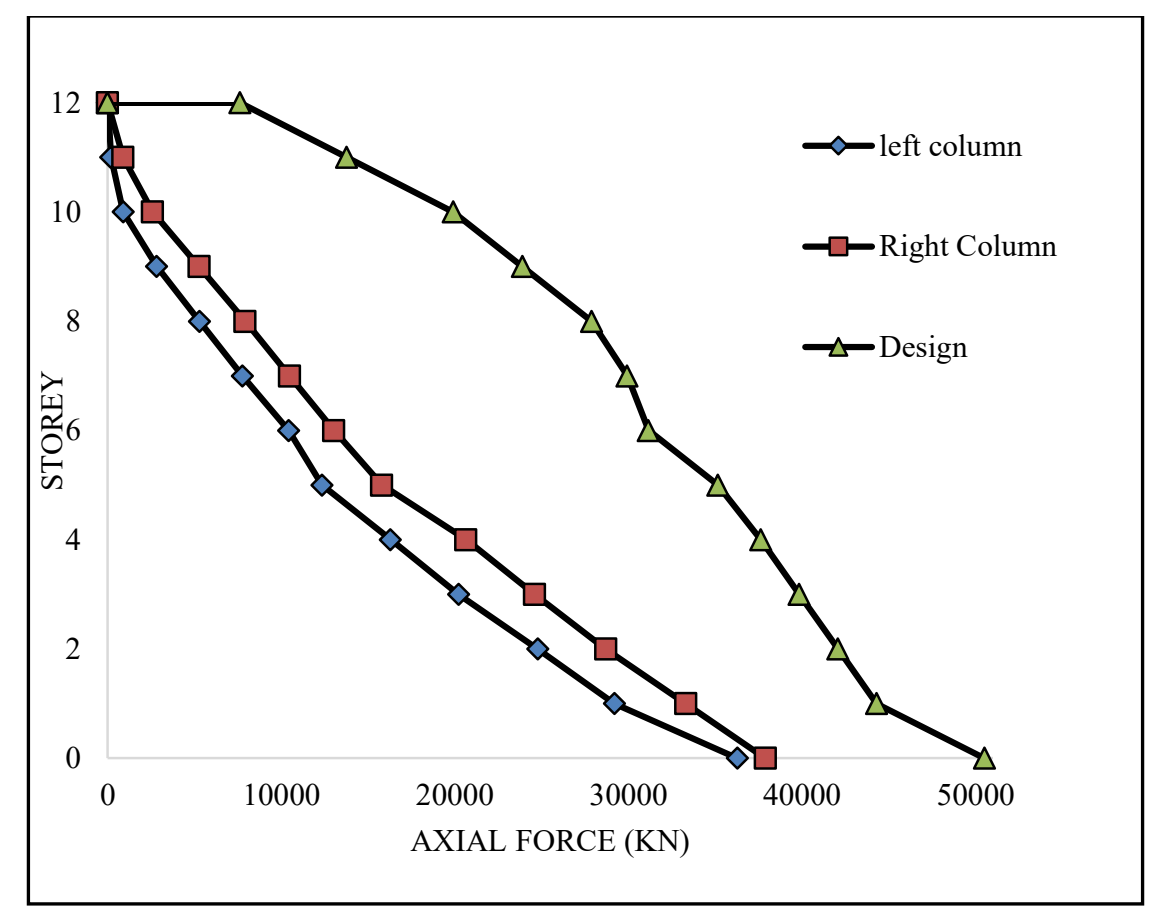

Figure 6.16: Axial force from MSM and design for 12-storey P-SPSW

\subsection{Summary}

The applicability of modified strip model for the perforated SPSW has been evaluated in this chapter. Two experiments have been validated for modified strip model in SAP2000 (CSI 2014), among of them one was for the solid infill SPSW by Driver et al. (1997, 1998a) and another one was for the perforated SPSW by Vian et al. (2005). Same modeling technique has been implemented for both 4-, 8- and 12-storey P-SPSW. Incorporating inelastic behavior by user defined plastic hinges in the frame members, the model has been efficiently assessed the postyielding behavior of large-scale P-SPSW. The compression strut has been provided to simulate the initial stiffness, and the material strength of the compression strut has been taken as $15 \%$ of the tension strip to account for buckling strength due to a small amount of lateral load. Moreover, 
along with tension strips, two deterioration strips have been provided to project the strength degradation away from ultimate strength. With exact and cross-hatch strips layout, two different strips width $(\mathrm{C} / \mathrm{C} \& \mathrm{E} / \mathrm{E})$ have been considered separately for responses evaluation. From the pushover analysis, it has been found that exact layout along with $\mathrm{C} / \mathrm{C}$ tension strips sufficiently predict the post-buckling behavior of the selected P-SPSWs. Even though, the initial stiffness has been slightly underestimated the ultimate strength was predicted with reasonable accuracy when compared with detailed finite element model by ABAQUS (2011). The column axial forces of the selected structures have been compared with the design. 


\section{Chapter 7. Summary, Conclusions, and Recommendations}

\subsection{Summary}

Seismic Performance of perforated steel plate shear walls (P-SPSW) designed according to NBCC2010 and CSA/CAN S16-09 were evaluated in this research project. A detailed and comprehensive finite element modeling technique was developed to study the behavior of unstiffened P-SPSW. The FE model considered both material and geometric non-linarites. Two experiments were taken into consideration for validating the developed FE model. Nonlinear quasi-static monotonic and cyclic analysis were conducted for the two selected specimens. Excellent correlation was observed between FEM and experiment results. The validated FE model was used to study seismic performance of P-SPSWs. Three multi-storey (4-, 8- and 12-storey) PSPSWs designed according to seismic design guidelines of NBCC 2010 and CSA/CAN S16-09 were used for the study. The buildings were located in Vancouver consist of two identical PSPSW in the same direction. For the design of boundary members of the P-SPSWs, Berman and Bruneau (2008) capacity design approach was taken into account allowing uniform collapse mechanism. Prior to non-linear time history analysis, monotonic pushover analyses were performed to check the performance of selected P-SPSWs. In addition, buckling and frequency analysis were performed for the chosen P-SPSWs. A series of real and synthetic ground motions data were selected which were compatible with Vancouver response spectrum. The earthquake records were scaled to match with design response spectrum of Vancouver. 
From the seismic analysis, critical response parameters including inter-storey drift, base shear, storey shear were estimated. Most importantly, from the dynamic analysis, the current code equation for the perforated infill plate strength was evaluated.

Later, the applicability of a reasonably simple analysis procedure, N2 method, to estimate seismic response parameters of P-SPSW was investigated. The N2 method is a non-linear static analysis procedure both drift and ductility demand were evaluated for selected P-SPSWs. The effectiveness of the N2 method was verified by comparing the response parameters obtained from a more accurate nonlinear time history analysis.

Usually, design engineers prefer simplified analysis tool and monotonic pushover analysis over more rigorous and time expensive nonlinear seismic analysis. Currently, strip model is used for analysis of SPSWs with solid infill plates. Several modifications are done to the strip model to use it for SPSW with perforated infill plate. The modified strip model was first validated for two test specimens for monotonic pushover analysis. Sufficient correlation was observed for the test specimens. Later, the modified strip model was used for analysis of the selected 4-, 8-, and 12storey P-SPSWs. The effectiveness of the modified strip model for chosen P-SPSWs was investigated by comparing results from detailed finite element technique.

\subsection{Conclusions}

- The detailed finite element model showed excellent agreement with the experimental result in the case of both quasi-static pushover and cyclic analyses. The FE model was capable of capturing all important features of the test specimens including elastic stiffness and ultimate strength. 
- Good initial stiffness and tremendous post-buckling strength were observed during pushover analysis of the selected P-SPSWs. Yielding of infill plate prior to beam plastic hinges and formation of plastic hinges at the base of the both columns depicted the optimum behavior of P-SPSW as per capacity design.

- Nonlinear time history analysis showed that the critical response parameters such as interstorey drift, dynamic base shear, dynamic storey shear, axial force were within the design limit.

- It was observed from NTHA that the current code equation provided a good estimation of the shear strength of the perforated plate when the plate was fully yielded. Thus, for selection of perforated infill plate thickness as well as for the design of boundary members as per capacity design, the current code equation of CSA/CAN S16-09 can be considered adequate.

- Roof displacements for 4-storey and 8-storey were predicted well by the simplified N2 method. However, inner storey-drifts well were not predicted well when compared with nonlinear seismic analysis results. Based on the observation in this research, it can be concluded that $\mathrm{N} 2$ method could be used for the preliminary design of low to medium-rise P-SPSWs such as 4- and 8-storey P-SPSWs of this study. For the high-rise P-SPSW, such as 12-storey P-SPSW of this study, the method was not capable of providing good result due to higher mode effect in few instance.

- Excellent correlation was found for selected test specimens using modified strip model in the case of exact layout of tension strip and C/C strip width. The modified strip model was capable of predicting the behavior of P-SPSW well when compared to detailed finite element modeling of large scale P-SPSW (4-, 8-, and 12- storey P-SPSWs). It was found 
that the modified strip model slightly underestimated the initial stiffness; however, the ultimate strength was predicted very well.

\subsection{Recommendations for Future Works}

For nonlinear time history analysis, three perforated steel plate shear wall were considered. Further research works are required on P-SPSWs of different types, geometry and height to investigate the performance of P-SPSW designed according to Canadian current provisions. It is recommended that future research also includes different orientation and various diameters of circular openings. In N2 method, the post-yielding behavior of the structure is neglected. After yielding, the stiffness of any lateral load resisting system changes considerably. Thus, future research is required to include post-yielding hardening in N2 method. On the other hand, one of the other limitations of this method is not capable of capturing seismic demand for high-rise structure. So, further study for high-rise structures is needed as well.

More study is required to capture the exact initial stiffness in the corresponding load-displacement curve in modified strip model. Besides, in future, the applicability of the modified strip model for non-linear time history analysis shall be investigated. 


\section{References}

ANSI/AISC. 2005. Seismic Provisions for Structural Steel Buildings. American Institute of Steel Construction Inc, Chicago, Illinois.

ANSI/AISC. 2010. Seismic Provisions for Structural Steel Buildings. American Institute of Steel Construction Inc, Chicago, Illinois.

ASCE/SEI. 2007. Seismic rehabilitation of existing buildings. American Society of Civil Engineers, Reston, VA, USA

Aschheim, M. 2000. Yield Point Spectra: A Simple Alternative to the Capacity Spectrum Method, Advanced Technology in Structural Engineering, American Society of Civil Engineering (ASCE) Structures Congress 2000, Philadelphia, Pennsylvania, USA.

Atkinson, G.M. 2009. Earthquake Time Histories Compatible with the 2005 NBCC Uniform Hazard Spectrum. www.seismotoolbox.ca.

Basler, K.,1961. Strength of Plate Girders in Shear. ASCE Journal of the Structural Division, 87 (7):151-180

Behbahanifard, M., Grondin, G.Y., and Elwi, A.E., 2003. Experimental and Numerical Investigation of Steel Plate Shear Walls. Department of Civil and Environmental Engineering, University of Alberta, Edmonton.

Berman, J.W., and Bruneau, M. 2008. Capacity design of vertical boundary elements in steel plate shear walls. ASCE, Engineering Journal, first quarter 57-71. 125.

Berman, J.W., and Bruneau, M. 2003. Plastic Analysis and Design of Steel Plate Shear Walls. ASCE Journal of Structural Engineering 11 (129): 1448-1456. 
Berman, J.W., and Bruneau, M. 2004. Steel Plate Shear Walls Are Not Plate Girders. AISC Engineering Journal, Third Quarter: 95-106.

Bhowmick, A.K., Grondin, G.Y. and Driver, R.G. 2011. Estimating Fundamental Periods of Steel Plate Shear Walls. Journal of Engineering Structures 33: 1883-1893.

Bhowmick, A.K., Driver, R.G. and Grondin, G.Y. 2009. Seismic Analysis of Steel Plate Shear Walls Considering Strain Rate and P-Delta Effects. Journal of Constructional Steel Research 65 (5): 1149-1159. doi: 10.1016/j.jcsr.2008.08.003.

Bhowmick, A.K. 2009. Seismic Analysis and Design of Steel Plate Shear Walls. University of Alberta, Edmonton.

Caccese, V., Elgaaly, M. and Chen, R. 1993. Experimental Study of Thin Steel-pate Shear Walls Under Cyclic Load. ASCE Journal of Structural Engineering 199 (2): 573-587.

Computers and Structures, Inc., 1984-2014, SAP 2000 (V.14) Nonlinear, Computers and Structures, Inc., Berkeley, CA.

CSA.1994. Limit State Design of Steel Structures. Canadian Standards Association, Toronto, Ontario.

CSA. 2001. Limit States Design of Steel Structures. Canadian Standards Association, Ontario, Canada.

CSA. 2009. Limit states design of steel structures. Canadian Standards Association. Toronto, Ontario.

Driver, R.G., Kulak, G.L. Elwi, A.E. and Kennedy, D.J.L. 1998a. Cyclic Tests of Four-Story Steel Plate Shear Wall. ASCE Journal of Structural Engineering 124 (2): 112-120. 
Driver, R.G., Kulak, G.L. Elwi, A.E. and Kennedy, D.J.L 1998b. FE and Simplified Models of Steel Plate Shear Wall. ASCE Journal of Structural Engineering 124(2): 121-130.

Driver, R.G., Kulak, G.L., Kennedy, D.J.L. and Elwi, A.E. 1997. Seismic Behaviour of Steel Plate Shear Walls; Structural Engineering Report No. 215. Department of Civil Engineering, University of Alberta, Edmonton, Alberta, Canada. 127.

Elgaaly, M.1998. Thin Steel Plate Shear Walls Behavior and Analysis. Thin-walled Structures 32: 151-180.

Elgaaly, M., Caccese, V. and Du, C. 1993. Post-Buckling Behaviorof Steel-Plate Shear Walls under Cyclic Loads. ASCE Journal of Structural Engineering 199 (2): 588-605.

Eurocode-8.2004. Design of structures for earthquake resistance - Part 1: General rules, Seismic Actions, and Rules for Buildings. European Committee Standardization, Brussels, Belgium.

FEMA. 2005. Improvement of Nonlinear Static Seismic Analysis Procedures, FEMA-440. Applied Technology Council (ATC-55 Project), Washington, D.C.

FEMA. 1997. NEHRP Guidelines for the Seismic Rehabilitation of Buildings, FEMA-273. Applied Technology Council for the Building Seismic Safety Council, the Federal Emergency Management Agency, Washinton, D.C, USA.

FEMA. 2000. Pre-standard and Commentary for the Seismic Rehabilitation of Buildings, FEMA365. American Society of Civil Engineers Federal Emergency Management Agency, Washington, D.C. USA.

Fajfar, P. 1999. Capacity Spectrum Method Based on Inelastic Demand Spectra. Earthquake Engineering and Structural Dynamics 28 (9): 979-993. 
Freeman SA, Nicoletti JP, Tyrell JV. 1975. Evaluations of existing buildings for seismic risk-A case study of Puget Sound Naval Shipyard, Bremeton, Washington. In Proceedings of 1st U.S. National Conference on Earthquake Engineering, EERI, Berkeley, CA; 113-122.

Hibbitt, Karlsson, and Sorensen. 1994. ABAQUS/Standard User's Manual.Version 5.4, HKS Inc., Pawtucket, RI.

Hibbitt, Karlsson, and Sorensen. 2007. ABAQUS/Standard User's Manual. Version 6.7, HKS Inc., Pawtucket, RI.

Hibbitt, Karlsson, and Sorensen. 2011. ABAQUS/Standard User's Manual. Pawtucket, RI: HKS.Inc.

Hilber, H.M., Hughes, T.J.R., and Taylor, R.L. 1978. Collocation, dissipation and 'overshoot' for time integration schemes in structural dynamics. Earthquake Engineering and Structural Dynamics, 6: 99-117.

Humar J, Ghorbanie-Asl M. 2005. A New Displacement-Based Design Method for Building, 33rd Annual General Conference of the Canadian Society for Civil Engineering, GC-136, Toronto, Ontario, Canada.

Lamontagne, M.S., Halchuk, J.F., Cassidy, and Rogers, G.C.2008.Significant Canadian Earthquakes of the period 1600-2006. Seismological Research Letters 79(2): 211-224. Doi: 10.1785/gssrl.79.2.211.

Lubell, A.S., Prion, H.G.L., Ventura C.E., and Rezai, M. 2000. Unstiffened Steel Plate Shear Wall Performance Under Cyclic Load. Journal of Structural Engineering, ASCE 126 (4): 453-460.

Naumoski, N., Murat S., and Kambiz, Amiri-Hormozaki. 2004. Effects of Scaling of Earthquake Excitations on the Dynamic Response of Reinforced Concrete Frame Buildings.13 ${ }^{\text {th }}$ World Conference on Earthquake Engineering, Vancouver, Canada. 
NBCC. 2010. National Building Code of Canada. Canadian Commission on Building and Fire Codes. National Research Council of Canada (NRCC), Ottawa, Ontario.

Neilson, D.A.H., Grondin, G.Y., and Driver, R.G. 2010. Welding of Light Gauge Infill Panels for Steel Plate Shear Walls. Structural Engineering Report No. 290, Department of Civil and Environmental Engineering, University of Alberta, Edmonton, AB.

Oyarzo-Vera, C., and Chouw, N. 2008. Comparison of Record Scaling Methods Proposed by Standards Country Applied Different Countries.14th World Conference on Earthquake Engineering, October 12-17, 2008, Beijing, China.

PEER. 2010. Next Generation Attenuation of Ground Motions Project (NGA) Database. Pacific Earthquake Engineering Research Center, Berkeley, California.

Purba, R. H. 2006. Design recommendations for perforated steel plate shear walls. M.Sc. Thesis, State Univ. of New York at Buffalo, Buffalo, N.Y.

Rezai, M. 1999. Seismic Behavior of Steel Plate Shear Walls by Shake Table Testing. Department of Civil Engineering, University of British Columbia. Vancouver, Canada.

Rezai, M., Ventura, C.E., and Prion, H.G.L. 2000. Numerical Investigation of Thin Unstiffened Steel Plate Shear Walls. 12 World Conference on Earthquake Engineering. Auckland, New Zealand.

Roberts, T.M. and Sabouri-Ghomi, S. 1992. Hysteretic characteristics of unstiffened perforated steel plate shear panels. Thin-Walled Structures, 14: 139-151.

Shishkin, J.J., Driver, R.G., and Grondin, G.Y., 2005. Analysis of Steel Plate Shear Walls Using the Modified Strip Model. Structural Engineering Report No. 261, Department of Civil and Environmental Engineering, University of Alberta, Edmonton, AB. 
Seismosoft, 2015. SeismoMatch (V.2.1.2) -A computer program for spectrum matching of earthquake records. WWW. Seismosoft.com

Thorburn, L.J., Kulak, G.L and Montgomery, C.J.1983. Analysis of Steel Plate Shear Walls, Structural Report No.107. Department of Civil and Environment Engineering. University of Alberta, Edmonton, AB.

Timler, P.A., and Kulak, G.L. 1983. Experimental Study of Steel Plate Shear Walls. Structural Engineering Report No. 114. Dept. of Civil Engineering, University of Alberta, Edmonton, AB.

Tromposch, E.W., and Kulak, G.L.1987.Cyclic and Static Behaviour of Thin Panel Steel Plate Shear Walls. Structural Engineering Report No. 145. Department of Civil Engineering, University of Alberta, Edmonton, AB.

Vidic, T, Fajfar, P., and Fischinger, M. 1994. Consistent Inelastic Design Spectra: Strength and Displacement. Earthquake Engineering and Structural Dynamics 23 (5): 507-521. doi:10.1002/eqe.4290230504.

Vian, D., and Bruneau, M. 2005. Steel Plate Shear Wall for Seismic design and retrofit of building structures. Technical Report No. MCEER -05-0010, Multidisciplinary Center for Earthquake Engineering Research, The State university of New York at Buffalo, Buffalo, N.Y. USA.

Wagner, H. 1931. Flat Sheet Metal Girders with Very Thin Webs, Part-1- General Theories and Assumptions. Technical Memo No. 604. National Advisory Committee for Aeronautics. Washington, DC.

Xue, M., and Lu, L.W. 1994. Interaction of Infilled Steel Shear Wall Panels with Surrounding Frame Members. Structural Stability Research Council Annual Technical Session, Bethlehem, PA. $339-354$. 